\title{
THERMAL MODELING OF SOLID OXIDE FUEL CELL BASED BIOMASS GASIFICATION SYSTEMS
}

\author{
by \\ Can Ozgur Colpan \\ B.Sc., M.Sc. \\ A thesis submitted to \\ the Faculty of Graduate Studies and Research \\ in partial fulfillment of \\ the requirement for the degree of \\ Doctor of Philosophy \\ in Mechanical Engineering \\ Ottawa-Carleton Institute for Mechanical and Aerospace Engineering \\ Department of Mechanical and Aerospace Engineering \\ Carleton University \\ Ottawa, Ontario, Canada \\ (C) Can Ozgur Colpan
}

August 2009 
Library and Archives Canada

\section{Published Heritage} Branch

395 Wellington Street Ottawa ON K1A ON4 Canada
Bibliothèque et

Archives Canada

Direction du

Patrimoine de l'édition

395, rue Wellington

Ottawa ON K1A ON4

Canada
Your file Votre refférence
ISBN: 978-0-494-60102-0
Our file Notre référence
ISBN: $978-0-494-60102-0$
NOTICE:

The author has granted a nonexclusive license allowing Library and Archives Canada to reproduce, publish, archive, preserve, conserve, communicate to the public by telecommunication or on the Internet, loan, distribute and sell theses worldwide, for commercial or noncommercial purposes, in microform, paper, electronic and/or any other formats.

The author retains copyright ownership and moral rights in this thesis. Neither the thesis nor substantial extracts from it may be printed or otherwise reproduced without the author's permission.

\section{AVIS:}

L'auteur a accordé une licence non exclusive permettant à la Bibliothèque et Archives Canada de reproduire, publier, archiver, sauvegarder, conserver, transmettre au public par télécommunication ou par l'Internet, prêter, distribuer et vendre des thèses partout dans le monde, à des fins commerciales ou autres, sur support microforme, papier, électronique et/ou autres formats.

L'auteur conserve la propriété du droit d'auteur et des droits moraux qui protège cette thèse. $\mathrm{Ni}$ la thèse ni des extraits substantiels de celle-ci ne doivent être imprimés ou autrement reproduits sans son autorisation.
In compliance with the Canadian Privacy Act some supporting forms may have been removed from this thesis.

While these forms may be included in the document page count, their removal does not represent any loss of content from the thesis.
Conformément à la loi canadienne sur la protection de la vie privée, quelques formulaires secondaires ont été enlevés de cette thèse.

Bien que ces formulaires aient inclus dans la pagination, il n'y aura aucun contenu manquant. 


\begin{abstract}
In this thesis, several models of solid oxide fuel cells (SOFC) were developed in cell and system levels. These models were used in several case studies to simulate the performance of the cells and systems studied. In addition, the effectiveness of SOFC in reducing greenhouse gases was assessed through a case study.
\end{abstract}

In cell level, a thermodynamic model, a carbon deposition model, and a quasi 2-D transient heat transfer model were developed. The thermodynamic model is capable of determining the performance of a SOFC including polarization curve, power output, and electrical efficiency. This model takes into account the recirculation of depleted fuel and internal reforming processes. The original model was improved by addressing problems associated with carbon deposition. The occurrence of carbon deposition was investigated using $\mathrm{C}-\mathrm{H}-\mathrm{O}$ triangular phase diagrams and calculation of carbon activities. More detailed modeling of SOFC was accomplished by including the heat transfer mechanisms inside the fuel cell such as conduction, convection and radiation. In this heat transfer model, the transient behaviour of the cell was simulated during the heat-up and start-up stages. Several parametric studies, such as effect of Reynolds number and excess air coefficient on the performance of the cell, were conducted to better examine co- and counter-flow configurations of SOFC.

In system level, integrated SOFC systems were modeled using energy and exergy analyses. The analyses were done using the models developed for SOFC in cell level and through development of thermodynamic models for other components of integrated 
systems (e.g. gasifier, afterburner, and heat exchanger). These integrated systems included a gas turbine and SOFC-based cogeneration system and two SOFC and biomass gasification-based cogeneration systems. Performance assessment parameters, e.g. electrical efficiency, fuel utilization efficiency, power-to-heat ratio, and exergetic efficiency, as well as the exergy destructions and losses were calculated in these systems.

The models developed in cell level were validated using the published data in the literature and used to simulate the performance of several cases. The results from the thermodynamic model showed that lower recirculation ratio, which quantifies the amount of depleted fuel that is recirculated to the fuel channel inlet, and higher fuel utilization increased the performance of the system. From the carbon deposition model, it was found that in order to operate the SOFC with the minimum recirculation ratio as required for higher electrical efficiency, the maximum possible operating temperature level and fuel utilization ratio should be chosen to prevent carbon deposition. It was also shown that gases produced from advanced gasification systems, such as twin-fluid bed and multisolid fluid bed, yield higher electrical efficiency for SOFC compared to those produced from downdraft and updraft gasifiers. The heat transfer model yielded that the counterflow configuration takes slightly more time to reach the steady state condition, and it has a better electrical efficiency for low Reynolds numbers. The study on the effect of excess air coefficient on the performance of the SOFC showed that taking this coefficient higher provides better electrical efficiency. 
The system level models were used to simulate the performance of several cases. The case study, in which a SOFC and gas turbine based cogeneration system was simulated, pointed out that this system has a better thermodynamic performance compared to its competing technologies. The simulation of SOFC and biomass gasification system showed that selecting steam as the gasification agent yields higher electrical efficiency, power-to-heat ratio, and exergetic efficiency.

Greenhouse gas emissions from uncontrolled and controlled landfill sites were compared through a case study. In the controlled landfill sites, the following systems were used for utilizing the landfill gas: flaring, internal combustion engine, gas turbine, and SOFC. The results showed that the SOFC has a better potential to reduce GHG emissions among the different technologies studied. 
To My Family 


\section{ACKNOWLEDGEMENTS}

The author wishes to express deep gratitude to co-supervisors Prof. Feridun Hamdullahpur and Prof. Ibrahim Dincer for their invaluable supervision, advice, encouragement, support, and insight throughout the research process.

The author would like to express sincere thanks to Mr. Yeong Yoo, a senior research officer from the NRC Institute for Chemical Process and Environmental Technology (NRC-ICPET), for his support.

The author would like to express special thanks to Catherine Hamdullahpur and Prof. Susan Logie for proofreading his thesis.

The author would also like to thank to Dr. Mohammad Golriz, a visiting researcher, and his colleagues, David Cerantola, Siamak Farhad, Fahad Al-Sulaiman, Maryam YounessiSinaki, and Scott R. Wilson, in the Mechanical and Aerospace Engineering Department of Carleton University for their technical support.

The author gratefully thanks to his parents Melih and Nesrin Çolpan, and his sister Aslı Çolpan for their invaluable support in his entire life. 


\section{TABLE OF CONTENTS}

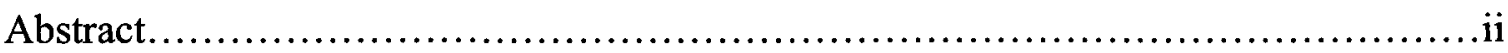

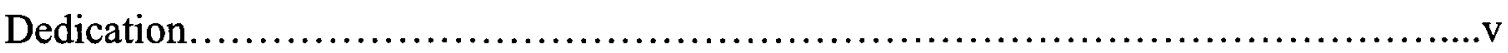

Acknowledgements..............................................................

Table of contents..................................................................

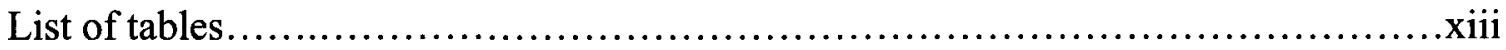

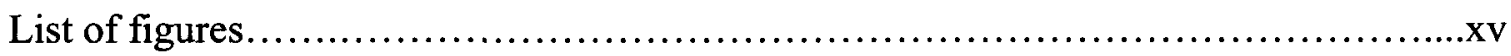

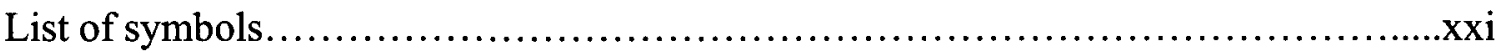

CHAPTER 1: Introduction.........................................................

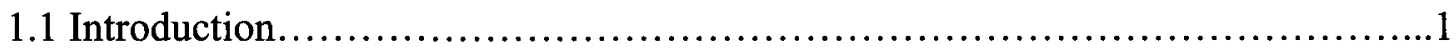

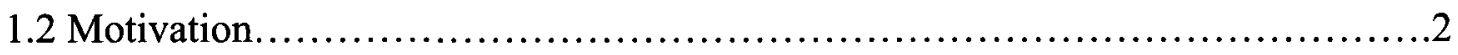

1.3 Objectives...............................................................

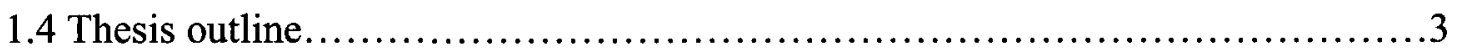

CHAPTER 2: Background and literature review.....................................

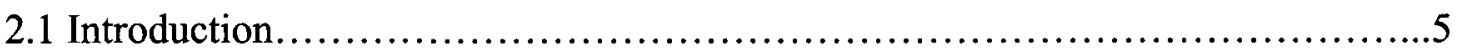

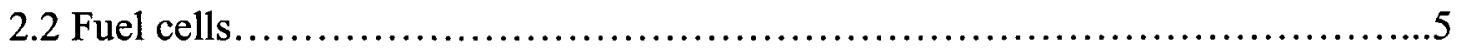

2.2.1 Technologies.......................................................... 6

2.2.1.1 Proton exchange membrane fuel cell (PEMFC) $\ldots \ldots \ldots \ldots \ldots \ldots \ldots \ldots . \ldots$

2.2.1.2 Direct methanol fuel cell (DMFC) ................................9

2.2.1.3 Alkaline fuel cell (AFC) ..........................................

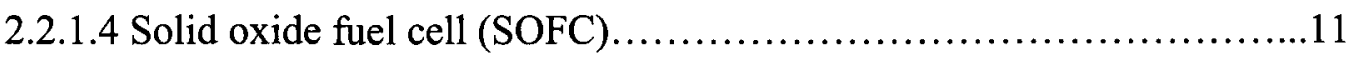

2.2.1.5 Other fuel cell types..............................................12

2.2.2 Applications....................................................... 
2.3 Solid oxide fuel cells.................................................... 15

2.3.1 Classification of SOFC systems...................................... 17

2.3.1.1 Classification according to the temperature level.....................17

2.3.1.2 Classification according to cell and stack design....................18

2.3.1.3 Classification according to the type of support.......................19

2.3.1.4 Classification according to the flow configuration....................20

2.3.1.5 Classification according to the fuel reforming type ...................20

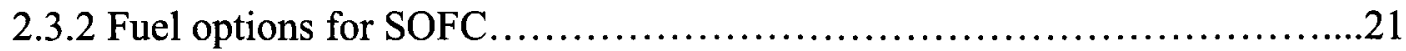

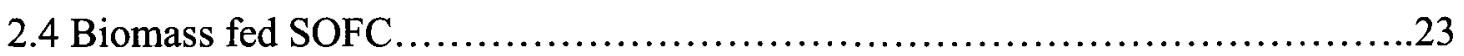

2.4.1 Integrated SOFC systems fuelled with ethanol produced from fermentation

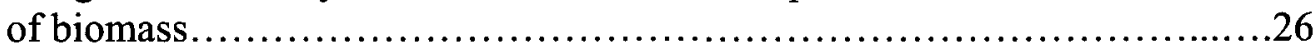

2.4.2 Integrated SOFC systems fuelled with biogas produced from anaerobic digestion of biomass....................................................

2.4.3 Integrated SOFC systems fuelled with bio-oil produced from fast pyrolysis

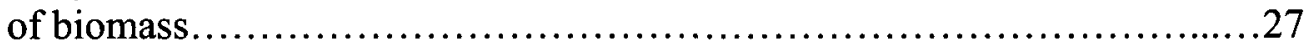

2.4.4 Integrated SOFC systems fuelled with syngas produced from gasification

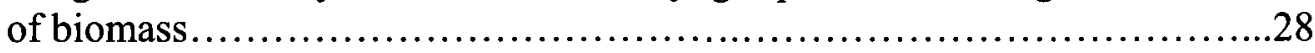

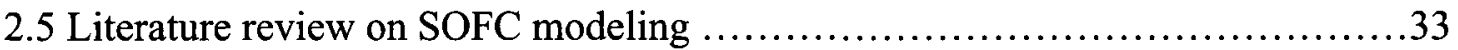

2.5.1 Cell and stack level modeling ......................................33

2.5.1.1 0-D, 1-D, 2-D and 3-D modeling techniques........................33

2.5.1.2 Transient modeling..............................................

2.5.1.3 Thermomechanical modeling ....................................37

2.5.1.4 Carbon deposition problem......................................38

2.5.2 System level modeling ............................................41

2.5.3 Current issues in SOFC models......................................44 


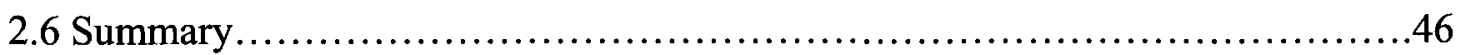

CHAPTER 3: SOFC modeling................................................. 49

3.1 Introduction.................................................................

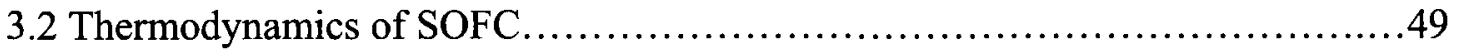

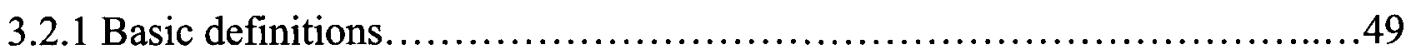

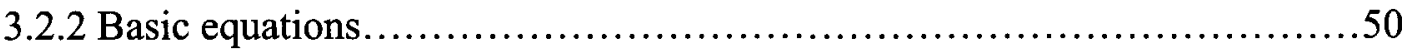

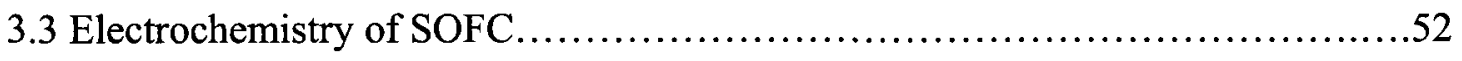

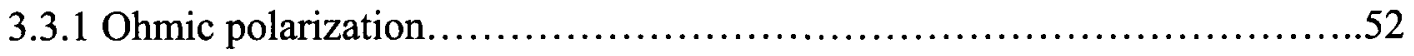

3.3.2 Activation polarization...........................................56

3.3.3 Concentration polarization. ...........................................56

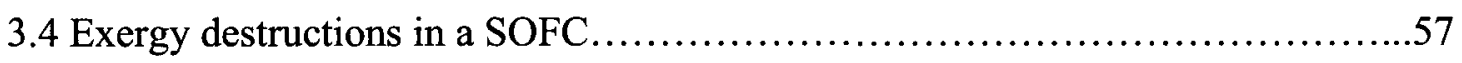

3.5 Thermodynamic modeling of direct internal reforming SOFCs operating with

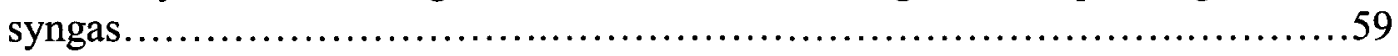

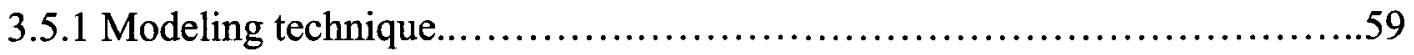

3.5.2 Calculation of the gas composition at the fuel channel exit...................61

3.5.3 Calculation of the output parameters.....................................66

3.6 Carbon deposition modeling in direct internal reforming SOFCs................68

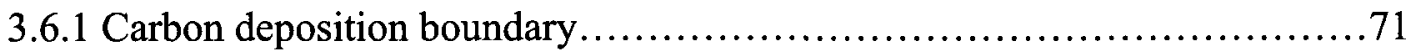

3.6.2 Calculation of gas composition at the fuel channel inlet...................73

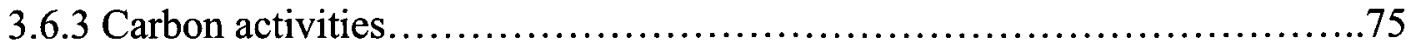

3.7 Transient heat transfer modeling of SOFC ............................... 76

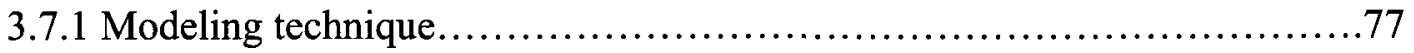

3.7.2 Modeling equations for co-flow DIR-SOFC operating with syngas...........81

3.7.2.1 Governing equations............................................ 81 
3.7.2.2 Dimensionless numbers.

3.7.2.3 Output parameters.

3.7.3 Numerical solution scheme .......................................90

3.8 System level modeling............................................... 100

3.8.1 Energy analysis.................................................... 100

3.8.2 Exergy analysis.................................................. 102

3.8.3 Modeling approaches and equations of the systems studied................106

3.8.3.1 SOFC and gas turbine based cogeneration system...................106

3.8.3.2 SOFC and biomass gasification system - Study I..................109

3.8.3.3 SOFC and biomass gasification system - Study II.................113

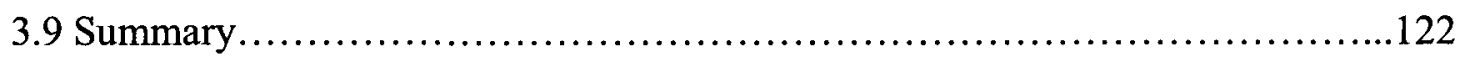

CHAPTER 4: Results and discussion........................................... 125

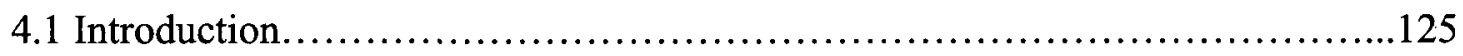

4.2 Thermodynamics and electrochemistry of SOFC ............................125

4.3 Thermodynamic modeling of direct internal reforming SOFCs operating with syngas................................................................... 127

4.3.1 Model validation................................................. 128

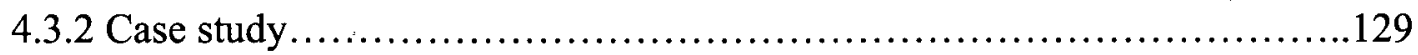

4.3.2.1 Effect of recirculation ratio..................................... 130

4.3.2.2 Effect of fuel utilization........................................132

4.4 Carbon deposition modeling in direct internal reforming SOFCs.................135

4.4.1 Carbon deposition boundary ......................................... 135

4.4.2 Effect of temperature level....................................... 136

4.4.2.1 Fuel as methane...................................................137 
4.4.2.2 Fuel as gas mixture obtained from pyrolysis.

4.4.3 Effect of chemical composition of gases from biomass gasification.........144

4.5 Transient heat transfer modeling of SOFC................................... 149

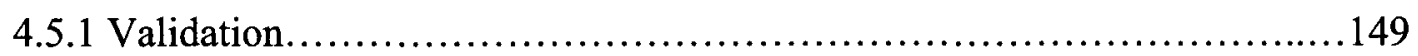

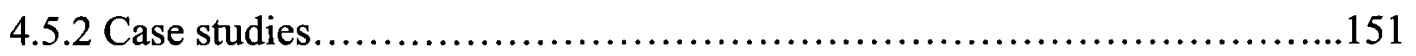

4.5.2.1 Case study-1: SOFC operating with humidified hydrogen.............151

4.5.2.1.1 Nodal Analysis............................................. 152

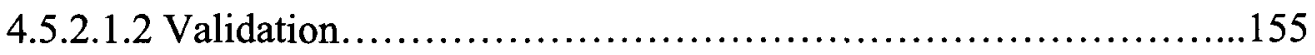

4.5.2.1.3 Transient behavior of the cell..................................162

4.5.2.1.4 Parametric studies.........................................178

4.5.2.2 Case study-2: DIR-SOFC operating with a gas mixture..............188

4.5.2.2.1 Model validation........................................ 188

4.5.2.2.2 Transient behavior of the cell................................194

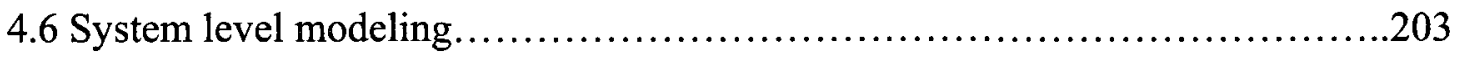

4.6.1 SOFC and gas turbine based cogeneration system......................204

4.6.2 SOFC and biomass gasification system - Study I......................209

4.6.3 SOFC and biomass gasification system - Study II......................213

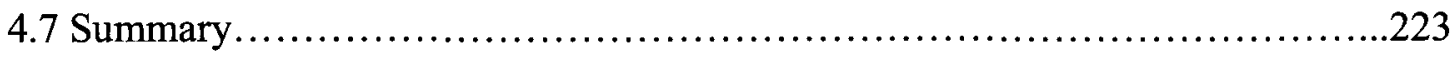

CHAPTER 5: Reduction of greenhouse gas emissions using various thermal systems

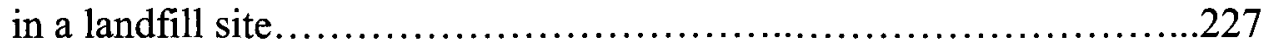

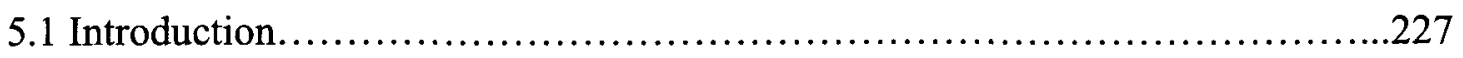

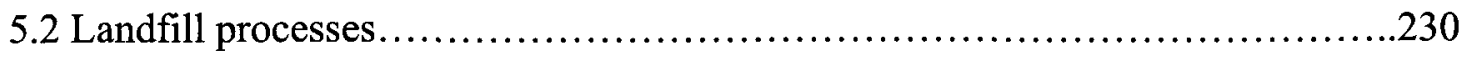

5.2.1 Calculation of landfill gas generation................................230

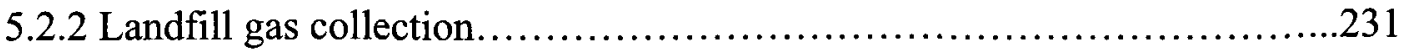




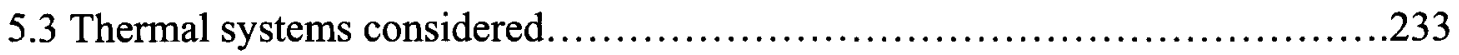

5.3.1 Internal combustion engine.......................................233

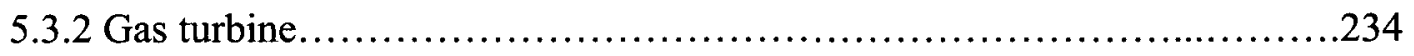

5.3 .3 Solid oxide fuel cell............................................235

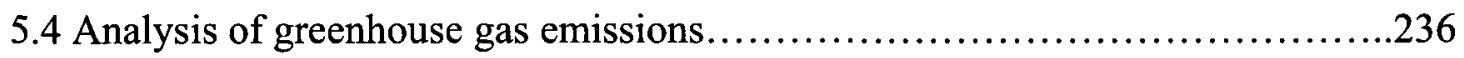

5.4.1 Landfill site without an active collection system......................236

5.4.2 Landfill site with an active collection system............................237

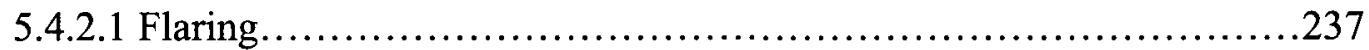

5.4.2.2 Electricity generation technologies from $\mathrm{LFG} \ldots \ldots \ldots \ldots \ldots \ldots \ldots \ldots . \ldots 238$

5.4.2.2.1 Internal combustion engine....................................238

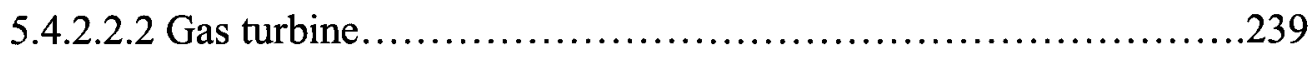

5.4.2.2.3 Solid oxide fuel cell....................................240

5.4.3 Comparison of LFG utilization technologies...........................240

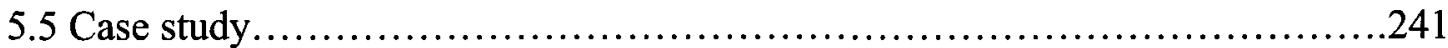

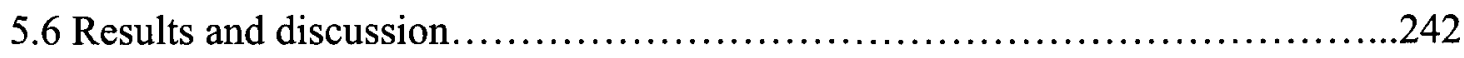

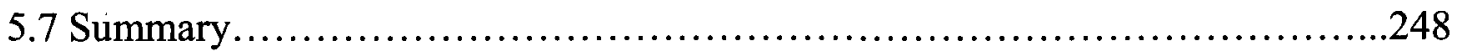

CHAPTER 6: Conclusions and recommendations.............................250

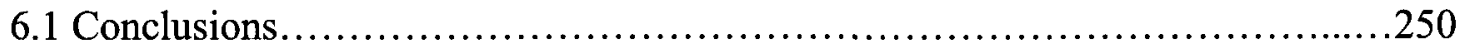

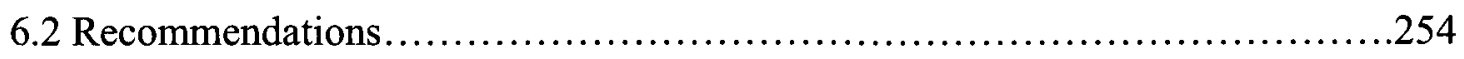

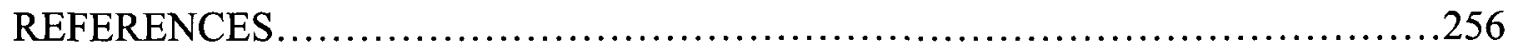




\section{LIST OF TABLES}

Table 2.1: Common fuel cell types.................................................

Table 2.2: Classification of solid oxide fuel cells....................................17

Table 2.3: Biomass feedstock that might be used as fuel in SOFC systems and their conversion methods...................................................

Table 2.4: Tolerance limits of SOFC to contaminants..............................25

Table 2.5: Advantages and disadvantages of main biomass gasification reactor types....30

Table 2.6: Comparison of planar SOFC models....................................45

Table 3.1: Coefficients of Equation (3.16) to calculate the resistivity of electrolyte

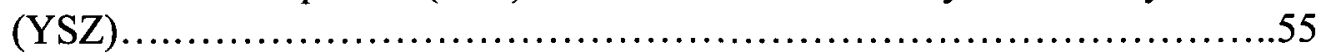

Table 3.2: Coefficients of Equation (3.16) to calculate the resistivity of other components made of common SOFC materials.............................55

Table 3.3: Chemical equilibrium constants of reactions...........................72

Table 3.4: Exergy balances for the control volumes of the system....................109

Table 4.1: Comparison of the model developed with the experimental data...............128

Table 4.2: Input values that are fixed throughout the study........................129

Table 4.3: Typical product gas composition from different gasifiers..................145

Table 4.4: Carbon activities of the syngases produced from different gasifiers..........146

Table 4.5: Input data used in the benchmark tests...............................150

Table 4.6: Cell voltage for the benchmark test-1...............................156

Table 4.7: Validation of maximum and minimum values of current density ............158

Table 4.8: Validation of maximum and minimum values of solid temperature..........158

Table 4.9: Validation of air and fuel channel outlet temperatures......................159

Table 4.10: Validation of the Model-V1 and Model-V2 of the co-flow configuration with the benchmark test-2 and Braun's model.............................190 
Table 4.11: Validation of the Model-V1 and Model-V2 of the counter-flow configuration with the benchmark test- 2 and Braun's model.

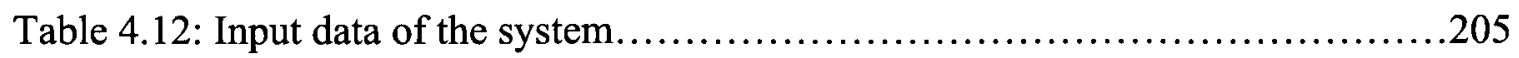

Table 4.13: Carbon activity for different recirculation ratios......................206

Table 4.14: Thermodynamic properties and exergy flow rates of the states...........207

Table 4.15: Exergy destructions and losses....................................207

Table 4.16: Input data and modeling parameters used in the case study ..............210

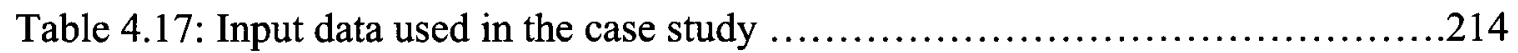

Table 4.18: Syngas compositions calculated for different cases $\ldots \ldots \ldots \ldots \ldots \ldots \ldots . \ldots 215$

Table 4.19: Output parameters of the SOFC model................................217

Table 4.20: Mass flow rate of substances entering the system.....................220

Table 4.21: Power demand for auxiliary components, net power and heat output.......220

Table 4.22: Performance assessment parameters...............................221

Table 4.23: Exergy destructions in the components and exergy loss to the

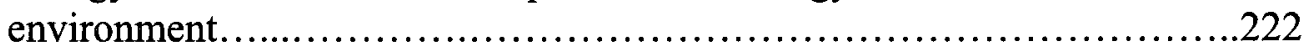

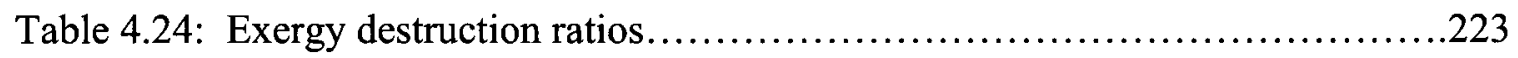

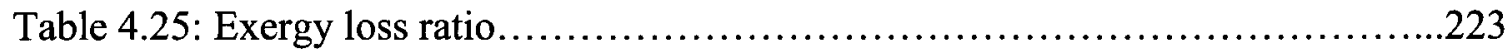

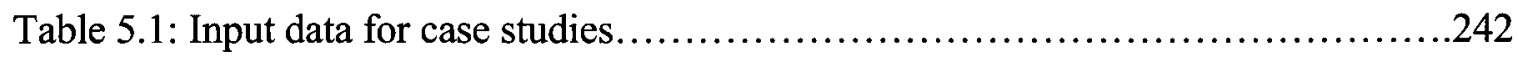




\section{LIST OF FIGURES}

Figure 2.1: Schematic diagram of a fuel cell with its main components...................6

Figure 2.2: Bipolar plates (Interconnect) that are used to connect single cells (a) end plates, (b) intermediate plates......................................

Figure 2.3: Planar SOFC stack with (a) co-flow or counter-flow (b) cross-flow configuration..........................................................

Figure 2.4: SOFC and biomass gasifier system..................................

Figure 2.5: Selection of a 2-D cross-section in a co-flow or counter-flow planar SOFC...35

Figure 3.1: Ionic resistivity of YSZ as a function of temperature ....................55

Figure 3.2: Schematic of the DIR-SOFC with anode recirculation....................60

Figure 3.3: Flow chart of the MathCAD program................................69

Figure 3.4: Schematic of a repeat element of a SOFC with anode recirculation...........70

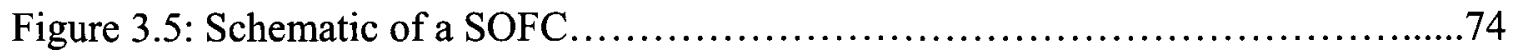

Figure 3.6: Nusselt number as a function of aspect ratio for fully developed laminar

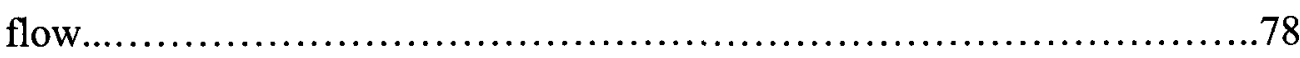

Figure 3.7: Numbering scheme for finite difference solution of the repeat element of

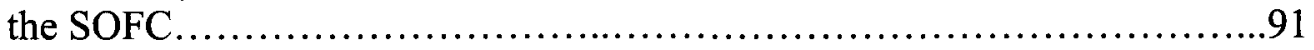

Figure 3.8: A SOFC and gas turbine based cogeneration system.....................107

Figure 3.9: Integrated biomass gasification and SOFC systems.....................114

Figure 4.1: Effect of (a) fuel utilization and temperature, (b) air utilization and temperature, on Nernst voltage.....................................126

Figure 4.2: Contribution of different polarizations and specific exergy destruction for a hydrogen fuelled SOFC.

Figure 4.3: Effect of recirculation ratio and current density on air utilization ratio for fuel utilization ratio of 0.85 . 
Figure 4.4: Effect of recirculation ratio and current density on terminal voltage for fuel utilization ratio of 0.85 .

Figure 4.5: Effect of recirculation ratio and current density on power output for fuel utilization ratio of 0.85 .

Figure 4.6: Effect of recirculation ratio and current density on electrical efficiency for fuel utilization ratio of 0.85

Figure 4.7: Effect of fuel utilization ratio and current density on air utilization ratio for recirculation ratio of 0.2

Figure 4.8: Effect of fuel utilization ratio and current density on terminal voltage for recirculation ratio of 0.2 .

Figure 4.9: Effect of fuel utilization ratio and current density on power output for recirculation ratio of 0.2

Figure 4.10: Effect of fuel utilization ratio and current density on electrical efficiency for recirculation ratio of 0.2 .

Figure 4.11: Carbon deposition boundary of C-H-O systems at $100 \mathrm{kPa}$ 136

Figure 4.12: C-H-O diagram of a LT-SOFC operating with methane. .138

Figure 4.13: C-H-O diagram of an IT-SOFC operating with methane 138

Figure 4.14: C-H-O diagram of a HT-SOFC operating with methane.

Figure 4.15: Carbon activity at the inlet for a LT-SOFC operating with methane 140

Figure 4.16: Carbon activity at the inlet for an IT-SOFC operating with methane.

Figure 4.17: Carbon activity at the inlet for a HT-SOFC operating with methane

Figure 4.18: Minimum recirculation ratio for preventing the carbon deposition for a SOFC operating with methane.

Figure 4.19: C-H-O diagram of a LT-SOFC operating with a gas mixture produced from pyrolysis.

Figure 4.20: $\mathrm{C}-\mathrm{H}-\mathrm{O}$ diagram of an IT-SOFC operating with a gas mixture produced from pyrolysis. 
Figure 4.21: Carbon activity at the inlet for a LT-SOFC operating with a gas mixture produced from pyrolysis.

Figure 4.22: Carbon activity at the inlet for an IT-SOFC operating with a gas mixture produced from pyrolysis.

Figure 4.23: Minimum recirculation ratio for preventing the carbon deposition for a SOFC operating with a gas mixture produced from pyrolysis

Figure 4.24: $\mathrm{C}-\mathrm{H}-\mathrm{O}$ diagram for determining the carbon deposition possibility for fluid bed-air, updraft-air, and downdraft-air. 146

Figure 4.25: C-H-O diagram for determining the carbon deposition possibility for downdraft- $\mathrm{O}_{2}$, multi-solid fluid bed, and twin fluid bed.

Figure 4.26: Effect of gasifier type on the air utilization ratio

Figure 4.27: Effect of gasifier type on the cell voltage 147

Figure 4.28: Effect of gasifier type on the power output.

Figure 4.29: Effect of gasifier type on the electrical efficiency.... 148

Figure 4.30: Sensitivity of number of nodes in the spatial domain to average solid temperature.

Figure 4.31: Sensitivity of number of nodes in the spatial domain to temperature of air channel.

Figure 4.32: Sensitivity of number of nodes in the spatial domain to the heat-up time..154

Figure 4.33: Sensitivity of nodes in spatial domain to current density.... 154

Figure 4.34: Sensitivity of nodes in spatial domain to temperature of fuel channel......155

Figure 4.35: Sensitivity of nodes in spatial domain to molar fraction of hydrogen......155

Figure 4.36: Comparison of current density distribution found using the Model-V1 and Model-V2 with the benchmark test (ECN's data [107])...161 
Figure 4.37: Comparison of temperature distribution in the fuel channel found using the Model-V1 and Model-V2 with the benchmark test (ECN's data [107]).

Figure 4.38: Comparison of molar hydrogen fraction distribution in the fuel channel found using the Model-V1 and Model-V2 with the benchmark test (ECN's data [107]).

Figure 4.39: 2-D temperature distributions during heat-up period (co-flow)............166

Figure 4.40: 2-D temperature distributions during start-up period (co-flow).............169

Figure 4.41: 2-D temperature distributions during heat-up period (counter-flow).......172

Figure 4.42: 2-D temperature distributions during start-up period (counter-flow)........175

Figure 4.43: Transient behavior of SOFC fueled with humidified hydrogen:

(a) average solid temperature, (b) air channel outlet temperature,

(c) fuel channel temperature.

Figure 4.44: Change of fuel utilization and current density with time for the SOFC fueled with humidified hydrogen

Figure 4.45: Change of electrical efficiency and power density with time for the SOFC fueled with humidified hydrogen.

Figure 4.46: Change of molar fraction of hydrogen with time for the SOFC fueled with humidified hydrogen for (a) co-flow case, (b) counter-flow case.....179

Figure 4.47: Effect of mass flow rate of air at the heat-up stage on the heat-up time....180

Figure 4.48: Effect of Reynolds number on the fuel utilization and average current density.

Figure 4.49: Effect of Reynolds number on the electrical efficiency and power density

Figure 4.50: Effect of excess air coefficient on the air channel outlet temperature. .184

Figure 4.51: Effect of excess air coefficient on the fuel utilization and average current density 184

Figure 4.52: Effect of excess air coefficient on the electrical efficiency and power density. 
Figure 4.53: Effect of current density and Reynolds number on cell voltage...........185

Figure 4.54: Effect of current density and Reynolds number on power density..........186

Figure 4.55: Effect of current density and Reynolds number on fuel utilization........186

Figure 4.56: Effect of current density and Reynolds number on electrical efficiency...187

Figure 4.57: Effect of thickness of air and fuel channels on fuel utilization and average current density

Figure 4.58: Effect of thickness of air and fuel channels on electrical efficiency and

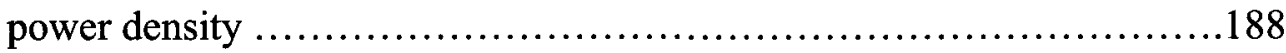

Figure 4.59: Validation for the distribution of the average solid temperature............192

Figure 4.60: Validation for the distribution of the current density ...................192

Figure 4.61: Change of voltage for co-flow configuration of Model-V1..............193

Figure 4.62: Change of voltage for co-flow configuration of Model-V2 ..............194

Figure 4.63: 2-D temperature distributions for co-flow SOFC at different time steps....198

Figure 4.64: 2-D temperature distributions for counter-flow SOFC at different time

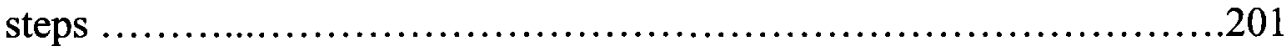

Figure 4.65: Average temperature gradient of the solid structure in the fuel flow

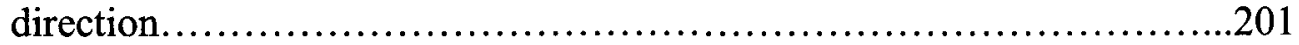

Figure 4.66: Change of average solid temperature with time for the DIR-SOFC operating with a gas mixture ........................................202

Figure 4.67: Change of air channel outlet temperature with time for the DIR-SOFC operating with a gas mixture.

Figure 4.68: Change of fuel channel temperature with time for the DIR-SOFC operating with a gas mixture.

Figure 4.69: Change of fuel utilization and average current density with time for the DIR-SOFC operating with a gas mixture. .203

Figure 4.70: Change of electrical efficiency and power density with time for the DIR-SOFC operating with a gas mixture. .204

Figure 4.71: Exergy destructions and losses compared to the exergy of the fuel. 207 
Figure 4.72: Exergy destructions of the components compared to the total exergy destruction. .208

Figure 4.73: Effect of ambient temperature on the fuel utilization efficiency and exergetic efficiency of the system.

Figure 4.74: Syngas composition for different gasifier temperature .211

Figure 4.75: Change of air utilization ratio with current density ....................212

Figure 4.76: Change of cell voltage with current density 212

Figure 4.77: Change of power output of a single cell with current density.

Figure 4.78: Change of electrical efficiency with current density 213

Figure 4.79: Change of maximum carbon activity with distance. .216

Figure 4.80: Change of current density with distance. .217

Figure 4.81: 2-D temperature profile of SOFC for Case-1 (air gasification) .218

Figure 4.82: 2-D temperature profile of SOFC for Case-2 (Enriched oxygen gasification).

Figure 4.83: 2-D temperature profile of SOFC for Case-3 (Steam gasification). .219

Figure 5.1: Greenhouse gas emission routes in a landfill site with LFG collection system. .232

Figure 5.2: Annual gas generation of LFG and its components .243

Figure 5.3: Collected and uncollected amount of LFG and its components. 243

Figure 5.4: Total GHG emissions for various LFG utilization methods .245

Figure 5.5: Performance of the SOFC .246

Figure 5.6: Global warming impact ratio for different scenarios .247

Figure 5.7: Specific lifetime GHG emission for different scenarios .248 


\section{LIST OF SYMBOLS}

a extent of steam reforming reaction for methane, mole/s

$a_{c} \quad$ carbon activity

$A \quad$ active surface area, $\mathrm{cm}^{2}$

$A S R$ area specific resistance, $\mathrm{ohm}-\mathrm{cm}^{2}$

$b \quad$ extent of water gas shift reaction, mole/s

$B i \quad$ Biot number

c extent of electrochemical reaction, mole/s

C number of components; weight percentage of carbon in biomass

$c_{p} \quad$ specific heat at constant pressure, $\mathrm{J} / \mathrm{g}-\mathrm{K}$

$\bar{c}_{p} \quad$ specific molar heat at constant pressure, $\mathrm{J} / \mathrm{mol}-\mathrm{K}$

$D \quad$ diffusivity, $\mathrm{cm}^{2} / \mathrm{s}$

$D_{h} \quad$ hydraulic diameter, $\mathrm{m}$

$e \quad$ specific exergy, $\mathrm{kJ} / \mathrm{kg}$; extent of steam reforming reaction for methane, mole/s

ex specific molar exergy, $\mathrm{J} /$ mole

Ex $\quad$ exergy flow rate, $\mathrm{W}$

$f$ extent of water gas shift reaction, mole/s

F Faraday constant, C; view factor; degree of freedom

Fo Fourier number

FUE fuel utilization ratio

$g \quad$ standard gravity, $\mathrm{cm} / \mathrm{s}^{2}$

$\bar{g} \quad$ specific molar gibbs free energy, $\mathrm{J} / \mathrm{mole}$

GWP global warming potential 
$h$ heat transfer coefficient, W/cm ${ }^{2-} \mathrm{K}$; specific molar enthalpy, J/mole

$\bar{h} \quad$ specific molar enthalpy, $\mathrm{J} /$ mole

$H \quad$ weight percentage of hydrogen in biomass

$\dot{H} \quad$ enthalpy flow rate, $\mathrm{W}$

HHV higher heating value, $\mathrm{MJ} /$ tonnes

$i \quad$ current density, $\mathrm{A} / \mathrm{cm}^{2}$

$i_{o} \quad$ exchange current density, $\mathrm{A} / \mathrm{cm}^{2}$

$i_{a s} \quad$ anode-limiting current density, $\mathrm{A} / \mathrm{cm}^{2}$

$i_{c s} \quad$ cathode-limiting current density, $\mathrm{A} / \mathrm{cm}^{2}$

I current, A

$k \quad$ thermal conductivity, W/cm-K; methane generation rate, year ${ }^{-1}$

$K \quad$ equilibrium constant

$L \quad$ thickness of a cell component, $\mu \mathrm{m}$

$L_{c} \quad$ characteristic length, $\mathrm{cm}$

$L_{\text {cell }} \quad$ length of the cell, $\mathrm{cm}$

$L_{o} \quad$ potential methane generation capacity, $\mathrm{m}^{3} /$ tonnes

$L H V$ lower heating value, $\mathrm{J} / \mathrm{mole}$

$m$ mass, tonnes- $\mathrm{CO}_{2}$.eq; molar ratio of water to dry biomass

$\dot{m} \quad$ mass flow rate, $\mathrm{g} / \mathrm{s}$

$M \quad$ molecular weight, $\mathrm{g} /$ mole

$M_{i} \quad$ mass of waste accepted in the $\mathrm{i}^{\text {th }}$ year, tonnes

MC moisture content 
$n \quad$ number

$\dot{n} \quad$ molar flow rate, mole/s

$\dot{N} \quad$ molar flow rate, mole/s

$N \quad$ weight percentage of nitrogen in biomass

$\mathrm{Nu} \quad$ Nusselt number

$O$ weight percentage of oxygen in biomass

$O X \quad$ fraction of methane oxidized in the soil

$P \quad$ pressure, $\mathrm{kPa}$

PHR power to heat ratio

$q \quad$ specific molar heat, $\mathrm{J} / \mathrm{mole}$

$\dot{Q} \quad$ heat transfer rate, $\mathrm{W}$

$Q_{C H 4}$ annual methane generation, $\mathrm{m}^{3} /$ year

$r \quad$ recirculation ratio

$\dot{r} \quad$ conversion rate, mole/s

$R \quad$ universal gas constant, $\mathrm{J} /$ mole-K

$\operatorname{Re}_{D_{h}} \quad$ Reynolds number in an internal flow

$s \quad$ specific entropy rate, $\mathrm{J} / \mathrm{mol}-\mathrm{K}$

$\dot{S} \quad$ entropy rate, $\mathrm{W} / \mathrm{K}$

$t \quad$ time, s; thickness, $\mathrm{cm}$

$t_{i j} \quad$ age of the $\mathrm{j}^{\text {th }}$ section of waste mass $\mathrm{M}_{\mathrm{i}}$ accepted in the $\mathrm{i}^{\text {th }}$ year, years

$T \quad$ temperature, $\mathrm{K}$

$u \quad$ velocity, $\mathrm{cm} / \mathrm{s}$

$U_{f} \quad$ fuel utilization ratio 


$\begin{array}{ll}U_{a} & \text { air utilization ratio } \\ U_{o x} & \text { oxidant utilization ratio } \\ V & \text { voltage, } \mathrm{V} \\ v e n t & \text { fraction of vented gas in flare } \\ V_{v} & \text { porosity } \\ w & \text { width, cm; power output of a single cell, W } \\ \dot{W} & \text { power output, W } \\ x & \text { molar concentration } \\ y & \text { exergetic ratio }\end{array}$

\section{Greek Letters}

$\beta \quad$ exergetic correlation constant

$\rho \quad$ electrical resistivity of cell components, ohm-cm; mass density, $\mathrm{g} / \mathrm{cm}^{3}$

$\eta_{e l} \quad$ electrical efficiency

$\eta_{\text {coll }} \quad$ collection efficiency

$\eta_{\text {ICE }} \quad$ electrical efficiency of internal combustion engine

$\eta_{s c} \quad$ isentropic efficiency of compressor

$\eta_{s t} \quad$ isentropic efficiency of steam turbine

$\lambda_{\text {air }} \quad$ excess air coefficient

$\tau \quad$ tortuosity

$\mu \quad$ viscosity, $\mathrm{g} / \mathrm{s}-\mathrm{cm}$; chemical potential, $\mathrm{J} / \mathrm{mole}$

$\sigma \quad$ Stefan-Boltzmann constant; specific lifetime $\mathrm{GHG}$ emission, tonnes.eq. $\mathrm{CO}_{2} / \mathrm{MWh}$

$\varepsilon \quad$ emissivity; exergetic efficiency 
$\varepsilon_{\text {ICE }}$ specific GHG emission ratio of internal combustion engine, tonnes.eq. $\mathrm{CO}_{2} / \mathrm{MWh}$

$\alpha \quad$ thermal diffusivity, $\mathrm{cm}^{2} / \mathrm{s}$; aspect ratio

$\Gamma \quad$ global warming impact ratio

$T \quad$ number of days that electricity producing technology operates per year, days

$\lambda$ molar ratio of steam entering the gasifier to the drybiomass

$\bar{\lambda} \quad$ fuel-air ratio on molar basis

$v \quad$ specific volume, $\mathrm{cm}^{3} / \mathrm{g}$

\section{Subscripts}

$\begin{array}{ll}a & \text { anode; air } \\ a c & \text { air channel } \\ a c t & \text { activation } \\ a i & \text { anode interconnect } \\ a v e & \text { average } \\ b & \text { Boudard } \\ c & \text { cathode; convection } \\ c, i & \text { combustor inlet } \\ c, o & \text { combustor outlet } \\ c i & \text { cathode interconnect } \\ c o n c & \text { concentration } \\ c p s & \text { cell per stack } \\ C V & \text { control volume } \\ D & \text { destruction }\end{array}$


e electrolyte; exit

eff effective

el electrochemical; electrical

eq equilibrium

fc fuel channel

F fuel

$F C \quad$ fuel cell

fi fuel channel inlet

g gas

gen generated

GHG greenhouse gas

$i \quad$ inlet

L loss

ohm ohmic

$m \quad$ cracking of methane reaction

mix mixture

$N \quad$ Nernst

o standard

$P \quad$ product

$P E N$ positive/electrolyte/negative

prod product

$r \quad$ reaction; radiation

react reactant 


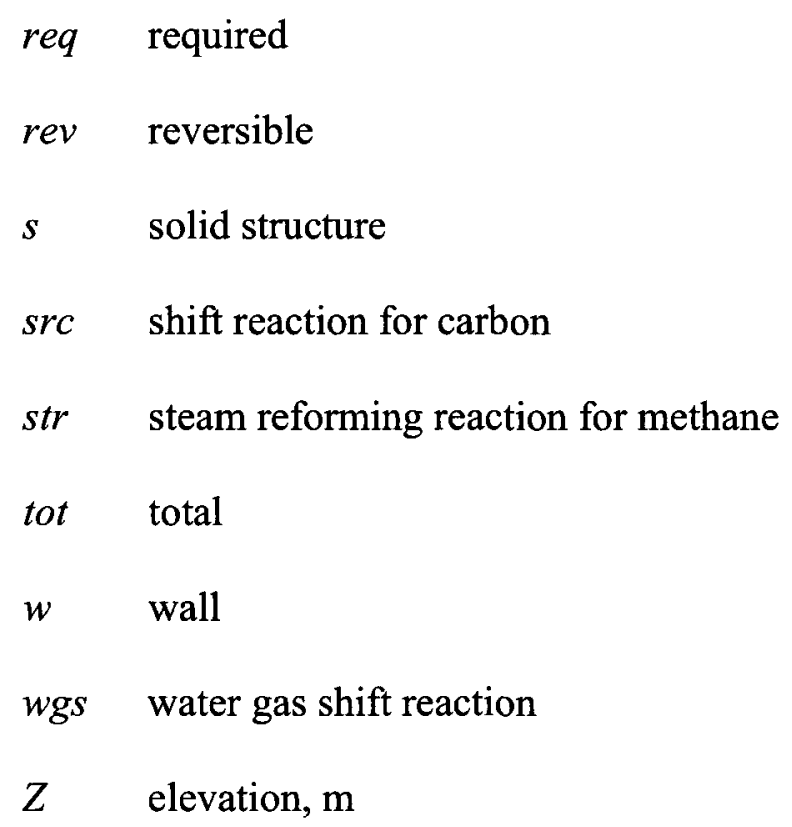

\section{Superscripts}

a anode

b bulk

c cathode

$\mathrm{CH}$ chemical

$P H \quad$ physical

o standard state 


\section{CHAPTER 1}

\section{INTRODUCTION}

\subsection{Introduction}

Fossil fuels (oil, natural gas, and coal) have been used as the main energy source since the beginning of the industrial revolution. Traditionally, these fuels have mainly been converted into electricity using technologies such as internal combustion engine, gas turbine, and steam turbine. Due to the increase in the global energy demand, depletion of fossil fuels, and increased concern over the impact of greenhouse gases on global warming, alternative fuel and energy systems are being sought out. Among the alternative fuels, biomass and hydrogen have received significant attention since these fuels can increase the global energy supply security, reduce the dependency on fossil fuel resources, and reduce the discharge of the greenhouse gas emissions to the atmosphere. Equally important to new fuel sources is the conversion of these fuels into electricity in an efficient and environmentally friendly manner. In this regard, many companies and researchers have been developing new electricity generation technologies to provide answers to the issues raised above. For example, fuel cells can convert the chemical energy of the fuel into electricity with high efficiency and low environmental impacts. Furthermore, integration of fuel cells with other technologies can even yield higher efficiencies. 


\subsection{Motivation}

As discussed in Section 1.1, several factors such as the global energy supply security and the need for generating efficient and clean energy have increased the interest in research related to alternative fuel and energy systems. Among these alternative systems, the biomass-fuelled integrated solid oxide fuel cell (SOFC) system has been identified as one of key energy technologies for the future since it combines the merits of renewable energy sources and hydrogen energy systems.

The modeling of energy systems plays a crucial role in the estimation of the performance and selection of the configuration and the operation parameters of these systems. In the case of integrated SOFC systems, there are many aspects that should be considered for a complete and robust model. These include: a) taking into account different heat transfer and polarization modes in the SOFC, b) considering transient behavior of the SOFC, c) taking into account the carbon deposition problem, and d) using advanced thermodynamics tools such as exergy analysis. The lack of such a model for integrated SOFC and biomass gasification systems in the literature has been the main motivation of this thesis.

\subsection{Objectives}

The objectives of this thesis were:

- To develop a thermodynamic model of a direct internal reforming SOFC operating with syngas.

- To study the carbon deposition problem in direct internal reforming SOFC. 
- To develop a transient and quasi 2-D heat transfer model to study heat-up and start-up stages of SOFCs.

- To develop system level models to study the performance of integrated SOFC systems through energy and exergy analyses.

- To compare SOFC with other technologies in terms of the greenhouse gas emissions produced from these systems.

\subsection{Thesis Outline}

The following chapter provides an overview of fuel cells, solid oxide fuel cells in particular, and biomass fed integrated solid oxide fuel cell systems. A literature review on SOFC modeling in cell, stack and system levels was also included.

The third chapter included several modeling techniques and equations at different levels, i.e. from cell level to system level. Firstly, basic definitions and equations for thermodynamics and electrochemistry of SOFC systems were outlined. Secondly, the thermodynamic model for a direct internal reforming SOFC operating with syngas was explained. Thirdly, carbon deposition modeling in a direct internal reforming SOFC was discussed. Fourthly, modeling technique and equations for the transient heat transfer model of SOFC systems were given. Finally, modeling techniques of several integrated SOFC systems were discussed. 
The fourth chapter included the results and discussion of several case studies that were carried out using the models discussed in Chapter 3. The validation of the models and several parametric studies were also included in this chapter.

The fifth chapter was devoted to the study of a comparison of landfill site greenhouse gas emissions from several technologies including SOFC, gas turbine, and internal combustion engine.

In the last chapter, the conclusions derived from this thesis were discussed with recommendations for future research. 


\section{CHAPTER 2}

\section{BACKGROUND AND LITERATURE REVIEW}

\subsection{Introduction}

This chapter provides an introduction to the systems studied in this thesis including a literature review of SOFC modeling techniques. The introductory section discussed fuel cells, fuel cell types and applications, SOFC systems, SOFC classification as well as fuel options, and biomass fed SOFC systems including various integrated SOFC systems operating with fuel derived from biomass. In the literature review included, studies conducted on cell, stack and system levels in the literature were discussed in detail.

\subsection{Fuel Cells}

Fuel cells are electrochemical devices that convert the energy in the fuel into electricity with high efficiency and low environmental impact. A unit cell, which is the core component of a fuel cell, has mainly three components as shown in Figure 2.1, anode, cathode and electrolyte. Fuel and air are continuously supplied to the anode and cathode, respectively. Ions which are produced during the electrochemical reactions at one of the electrodes are conducted to the other electrode through the electrolyte. Electrons are cycled via load. An electric current is formed by the flow of electrons and it effectuates work on the load. 


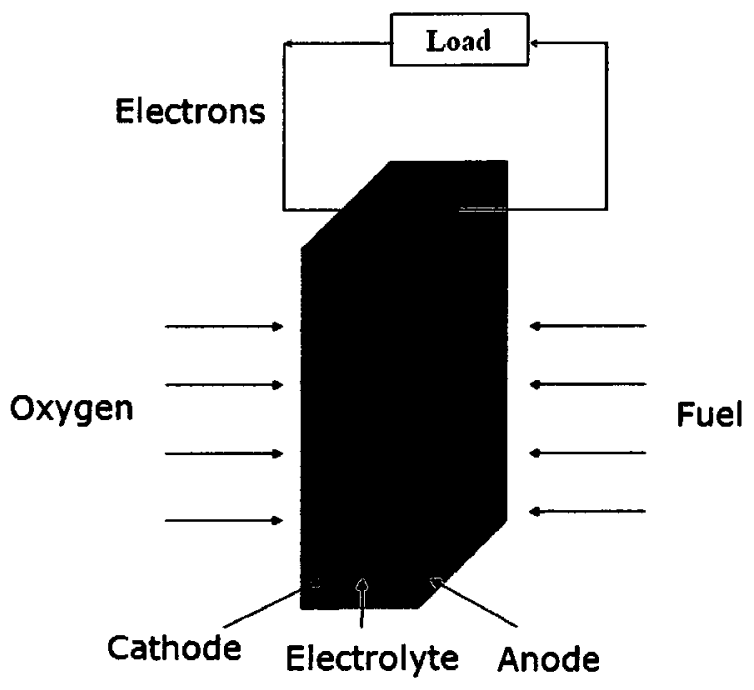

Figure 2.1: Schematic diagram of a fuel cell with its main components.

A single cell can only generate a small amount of power. To generate meaningful quantities of power, many single cells should be brought together; a process referred to as 'stacking'. This process is generally done by connecting single cells in series using bipolar plates. A bipolar plate, which is shown in Figure 2.2, is manufactured such that it forms channels for air and fuel to flow inside the stack.

\subsubsection{Technologies}

There are different types of fuel cells which differ from each other according to the type of electrolyte and fuel used. Hence, the electrochemical reactions that occur at the electrode/electrolyte interface and the type of ion conducting at the electrolyte change according to the different type of fuel cell used. Among these fuel cells, Molten Carbonate Fuel Cell (MCFC) and SOFC are known as high-temperature fuel cells since 
their operating temperatures are considerably higher than the other fuel cell types. A comparison of the common fuel cell types is given in Table 2.1.

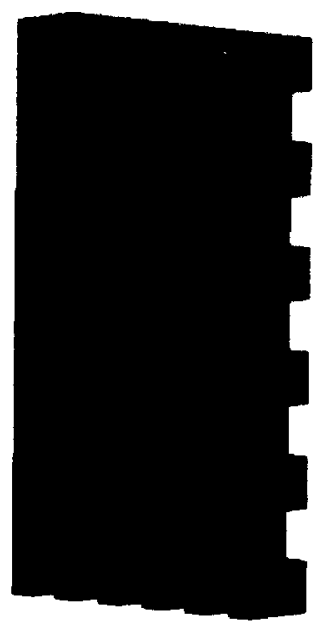

(a)

(b)

Figure 2.2: Bipolar plates (Interconnect) that are used to connect single cells (a) end plates, (b) intermediate plates.

Table 2.1: Common fuel cell types.

\begin{tabular}{|l|l|l|l|}
\hline $\begin{array}{l}\text { Fuel Cell } \\
\text { Type }\end{array}$ & $\begin{array}{l}\text { Mobile } \\
\text { Ion }\end{array}$ & $\begin{array}{l}\text { Operating } \\
\text { Temperature }\end{array}$ & Applications \\
\hline AFC & $\mathrm{OH}^{-}$ & $50-200^{\circ} \mathrm{C}$ & Used in space vehicles \\
\hline PEMFC & $\mathrm{H}^{+}$ & $30-100^{\circ} \mathrm{C}$ & $\begin{array}{l}\text { Vehicles and mobile applications, and for lower } \\
\text { power CHP systems }\end{array}$ \\
\hline DMFC & $\mathrm{H}^{+}$ & $20-90{ }^{\circ} \mathrm{C}$ & $\begin{array}{l}\text { Suitable for portable electronic systems of low } \\
\text { power, running for long times }\end{array}$ \\
\hline PAFC & $\mathrm{H}^{+}$ & $\sim 220^{\circ} \mathrm{C}$ & Large numbers of $200-\mathrm{kW} \mathrm{CHP} \mathrm{systems} \mathrm{in} \mathrm{use}$ \\
\hline MCFC & $\mathrm{CO}^{2-}$ & $\sim 6500^{\circ} \mathrm{C}$ & $\begin{array}{l}\text { Suitable for medium- to large-scale CHP systems, } \\
\text { up to MW capacity }\end{array}$ \\
\hline SOFC & $\mathrm{O}^{2-}$ & $500-1000^{\circ} \mathrm{C}$ & $\begin{array}{l}\text { Suitable for all sizes of CHP systems, } 2 \mathrm{~kW} \text { to } \\
\text { multi-MW }\end{array}$ \\
\hline
\end{tabular}

Source: Larminie and Dicks [1]. 
Proton Exchange Membrane Fuel Cell (PEMFC), Direct Methanol Fuel Cell (DMFC), and Alkaline Fuel Cell (AFC) are the most common low temperature fuel cell types, whereas SOFC is the mostly employed high temperature fuel cell type. These fuel cell types are discussed in detail in the next section.

\subsubsection{Proton exchange membrane fuel cell (PEMFC)}

This type of fuel cell is also known as the polymer electrolyte membrane fuel cell. It consists of a proton conducting membrane, such as Nafion, which is chemically highly resistant, mechanically strong, acidic, good proton conductor, and water absorbent.

The reactions occurring at the anode and cathode and the overall reaction are given in Equations (2.1)-(2.3), respectively.

$$
\begin{aligned}
& \mathrm{H}_{2} \rightarrow 2 \mathrm{H}^{+}+2 e^{-} \\
& 0.5 \mathrm{O}_{2}+2 \mathrm{H}^{+}+2 e^{-} \rightarrow \mathrm{H}_{2} \mathrm{O} \\
& \mathrm{H}_{2}+0.5 \mathrm{O}_{2} \rightarrow \mathrm{H}_{2} \mathrm{O}
\end{aligned}
$$

Some main advantages of the PEMFC are: a) fast startup capability since it works at low temperatures, b) compactness since thin membrane electrode assemblies (MEAs) can be made, and c) elimination of corrosion problems since the only liquid present in the cell is water. 
The main disadvantage of this type of fuel cell is the need for expensive catalysts as promoters for the electrochemical reaction. In addition, carbon monoxide cannot be used as a fuel since it poisons the cell. On the other hand, the main challenge for PEMFC is water management problems. Because the proton conductivity of the electrolyte is directly proportional to the water content, there must be sufficient water to avoid membrane dehydration. However, low levels of water should be present in the electrolyte to avoid flooding the electrodes. Hence, a balance between the production of water by oxidation of the hydrogen and evaporation has to be controlled.

\subsubsection{Direct methanol fuel cell (DMFC)}

This type of fuel cell also uses a proton conducting membrane similar to the PEMFC. The main difference between PEMFC and DMFC is the direct feeding of methanol to the fuel cell instead of reforming methanol before feeding. The reactions occurring at the anode and the cathode and the overall reaction are given in Equations (2.4)-(2.6), respectively.

$$
\begin{aligned}
& \mathrm{CH}_{3} \mathrm{OH}+\mathrm{H}_{2} \mathrm{O} \rightarrow \mathrm{CO}_{2}+6 \mathrm{H}^{+}+6 e^{-} \\
& 1.5 \mathrm{O}_{2}+6 \mathrm{H}^{+}+6 e^{-} \rightarrow 3 \mathrm{H}_{2} \mathrm{O} \\
& \mathrm{CH}_{3} \mathrm{OH}+1.5 \mathrm{O}_{2} \rightarrow \mathrm{CO}_{2}+2 \mathrm{H}_{2} \mathrm{O}
\end{aligned}
$$

The main advantages of the DMFC are: a) usage of methanol as fuel which is a readily available and less expensive fuel, b) high energy density of methanol, and c) simple to use and very quick to refill. 
The main disadvantage of the DMFC is the slow reaction kinetics of the methanol oxidation, which results in a lower power for a given size. The second major problem is the fuel crossover; the polymer membrane of DMFC is permeable to methanol which means it may diffuse from the anode through the electrolyte to the cathode. Hence, migrated fuel is wasted which will decrease the amount of electrons produced. It also reduces the cell voltage, hence the cell performance. The current approach to minimizing the methanol permeation rate is to limit the methanol concentration to approximately 5 $\mathrm{wt} \%$ despite the loss in performance [2].

There are two types of DMFC: active and passive. In the active type, fuel and air flows are controlled to get high performance. In the passive type, the air is introduced into the cell by natural flow, i.e. self breathing, and the fuel is infiltrated into the cells. There is less control over the variables of fuel and air stoichiometry in the passive type. The passive one is much simpler compared to the active type, but the performance is not as high. The active type of DMFC is useful for high power products such as laptops, LCDTVs, and digital cameras. Alternatively, the passive type of DMFC is good for small and low power products such as the fuel cell powered $\mathrm{mp} 3$ player.

\subsubsection{Alkaline fuel cell (AFC)}

The alkaline fuel cell has become popular particularly for powering space vehicles. However, the success of other low-temperature fuel cells has led to a decline in the interest in the AFC mainly due to issues related to cost, reliability, and ease of use. 
However, there is one type of AFC which still receives attention. It is the Direct Borohydride Fuel Cell (DBFC) which uses a solution of sodium borohydride as fuel.

The reactions occurring at the anode and the cathode and the overall reaction for this fuel cell type are given in Equations (2.7)-(2.9), respectively.

$$
\begin{aligned}
& \mathrm{NaBH}_{4}+8 \mathrm{OH}^{-} \rightarrow \mathrm{NaBO}_{2}+6 \mathrm{H}_{2} \mathrm{O}+8 e^{-} \\
& 2 \mathrm{O}_{2}+8 e^{-}+4 \mathrm{H}_{2} \mathrm{O} \rightarrow 8 \mathrm{OH}^{-} \\
& \mathrm{NaBH}_{4}+2 \mathrm{O}_{2} \rightarrow \mathrm{NaBO}_{2}+2 \mathrm{H}_{2} \mathrm{O}
\end{aligned}
$$

The main advantages of DBFC are as follows: a) formation of eight electrons from one mole of fuel, b) prevention of $\mathrm{CO}_{2}$ poisoning since highly alkaline fuel and waste borax are used, and c) simple to make it as the electrolyte and the fuel are mixed.

The main disadvantage of DBFC is the side reaction known as hydrolysis reaction. Hydrogen is produced as $\mathrm{NaBH}_{4}$ reacts with water. However, with modern techniques, hydrogen can be oxidized immediately giving eight electrons provided that the hydrolysis reaction is well controlled and does not proceed too quickly.

\subsubsection{Solid oxide fuel cell (SOFC)}

Solid oxide fuel cell is a high temperature fuel cell that can be designed to operate in temperatures ranging from $500{ }^{\circ} \mathrm{C}$ to $1000^{\circ} \mathrm{C}$. Compared to low temperature fuel cells, it has the advantage to be simpler in design concept since there is no liquid phase. A wide 
range of fuel such as methane, methanol, ethanol, and biomass produced gas can be used in this type of fuel cell; however these gases need to be reformed inside or outside the fuel cell. Using gases containing carbon as fuel can cause problems related to carbon deposition. This problem can be avoided by adjusting the steam-to-carbon ratio at the inlet of the fuel channel. Another advantage of this fuel cell is the ability to integrate with other systems, e.g. gas turbine, gasification system, etc., due to the high temperature exits. More details on this kind of fuel cell can be found in Section 2.3.

\subsubsection{Other fuel cell types}

Direct Formic Acid Fuel Cell (DFAFC), Direct Ethanol Fuel Cell (DEFC) and Bio-Fuel Cells (BFC) may be used in some of the small scale applications. The first two uses a PEM where formic acid and ethanol are used as fuel, respectively. DFAFC is advantageous due to its high catalytic activity, easier water management, and minimal balance of plant. However, performance of the cell strongly depends on the feed concentration of formic acid due to mass transport limitations. Generally, high feed concentrations are needed. DEFC may be preferable due to the advantages of ethanol such as high energy density, safety to use, and ease of storage. However, in the electrochemical reactions a lot of acetaldehyde is produced which is a very flammable and harmful liquid. Further, DEFC reaction kinetics is very slow and ethanol crossover is a problem.

BFC may be used in very low power applications. Mainly, there are two classes of BFC; microbial fuel cell and enzymatic fuel cell. The first one has higher efficiency and 
complete oxidation of fuel, but lower power density. Hence, it is more applicable for larger scale applications such as powering underwater equipment. The latter one has high power density but lower efficiency and incomplete oxidation of fuel. It may be used in small scale application such as implantable devices.

\subsubsection{Applications}

Fuel cells can be used in different application areas, which are generally distinguished from each other according to their power requirements. Main application areas are niche, military, transportation, and stationary power and heat generation.

Niche applications are now becoming the main market area for fuel cells, which include laptops, mobile phones, camcorders, digital cameras, portable generators for camping and other recreational activities, and battery chargers. In each of these applications, the consumer prefers small, lightweight and long operated devices which may be provided by portable fuel cells. Further, because batteries might not be able to supply the power needed for the new devices with a greater amount of functions, portable fuel cells should be preferred since they have a higher power density. For example, fuel cells can enable the universal connectivity of wireless devices such as laptop computers and $3 \mathrm{G}$ phones. Currently, there are several companies developing portable fuel cells using DMFC technology.

Military defense research plays an important role in the development of fuel cells since there is a great deal of funding in this area. Fuel cells are important for military purposes 
because the future soldiers are intended to have equipment needing high power such as night vision devices, global positioning systems, target designators, climate controlled body suits, and digital communication systems. These should be light enough for soldiers to carry. They should also be able to operate for a long time. It is obvious that batteries cannot provide these energy needs at an acceptable weight. Therefore, fuel cells are expected to be essential for the military operations. Another important topic for military is using a fuel such as diesel and JP-8 that is available in the battle area in any part of the world. Hence, SOFC is one of the best options for the purposes where the fuel availability is the main criteria. PEMFC and DMFC may also be preferred depending on the size and purpose of a military application.

The primary fuel for the transport sector is oil. Oil accounts for $97 \%$ of transport fuel in the industrialized countries with natural gas only $2 \%$ and electricity $1 \%$. For developing countries, growing dependence on oil is more severe since energy demand is growing three times faster than in OECD countries [3]. Due to the depletion of fossil fuels, fuel cells have begun to replace internal combustion engines in the transportation sector. Among the different fuel cell types, PEMFC is the leading candidate for transportation sector because of its cost, high power density, size, weight, simple design, low operating temperature $\left(<120^{\circ} \mathrm{C}\right)$, and rapid start-up. On the other hand, SOFC and DMFC may be also used in some specific applications. For example, SOFC systems are being developed as an auxiliary power unit for high class car conveniences at BMWAG in Munich [4]. Ballard Power Systems and Daimler Chrysler unveiled a DMFC prototype in Stuttgart, 
Germany [5]. In this system, methanol was used to power a small one-person demonstration vehicle.

Stationary power and heat generation is another application area of fuel cells. MCFC and SOFC are the most promising fuel cell types for this kind of application due to their high operation temperature. These fuel cells can be used alone or together with other technologies such as gas turbine, steam turbine, and gasification systems in combined heat and power, i.e. cogeneration, applications.

\subsection{Solid Oxide Fuel Cells}

Solid oxide fuel cell (SOFC) is an energy conversion device that contains an oxide ionconducting electrolyte made from a ceramic material and operates at temperatures ranging from $500^{\circ} \mathrm{C}$ to $1000{ }^{\circ} \mathrm{C}$. The main application area of SOFC is stationary power and heat generation. It may also be used in transportation applications such as auxiliary power unit of automobiles and portable applications.

The operation principle of a SOFC is simple. Fuel and air are continuously supplied to the fuel and air channels, respectively. Oxygen molecules in the air stream react with the electrons which are cycling via the load at the cathode/electrolyte interface and oxide ions are formed. These oxide ions conduct through the electrolyte and react with the hydrogen and carbon monoxide molecules in the fuel stream at the anode/electrolyte interface, and water vapor, carbon dioxide and electrons are formed. An electric current is formed by the flow of electrons and it effectuates work on the load. Many cells should be 
connected to form meaningful amount of power, which is called stacking. Schematics of planar co-, counter- and cross-flow SOFC stacks are shown in Figure 2.3.

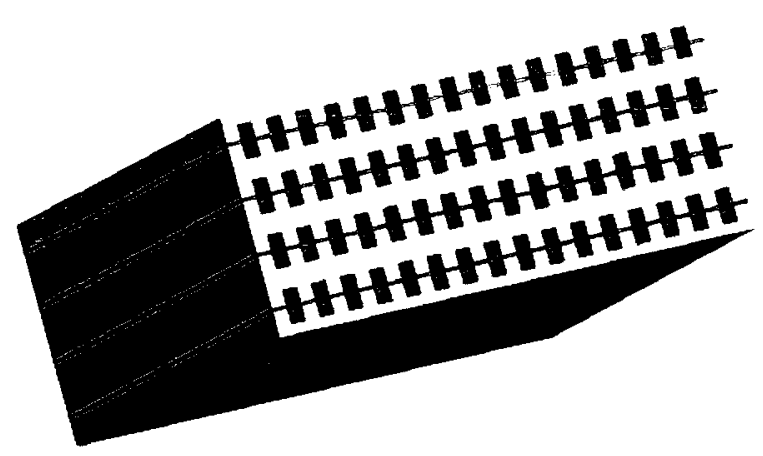

(a)

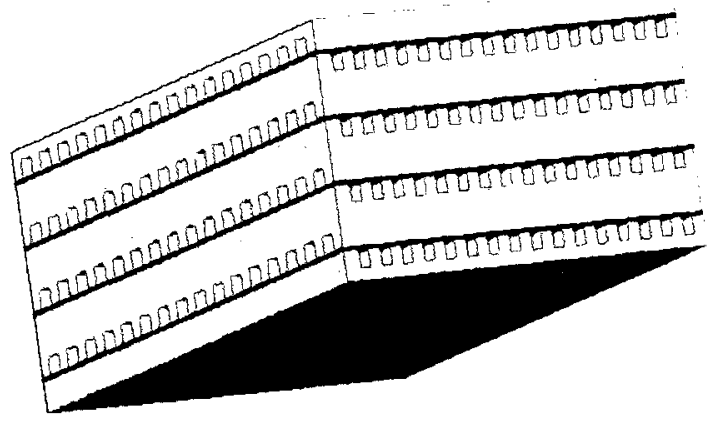

(b)

Figure 2.3: Planar SOFC stack with (a) co-flow or counter-flow (b) cross-flow configuration.

SOFCs have important advantages when compared to other fuel cell types including: a) simpler in concept since only solid and gas phases exist, b) no electrolyte management issues, c) no need for precious metal electrocatalysts, d) internal reforming of gas mixtures including hydrocarbons, e) ability to use carbon monoxide as fuel, and f) efficient thermal integration with bottoming cycles such as gas turbines.

Some disadvantages of SOFCs over other fuel cells are: a) challenges for construction and durability due to its high temperature, and b) carbon deposition problem. 


\subsubsection{Classification of SOFC systems}

SOFCs may be classified according to their temperature level, cell and stack design, type of support, flow configuration, and fuel reforming type, as shown in Table 2.2.

Table 2.2: Classification of solid oxide fuel cells.

\begin{tabular}{|l|l|}
\hline $\begin{array}{l}\text { Classification } \\
\text { criteria }\end{array}$ & Types \\
\hline $\begin{array}{l}\text { Temperature } \\
\text { level }\end{array}$ & $\begin{array}{l}\text { Low temperature SOFC (LT-SOFC) }\left(500^{\circ} \mathrm{C}-650^{\circ} \mathrm{C}\right) \\
\text { Intermediate temperature SOFC (IT-SOFC) }\left(650^{\circ} \mathrm{C}-800^{\circ} \mathrm{C}\right) \\
\text { High temperature SOFC (HT-SOFC) }\left(800^{\circ} \mathrm{C}-1000^{\circ} \mathrm{C}\right)\end{array}$ \\
\hline $\begin{array}{l}\text { Cell and stack } \\
\text { design }\end{array}$ & $\begin{array}{l}\text { Planar SOFC (Flat-planar, radial-planar) } \\
\text { Tubular SOFC (Micro-tubular, tubular) } \\
\text { Segmented-in-Series SOFC (or Integrated-planar SOFC) } \\
\text { Monolithic SOFC }\end{array}$ \\
\hline Type of support & $\begin{array}{l}\text { Self-supporting (Anode-supported, cathode-supported, electrolyte- } \\
\text { supported) } \\
\text { External-supporting (Interconnect supported, porous substrate } \\
\text { supported) }\end{array}$ \\
\hline $\begin{array}{l}\text { Flow } \\
\text { configuration }\end{array}$ & $\begin{array}{l}\text { Co-flow } \\
\text { Cross-flow } \\
\text { Counter-flow }\end{array}$ \\
\hline $\begin{array}{l}\text { Fuel reforming } \\
\text { type }\end{array}$ & $\begin{array}{l}\text { External reforming SOFC (ER-SOFC) } \\
\text { Direct internal reforming SOFC (DIR-SOFC) } \\
\text { Indirect internal reforming SOFC (IIR-SOFC) }\end{array}$ \\
\hline
\end{tabular}

\subsubsection{Classification according to the temperature level}

SOFCs may be classified as low-temperature (LT-SOFC), intermediate-temperature (ITSOFC), or high-temperature (HT-SOFC). The advantages of HT-SOFC over LT-SOFC and IT-SOFC include: a) resistivity of cell components decreases, hence ohmic polarization decreases; b) electrode kinetics increase, hence the sluggishness of reactions decreases; which in turn decreases the activation polarization; and c) since the 
temperature of the anode output is higher, HT-SOFC have better thermal integration with bottoming cycles which results in a higher system efficiency.

Some disadvantages of HT-SOFC over LT-SOFC and IT-SOFC are: a) they require longer start-up and shut-down time; b) their structural integrity is weaker; c) corrosion rates increase; and d) material costs are higher.

\subsubsection{Classification according to the cell and stack design}

According to the cell and stack design, SOFCs may be classified as tubular, planar, segmented-in-series, and monolithic. Among these cell designs, tubular is the most common and developed one. Siemens (previously known as Siemens-Westinghouse) has been working on this design for more than 30 years. In this design, the cell components are deposited in the form of thin layers on cylindrical tube. Despite its simpler geometric configuration, planar type has not been considered at the first development stages of SOFC because of the issues with the sealing. However, recently there are more manufacturers developing planar-type SOFCs than other types because sealing problem is eliminated thanks to the developments in SOFC materials and using lower temperature SOFC. Main manufacturers are Ceramic Fuel Cells Ltd., Sulzer Hexis, General Electric and Mitsubishi Heavy Industries. In the monolithic design, the different cell components are fabricated as thin layers. The cell consists of a honeycomb like array of adjacent fuel and oxidant channels. Although the monolithic SOFC offer potentially the highest power density of all SOFC designs, their fabrication has proven to be a formidable task. As a result, this design is not being pursued further [6]. Mitsubishi Heavy Industries and Rolls 
Royce [7] are manufacturing segmented-in-series SOFC which is the newest design of the SOFC. This design is a cross between tubular and planar geometries which have the advantages of thermal expansion freedom like the tubular and low cost component fabrication like the planar.

The advantages of planar design over tubular design are: a) it is more compact since cells can be stacked without giving large voids like in the case of tubular design; b) bipolar plates provide simpler series of electrical connection between cells; c) since the current path is shorter, ohmic losses are lower; and d) fabrication costs are lower.

The disadvantage of planar design over tubular design is the need for gas-tight sealing in planar design. However, in tubular design, the cells may expand and contract without any constraints.

\subsubsection{Classification according to the type of support}

SOFCs may be manufactured as anode-supported, cathode-supported, or electrolytesupported. As the temperature of a SOFC increases, the ionic resistivity of its electrolyte decreases. For this reason, for high temperature SOFCs, electrolyte-supported configuration is generally selected. For intermediate and low temperature fuel cells, the electrolyte is manufactured in a very thin form and the fuel cell is either manufactured in an anode or cathode-supported manner. These three types of manufacturing may be called self-supporting configuration. There is also an external supporting configuration: 
interconnect- supported and porous substrate supported. However, this type of configuration is not commonly used.

\subsubsection{Classification according to the flow configuration}

Fuel and oxidant flows in a SOFC can be cross-flow, co-flow, or counter-flow. The choice of the flow configuration has significant effects on the temperature distribution within the stack. Recknagle et al. [8] have shown that, for similar fuel utilization and average cell temperature, the co-flow case has the most uniform temperature distribution and the smallest thermal gradients.

\subsubsection{Classification according to the fuel reforming type}

Fuels that can be used in a SOFC other than $\mathrm{H}_{2}$ and $\mathrm{CO}$, which are discussed in Section 2.3.2, must be reformed into $\mathrm{H}_{2}$ and/or CO. This reforming process may be outside the stack which is called external reforming, or inside the stack, which is called internal reforming. There are two types of internal reforming which are indirect internal reforming (IIR-SOFC) and direct internal reforming (DIR-SOFC). In the IIR-SOFC, the reformer section is separate from the other components inside the cell but in close thermal contact with the anode section. In the DIR-SOFC, the reforming takes place directly on the anode catalyst.

The advantages of indirect reforming over direct reforming are: a) since electrochemical reaction and reforming reaction occur at separate catalysts, there are less simultaneous reactions on catalysts, which makes this type easier to control thermodynamically; b) 
more highly dispersed catalysts may be chosen since the catalyst at the reformer section is only responsible for reforming; and c) carbon deposition problem is less serious.

The disadvantages of indirect reforming over direct reforming are: a) it is difficult to preserve the uniform temperature distribution in the stack since the cells closer to the reforming section will be cooler due to the endothermic reforming reaction; and $b$ ) it is less efficient than direct internal reforming type.

\subsubsection{Fuel options for SOFC}

One of the main advantages of SOFC is its fuel flexibility. There might be many options for choosing the fuel. If these fuels are not $\mathrm{H}_{2}$ and $\mathrm{CO}$, they are reformed to these gases which are electrochemically oxidized at the anode.

Methane and higher hydrocarbons are reformed to $\mathrm{H}_{2}, \mathrm{CO}, \mathrm{H}_{2} \mathrm{O}$ and $\mathrm{CO}_{2}$ by the steam reforming and water-gas shift reactions, which are shown by Equations (2.10) and (2.11), respectively.

Steam reforming of hydrocarbons: $\mathrm{C}_{x} \mathrm{H}_{y}+x \mathrm{H}_{2} \mathrm{O} \rightleftharpoons x \mathrm{CO}+\left(x+\frac{y}{2}\right) \mathrm{H}_{2}$

Water-gas shift: $\mathrm{CO}+\mathrm{H}_{2} \mathrm{O} \rightleftharpoons \mathrm{CO}_{2}+\mathrm{H}_{2}$

Methanol is a preferable fuel due to its availability, high energy density, ready storage, and distribution [9]. It is an effective fuel for LT-SOFC and IT-SOFC because it can be efficiently reformed at lower temperatures compared to natural gas and higher 
hydrocarbons [10]. The reactions involved in the production of hydrogen from the steam reforming of methanol can be represented by the widely accepted decomposition-shift mechanisms, which consist of Equations (2.11) and (2.12) [11].

Decomposition of methanol: $\mathrm{CH}_{3} \mathrm{OH} \rightleftharpoons 2 \mathrm{H}_{2}+\mathrm{CO}$

Ethanol can be considered as a very promising and reliable fuel option for fuel cells because it can be biochemically produced from biomass [12]. It is an effective fuel due to its high heating value and high hydrogen atom content. The steam reforming reaction for ethanol may be given as

Steam reforming of ethanol: $\mathrm{C}_{2} \mathrm{H}_{5} \mathrm{OH}+3 \mathrm{H}_{2} \mathrm{O} \rightleftharpoons 2 \mathrm{CO}_{2}+6 \mathrm{H}_{2}$

Gas mixture produced from gasification, pyrolysis, or anaerobic digestion of biomass is another fuel option for SOFC [13]. This gas, which consists of various gaseous components such as $\mathrm{H}_{2}, \mathrm{CO}, \mathrm{CO}_{2}, \mathrm{H}_{2} \mathrm{O}$ as well as impurities such as particulate matter and tars, should be treated before entering the fuel cell. There are two different options, a cold process involving gas cleaning at a reduced temperature and a hot process involving gas cleaning at a high temperature. A discussion regarding use of hot and cold gas cleanup subsystems in a SOFC system may be found in Reference [14].

Another option is using ammonia as a fuel in SOFC. Ammonia presents an inexpensive and convenient way of storing hydrogen. However, the potential impact of ammonia as a 
fuel for solid oxide fuel cells has not been fully appreciated by the SOFC community. Catalytic cracking of ammonia reaction which is shown in Equation (2.14) represents the production of hydrogen from ammonia [15].

Catalytic cracking of ammonia: $2 \mathrm{NH}_{3} \rightleftharpoons \mathrm{N}_{2}+3 \mathrm{H}_{2}$

Lu and Schaefer [16] investigated the possibility of using hydrogen sulfide in SOFC. Hydrogen sulfide is known to be an extremely corrosive and noxious gas. Hence, direct use of $\mathrm{H}_{2} \mathrm{~S}$ in a SOFC causes anode deterioration over time. A possible option is using a $\mathrm{H}_{2} \mathrm{~S}$ decomposition reactor integrated with an SOFC. The decomposition reaction of $\mathrm{H}_{2} \mathrm{~S}$ is given in Equation (2.15).

The decomposition of $\mathrm{H}_{2} \mathrm{~S}: \mathrm{H}_{2} \mathrm{~S} \rightleftharpoons \mathrm{H}_{2}+\frac{1}{x} S_{x}$

\subsection{Biomass Fed SOFC}

Biomass has increased its importance due to the fact that it can be utilized as a potential fuel source in advanced energy systems. Also, systems based on biomass fuel are considered to contribute to the sustainable development in industrialized and developing countries. In this regard, researchers tend to find solutions to obtain efficient and economical heat and electricity generation from biomass fuel.

There are various types of biomass such as wood, crops, and municipal solid waste. According to 2001 data [3], biomass has a share of $10.7 \%$ in the total global primary 
energy use and $1.1 \%$ in the world electricity production. It is expected that the biomass share of electricity output will increase to a point between $2 \%$ and $5.1 \%$ in 2050 according to different scenarios [17]. Today's technology of converting biomass to electricity is mostly based on combustion of feedstock to generate steam that is used to drive the steam turbine [18]. Other technologies include externally fired gas turbines and biomass integrated gasification combined cycles [19].

Among the different types of fuel cells, MCFC and SOFC are considered the most promising ones for biomass-fueled fuel cells due to their high operating temperatures, flexibility to different fuel, and greater tolerance to contaminants. According to the biomass conversion method, some of the other fuel cell types may also be useful. For example, landfill gas and digester gas are mostly used with Phosphoric Acid Fuel Cell (PAFC) today and their usage with this kind of fuel cell has been successfully demonstrated [20]. Additionally, the suitability of biogas as a fuel for PEMFC has been experimentally confirmed [21].

Biomass fuelled integrated SOFC system is one of the key energy technologies of the future since it combines the merits of renewable energy sources and hydrogen energy systems. There has been an increasing interest in converting biomass to a product gas by various methods for using it as a fuel in SOFC. These methods include thermochemical, biochemical, or mechanical extraction methods. The last method is mostly used to produce bio-diesel with esterification. Thermochemical conversion methods may be classified as combustion, gasification, pyrolysis, and liquefaction. Biochemical 
conversion methods are fermentation and anaerobic digestion. Among them, products obtained from fermentation, anaerobic digestion, fast pyrolysis, and gasification of biomass are suitable to be used in SOFC systems due to the compatibilities of these technologies, which are described in the following subsections. In Table 2.3, the conversion methods of several biomass feedstocks that might be used as a fuel in a SOFC system are shown. In all of them, the product obtained from the conversion of biomass must be cleaned up according to the tolerance limits of the SOFC to the contaminants, which are given in Table 2.4.

Table 2.3: Biomass feedstock that might be used as fuel in SOFC systems and their conversion methods.

\begin{tabular}{|l|l|l|}
\hline Examples of Biomass Feedstock & Conversion Method & Product \\
\hline $\begin{array}{l}\text { Cellulosic waste, corn stover, sugarcane waste, } \\
\text { wheat or rice straw }\end{array}$ & Fermentation & Ethanol \\
\hline Sewage sludge, animal waste & Anaerobic digestion & Biogas \\
\hline $\begin{array}{l}\text { Wood, tyre rubber, starch, grape wastes, coconut } \\
\text { shells }\end{array}$ & Fast pyrolysis & Bio-oil \\
\hline $\begin{array}{l}\text { Wood, black liquor, municipal solid waste, dairy } \\
\text { manure }\end{array}$ & Gasification & Syngas \\
\hline
\end{tabular}

Table 2.4: Tolerance limits of SOFC to contaminants.

\begin{tabular}{|l|l|}
\hline Contaminant & Tolerance Limit \\
\hline $\mathrm{H}_{2} \mathrm{~S}$ & $\begin{array}{l}<0.1 \mathrm{ppm} \\
<1 \mathrm{ppm} \text { (Poison gas) }\end{array}$ \\
\hline $\mathrm{HCl}$ & $<1 \mathrm{ppm}$ (Poison gas) \\
\hline $\mathrm{NH}_{3}$ & $<5000 \mathrm{ppm}$ \\
\hline $\mathrm{SiO}_{2}$ & $<1 \mathrm{mg} / \mathrm{Nm}^{3}$ (Deposition) \\
\hline
\end{tabular}

Source: $[20,23]$ 


\subsubsection{Integrated SOFC systems fuelled with ethanol produced from fermentation of}

\section{biomass}

Ethanol fermentation is a biological process in which organic material is converted to simpler compounds by microorganisms. These compounds are then fermented by microorganisms to produce ethanol and $\mathrm{CO}_{2}$. Approximately $80 \%$ of the ethanol produced in the world is obtained from fermentation [22]. The advantages of ethanol are: abundant production capacity, easy to transport, relatively free of impurities and low toxicity; whereas the main drawback is its cost on a dollar per Btu basis compared to other hydrocarbon alternatives [20].

Ethanol should be reformed to hydrogen to be used in a SOFC. Steam reforming, reforming with $\mathrm{CO}_{2}$, and partial oxidation with air are the possible ways [24]. Steam reforming is considered to be a better choice for integrated SOFC systems [25], which is shown in Equation (2.13).

In Lully, Switzerland, Sulzer Hexis has installed an agricultural biogas plant based on SOFC. They successfully operated the unit for more than $5000 \mathrm{~h}$ with fermentation gas. The electrical power and maximum electrical stack efficiency of the system are $857 \mathrm{~W}$ (DC) and 33\% (DC, gross), respectively [25]. 


\subsubsection{Integrated SOFC systems fuelled with biogas produced from anaerobic}

\section{digestion of biomass}

Anaerobic digestion is the biological process of microbial consumption of organic material to produce biogas, which is a mixture mainly consisting of methane and carbon dioxide, in the absence of oxygen. The chemical composition of an anaerobic digester gas is in the following range [26]: $55-65 \% \mathrm{CH}_{4}, 30-40 \% \mathrm{CO}_{2}, 1-10 \% \mathrm{~N}_{2}$, and less than $0.5 \%$ $\mathrm{O}_{2}$. Contaminants include up to $200 \mathrm{ppm}_{2} \mathrm{~S}, 4 \mathrm{ppm}$ halogens, and other hydrocarbons. Biogas produced from the anaerobic digestion has an energy content of about $20-40 \%$ of the lower heating value of the feedstock, which has generally high moisture content organic wastes (80-90\% moisture) [27].

The product gas from anaerobic digestion of biomass needs extensive gas cleanup process before it enters to SOFC due to high levels of contaminants in the gas. Then, the methane content in the gas should be reformed to hydrogen and carbon monoxide to be electrochemically reacted in the SOFC.

In Hammarby, Sweden, biogas produced in a sewage treatment plant is converted into heat and electricity using three $5 \mathrm{~kW}$ SOFC systems [28].

\subsubsection{Integrated SOFC systems fuelled with bio-oil produced from fast pyrolysis of}

\section{biomass}

Fast pyrolysis is a thermochemical process in which feedstock is rapidly heated to a temperature around $500{ }^{\circ} \mathrm{C}$ in the absence of oxygen, and then vaporized and condensed 
to liquid oil, which has approximately half of the heating value of the fossil oil. Other than the main product, bio-oil, which is up to $80 \%$ wt on dry feed, byproduct gases and solid char are formed. These by-products are used within the process so there are no waste streams $[20,29]$.

Bio-oil produced from pyrolysis of biomass is a liquid mixture of oxygenated compounds containing various chemical functional groups such as carbonyl, carboxyl, and phenolic [26]. This mixture should be reformed to hydrogen with a catalytic steam reforming

process to be used in SOFC. The overall steam-reforming reaction of bio-oil is given by Equation (2.16) [30].

$\mathrm{C}_{n} \mathrm{H}_{m} \mathrm{O}_{k}+(2 n-k) \mathrm{H}_{2} \mathrm{O} \rightleftharpoons n \mathrm{CO}_{2}+(2 n+m / 2-k) \mathrm{H}_{2}$

Until today, there have not been any demonstration projects on bio-oil fuelled integrated SOFC systems. However, research and development is continuing on this subject.

\subsubsection{Integrated SOFC systems fuelled with syngas produced from gasification of biomass}

Biomass gasification is a thermochemical conversion technology where fuel is converted into a gas mixture called syngas, mainly consisting of carbon monoxide, carbon dioxide, hydrogen, methane, water vapor, nitrogen, but also contaminants. The composition of the product gas depends mainly on the fuel, gasifier type, and gasification agent. 
Woody biomass such as residues from forestry operations or herbaceous biomass such as purpose-grown miscanthus can have moisture content ranging from $15 \%$ to over $60 \%$ at the point of harvest. Higher levels of moisture in the feedstock cause more energy requirement for evaporation in the gasifiers, hence the reaction temperature decreases, which results in poorer product gas with higher levels of tar. Due to this fact, forced drying of the biomass in general becomes necessary in such systems; which can represent the highest capital cost in the pretreatment section. In these driers, the medium needed to dry the solid may be selected as pure vapor or a mixture of vapor and non-condensable gas or combustion products [31]. In the case of SOFC, hot exit gas streams of the fuel cell may be circulated to the drier to reduce the moisture of the biomass.

Since the gasification is an endothermic process, heat must be added to the gasifier; which may be done in two ways: autothermal or allothermal. In autothermal gasification, necessary heat is provided by partial oxidation within the process; whereas in allothermal gasification, an external source supplies the necessary amount of heat. In the latter case, heat for gasification may be supplied from the depleted fuel and air streams of SOFC.

There are various gasifier types for different purposes with each of them having advantages and disadvantages, which are listed in Table 2.5. A survey has revealed the percentage of the commercially offered gasifiers as follows [32]: $75 \%$ downdraft, $20 \%$ fluid bed (including circulating fluid bed), $2.5 \%$ updraft, and $2.5 \%$ other types. According to Brigwater [32], the following selection may be done according to the scale 
of the application: downdraft-fixed bed for small scale, bubbling fluidized bed for medium scale, and circulating fluidized bed for large scale.

Table 2.5: Advantages and disadvantages of main biomass gasification reactor types.

\begin{tabular}{|c|c|c|}
\hline Reactor type & Advantages & Disadvantages \\
\hline Downdraft-fixed bed & $\begin{array}{l}\text { Very simple and robust } \\
\text { Low particulates and tar } \\
\text { High exit gas temperature } \\
\text { Moderate cost }\end{array}$ & $\begin{array}{l}\text { Lower moisture level tolerability } \\
\text { Scale-up limitations } \\
\text { Feed size limitations }\end{array}$ \\
\hline Updraft-fixed bed & $\begin{array}{l}\text { Simple and reliable } \\
\text { Higher moisture level tolerability } \\
\text { Low cost } \\
\text { High thermal efficiency and } \\
\text { carbon conversion }\end{array}$ & $\begin{array}{l}\text { Very dirty product gas with high levels of } \\
\text { tars } \\
\text { Scale-up limitations } \\
\text { Intolerant to high portions of fines in feed } \\
\text { Low exit gas temperature }\end{array}$ \\
\hline Bubbling fluid bed & $\begin{array}{l}\text { Good temperature control } \\
\text { Good scale-up potential } \\
\text { Greater tolerance to particle size } \\
\text { range } \\
\text { Large scale applications }\end{array}$ & $\begin{array}{l}\text { High particulates and moderate tar } \\
\text { Limited turn-down capability } \\
\text { Some carbon loss with ash } \\
\text { Higher particle loading }\end{array}$ \\
\hline Circulating fluid bed & $\begin{array}{l}\text { Good temperature control } \\
\text { Good scale-up potential } \\
\text { Greater tolerance to particle size } \\
\text { range } \\
\text { Large scale applications } \\
\end{array}$ & $\begin{array}{l}\text { High cost at low capacity } \\
\text { High particulates and moderate tar } \\
\text { Higher particle loading } \\
\text { Difficulties with in-bed catalytic } \\
\text { processing }\end{array}$ \\
\hline Entrained flow & $\begin{array}{l}\text { Simple design } \\
\text { Good scale-up potential } \\
\text { Potential for low tar }\end{array}$ & $\begin{array}{l}\text { Costly feed preparation } \\
\text { Carbon loss with ash } \\
\text { Limitations with particle size }\end{array}$ \\
\hline Twin fluid bed & $\begin{array}{l}\text { Good temperature control } \\
\text { Greater tolerance to particle size } \\
\text { range } \\
\text { Large scale applications }\end{array}$ & $\begin{array}{l}\text { High tar levels } \\
\text { Difficult to scale-up } \\
\text { High cost }\end{array}$ \\
\hline
\end{tabular}

Source: Adapted from [32, 33].

Air, oxygen, steam or a combination of these may be used as gasification agents. Partial oxidation with air yields high $\mathrm{N}_{2}$ content in the product gas (i.e. $\sim 50 \%$ ). For this case, the heating value of gas is around $5 \mathrm{MJ} / \mathrm{m}^{3}$. In the case of partial oxidation with oxygen, heating value of gas around $11 \mathrm{MJ} / \mathrm{m}^{3}$ without any significant $\mathrm{N}_{2}$ content achieved. However, providing and using oxygen is costly. On the other hand, gasification with 
steam gives higher heating value of gas around $17 \mathrm{MJ} / \mathrm{m}^{3}$, but at the expense of lower overall efficiency [32].

For selecting the gasifier and gasification agent for a SOFC based system, application area and system configuration plays an important role. There are several demonstration projects of SOFC based power generation systems on different power ranges such as 25 $\mathrm{kW}, 100 \mathrm{~kW}$, and $250 \mathrm{~kW}$ [34]. Downdraft gasifier might be selected for these kinds of sizes since it has a moderate cost and produce low level of contaminants. The largest demonstration project for SOFC based power generation system is the $1 \mathrm{MW}$ hybrid SOFC/micro-turbine generator [35]. For this size, bubbling fluid bed might be a good option due to its advantages mentioned above. In this selection, as long as an effective gas cleanup system is designed, level of contaminant in the product gas is not an issue. However, more energy input and capital cost is required to clean higher level amounts of contaminants. On the other hand, gasification agent affects the system performance and cost. Since supplying oxygen is costly and air yields low heating value of the product gas, steam gasification seems the best option. But, if it is also desired to produce heat as well as electricity, this may yield lower fuel utilization efficiency since less amount of steam is sent for generating process heat. It should also be noted that syngas produced from gasification may be directly reformed in the SOFC with the steam-reforming and watergas shift reactions. A schematic diagram of an integrated SOFC and biomass gasification system is given in Figure 2.4. 


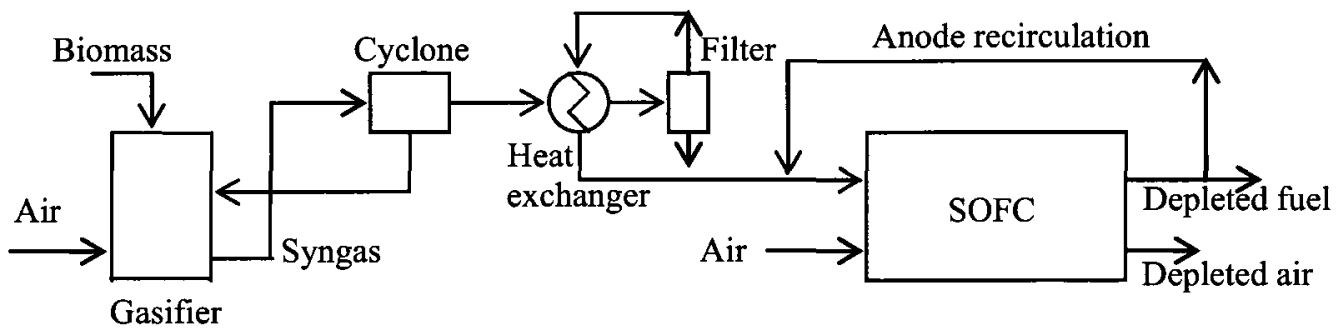

Figure 2.4: SOFC and biomass gasifier system.

There are more research, development, and demonstration projects on biomass gasification and SOFC systems compared to SOFC systems operating with gases produced from other biomass conversion methods. For example, in the University of North Dakota, an integrated IT-SOFC and downdraft gasifier system working with wood chips with very low ash and alkali content has been developed [36]. The main objective of their project was to design and build a working, self-contained biomass gasification power system without external heating or cooling sources and integrate it with a SOFC. The Norwegian University of Science and Technology (NTNU) researchers have been developing an integrated SOFC and gasification system with high temperature gas cleaning for high efficiency electricity production from biomass [37]. The main objectives of their study were onsite testing of a $10 \mathrm{~kW}$ SOFC stack integrated with a high temperature filter at a gasification plant and optimizing the system's overall performance. There are also two notable European Union financed projects which are Green Fuel Cell [38] and BioCellus [39]. The objective of the first one was to produce a gas that can meet the requirements as fuel for SOFC through reliable, up-scalable and cost-effective staged gasification of biomass; whereas the second one aimed to develop 
an integrated SOFC and allothermal gasifier system in which the waste heat of the fuel cell is transferred into the reformer by means of liquid metal heat pipes.

\subsection{Literature Review on SOFC Modeling}

According to the purpose and needs of the model, different considerations may be taken into account in a SOFC model. In cell and stack level modeling, 0-D, 1-D, 2-D, and 3-D approaches may be chosen. Additionally, transient modeling should be used if any of the following or combination of them needs to simulated: heat-up, start-up, shut-down and load change. Stresses occurring inside the fuel cell may be calculated using thermomechanical modeling. Carbon deposition modeling helps in preventing the carbon deposition at the anode catalyst. In system level, integration of SOFC with other systems can be assessed through energy and exergy analyses. The studies found in the literature using these approaches are discussed in the following subsections.

\subsubsection{Cell and stack level modeling}

\subsubsection{0-D, 1-D, 2-D and 3-D modeling techniques}

0-D modeling is the simplest approach to model SOFC. In this approach, the fuel cell is considered as a black box. Using the principles of thermodynamics and electrochemistry, the fuel cell is modeled to find the output parameters such as cell voltage, power output, and cell efficiency for different input parameters such as inlet gas composition, temperature of the inlet fuel and air, and fuel and air utilization ratios. For example, using this approach, an analysis on different options of external reforming of methane for SOFC was carried out by Demin et al. [40]. Steam reforming, partial oxidation, and 
exhaust gas reforming options, i.e. reforming methane by recirculating the depleted fuel stream, were compared. The results showed that the most efficient way to feed a SOFC is by exhaust gas reforming, while the partial oxidation efficiencies showed lower values, especially at high temperatures.

In 1-D modeling, two of the geometrical dimensions are ignored which leads to an assumption that variation of gas and electrical properties at those two dimensions are uniform. In this approach, co-flow and counter-flow configurations may be modeled; but, cross-flow cannot be modeled. The variation of gas composition, temperature, and current density along the fuel and air channels direction may be investigated. For example, Rao [41] developed a 1-D model for a tubular SOFC which accounts for the heat and mass transfer processes occurring within the cell as well as the electrochemistry. The calculated performance reflects the effect of particular system design conditions such as fuel composition, operating pressure, fuel utilization, and geometric parameters such as tube dimensions.

When using the 2-D modeling technique, one dimension is neglected and a 2-D section is considered for representing the fuel cell. There might be possible selections for a 2-D cross-section. The most reasonable selection for a co-flow or counter-flow SOFC is shown in Figure 2.5. This selection includes all the components of the repeat element and the gas flow direction. However, the part at which the interconnect is in contact with the Positive/Electrolyte/Negative (PEN) structure cannot be fully taken into account with this 
selection. There are also some studies using this approach to model cross-flow SOFC [e.g. 42, 43].

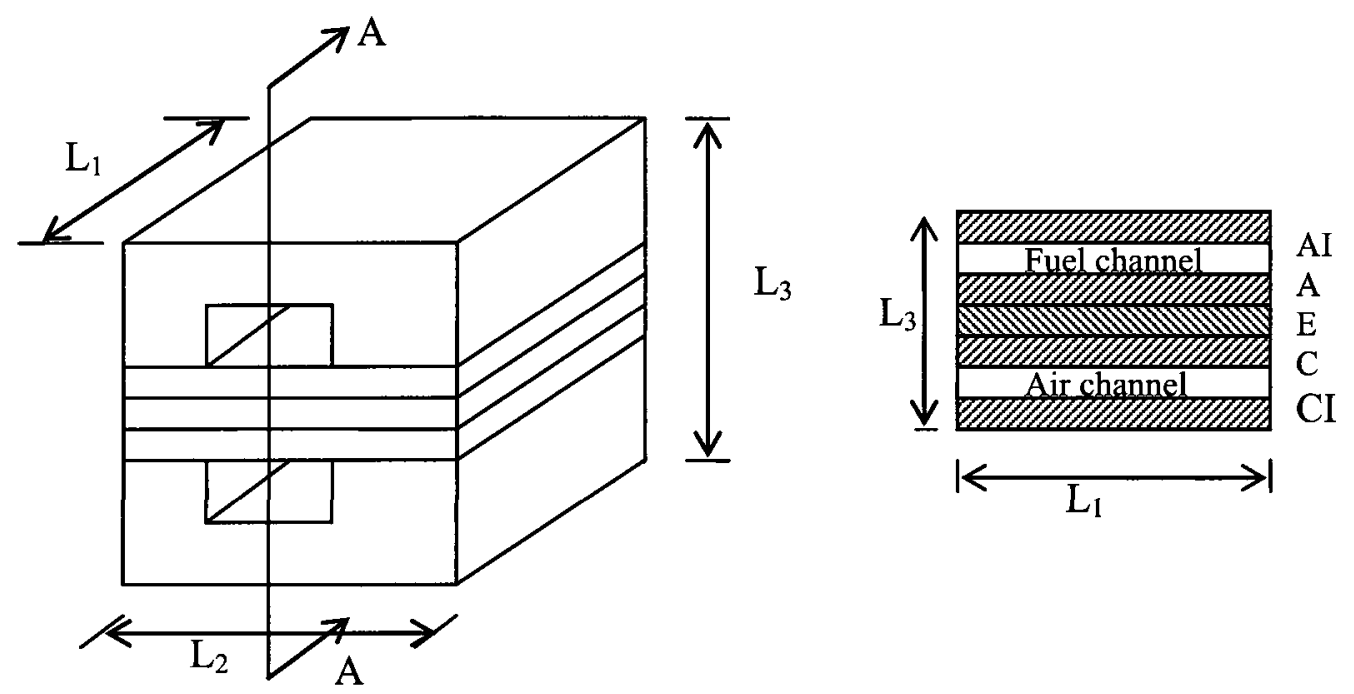

Figure 2.5: Selection of a 2-D cross-section in a co-flow or counter-flow planar SOFC.

3-D modeling is used when a detailed knowledge of the SOFC behavior is needed. Usually, commercial computational fluid dynamics (CFD) software are used for modeling. For instance, Yakabe et al. [44] used STAR-CD software for the thermo-fluid model of a planar SOFC. The molar gas composition, temperature, voltage, and current density distributions were calculated using a single-unit model for co-flow and counterflow configurations. Pasaogullari and Wang [45] developed a 3-D SOFC model which fully couples electrochemical kinetics with multi-dimensional gas dynamics and multicomponent transport of species. The model was implemented into the Fluent software, using its customization ability via user defined functions. The polarization curve, flow 
field, species concentrations, potential, and current distributions throughout the cell were determined using this model.

\subsubsection{Transient modeling}

Understanding the transient behavior of a SOFC is important for the control of stationary utility generators during power system faults, surges, and switching. This analysis also plays a central role in the design and optimization of a SOFC during startup and shutdown because of the potential for damaging thermal gradients to develop within the SOFC components. In transportation applications, transient and partial load operations predominate [46].

At BMWAG in Munich, high-temperature SOFCs have been developed as an auxiliary power unit (APU) for high class car conveniences. Petruzzi et al. [4] developed a transient SOFC model for this system. They wrote a code in Matlab which produces a time-dependent profile of temperatures, currents, electrical and thermal power densities, and gases concentrations for the whole system. The heat-up and start-up simulations allow researchers: (a) to evaluate the time the cell stack needs to reach operating temperature from an initial temperature distribution, (b) to check the steepest temperature gradients occurring in the ceramic layers (which result in material stresses), and (c) to obtain important information about the pre-operating strategy. In the paper by Li et al. [47], the effect of step changes in fuel flow rate, air flow rate, and stack voltage on the dynamic performance of a cross-flow DIR-SOFC was discussed. They found that a moderate increase in the fuel flow rate improves the performance; a decrease in the air 
flow rate can raise the stack temperature and increase the gas utilization ratios. In addition, an increased output voltage was found to reduce the gas utilization ratios and current density. Damm and Fedorov [48] developed a reduced order transient thermal model of a SOFC at which heating time and maximum temperature gradient are calculated. Their analysis showed that increasing the velocity of the hot air stream, and lowering the Peclet number leads to the optimal design, which minimizes heating time under the constraint of maximum allowable temperature gradients. Ferrari et al. [49] studied the transient response of a system consisting of a recuperated micro-gas turbine with a tubular SOFC. They developed and validated dynamic and lumped volume ejector models for SOFC circulation circuit. Rancruel and von Spakovsky [50] studied the effects of control laws and strategies and transients on the performance of a $5 \mathrm{kWe}$ net power SOFC based auxiliary power unit. Apfel et al. [51] developed finite element simulation for SOFC systems for steady state and transient operation. Larrain [52] performed transient simulations to a counter-flow SOFC. He found that the temperature response to a load change is generally in the order of 10 minutes for transients from open cell voltage to $70 \%$ fuel utilization. Thorud et al. [53] developed a quasi two-dimensional dynamic model for tubular SOFC. Their results showed that air utilization should be set constant during load changes.

\subsubsection{Thermomechanical modeling}

For planar SOFC, the internal stresses in cell components are one of the problems to be solved. The planar SOFCs require high temperature gas seals at the edges or around the internal gas manifolds. For this purpose, cement, glass, and glass-ceramic seals are 
expected to give sufficient sealing efficiency. However, the strict binding among each cell component generates mechanical constraints, thus a slight mismatch in thermal expansion coefficient among the cell components can cause a large stress. Moreover, because of non-homogeneous temperature distribution inside the cell, the cell components are irregularly deformed, adding a large internal stress [44].

In the study by Yakabe et al. [44], stresses in cell components were computed from temperature profiles. The internal stresses were estimated as a function of the cell size, the operating voltage, and the thermal conductivity of the cell components. Suitable operating conditions to reduce the internal stresses were proposed.

\subsubsection{Carbon deposition problem}

As discussed earlier, SOFC has the disadvantage of having the possibility of carbon deposition which will cause degradation in the performance of the fuel cell and eventually its breakdown. To prevent carbon deposition, operating parameters such as steam to carbon ratio and temperature, and materials should be carefully selected.

In the literature, some theoretical and experimental studies have been carried out to investigate the carbon deposition problem. In theoretical studies, equilibrium thermodynamics is generally taken into account and possibility of carbon deposition for different input parameters is studied. There are also very few studies that take into account the chemical kinetics. For example, Assabumrungrat et. al. [54] analyzed the carbon formation in a DIR-SOFC fueled by methanol. In their study, equilibrium 
calculations were performed to find the range of inlet steam to methanol ratio where carbon formation is thermodynamically unfavourable in the temperature range of 500 to $1200 \mathrm{~K}$. Sangtongkitcharoen et al. [55] compared the different reforming types, namely external reforming, direct internal reforming, and indirect internal reforming on carbon formation. They also considered hydrogen-conducting electrolytes as well as oxygenconducting electrolytes. Their study showed that DIR-SOFC with the oxygen-conducting electrolyte is the most promising choice for operation. Singh et al. [56] studied the risk of carbon deposition due to the tars present in the feed stream and the effect various parameters like current density, steam, and temperature on carbon deposition. A total of 32 species were considered for the thermodynamic analysis, which was done by the Gibbs energy minimization technique. The results showed that the carbon deposition decreases with an increase in current density and becomes zero after a critical current density was reached. Steam in the feed stream also decreases the amount of the deposited carbon. A study similar to Singh et al.'s was done by Koh et al. [57]. The rate of carbon deposition and the composition of an anode gas mixture in equilibrium were predicted as a function of current density by minimizing the total Gibbs free energy of a system with 21 chemical species, including a condensed phase for carbon deposition. Using temperatures ranging from 100 to $1000^{\circ} \mathrm{C}$, Sasaki and Teraoka [58] calculated the amounts of equilibrium products for various fuels including alkanes, alkenes, alicyclic hydrocarbons, and dimethyl ether, as well as for other hydrocarbon-containing fuels such as biogas and coke oven gas. They concluded that, with increasing carbon number of hydrocarbon-related species and with decreasing temperature, a higher steam to carbon 
ratio $(\mathrm{S} / \mathrm{C})$ is required to prevent carbon deposition. The addition of $\mathrm{CO}_{2}$ or $\mathrm{O}_{2}$ was also found useful to prevent carbon deposition.

In experimental works, the effect of different anode materials and input parameters are generally observed. For example, Takeguchi et al. [59] showed that CaO-modified NiYSZ cermet is effective in suppressing carbon deposition without deteriorating the reforming activity. Finnerty et al. [60] studied two different nickel/zirconia anode formulations and a molybdenum-doped nickel/zirconia anode. They investigated the effects of adding steam to the methane, the operating temperature, and doping the nickel/zirconia anode with a small quantity of molybdenum, on the methane reforming activity of the anode, the surface chemistry and the nature and level of carbon deposition. The main conclusion of this study was that doping the anode with small quantities of molybdenum $(<1 \%)$ led to a substantial reduction in the level of carbon deposited on the anode. Koh et al. [61] tested the single cell of an anode-supported planar SOFC operating with hydrogen and methane to investigate the carbon deposition effects. These researchers suggested two different carbon formation mechanisms; which are reversible carbon formation at which deposited carbon may be oxidized electrochemically; and irreversible carbon formation where carbon particulate are formed. They concluded that irreversible carbon particulate is the main reason for cell performance degradation. In the study by Macek et al. [62], Ni-YSZ cermet materials prepared by different processes (sol-gel and combustion synthesis) with variations in composition and presence of dopants were tested by exposing these materials to methane at elevated temperatures. The effects of anode composition, its microstructure, and some dopants on carbon deposition 
were studied; and the amount of the carbon deposited was determined. Their results showed that the sample $\mathrm{Cs}-50-\mathrm{Ag}-\mathrm{Cu}$ doped with silver and copper and prepared by the combustion synthesis gives less carbon deposits than other tested samples. In the paper by Horita et al. [63], the effect of applied voltages on surface catalytic activities at the Nimesh/YSZ interfaces for $\mathrm{CH}_{4}$ decomposition and elimination of carbon deposition by secondary ion mass spectrometry (SIMS) imaging analysis were discussed. They observed a significant carbon deposition at the Ni-mesh under zero-voltage condition. However, they found that the applied voltages can eliminate the deposited carbon on the Ni-mesh effectively. In addition, they concluded that oxygen spill-over around the $\mathrm{Ni} / \mathrm{YSZ}$ interfaces can eliminate the deposited carbon.

\subsubsection{System level modeling}

The system level modeling generally includes energy and exergy analyses of the systems. In energy analysis, energy balances are applied to the system and its components to find the thermodynamic properties of each state, and work and heat transfers within those components. Performance assessment parameters such as fuel utilization efficiency and power-to-heat ratio of the system may also be calculated. Exergy analysis is a method that uses the conservation of mass and conservation of energy principles together with the second law of thermodynamics for the analysis, design, and improvement of energy systems. Using this method, the locations and magnitudes of the exergy destructions and exergy losses may be found. 
Solid oxide fuel cells have high operating temperatures which enable successful thermal integration with bottoming cycles. Most of the studies in the literature investigate the opportunities of integration of SOFC with gas turbine cycles, e.g. [64-66]. Integration of SOFC with gasification cycles, e.g. [67-69], is another promising option. There are a few studies searching the integration of renewable systems with SOFC. For example, Ntziachristos et al. [70] studied the integration of a wind turbine with a SOFC.

Researches on analysis and modeling of biomass fueled SOFC have increased recently. These studies mainly focus on the effect of biomass fuel, its conversion, and operating conditions on the performance of SOFC and overall system, and selection of gas clean-up system for efficient and economical solutions. For example, Aloui and Halouani [71] developed an analytical model to study the effect of fuel type on polarizations and performance of SOFC using syngas as fuel. Yin et al. [72] calculated the electromotive force (EMF) for SOFC based on doped ceria electrolytes using biomass produced gas. Their study revealed that biomass produced gas derived EMF is very close to that of hydrogen. Panopoulos et al. [73] investigated the integration of a SOFC with a novel allothermal biomass steam gasification process. They calculated the electrical efficiency of the system as $36 \%$ and exergetic efficiency as $32 \%$ [74]. Cordiner et al. [75] studied the integration of a downdraft gasifier with a SOFC in which woody material is used as the fuel. Electrical efficiency of the system was calculated as $45.8 \%$. In the paper by Athanasiou et al. [76], integrated SOFC, steam turbine and gasifier system was studied in terms of thermodynamics. The electrical efficiency of the system was found to be $43.3 \%$. Landfill gas fueled SOFC systems were studied by Vasileiadis and Ziaka-Vasileiadou 
[77], and Liberati and Spazzafumo [78]. The first one studied the catalytic reforming and SOFC system; whereas the latter one studied the SOFC, reformer and gas turbine system. In the latter one, the overall electrical efficiency was calculated as $58 \%$. The comparison of cold gas cleanup and hot gas cleanup systems to be used in biomass gasification and SOFC systems was done by Omosun et al. [14]. They chose co-current fixed bed gasifier for cold gas cleanup and fluidized bed gasifier for hot gas cleanup. After taking into account thermodynamic and economical considerations, they concluded that hot gas cleanup should be preferred.

Exergy analysis provides more insight compared to traditional energy analysis. There are many studies in literature on the exergy analysis of different thermal systems [79-83]. Exergy analysis of SOFC based systems has also increased recently. In these systems, gas turbine, steam turbine and/or gasification system are generally integrated with SOFC. Ghosh and De [84] studied the thermodynamic analysis of an integrated gasification combined cycle with a high-temperature pressurized SOFC in the topping cycle and a single-pressure, non-reheat steam turbine in the bottoming cycle. In their study, they assumed a constant temperature for the SOFC. They neglected polarization losses. The results of their study showed that an overall efficiency above $54 \%$ is achievable for the combined cycle. The same authors studied the exergy analysis of the same system in their following paper [85]. They discussed the effect of pressure ratio and temperature on the exergy destructions and exergetic efficiencies at the system's components. Douvartzides et al. [86] studied the effect of operation parameters on exergy destructions and losses within an ethanol-fueled SOFC system including an external steam reformer, an 
afterburner, a mixer, and two heat exchangers. The paper by Calise et al. [87] presents a full and partial load exergy analysis of a hybrid SOFC and gas turbine based power plant which consists of: an air compressor, a fuel compressor, several heat exchangers, a radial gas turbine, mixers, a catalytic burner, an internal reforming tubular SOFC stack, bypass valves, an electrical generator, and an inverter. The plant was simulated at full-load and part-load operations, showing energy and exergy flows through all its components and thermodynamic properties at each key-point.

\subsubsection{Current issues in SOFC models}

Some models found in the literature were compared in terms of the methodology for the modeling. The comparison is shown in Table 2.6. This table shows that the current models mostly focus on DIR-SOFC which is meaningful since the material of the anode catalyst and the temperature level of the SOFC are suitable for internal reforming. Gas mixture is used commonly as the fuel since one of the advantages of the SOFC is fuel flexibility and CO may be electrochemically oxidized at the anode. It is possible to find O-D to 3-D modeling techniques in the literature. However, it should be noted that even authors call their papers as 3-D; some components might be modeled as 1-D, such as PEN structure or fuel and air channels. It may be also seen from this table that most of the models use finite volume method, especially the 3-D models. In addition, radiation is not included in the modeling in general, and thermomechanical modeling is not used to investigate the internal stresses in the components of a SOFC in most of the studies. 
Table 2.6: Comparison of planar SOFC models.

\begin{tabular}{|c|c|c|c|c|c|c|c|c|c|c|c|}
\hline \multicolumn{2}{|l|}{ Paper number } & 1 & 2 & 3 & $\overline{4}$ & 5 & 6 & 7 & 8 & 9 & 10 \\
\hline \multicolumn{2}{|l|}{ Reference number } & [44] & [88] & [4] & [8] & [89] & [90] & [42] & [91] & [92] & [43] \\
\hline \multirow{3}{*}{$\begin{array}{l}\text { Reforming } \\
\text { Type }\end{array}$} & External & $\mathbf{X}$ & & $\mathbf{X}$ & & & $\mathrm{X}$ & & $\mathrm{X}$ & & \\
\hline & DIR & $\mathbf{X}$ & $\mathbf{X}$ & & $\mathbf{X}$ & & & $\mathbf{X}$ & $\mathbf{X}$ & $\mathbf{X}$ & $\mathbf{X}$ \\
\hline & IIR & & & & & & & & & & \\
\hline \multirow{4}{*}{ Fuel } & Hydrogen & & & & & $\mathbf{X}$ & & & $\mathbf{X}$ & & \\
\hline & Methane & & & & & & $\mathbf{X}$ & & & & $\mathbf{X}$ \\
\hline & Gas mixture & $\mathbf{X}$ & $\mathbf{X}$ & $\mathbf{X}$ & $\mathbf{X}$ & & & $\mathbf{X}$ & $\mathbf{X}$ & $\mathbf{X}$ & \\
\hline & Other & & & & & & & & & & \\
\hline \multirow{3}{*}{$\begin{array}{l}\text { Flow } \\
\text { Configuration }\end{array}$} & Co-flow & $\mathbf{X}$ & $\mathbf{X}$ & & $\mathbf{X}$ & $\mathbf{X}$ & $\mathbf{X}$ & & $\mathbf{X}$ & $\mathbf{X}$ & \\
\hline & Counter-flow & $\mathbf{X}$ & $\mathbf{X}$ & & $\mathbf{X}$ & $\mathbf{X}$ & $\mathbf{x}$ & & & & \\
\hline & Cross-flow & & $\mathbf{X}$ & $\mathbf{X}$ & $\mathbf{X}$ & $\mathbf{X}$ & & $\mathbf{X}$ & & & $\mathbf{X}$ \\
\hline \multirow{4}{*}{$\begin{array}{l}\text { Dimensional } \\
\text { Modeling }\end{array}$} & O-D & & & & & & & & & & \\
\hline & $1-\mathrm{D}$ & & & & & & & & $\bar{X}$ & $\mathbf{X}$ & $\mathbf{X}$ \\
\hline & $2-\mathrm{D}$ & & & & & $\mathbf{X}$ & $\bar{X}$ & $\mathbf{X}$ & $\mathbf{X}$ & & $\mathbf{X}$ \\
\hline & $3-\mathrm{D}$ & $\mathbf{X}$ & $\mathbf{X}$ & $\mathbf{X}$ & $\bar{X}$ & & & & & & \\
\hline \multirow{3}{*}{$\begin{array}{l}\text { Level of } \\
\text { Modeling }\end{array}$} & Cell & $\mathbf{X}$ & $\mathbf{X}$ & & $\bar{X}$ & $\mathbf{X}$ & $\mathbf{X}$ & $\mathbf{X}$ & $\mathbf{X}$ & $\mathbf{X}$ & $\mathbf{X}$ \\
\hline & Stack & & $\bar{X}$ & $\mathbf{X}$ & & & $\mathbf{X}$ & $\mathbf{X}$ & $\mathbf{X}$ & & $\mathbf{X}$ \\
\hline & System & & & & & & & $\mathbf{X}$ & & & \\
\hline \multirow{2}{*}{$\begin{array}{l}\text { Dependence } \\
\text { To Time }\end{array}$} & Steady-state & $\mathbf{X}$ & & & $\mathbf{X}$ & $\mathbf{X}$ & & $\mathbf{X}$ & $\mathbf{X}$ & $\mathbf{X}$ & $\mathbf{X}$ \\
\hline & Transient & & $\underline{\mathbf{X}}$ & $\mathbf{X}$ & & & $\mathbf{X}$ & & & & \\
\hline \multirow{3}{*}{ Method of Modeling } & FCV & $\mathbf{X}$ & \multirow{3}{*}{$\mathrm{n} / \mathrm{a}$} & \multirow{3}{*}{$\mathrm{n} / \mathrm{a}$} & $\mathbf{X}$ & $\mathbf{X}$ & $\bar{X}$ & $\mathbf{X}$ & \multirow{3}{*}{$\mathrm{n} / \mathrm{a}$} & & \\
\hline & FDM & & & & & & & & & $\mathbf{X}$ & $\mathbf{X}$ \\
\hline & FEM & $\mathbf{X}$ & & & & & & & & & \\
\hline \multirow{2}{*}{ Balances Included } & Energy & $\mathbf{X}$ & $\mathbf{X}$ & $\mathbf{X}$ & $\mathbf{x}$ & $\mathbf{X}$ & $\mathbf{X}$ & $\mathbf{X}$ & $\mathbf{X}$ & $\mathbf{X}$ & $\mathbf{X}$ \\
\hline & Momentum & $\mathbf{x}$ & & & $\mathbf{x}$ & $\mathbf{X}$ & $\mathbf{X}$ & & $\mathbf{X}$ & & \\
\hline \multirow{2}{*}{$\begin{array}{l}\text { Heat Transfer } \\
\text { Considerations }\end{array}$} & Convection & $\mathbf{X}$ & $\mathbf{X}$ & $\mathbf{x}$ & $\mathbf{x}$ & $\mathbf{X}$ & $\mathbf{X}$ & $\mathbf{X}$ & $\mathbf{X}$ & $\mathbf{X}$ & $\mathbf{X}$ \\
\hline & Radiation & $\mathbf{x}$ & $\mathbf{X}$ & & & & $\mathbf{X}$ & & & & \\
\hline \multirow{2}{*}{$\begin{array}{l}\text { Thermomechanical } \\
\text { Modeling }\end{array}$} & Yes & $\mathbf{X}$ & & & & & & & & & \\
\hline & No & & $\mathbf{X}$ & $\mathbf{X}$ & $\mathbf{X}$ & $\mathbf{X}$ & $\mathbf{X}$ & $\mathbf{X}$ & $\mathbf{X}$ & $\mathbf{X}$ & $\mathbf{X}$ \\
\hline \multirow{2}{*}{$\begin{array}{l}\text { Validation with } \\
\text { Experimental Data }\end{array}$} & Yes & & & & & $\mathrm{X}$ & $X$ & & & & \\
\hline & No & $\mathbf{X}$ & $\mathbf{X}$ & $\mathbf{X}$ & $\mathbf{X}$ & & & $\mathbf{X}$ & $\bar{X}$ & $\mathbf{X}$ & $\mathbf{X}$ \\
\hline
\end{tabular}

The key findings of this review study may be given as follows:

- Thermodynamic modeling (0-D modeling) of SOFC is well developed. However, effect of anode recirculation has not been significantly considered in previous models. 
- Most of the studies use only common SOFC materials in their modeling. More studies are needed to compare the alternative materials in overall modeling to assess the effect of material on the efficiency and degradation of the cell.

- Electrochemical modeling that relates the microstructure, geometry, material properties, and operating parameters with voltage drop is still under development.

- Contact resistance between anode, cathode, and electrolyte is generally neglected. Theoretical models are needed to obtain more accurate results.

- Carbon deposition problem is mainly prevented by sending external steam to the SOFC. There have not been significant studies on preventing the carbon deposition by recirculating the depleted fuel.

- Literature lacks on the radiative properties for the materials used in SOFC in the high temperature level. Some experimental studies need to be conducted in this aspect.

- In multi-dimensional models, not all the heat transfer and polarization modes are considered. Better models are needed to assess the performance of the cell and stack.

- Finite element method is generally used in calculating internal stresses in the components of the SOFC in the literature. However, this method may be also very useful in heat transfer modeling of the fuel cell.

- There is a need for more experimental works, which will provide data for validation of the models in this area.

\subsection{Summary}

Fuel cells are electrochemical devices that convert the energy in the fuel into electricity with high efficiency and low environmental impact. There are different types of fuel 
cells, which differ from each other according to the type of electrolyte and fuel used. Among these different types, PEMFC, DMFC, AFC, PAFC, MCFC, and SOFC are the main fuel cell types. Currently, the main application area of fuel cells is niche applications. Other areas include military, transportation and stationary power and heat generation.

SOFCs have taken significant attention from the researchers because of their advantages such as: being simpler in concept, internal reforming of gases, fuel flexibility (e.g. methane, higher hydrocarbons, methanol, ethanol, biomass produced gas, ammonia, and hydrogen sulfide) and efficient thermal integration with other systems (e.g. gas turbine and gasification). However, there are some challenges for construction and durability due to its high temperature. In addition, carbon can be deposited at the anode catalyst which should be prevented to maintain the proper operation of the cell. On the other hand, different SOFC types can be found in the literature. These types may be classified according to their temperature level, cell and stack design, type of support, flow configuration and fuel reforming type.

Biomass fed SOFCs are one of the most promising energy technologies of the future since the merits of renewable and hydrogen energies are combined in them. Once appropriate gas cleanup and reforming systems are designed, the following fuel can be used in these technologies: ethanol produced from fermentation, biogas produced from anaerobic digestion, bio-oil produced from fast pyrolysis, and syngas produced from gasification. 
In the literature, different types and levels of SOFC models are available. In cell and stack level, 0-D, 1-D, 2-D, and 3-D techniques may be chosen according to the purpose of the model. Transient modeling is used if any of the following or combination of them needs to simulated: heat-up, start-up, shut-down, and load change. Thermomechanical modeling mainly helps us to find the stresses inside the fuel cell due to the temperature gradients. Suggestions to prevent carbon deposition in the SOFC can be given conducting numerical studies. Finally, energy and exergy analyses can be applied to integrated SOFC systems to assess the performance of these systems. After carrying out a literature survey on SOFC modeling, the current issues in this area are identified. It is found that anode recirculation, which is especially useful for preventing the carbon deposition, has not been sufficiently considered in modeling. It is also found that better models including all the heat transfer and polarization modes are required to assess the performance of the SOFC. 


\section{CHAPTER 3}

\section{SOFC MODELING}

\subsection{Introduction}

The modeling of a SOFC necessitates knowledge from different disciplines such as thermodynamics, heat transfer, fluid mechanics, mechanical design, materials science, economics, etc. According to the purpose of modeling, different methods may be applied which are discussed in detail in the following sections.

\subsection{Thermodynamics of SOFC}

\subsubsection{Basic definitions}

Fuel utilization ratio: It is the ratio of the amount of hydrogen that is electrochemically reacted to the amount of hydrogen in the inlet stream. It may be shown as

$$
U_{f}=\frac{\dot{N}_{\mathrm{H}_{2}, \text { utilized }}}{\dot{N}_{\mathrm{H}_{2} \text {, inlet }}}
$$

Air utilization ratio: It is the ratio of the amount of oxygen that is electrochemically reacted to the amount of oxygen in the inlet stream. It may be shown as

$$
U_{a}=\frac{\dot{N}_{O_{2}, \text { utilized }}}{\dot{N}_{O_{2}, \text { inlet }}}
$$


Excess air coefficient: Instead of air utilization ratio, excess air coefficient may be used. It may be defined as the amount of the oxygen in the inlet stream divided by the amount of oxygen that is needed for a stoichiometric reaction. The divider is equal to the half of the amount of the hydrogen in the inlet stream. Hence, it results in

$$
\lambda_{\text {air }}=\frac{2 \cdot \dot{N}_{O_{2, \text { inlet }}}}{\dot{N}_{H_{2, \text { inlet }}}}
$$

Using the fact $\dot{N}_{O_{2, \text { utilized }}}=\left(\dot{N}_{H_{2, \text { utilized }}}\right) / 2$ and combining Equations (3.1)-(3.3), the relation between these definitions becomes

$$
U_{f}=U_{a} \cdot \lambda_{\text {air }}
$$

It should be noted that if the fuel is reformed internally at the anode catalyst, hydrogen produced by the reforming reaction(s) should be added to the term $\dot{N}_{H_{2, \text { inlet }}}$.

\subsubsection{Basic equations}

The electrochemical reactions occurring at the electrodes when using $\mathrm{H}_{2}$ as the fuel are as follows:

At Anode: $\mathrm{H}_{2}+\mathrm{O}^{2-} \rightarrow \mathrm{H}_{2} \mathrm{O}+2 e^{-}$

At Cathode: $\frac{1}{2} \mathrm{O}_{2}+2 e^{-} \rightarrow \mathrm{O}^{2-}$ 
Overall: $\mathrm{H}_{2}+\frac{1}{2} \mathrm{O}_{2} \rightarrow \mathrm{H}_{2} \mathrm{O}$

Electric current, $I$, may be shown as

$I=2 \dot{N}_{H_{2}, \text { utilized }} \cdot F$

where $\mathrm{F}$ is the Faraday constant, which is approximately equal to $96485 \mathrm{C} / \mathrm{mol}$.

The reversible cell voltage (Nernst voltage) may be shown as

$V_{N}=\frac{-\Delta \bar{g}_{r}^{\circ}}{2 F}-\frac{R T}{2 F} \cdot \ln \left(\frac{P_{H_{2} O}}{P_{H_{2}} \cdot \sqrt{P_{O_{2}} / P^{\circ}}}\right)$

Winkler [93] derived the Nernst (or reversible) voltage in terms of temperature, pressure, fuel utilization ratio and excess air coefficient for a SOFC operating with pure hydrogen as the fuel and air $\left(21 \% \mathrm{O}_{2}, 79 \% \mathrm{~N}_{2}\right)$ as the oxidant by considering the SOFC as a blackbox. Based on his derivation and assumptions, and instead of using excess air coefficient, if we use air utilization ratio; Nernst voltage may be shown as

$$
V_{N}=\frac{-\Delta \bar{g}_{r}^{\circ}}{2 F}-\frac{R T}{2 F} \cdot \ln \left(\frac{U_{f}}{\left(1-U_{f}\right) \cdot \sqrt{\left(\frac{1-U_{a}}{1 / 0.21-U_{a}}\right) \cdot \frac{P}{P^{\circ}}}}\right)
$$


The actual cell voltage may be defined after calculating polarizations, which are defined in Section 3.3, as follows,

$$
V=V_{N}-V_{o h m}-V_{a c t}-V_{c o n}
$$

Power output of the cell may be found as

$\dot{W}_{F C}=I \cdot V$

The electrical efficiency of the cell is calculated as

$$
\eta_{e l, c e l l}=\frac{\dot{W}_{F C}}{\dot{N}_{f, \text { inlet }} \cdot L H V}
$$

\subsection{Electrochemistry of SOFC}

There are three types of polarizations in fuel cells, which are ohmic, activation and concentration polarizations. These are described in detail in the following sections.

\subsubsection{Ohmic polarization}

Ohmic polarization is caused by the resistance to the flow of oxide ions through the electrolyte and resistance to the flow of electrons. Ohm's law describes that there is a linear relationship between voltage drop and current density. 


$$
V_{\text {ohm }}=\left(A S R_{\text {contact }}+A S R_{\text {bulk }}\right) \cdot i
$$

where

$$
A S R_{\text {bulk }}=\sum_{k} \rho_{k} \cdot L_{k}
$$

Resistivities of the materials are determined by experiments. The bulk area specific ohmic resistance $\left(A S R_{\text {bulk }}\right)$ is calculated by using the values of the resistivities obtained empirically and the length of the electron and oxide ion paths using Equation (3.15). As a simplification in the macro-level models in the literature, the lengths of the paths that the conducting substances follow are generally taken as the thickness of the components of the cell assuming that they are conducting in the vertical direction.

The contact resistance is generally neglected in studies because there is not a robust theoretical model to calculate this resistance in literature. One of the most significant studies to calculate and measure contact resistances in SOFC was carried out by Koch [94]. In his thesis, instead of measuring the contact resistance between different components made of different materials, contact pairs of identical materials are investigated to eliminate the influence of resistive phases formed because of chemical incompatibility between the two materials. Although, the results of his study do not reflect the case in SOFC, they are still very important. He found that the measured resistance for a ceramic contact is a sum of two contributions which are current constriction due to low contact area and interface resistance due to resistive phases or 
potential barriers at the interface. For LSM (cathode material), the interface resistance generally dominates at low temperatures; and, for YSZ (electrolyte material), current constriction dominates at all investigated temperatures.

The common materials used in a SOFC are as follows: Ni-YSZ for anode, YSZ for electrolyte, LSM for cathode and magnesium-doped lanthanum chromite for the interconnect. However, researchers tend to find other alternatives that will increase the performance of the SOFC. For example, the interconnect material is nowadays high chromium containing steel such as Crofer22APU or E-Brite. Researchers have put more efforts in finding the relation between the temperature and resistivity for YSZ since the resistivity of the electrolyte is much higher than other components. The temperature dependence of the resistivities is modeled by the Arrhenius equation or modified Arrhenius equation. To compare the different equations for the resistivity of SOFC components in literature, Equation (3.16) is formed. The coefficients of this equation are shown in Table 3.1 and Figure 3.1 for YSZ, and Table 3.2 for the other components. It is seen from Figure 3.1 that there is not a significant difference between different formulas found in literature for YSZ. The resistivity for anode material is on the order of $10^{-3}$, whereas this for cathode and interconnect materials is on the order of $10^{-2}$ for the temperature between $500^{\circ} \mathrm{C}$ and $1000^{\circ} \mathrm{C}$.

$\rho=\left[C_{1}+\frac{C_{2}}{T^{C_{3}}} \cdot \exp \left(\frac{C_{4}}{T}+C_{5}\right)\right]^{C_{5}}(\Omega-\mathrm{cm})(\mathrm{T}$ is in $\mathrm{K})$ 
Table 3.1: Coefficients of Equation (3.16) to calculate the resistivity of electrolyte (YSZ).

\begin{tabular}{|l|r|l|r|r|r|r|}
\hline \multicolumn{1}{|c|}{ Author } & \multicolumn{1}{c|}{$C_{1}$} & \multicolumn{1}{c|}{$C_{2}$} & \multicolumn{1}{c|}{$C_{3}$} & \multicolumn{1}{c|}{$C_{4}$} & \multicolumn{1}{c|}{$C_{5}$} & \multicolumn{1}{c|}{$C_{6}$} \\
\hline Bossel [95] & 0 & $3.34 \times 10^{2}$ & 0 & -10300 & 0 & -1 \\
\hline Bessette II et al. [96] & 0 & $2.94 \times 10^{-3}$ & 0 & 10350 & 0 & 1 \\
\hline Ahmed et al. [97] & 0.3685 & $2.838 \times 10^{-3}$ & 0 & 10300 & 0 & 1 \\
\hline Iwata et al. [98] & 0 & 10 & 0 & 10092 & -7.9277 & 1 \\
\hline
\end{tabular}

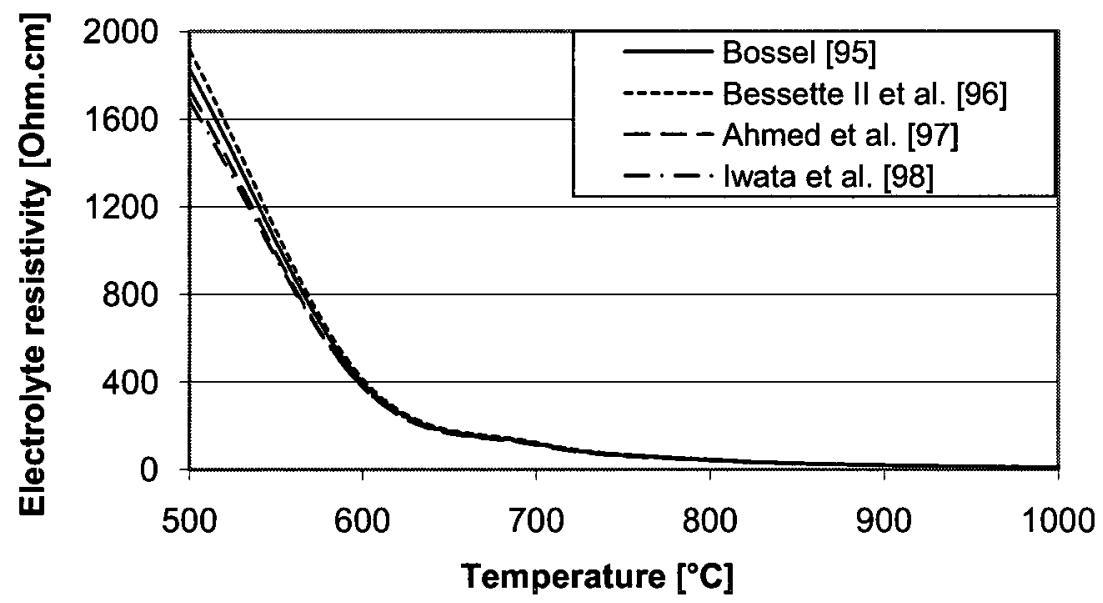

Figure 3.1: Ionic resistivity of YSZ as a function of temperature.

Table 3.2: Coefficients of Equation (3.16) to calculate the resistivity of other components made of common SOFC materials.

\begin{tabular}{|l|r|l|r|r|r|r|}
\hline \multicolumn{1}{|c|}{ Component } & \multicolumn{1}{c|}{$C_{1}$} & \multicolumn{1}{c|}{$C_{2}$} & \multicolumn{1}{c|}{$C_{3}$} & \multicolumn{1}{c|}{$C_{4}$} & \multicolumn{1}{c|}{$C_{5}$} & $C_{6}$ \\
\hline Anode & & $9.5 \times 10^{5}$ & 1 & -1150 & 0 & -1 \\
\hline Cathode & 0 & $4.2 \times 10^{5}$ & 1 & -1200 & 0 & -1 \\
\hline Interconnect & 0 & $9.3 \times 10^{4}$ & 1 & -1100 & 0 & -1 \\
\hline
\end{tabular}

Source: Bossel [95]. 


\subsubsection{Activation polarization}

The second type of polarization is activation polarization which is due to the sluggishness of the reactions. It is seen that different equations are used in literature to represent this polarization. From the most simple to the complex: a linear equation with constant coefficients, Tafel equation, and Butler-Volmer equation. The first two may be derived from Butler-Volmer equation with some assumptions. If we assume that charge transfer coefficient for anode and cathode is 0.5 and substitute this value in the Butler-Volmer equation, it takes the form as shown in Equation (3.17).

$$
V_{a c t}=V_{a c t, a}+V_{a c t, c}=\frac{R T}{F} \cdot \sinh ^{-1}\left(\frac{i}{2 i_{o, a}}\right)+\frac{R T}{F} \cdot \sinh ^{-1}\left(\frac{i}{2 i_{o, c}}\right)
$$

\subsubsection{Concentration polarization}

When gases at the channels diffuse through the porous electrodes, the gas partial pressure at the electrochemically reactive sites becomes less than that in the bulk of the gas stream. Hence, a voltage drop occurs which is called concentration polarization. If the microstructure is assumed not to be a function of position, this polarization may be given as follows [99].

$$
V_{\text {conc }, a}=-\frac{R T_{s}}{2 F} \ln \left(1-\frac{R T}{2 F} \cdot \frac{\tau_{a} l_{a}}{D_{a} V_{v(a)} P_{H_{2}}^{b}} i\right)+\frac{R T_{s}}{2 F} \ln \left(1+\frac{R T}{2 F} \cdot \frac{\tau_{a} l_{a}}{D_{a} V_{v(a)} P_{H_{2} O}^{b}} i\right)
$$




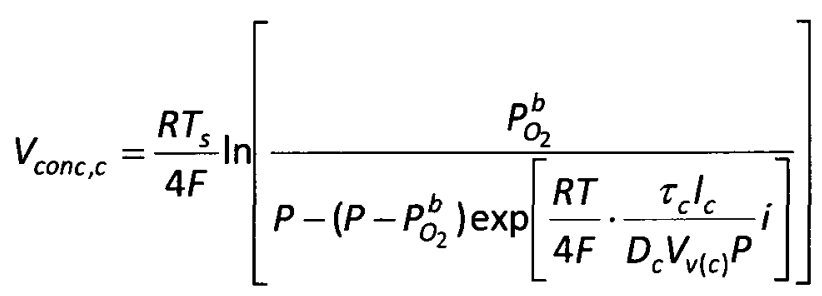

If the microstructure is taken to be a function of position, then the following modifications should be done to the Equations (3.18) and (3.19);

$$
\begin{aligned}
& \frac{D_{a} V_{v(a)}}{\tau_{a}}=\frac{D_{a} I_{a}}{\left(\frac{\tau_{a} I_{a}}{V_{v(a)}}\right)_{e f f}}=\frac{D_{a} I_{a}}{\int_{o}^{I_{a}} \frac{\tau_{a}(x) d x}{V_{v(a)}(x)}}=D_{a(e f f)} \\
& \frac{D_{c} V_{v(c)}}{\tau_{c}}=\frac{D_{c} I_{c}}{\left(\frac{\tau_{c} I_{c}}{V_{v(c)}}\right)_{e f f}}=\frac{D_{c} I_{c}}{\int_{o} \frac{\tau_{c}(x) d x}{V_{v(c)}(x)}}=D_{c(\text { eff })}
\end{aligned}
$$

It should be noted that binary diffusion is assumed to be the dominant mode of gas transport in this approach. These equations do not include either Knudsen diffusion or surface diffusion of the adsorbed species. They are also only valid for hydrogen/water system at the anode.

\subsection{Exergy Destructions in a SOFC}

Entropy is generated due to polarizations in fuel cells. Entropy generation rate may be written as follows after combining first and second laws of thermodynamics. 


$$
\dot{S}_{g e n}=\frac{\dot{W}_{r e v}-\dot{W}_{a c t}}{T_{o}}=\frac{I \cdot\left(V_{N}-V\right)}{T_{o}}
$$

Entropy generation rate per molar flow rate of hydrogen that is utilized may be shown as $s_{g e n}$. It may be calculated as follows.

$$
s_{\text {gen }}=\frac{\dot{S}_{\text {gen }}}{\dot{N}_{H_{2}, \text { utilized }}}=\frac{\left\lfloor 2 \cdot \dot{N}_{H_{2}, \text { utilized }} \cdot F \cdot\left(V_{N}-V\right)\right\rfloor / T_{o}}{\dot{N}_{H_{2}, \text { utilized }}}
$$

Using the definition of polarizations in fuel cells, Equation (3.23) may be shown as

$$
s_{g e n}=\frac{2 \cdot F \cdot\left(V_{o h m}+V_{a c t}+V_{c o n}\right)}{T_{o}}
$$

Specific exergy destruction in a process may be shown as Equation (3.25) which is also known as Guoy-Stodola theorem.

$$
e_{D}=T_{0} \cdot s_{g e n}
$$

Combining Equations (3.24) and (3.25), specific exergy destruction may be shown as

$$
e_{D}=2 \cdot F \cdot\left(V_{o h m}+V_{a c t}+V_{c o n}\right)
$$




\subsection{Thermodynamic Modeling of Direct Internal Reforming SOFCs Operating With}

\section{Syngas}

The purpose of this study is to develop a thermodynamic model of a SOFC taking into account the internal reforming processes and recirculation of the depleted fuel stream. The SOFC is modeled using the principles of thermodynamics and electrochemistry.

A unit cell is shown in Figure 3.2. The operation principle of the cell is as follows: Syngas (state f1) mixes with recirculated gas mixture (state f2) and the mixture enters the

fuel channel (state f3). Steam reforming of methane, water-gas shift and electrochemical reactions occur simultaneously at the fuel cell. The gas mixture exiting the fuel channel (state f4) has generally high water content; hence some portion of it may be recirculated especially for preventing the carbon deposition. The remaining depleted fuel (state f5) exits the SOFC. The oxidant (state a1), which is air, flows through the air channel. The oxygen molecules in the air react with the electrons. Oxide ions are produced at the cathode and they diffuse to the anode through the electrolyte. The gas mixture, having less oxygen content than the air entering, exits the air channel (state a2). Electric current is produced by the flow of electrons and it effectuates work on the load.

\subsubsection{Modeling technique}

In the modeling, exit gas composition is first derived in terms of molar flow rates of gas species at the inlet, recirculation ratio, fuel utilization, and extents of the chemical reactions. Then, the extents of the chemical reactions and mass flow rate of fuel at the inlet are calculated solving the chemical equilibrium relations and the relation between 
the electric current and the molar flow rate of hydrogen utilized. After finding these variables, air utilization ratio is calculated solving the energy balance of the fuel cell. Hence, cell voltage, power output, and electrical efficiency of the cell are calculated.

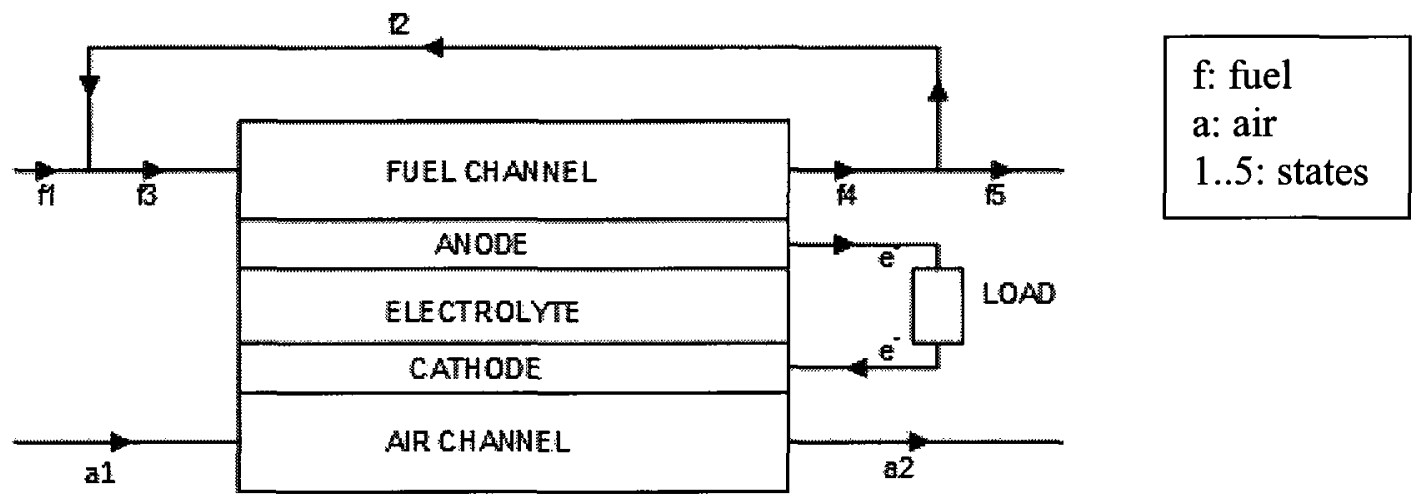

Figure 3.2: Schematic of the DIR-SOFC with anode recirculation.

The following assumptions are made in the analysis:

- Syngas consists of the following gas species. $\mathrm{i}=\left\{\mathrm{CH}_{4}, \mathrm{CO}_{2}, \mathrm{CO}, \mathrm{H}_{2} \mathrm{O}, \mathrm{H}_{2}, \mathrm{~N}_{2}\right\}$

- Air consists of $79 \% \mathrm{~N}_{2}$ and $21 \% \mathrm{O}_{2} . \mathrm{j}=\left\{\mathrm{O}_{2}, \mathrm{~N}_{2}\right\}$

- Fuel cell operates at steady state.

- Gas mixture at the fuel channel exit is at chemical equilibrium.

- Pressure drops along the fuel cell are neglected.

- Temperature at the channel inlets is same $\left(T_{y}=T_{f 3}=T_{a 1}\right)$. Also, temperature at the channel exits is same $\left(T_{z}=T_{f 4}=T_{a 2}\right)$. 
- Temperature of the solid structure is midway between the inlet and exit temperatures [14].

- Fuel cell is insulated, and there is no thermal interaction with environment.

- Only hydrogen is electrochemically reacted. $\mathrm{CO}$ is converted to $\mathrm{CO}_{2}$ and $\mathrm{H}_{2}$ by watergas shift reaction.

- Contact resistances are ignored.

- Radiation transfer between solid structure and gas channels is ignored.

\subsubsection{Calculation of the gas composition at the fuel channel exit}

Here the first step is the calculation of the equilibrium gas composition at the fuel channel exit. The equations in terms of total molar or mass flow rate of gas species at state ' $\mathrm{fl}$ ' are derived. Since it is more convenient to adjust the mass flow rate for a system operator, the equations are given in terms of mass flow rate of state ' $\mathrm{fl}$ '. In this regard, the molar flow rate of gas species at state ' $\mathrm{fl}$ ' may be written in terms of mass flow rate as

$\dot{N}_{f 1}^{i}=x_{f 1}^{i} \cdot \frac{\dot{m}_{f 1}}{\sum x_{f 1}^{i} \cdot M^{i}}$

The states ' $\mathrm{f2}$ ', ' $\mathrm{f4}$ ' and ' $\mathrm{f5}$ ' have the same molar compositions. The composition of gas species at these states is shown by $x_{f 4, e q}^{i}$. Then, the molar flow rate of gas species at the state ' $\mathrm{f}$ ' becomes 
$\dot{N}_{f 3}^{i}=\dot{N}_{f 1}^{i}+\dot{N}_{f 2}^{i}=\dot{N}_{f 1}^{i}+x_{f 4, e q}^{i} \cdot \dot{N}_{f 2}=\dot{N}_{f 1}^{i}+x_{f 4, e q}^{i} \cdot\left(r \cdot \dot{N}_{f 4}\right)$

In Equation (3.28), the recirculation ratio, $r$, is defined as

$r=\frac{\dot{N}_{f 2}}{\dot{N}_{f 4}}=\frac{\dot{m}_{f 2}}{\dot{m}_{f 4}}$

The steam reforming reaction for methane, water-gas shift reaction, and electrochemical reaction, which are shown in Equations (3.30)-(3.32), respectively, occur simultaneously at the cell as follows:

$$
\begin{aligned}
& \mathrm{CH}_{4}+\mathrm{H}_{2} \mathrm{O} \leftrightarrow \mathrm{CO}+3 \mathrm{H}_{2} \\
& \mathrm{CO}+\mathrm{H}_{2} \mathrm{O} \leftrightarrow \mathrm{H}_{2}+\mathrm{CO}_{2} \\
& \mathrm{H}_{2}+\frac{1}{2} \mathrm{O}_{2} \rightarrow \mathrm{H}_{2} \mathrm{O}
\end{aligned}
$$

Let the extents of reactions shown by Equations (3.30)-(3.32) be a, b and c, respectively. The molar flow rate of state ' $\mathrm{f} 4$ ' is given as

$$
\dot{N}_{f 4}^{i}=\dot{N}_{f 3}^{i}+d^{i}
$$

where 


$$
\begin{aligned}
& d^{\mathrm{CH}_{4}}=-a \\
& d^{\mathrm{H}_{2} \mathrm{O}}=-a-b+c \\
& d^{\mathrm{CO}}=a-b \\
& d^{\mathrm{CO}_{2}}=b \\
& d^{\mathrm{H}_{2}}=3 a+b-c \\
& d^{\mathrm{N}_{2}}=0
\end{aligned}
$$

Here, $c$ is the molar flow rate of hydrogen utilized in the fuel cell which can also be defined as follows:

$$
c=\left(\dot{N}_{f 3}^{H_{2}}+3 a+b\right) \cdot U_{f}
$$

We obtain the following equation by summing molar flow rate of gas species at state ' $\mathrm{f} 4$ ' by using Equations (3.33)-(3.33.6) and combining with Equation (3.28):

$$
\dot{N}_{f 3}^{i}=\dot{N}_{f 1}^{i}+x_{f 4, e q}^{i} \cdot r \cdot\left(\dot{N}_{f 3}+2 a\right)
$$

The total molar flow rate of state ' $\mathrm{f} 3$ ' is given as

$$
\dot{N}_{f 3}=\frac{\dot{N}_{f 1}+2 a r}{1-r}
$$


Combining Equations (3.33)-(3.33.6), (3.35) and (3.36), the equilibrium molar gas composition at the fuel channel exit results in

$$
x_{f 4, e q}^{i}=\frac{\dot{N}_{f 4}^{i}}{\dot{N}_{f 4}}=\frac{\dot{N}_{f 1}^{i}+d^{i}}{\dot{N}_{f 1}+2 a}
$$

The molar flow rate of hydrogen utilized, $c$, is redefined by combining Equations (3.33.5) and (3.34)-(3.37) as

$$
c=\frac{\left(\dot{N}_{f 1}^{H_{2}}+3 a+b\right) \cdot U_{f}}{1-r+r \cdot U_{f}}
$$

Hence, using Equations (3.33)-(3.33.6), (3.37), and (3.38), the equilibrium gas composition at the fuel channel exit is found as

$$
\begin{aligned}
& x_{f 4, e q}^{C H_{4}}=\frac{\dot{N}_{f 1}^{C H_{4}}-a}{\dot{N}_{f 1}+2 a} \\
& x_{f 4, e q}^{H_{2}}=\frac{\left(\dot{N}_{f 1}^{H_{2}}+3 a+b\right)}{\dot{N}_{f 1}+2 a} \cdot\left(\frac{(1-r)\left(1-U_{f}\right)}{1-r+r \cdot U_{f}}\right) \\
& x_{f 4, e q}^{c o}=\frac{\dot{N}_{f 1}^{C O}+a-b}{\dot{N}_{f 1}+2 a} \\
& x_{f 4, e q}^{C O_{2}}=\frac{\dot{N}_{f 1}^{C O_{2}}+b}{\dot{N}_{f 1}+2 a}
\end{aligned}
$$




$$
\begin{aligned}
& x_{f 4, e q}^{H_{2} \mathrm{O}}=\frac{\dot{N}_{f 1}^{H_{2} \mathrm{O}}+\left[-a-b+\frac{\left(\dot{N}_{f 1}^{H_{2}}+3 a+b\right) \cdot U_{f}}{1-r+r \cdot U_{f}}\right]}{\dot{N}_{f 1}+2 a} \\
& x_{f 4, e q}^{N_{2}}=\frac{\dot{N}_{f 1}^{N_{2}}}{\dot{N}_{f 1}+2 a}
\end{aligned}
$$

Here, $\mathrm{a}, \mathrm{b}$, and molar flow rates of gas species at state ' $\mathrm{fl}$ ' which are a function of $\dot{m}_{f 1}$ are unknown. We need three equations to be solved simultaneously to find $\mathrm{a}, \mathrm{b}$ and $\dot{m}_{f 1}$. These are the chemical equilibrium equations corresponding to the steam reforming and water-gas shift reactions, and the relation between electrical current and molar flow rate of hydrogen utilized; which are shown in Equations (3.45)-(3.47), respectively.

$$
\begin{aligned}
& K_{s t r}=\exp \left[-\Delta \bar{g}_{r}^{\circ} / R T_{z}\right]=\frac{\left(x_{f 4, e q}^{C O}\right) \cdot\left(x_{f 4, e q}^{H_{2}}\right)^{3}}{\left(x_{f 4, e q}^{H_{2} O}\right)\left(x_{f 4, e q}^{C H_{4}}\right)} \cdot\left(\frac{P}{P^{\circ}}\right)^{2} \\
& K_{w g s}=\exp \left[-\Delta \bar{g}_{s}^{\circ} / R T_{z}\right]=\frac{\left(x_{f 4, e q}^{H_{2}}\right) \cdot\left(x_{f 4, e q}^{C O}\right)}{\left(x_{f 4, e q}^{C O}\right)\left(x_{f 4, e q}^{H_{2} O}\right)} \\
& I=i \cdot A=2 \cdot F \cdot c=2 \cdot F \cdot \frac{\left(\dot{N}_{f 1}^{H_{2}}+3 a+b\right) \cdot U_{f}}{1-r+r \cdot U_{f}}
\end{aligned}
$$

The temperature dependent equilibrium constant is solved by the method in which the change in Gibbs free energy of the reactions is used. However, equilibrium constants for steam reforming and water-gas shift reactions may also be found by using a simple relation and equilibrium constant coefficients [95]. On the other hand, instead of doing 
calculations based on equilibrium constant, a more direct procedure which is based on minimization of the total Gibbs free energy may be used. In this method, it is not necessary to know the chemical reactions. Only, gas species that are present in the system, moles of species in the initial unreacted state, temperature and pressure should be known to calculate the equilibrium composition. Solution is found by using Lagrange multipliers. Further information on this may be found in the book by Perry and Green [100].

\subsubsection{Calculation of the output parameters}

The cell analyzed in this study is assumed to have adiabatic boundary conditions, and the heat produced in the cell is carried away by sending excess air. This excess air is controlled by the air utilization ratio, which depends on the cooling necessity of the fuel cell.

The molar flow rates of gas species at the air channel inlet and exit are defined as follows:

$$
\begin{aligned}
& \dot{N}_{a 1}^{O_{2}}=\frac{c}{2 \cdot U_{o x}} \\
& \dot{N}_{a 1}^{N_{2}}=\frac{c}{2 \cdot U_{o x}} \cdot \frac{79}{21}=\frac{79}{42} \cdot \frac{c}{U_{o x}} \\
& \dot{N}_{a 2}^{O_{2}}=\frac{c}{2 \cdot U_{o x}}-\frac{c}{2}=\frac{c}{2}\left(\frac{1}{U_{o x}}-1\right)
\end{aligned}
$$




$$
\dot{N}_{a 2}^{N_{2}}=\frac{79}{42} \cdot \frac{c}{U_{o x}}
$$

The gas composition at the air channel exit can be calculated as

$$
\begin{aligned}
& x_{a 2}^{O_{2}}=\frac{\dot{N}_{a 2}^{O_{2}}}{\dot{N}_{a 2}}=\frac{1-U_{o x}}{100 / 21-U_{o x}} \\
& x_{a 2}^{N_{2}}=1-x_{a 2}^{O_{2}}
\end{aligned}
$$

Here, the enthalpy flow rate of state ' $\mathrm{fl}$ ' is calculated using an energy balance around the control volume enclosing the junction point by Equation (3.54). The temperature of this state is then found by iteration.

$\dot{H}_{f 1}=\sum \dot{N}_{f 1}^{i} \cdot \bar{h}^{i}\left(T_{x}\right)=\sum \dot{N}_{f 3}^{i} \cdot \bar{h}^{i}\left(T_{y}\right)-\sum \dot{N}_{f 2}^{i} \cdot \bar{h}^{i}\left(T_{z}\right)$

For the insulated fuel cell, the energy balance around the control volume enclosing the fuel cell is written as

$\sum \dot{N}_{f 1}^{i} \cdot \bar{h}^{i}+\sum \dot{N}_{a 1}^{j} \cdot \bar{h}^{j}=\dot{W}_{F C}+\sum \dot{N}_{f 5}^{i} \cdot \bar{h}^{i}+\sum \dot{N}_{a 2}^{j} \cdot \bar{h}^{j}$

In Equation (3.55), the work output term can be written using Equations (3.11) and (3.12), which depend on Nernst voltage and polarizations: ohmic, activation, and 
concentration. The relations for Nernst voltage and these polarizations are given in Equations (3.9) and (3.14)-(3.21).

Here the air utilization ratio is calculated through an iterative solution method using Equation (3.55). After obtaining air utilization ratio by iteration, terminal voltage, power output, and electrical efficiency of the cell are found using Equations (3.11)-(3.13), respectively.

For the solution, a code is written in MathCAD. The flowchart of the MathCAD code used for the solution of the model is shown in Figure 3.3.

\subsection{Carbon Deposition Modeling in Direct Internal Reforming SOFCs}

Due to using fuel containing carbon, there is a possibility of carbon deposition in a SOFC. The carbon deposition problem should be prevented because it results in the growth of carbon filaments that are attached to anode crystallites, which generate massive forces within the electrode structure and, thereby, result in its rapid breakdown $[9,101]$.

Depending on the fuel, there might be different mechanisms causing carbon deposition.

For example, if we take methane and carbon monoxide as the fuel, the following three reactions are the most possible ones for the formation of carbon. 


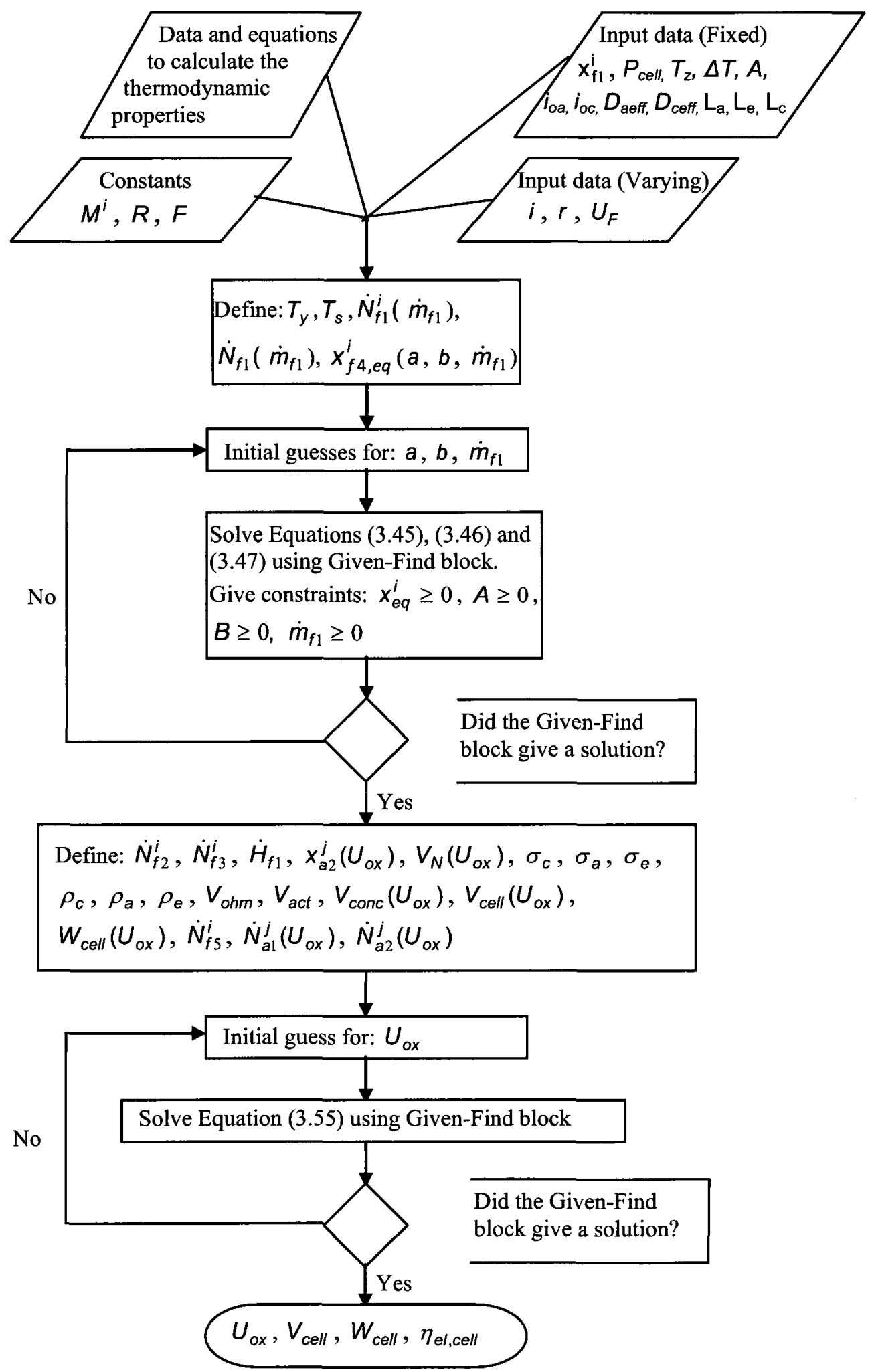

Figure 3.3: Flow chart of the MathCAD program. 


$$
\mathrm{CH}_{4} \rightleftharpoons \mathrm{C}_{(s)}+2 \mathrm{H}_{2}
$$

$2 \mathrm{CO} \rightleftharpoons \mathrm{CO}_{2}+\mathrm{C}_{(s)}$

$\mathrm{CO}+\mathrm{H}_{2} \rightleftharpoons \mathrm{C}_{(s)}+\mathrm{H}_{2} \mathrm{O}$

Steam-to-carbon ratio is one of the major parameters influencing the carbon deposition possibility. This ratio is generally adjusted by sending sufficient amount of water vapor from an external source to prevent carbon deposition. Another way of adjusting the molar composition of the inlet is recirculating the depleted fuel at the fuel channel exit, which has high water vapor content, to the fuel channel inlet, as shown in Figure 3.4.

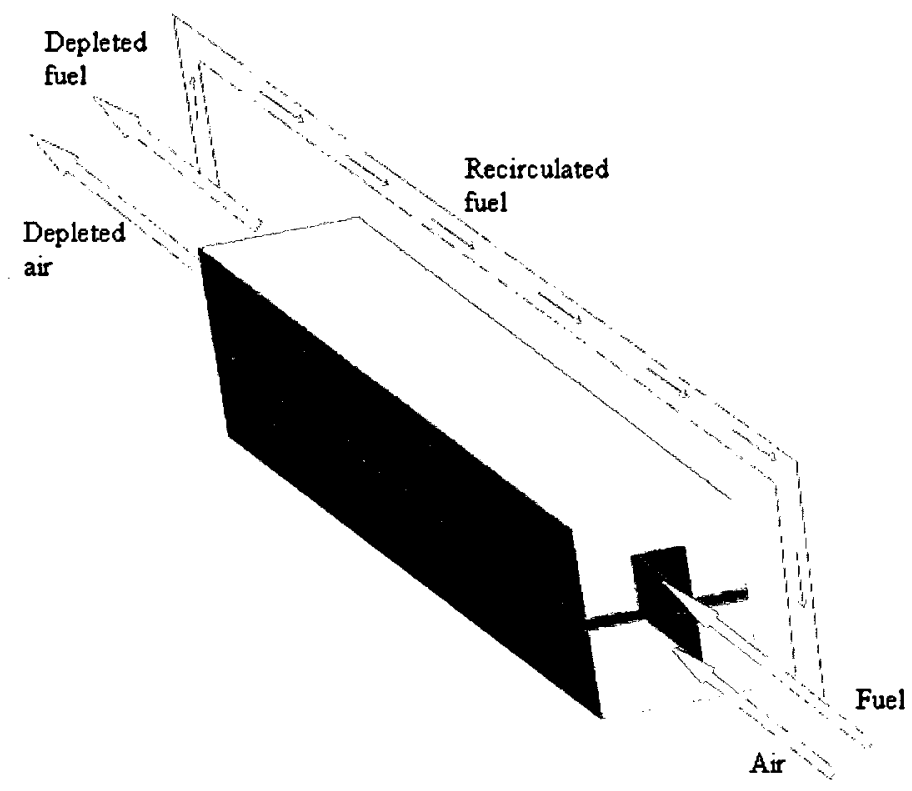

Figure 3.4: Schematic of a repeat element of a SOFC with anode recirculation. 


\subsubsection{Carbon deposition boundary}

Considering equilibrium thermodynamics, carbon deposition possibility at a certain temperature and pressure may be determined for all possible variations of $\mathrm{C}-\mathrm{H}-\mathrm{O}$ systems. In the determination of the carbon deposition boundary, $\mathrm{C}-\mathrm{H}-\mathrm{O}$ triangular phase diagrams are generally used, which is first introduced by Cairns and Tevebaugh [102]. In their study, they considered six species to be in chemical equilibrium which are $\mathrm{H}_{2} \mathrm{O}$, $\mathrm{CO}_{2}, \mathrm{H}_{2}, \mathrm{CO}, \mathrm{C}$, and $\mathrm{CH}_{4}$. According to the phase rule, $\mathrm{F}=(\mathrm{C}+\mathrm{P}-2)$, six degree of freedom are needed. These are selected as temperature, pressure, one material balance constraint and three equilibrium constant equations. The material constraint is selected as one mole of total reactants containing a fixed $\mathrm{O} / \mathrm{H}$ ratio. In the study by Broers and Treijtel [103], instead of $\mathrm{O} / \mathrm{H}$ ratio as the constraint parameter, the partial pressure of one of the gas species is used. Based on these two papers [102, 103], the carbon deposition boundary is determined with a more current thermodynamic data and a different solution method.

Three reactions needed to represent the equilibrium between gases are selected as steamreforming reaction, water-gas shift reaction, and cracking of methane reaction. Using the JANAF thermochemical tables [104], change of Gibbs free energy of formation of the chemical species are obtained for various temperatures; and using Equation (3.59), equilibrium constants for the selected reactions are calculated. Table 3.3 shows the chemical equilibrium constants of the following reactions: steam reforming reaction, i.e. Equation (3.30), water gas shift reaction, i.e. Equation (3.31), cracking of methane reaction, i.e. Equation (3.56), Boudard reaction, i.e. Equation (3.57), and shift reaction for carbon, i.e. Equation (3.58). 


$$
K(T)=\exp \left(\frac{-\Delta \bar{g}_{r}}{R T}\right)
$$

Table 3.3: Chemical equilibrium constants of reactions.

\begin{tabular}{|c|r|r|r|r|r|}
\hline $\mathrm{T}(\mathrm{K})$ & \multicolumn{1}{|c|}{$\mathrm{K}_{\text {str }}$} & \multicolumn{1}{c|}{$\mathrm{K}_{\text {wgs }}$} & \multicolumn{1}{c|}{$\mathrm{K}_{\mathrm{m}}$} & \multicolumn{1}{c|}{$\mathrm{K}_{\mathrm{b}}$} & \multicolumn{1}{c|}{$\mathrm{K}_{\text {src }}$} \\
\hline 800 & 0.03096 & 4.23010 & 0.72762 & 99.40913 & 23.50044 \\
\hline 900 & 1.29752 & 2.30504 & 3.16266 & 5.618433 & 2.43746 \\
\hline 1000 & 26.27617 & 1.43813 & 10.42663 & 0.570664 & 0.39681 \\
\hline 1100 & 311.63685 & 0.98837 & 27.98823 & 0.088766 & 0.08981 \\
\hline 1200 & 2463.98168 & 0.72956 & 64.19021 & 0.019006 & 0.026051 \\
\hline 1300 & 14224.63263 & 0.56841 & 130.16993 & 0.005202 & 0.009151 \\
\hline 1400 & 64018.71788 & 0.46162 & 239.28786 & 0.001725 & 0.003738 \\
\hline 1500 & 235779.25236 & 0.38736 & 406.29556 & 0.000668 & 0.001723 \\
\hline
\end{tabular}

Let's assume the partial pressures of the gases at the equilibrium as: $P_{\mathrm{CH}_{4}}=\alpha, P_{\mathrm{CO}_{2}}=\beta$, $P_{\text {CO }}=\delta, P_{\mathrm{H}_{2} \mathrm{O}}=\varepsilon$ and $P_{\mathrm{H}_{2}}=\zeta$ in atm. If we fix the partial pressure of methane and solve Equations (3.60)-(3.63) simultaneously, we may calculate the partial pressure of the gases at equilibrium for a fixed partial pressure of methane.

$$
\begin{aligned}
& \kappa_{s t r}=\frac{\delta \cdot \zeta^{3}}{\alpha \cdot \varepsilon} \\
& \kappa_{w g s}=\frac{\beta \cdot \zeta}{\delta \cdot \varepsilon} \\
& \kappa_{m}=\frac{\zeta^{2}}{\alpha} \\
& \alpha+\beta+\delta+\varepsilon+\zeta=P
\end{aligned}
$$


For the solution, Mathcad's 'Given-Find block', which can solve a set of nonlinear equations effectively, is used. First, the initial guesses for the partial pressures of $\mathrm{CO}_{2}$, $\mathrm{CO}, \mathrm{H}_{2} \mathrm{O}$, and $\mathrm{H}_{2}$ are given. The program solves the equations shown above for a given partial pressure of $\mathrm{CH}_{4}$ and finds the partial pressure of the gases. Then, the partial pressure of $\mathrm{CH}_{4}$ is changed between the values for which $\mathrm{H}$ ratio and $\mathrm{O}$ ratio become approximately zero. The atom ratios of $\mathrm{C}, \mathrm{H}$, and $\mathrm{O}$ are shown in Equations (3.64)-(3.66).

$$
\begin{aligned}
& C=\frac{\alpha+\beta+\delta}{5 \alpha+3 \beta+2 \delta+3 \varepsilon+2 \zeta} \\
& O=\frac{2 \beta+\delta+\varepsilon}{5 \alpha+3 \beta+2 \delta+3 \varepsilon+2 \zeta} \\
& H=1-C-O
\end{aligned}
$$

Using the set of data obtained by solving the equations shown above with changing the partial pressure of methane, carbon deposition boundary can be formed and shown in a $\mathrm{C}-\mathrm{H}-\mathrm{O}$ triangular diagram. If a given composition is above the boundary (towards the $\mathrm{C}$ vertex), then there is carbon deposition in the system. If the composition is below the boundary, then it may be interpreted that there is no risk of carbon deposition from the viewpoint of thermodynamics.

\subsubsection{Calculation of gas composition at the fuel channel inlet}

In this section, thermodynamic model to assess the performance of a DIR-SOFC, which is presented in Section 3.5, is improved to include the carbon deposition problem. In this model, gas composition at a location very close to the inlet which is at a thermodynamic 
equilibrium is first found. This location is labeled as ' $\mathrm{f6}$ ' in Figure 3.5. If we assume that local fuel utilization ratio is approximately zero at this location, only steam reforming and water-gas shift reactions occur. The gas composition at this location may be calculated as follows.

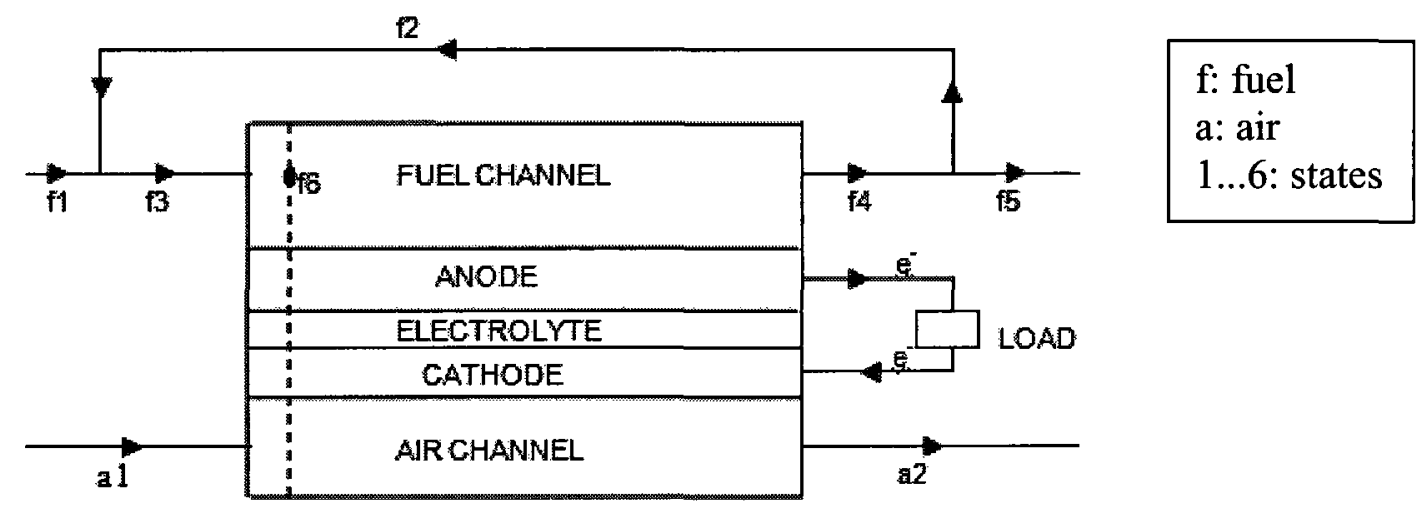

Figure 3.5: Schematic of a SOFC.

$$
\begin{aligned}
& x_{f 6, e q}^{\mathrm{CH}_{4}}=\frac{\dot{N}_{f 3}^{C H_{4}}-e}{\dot{N}_{f 3}+2 e} \\
& x_{f 6, e q}^{\mathrm{H}_{2}}=\frac{\dot{N}_{f 3}^{H_{2}}+3 e+f}{\dot{N}_{f 3}+2 e} \\
& x_{f 6, e q}^{C O}=\frac{\dot{N}_{f 3}^{C O}+e-f}{\dot{N}_{f 3}+2 e} \\
& x_{f 6, e q}^{C O}=\frac{\dot{N}_{f 3}^{C O}+f}{\dot{N}_{f 3}+2 e}
\end{aligned}
$$




$$
\begin{aligned}
& x_{f 6, e q}^{\mathrm{H}_{2} \mathrm{O}}=\frac{\dot{N}_{f 3}^{\mathrm{H}_{2} \mathrm{O}}-e-f}{\dot{N}_{f 3}+2 e} \\
& x_{f 6, e q}^{N_{2}}=\frac{\dot{N}_{f 3}^{N_{2}}}{\dot{N}_{f 3}+2 e}
\end{aligned}
$$

where

$$
\dot{N}_{f 3}^{i}=\dot{N}_{f 1}^{i}+x_{e q}^{i} \cdot\left(\dot{N}_{f 1}+2 a\right)\left(\frac{r}{1-r}\right)
$$

The extents of the reactions, e and $f$, can be found by solving the equilibrium reactions for steam reforming of methane and water-gas shift reaction simultaneously. Hence, the gas composition at state ' $\mathrm{f} 6$ ' is found.

\subsubsection{Carbon activities}

The equations given in Section 3.6.2 are valid when there is no carbon deposition at the inlet and exit of the fuel channel. Hence, if the carbon activities at the inlet and exit are both less than 1 , these equations can be used to estimate the gas composition and it means that there is no carbon deposition risk in the viewpoint of equilibrium thermodynamics. The carbon activity can be found from one of the following equations since they give the same results for the equilibrium at state ' $\mathrm{f} 6$ '. 


$$
\begin{aligned}
& a_{c 4}=\frac{K_{m} \cdot x_{e q}^{C H_{4}}}{\left(x_{e q}^{H_{2}}\right)^{2}} \\
& a_{c 5}=\frac{K_{b} \cdot\left(x_{e q}^{C O}\right)^{2}}{x_{e q}^{C O}} \\
& a_{c 6}=\frac{K_{s r c} \cdot x_{e q}^{C O} \cdot x_{e q}^{H_{2}}}{x_{e q}^{H_{2} O}}
\end{aligned}
$$

\subsection{Transient Heat Transfer Modeling of SOFC}

In the transient modeling of a SOFC, it is possible to carry out simulations of heat-up, start-up, shut-down, and load change. In this section, modeling of heat-up and start-up stages are covered. In the heat-up stage, air is sent through the air channel until the solid reaches a prescribed temperature, which is sufficient to produce a meaningful amount of power. As the heat-up stage ends, start-up stage begins. In the start-up stage, air and fuel are continuously fed to the cell until the system reaches steady state.

Quasi 2-D transient heat transfer models of the following configurations of planar SOFC are developed: 1) co-flow SOFC operating with humidified hydrogen, 2) counter-flow SOFC operating with humidified hydrogen, 3) co-flow DIR-SOFC operating with syngas consisting of $\mathrm{CH}_{4}, \mathrm{H}_{2}, \mathrm{CO}, \mathrm{CO}_{2}, \mathrm{H}_{2} \mathrm{O}$ and $\mathrm{N}_{2}, 4$ ) counter-flow DIR-SOFC operating with syngas consisting of $\mathrm{CH}_{4}, \mathrm{H}_{2}, \mathrm{CO}, \mathrm{CO}_{2}, \mathrm{H}_{2} \mathrm{O}$ and $\mathrm{N}_{2}$. 
The objective of this study is to model the heat-up and start-up stages for four different types of SOFC listed above and investigate the transient and steady-state behavior of these SOFC. It is intended to develop a better model considering all heat transfer modes namely, conduction, convection and radiation, and all polarization modes, ohmic, activation and concentration.

\subsubsection{Modeling technique}

The first step in the modeling of a SOFC is the formulation of the system considered together with the specification of the control volumes, and the coordinates. For this reason, the repeat element of a SOFC, found in the middle of a stack, is divided into five control volumes: anode interconnect, fuel channel, PEN (consisting of anode, electrolyte and cathode), air channel, and cathode interconnect. The Cartesian coordinate system is selected for all the control volumes given their specific geometry. Then, the general laws, e.g. conservation of mass, energy, and momentum, the particular laws, e.g. the relation between the cell voltage and polarizations, and the initial and boundary conditions are written for each of these control volumes.

In modeling, instead of solving the conservation of momentum, some simplifications are made assuming fully developed laminar flow conditions. This assumption is well justified since the gases flow with low velocity, which is required to obtain a high fuel utilization ratio. Under these flow conditions, the Nusselt number becomes a single function of the aspect ratio for rectangular ducts. This derivation is based on solutions of the differential momentum and energy equations for different boundary conditions [105]. Equations 
(3.77) and (3.78) show the Nusselt number as a function of aspect ratio for specified wall temperature and specified axial wall heat flux, respectively. The change of Nusselt number with aspect ratio $(\alpha)$ is also shown in Figure 3.6.

$$
\begin{aligned}
& N u_{T}=7.541 \cdot\left(1-2.601 \alpha+4.970 \alpha^{2}-5.119 \alpha^{3}+2.702 \alpha^{4}-0.548 \alpha^{5}\right) \\
& N u_{H}=8.235 \cdot\left(1-2.0421 \alpha+3.0853 \alpha^{2}-2.4765 \alpha^{3}+1.0578 \alpha^{4}-0.1861 \alpha^{5}\right)
\end{aligned}
$$
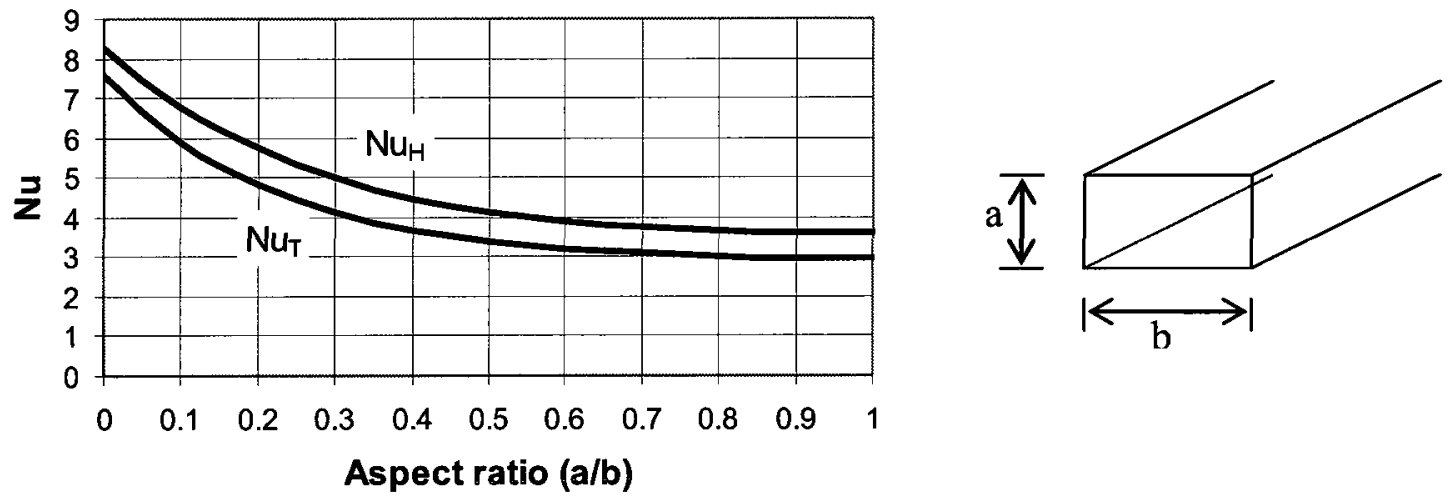

Figure 3.6: Nusselt number as a function of aspect ratio for fully developed laminar flow.

There is a discrepancy in the literature about how some of the input and output parameters of SOFC models are selected. Parameters such as average current density, fuel utilization ratio, cell voltage, and mass flow rate of the channel inlets may be chosen as input or output according to the purpose of the model. In the present model, the cell voltage, which is assumed to be equal at the top and bottom surfaces of the interconnect, the Reynolds number at the fuel channel inlet that controls the fuel mass flow rate, and the excess air coefficient that determines the mass flow rate at the air channel inlet are 
taken as input parameters. Other input parameters selected in this study are: the cell geometry, the properties of materials, the ambient temperature, the molar composition at the fuel and air channel inlets, the mass flow rate of air for the heat-up stage, and the cell pressure. The expected outcome parameters of the model are: the heat-up and start-up time, the fuel utilization ratio, the current density, the temperature and molar gas composition distributions, and the power output and electrical efficiency of the cell.

The strategy followed for the modeling of the heat-up and start-up stages is as follows. In modeling the heat-up period, only the heat transfer equations are solved since there is no fuel flow taking place in the fuel channel. At this stage, the temperature of the air channel is controlled so as not to cause excessive thermomechanical stresses [106]. The minimum solid temperature of the cell is calculated for each time step, and the air channel inlet temperature is set to $\mathrm{T}_{\min , \text { solid }}+100{ }^{\circ} \mathrm{C}$ for the subsequent time step. In modeling the startup period, the temperatures of the air and fuel channel inlets are kept constant, and mass balances are first solved for air and fuel channels for each time step. In this solution, the relation between the cell voltage and the polarizations (ohmic, activation, and concentration), chemical equilibrium relation for water-gas shift reaction, and chemical kinetics of steam reforming reaction are taken into account. The molar flow rates and the composition of the gas species, and current density distribution through the gas channels are determined after the mass balances are obtained. Using these data and the temperature distribution obtained from the previous time step, heat transfer equations are applied to each control volume. Considered in the heat transfer equations are conduction between PEN and interconnects, natural convection in the heat-up stage, forced convection in the 
start-up stage, and surface-to-surface radiation between the PEN and interconnects. Hence, the temperature distribution in a given time step is calculated, and the iterations are repeated until the absolute temperature difference between the two consecutive time steps for each node becomes less than the threshold value. This value is chosen as $10^{-4}$, which is low enough considering the operating temperature of the SOFC, in this study.

The second step in the modeling is the solution of the modeling equations. Among the different numerical solutions, e.g. finite difference, finite volume, and finite element, finite difference method is used in this study because this method is straightforward for orthogonal grids. In applying this method, spatial and temporal domains are divided into several sections, which is also called meshing. After generating the mesh, finitedifference approximations are substituted for the derivatives to convert the partial differential equations to an algebraic form. Then, a computer code, which is capable of solving the system of equations in an efficient way for different input parameters, is developed. In this thesis, the code for the heat transfer model of SOFC is developed in the Matlab.

Final step of modeling is validation. In general, this may be accomplished through conducting experiments or in the case of lack of facilities, gathering the results of experimental studies found in the literature. However, if no experimental results are found in the literature, the results of numerical or analytical solutions of other authors' may be used for comparison. In this study, due to lack of experimental results in the 
literature, the results of the SOFC benchmark test and Braun's model $[107,108]$ are used for validating the model.

\subsubsection{Modeling equations for co-flow DIR-SOFC operating with syngas}

Continuity and heat transfer equations are applied to the control volumes, e.g. interconnects, PEN, and gas channels. These equations are shown in Section 3.7.2.1. Dimensionless numbers used in these equations and the numerical solution are shown in Section 3.7.2.2. The output parameters of the model are shown in Section 3.7.2.3.

\subsubsection{Governing equations}

In a DIR-SOFC, steam reforming reaction, Equation (3.30), water-gas shift reaction, Equation (3.31), and electrochemical oxidation of hydrogen, Equation (3.32) occur. Based on these reactions, the continuity equations at the fuel channel are shown below. The transient terms are neglected because gases come to steady state very quickly.

$$
\begin{aligned}
& \frac{d \dot{n}_{C H_{4}}^{\prime \prime}}{d x}=\frac{-\dot{r}_{s t r}^{\prime \prime}}{t_{f c}} \\
& \frac{d \dot{n}_{H_{2}}^{\prime \prime}}{d x}=\frac{3 \dot{r}_{s t r}^{\prime \prime}}{t_{f c}}+\Delta \dot{n}_{w g s}^{\prime \prime \prime}-\frac{\dot{r}_{e l}^{\prime \prime}}{t_{f c}} \\
& \frac{d \dot{n}_{C O}^{\prime \prime}}{d x}=\frac{\dot{r}_{s t r}^{\prime \prime}}{t_{f c}}-\Delta \dot{n}_{w g s}^{\prime \prime \prime} \\
& \frac{d \dot{n}_{C O_{2}}^{\prime \prime}}{d x}=\Delta \dot{n}_{w g s}^{\prime \prime}
\end{aligned}
$$




$$
\begin{aligned}
& \frac{d \dot{n}_{H_{2} \mathrm{O}}^{\prime \prime}}{d x}=\frac{-\dot{r}_{s t r}^{\prime \prime}}{t_{f c}}-\Delta \dot{n}_{w g s}^{\prime \prime \prime}+\frac{\dot{r}_{e l}^{\prime \prime}}{t_{f c}} \\
& \frac{d \dot{n}_{N_{2}}^{\prime \prime}}{d x}=0
\end{aligned}
$$

The steam-reforming reaction is kinetically controlled. The rate of conversion for this reaction is given in Equation (3.85) [88]. The rate of conversion for electrochemical reaction depends on the current density, which is shown in Equation (3.86). Water-gas shift reaction is assumed to be in chemical equilibrium.

$$
\begin{aligned}
& \dot{r}_{s t r}^{\prime \prime}=4274 \cdot P_{C H_{4}} \cdot \exp \left(\frac{-8.2 \times 10^{4}}{R \times T}\right) \\
& \dot{r}_{e l}^{\prime \prime}=\frac{i}{2 F}
\end{aligned}
$$

The continuity equations at the air channel are as follows:

$$
\begin{aligned}
& \frac{d \dot{n}_{O_{2}}^{\prime \prime}}{d x}=\frac{-\dot{r}_{e l}^{\prime \prime} / 2}{t_{a c}} \\
& \frac{d \dot{n}_{N_{2}}^{\prime \prime}}{d x}=0
\end{aligned}
$$

The chemical equilibrium relation for water-gas shift reaction is solved together with the relation between the Nernst voltage and the polarizations, which is shown in Equation 
(3.11). The equations for the Nernst voltage and the polarizations are shown in Equations (3.9) and (3.14)-(3.21), respectively. The terms in Equation (3.11) depend on the temperature of the solid, pressure, gas composition, and current density.

Solving the equations given above, the current density and the volumetric molar change of water-gas shift reaction are found. Hence, we can calculate the molar flow rate and molar composition of gas species through the gas channels. After solving the continuity equations together with the equations related to chemical and electrochemical relations, heat transfer equations are solved. These equations and their associated initial and boundary conditions are given below.

The 2-D transient heat diffusion equation for the cathode interconnect can be written as follows:

$$
\frac{1}{\alpha_{c i}} \cdot \frac{\partial T}{\partial t}=\frac{\partial^{2} T}{\partial x^{2}}+\frac{\partial^{2} T}{\partial y^{2}}
$$

The boundary and initial conditions for the cathode interconnect can be given as follows:

$$
\begin{aligned}
& x=0 \& x=L \Rightarrow \frac{\partial T}{\partial x}=0 \\
& y=0 \Rightarrow \frac{\partial T}{\partial y}=0
\end{aligned}
$$




$$
\begin{aligned}
& y=t_{c i} \Rightarrow \\
& -k_{c i} \cdot \frac{\partial T}{\partial y}=\frac{w_{\text {gas }}}{w_{\text {solid }}} \cdot\left[h_{c, a} \cdot\left(T_{c i}-T_{a}\right)+h_{r, a} \cdot\left(T_{c i}-T_{\text {pen }}\right)\right]+\left(1-\frac{w_{\text {gas }}}{w_{\text {solid }}}\right) \cdot k_{c i} \cdot \frac{\left(T_{c i}-T_{P E N}\right)}{t_{a c}} \\
& t=0 \Rightarrow T=T_{o}
\end{aligned}
$$

The transient heat transfer equation and the boundary and initial conditions for the air channel are shown below.

$$
\begin{aligned}
& \rho_{a c} \cdot c_{p, a c} \cdot \frac{\partial T}{\partial t}+\sum_{i} \frac{\partial}{\partial x}\left(\dot{n}_{i}^{\prime \prime} \cdot \bar{h}_{i}\right)=\frac{h_{c, a}\left(T_{P E N}-T_{a}\right)+h_{c, a}\left(T_{c i}-T_{a}\right)-\left(\dot{r}_{e l}^{\prime \prime} / 2\right) \cdot \bar{h}_{O_{2}} \cdot w_{\text {solid }} / w_{\text {gas }}}{t_{a c}} \\
& \begin{array}{l}
x=0 \Rightarrow T=f(t)(\text { Heat }- \text { up }) \\
T=T_{w_{-} a c}(\text { Start }- \text { up })
\end{array} \\
& t=0 \Rightarrow T=T_{o}+100^{\circ} \mathrm{C}
\end{aligned}
$$

A 2-D transient heat diffusion equation for the PEN can be written as follows:

$$
\frac{1}{\alpha_{P E N}} \cdot \frac{\partial T}{\partial t}=\frac{\partial^{2} T}{\partial x^{2}}+\frac{\partial^{2} T}{\partial y^{2}}+\frac{1}{k_{P E N}} \dot{q}_{P E N}^{\prime \prime}
$$

The boundary and initial conditions for the PEN can be given as follows:

$$
x=0 \& x=L \Rightarrow \frac{\partial T}{\partial x}=0
$$




$$
\begin{aligned}
& y=t_{c i}+t_{a c} \Rightarrow \\
& k_{P E N} \cdot \frac{\partial T}{\partial y}=\frac{w_{\text {gas }}}{w_{\text {solid }}} \cdot\left[h_{c, a} \cdot\left(T_{P E N}-T_{a}\right)+h_{r, a} \cdot\left(T_{P E N}-T_{c i}\right)\right]+\left(1-\frac{w_{\text {gas }}}{w_{\text {solid }}}\right) \cdot k_{c i} \cdot \frac{\left(T_{P E N}-T_{c i}\right)}{t_{a c}} \\
& y=t_{c i}+t_{a c}+t_{P E N} \Rightarrow \\
& -k_{P E N} \cdot \frac{\partial T}{\partial y}=\frac{w_{g a s}}{w_{\text {solid }}} \cdot\left[h_{c, f} \cdot\left(T_{P E N}-T_{f}\right)+h_{r, f} \cdot\left(T_{P E N}-T_{a i}\right)\right]+\left(1-\frac{w_{\text {gas }}}{w_{\text {solid }}}\right) \cdot k_{a i} \cdot \frac{\left(T_{P E N}-T_{a i}\right)}{t_{f c}} \\
& t=0 \Rightarrow T=T_{0}
\end{aligned}
$$

The volumetric heat generation term, $\dot{q}_{P E N}^{\prime \prime}$, becomes

$$
\dot{q}_{P E N}^{\prime \prime \prime}=\frac{\sum \Delta \dot{H}^{\prime \prime}{ }_{k}-\dot{W}_{e l}^{\prime \prime}}{t_{P E N}}
$$

where electrical power output per area may be given as

$$
\dot{W}_{e l}^{\prime \prime}=i \cdot V_{c e l l}
$$

Thermal conductivity and volumetric heat capacity of PEN can be calculated using Equations (3.91g) and (3.91h), respectively.

$$
k_{P E N}=\frac{t_{a} \cdot k_{a}+t_{e} \cdot k_{e}+t_{c} \cdot k_{c}}{t_{P E N}}
$$




$$
\left(\rho c_{p}\right)_{P E N}=\frac{t_{a} \cdot\left(\rho c_{p}\right)_{a}+t_{e} \cdot\left(\rho c_{p}\right)_{e}+t_{c} \cdot\left(\rho c_{p}\right)_{c}}{t_{P E N}}
$$

The transient heat transfer equation and the boundary and initial conditions for the fuel channel are shown below.

$$
\begin{aligned}
& \rho_{f c} \cdot c_{p, f c} \cdot \frac{\partial T}{\partial t}+\sum_{i} \frac{\partial}{\partial x}\left(\dot{n}_{i}^{\prime \prime} \cdot \bar{h}_{i}\right)= \\
& \frac{h_{c, f}\left(T_{a i}-T_{f}\right)+h_{c, f}\left(T_{P E N}-T_{f}\right)+\left(\sum \dot{r}_{p r o d}^{\prime \prime} \cdot \bar{h}_{p r o d}-\sum \dot{r}_{\text {react }}^{\prime \prime} \cdot \bar{h}_{\text {react }}\right) \cdot w_{\text {solid }} / w_{\text {gas }}}{t_{f c}} \\
& x=0 \Rightarrow T=T w_{-} f c \text { (Start - up) } \\
& t=0 \Rightarrow T=T_{0}
\end{aligned}
$$

where $h_{c, f}$ is the heat transfer coefficient and represents the natural convection and forced convection in the heat-up and start-up stages, respectively.

The 2-D transient heat diffusion equation for the anode interconnect can be written as follows.

$$
\frac{1}{\alpha_{a i}} \cdot \frac{\partial T}{\partial t}=\frac{\partial^{2} T}{\partial x^{2}}+\frac{\partial^{2} T}{\partial y^{2}}
$$

The boundary and initial conditions for the anode interconnect can be given as follows. 


$$
\begin{aligned}
& x=0 \& x=L \Rightarrow \frac{\partial T}{\partial x}=0 \\
& y=t_{c i}+t_{a c}+t_{P E N}+t_{f c} \Rightarrow \\
& -k_{a i} \cdot \frac{\partial T}{\partial y}=\frac{w_{\text {gas }}}{w_{\text {solid }}} \cdot\left[h_{c, f} \cdot\left(T_{a i}-T_{f}\right)+h_{r, f} \cdot\left(T_{a i}-T_{P E N}\right)\right]+\left(1-\frac{w_{\text {gas }}}{w_{\text {solid }}}\right) \cdot k_{a i} \cdot \frac{\left(T_{a i}-T_{P E N}\right)}{t_{f c}} \\
& y=t_{c i}+t_{a c}+t_{P E N}+t_{f c}+t_{a i} \Rightarrow \frac{\partial T}{\partial y}=0 \\
& t=0 \Rightarrow T=T_{o}
\end{aligned}
$$

\subsubsection{Dimensionless numbers}

The Reynolds number is a dimensionless number that is generally used to characterize the flow regime: laminar or turbulent. In a fully developed internal flow, the critical Reynolds number corresponding to the onset of turbulence is given approximately as 2300 [109]. If the Reynolds number is less than this number, we can consider the flow as laminar. For example, Reynolds number for the fuel channel inlet is shown in Equation (3.94). Please note that the fuel channel has a rectangular cross section, and hydraulic diameter is used in the definition of Reynolds number due to this reason. In the present model, this number is given as input. Hence, using this number, mass flow rate of the gas mixture per cross section of the fuel channel at the inlet can be found.

$\operatorname{Re}_{D_{h}}=\frac{\dot{m}_{f i}^{\prime \prime} \cdot\left(2 \cdot t_{f c} \cdot w_{g a s}\right)}{\mu_{\text {mix }} \cdot\left(t_{f c}+w_{g a s}\right)}$ 
We can write Equation (3.94) in terms of molar flow rate of the gas species at the fuel channel inlet, as shown in Equation (3.95). Here, $\mathrm{k}$ denotes $\mathrm{CH}_{4}, \mathrm{H}_{2}, \mathrm{CO}, \mathrm{CO}_{2}, \mathrm{H}_{2} \mathrm{O}$ and $\mathrm{N}_{2}$.

$$
\operatorname{Re}_{D_{h}}=\frac{\dot{n}_{k, f i}^{\prime \prime} \cdot M_{\text {mix }} \cdot\left(2 \cdot t_{f c} \cdot w_{g a s}\right)}{x_{k, f i} \cdot \mu_{\text {mix }} \cdot\left(t_{f c}+w_{g a s}\right)}
$$

Excess air coefficient, as defined in Section 3.2.1, is another input parameter of the transient heat transfer model. This coefficient is used to calculate the molar flow rate of gas species per cross section of the air channel at the inlet as follows:

$$
\lambda_{\text {air }}=\frac{\dot{n}_{O_{2}, a i}^{\prime \prime}}{\left(2 \cdot \dot{n}_{C H_{4}, f i}^{\prime \prime}+\dot{n}_{C O, f i}^{\prime \prime} / 2+\dot{n}_{H_{2}, f i}^{\prime \prime} / 2\right)} \cdot \frac{t_{a c}}{t_{f c}}
$$

Nusselt number is the dimensionless temperature gradient at the solid-gas surface. It is used to calculate the convective heat transfer coefficient in the model. This number is shown below:

$$
N u=\frac{h_{c} \cdot D_{h}}{k}
$$

In the numerical solution, Biot number and Fourier number, which are shown in Equations (3.98) and (3.99), respectively, are used. Using the Biot number, the 
temperature drop in the solid can be compared to the temperature difference between the surface of the solid and the fluid. Fourier number is a dimensionless time used in transient heat transfer problems.

$$
\begin{aligned}
& B i=\frac{h \cdot L}{k} \\
& F O=\frac{\alpha \cdot t}{L_{c}{ }^{2}}
\end{aligned}
$$

\subsubsection{Output parameters}

Using the modeling equations shown above, the output parameters can be calculated.

These parameters are fuel utilization, power density, power output, and electrical efficiency of the cell.

Fuel utilization, which is defined in Section 3.2.1, is modified for the case where syngas is used as the fuel and it can be calculated using

$$
U_{f}=\frac{\sum_{i=2}^{m} \dot{r}_{e l}^{\prime \prime} \cdot\left(\Delta x \cdot w_{\text {solid }}\right)}{\left(4 \cdot \dot{n}_{C H_{4}, f i}^{\prime \prime}+\dot{n}_{H_{2}, f i}^{\prime \prime}+\dot{n}_{c O, f i}^{\prime \prime}\right) \cdot\left(w_{g a s} \cdot t_{f c}\right)}
$$

Power density and power output of the SOFC can be found using

$$
\dot{W}_{\text {SOFC }}^{\prime \prime}=i_{c, a v e} \cdot V_{\text {cell }}
$$


$\dot{W}_{\text {SOFC }}=\dot{W}_{\text {SOFC }}^{n} \cdot L_{\text {cell }} \cdot W_{\text {solid }}$

As the main purpose of operating the SOFC is generating electricity, its performance can be assessed by calculating the electrical efficiency of the cell. This efficiency can be found using

$\eta_{e l}=\frac{\dot{W}_{\text {SOFC }}}{L H V \cdot \sum_{k=1}^{6} \dot{n}_{k, f i}^{\prime \prime} \cdot t_{f c} \cdot w_{g a s}}$

where lower heating value, $L H V$, can be calculated using

$$
\begin{aligned}
L H V= & \sum_{k=1}^{6}\left(x_{k, f i} \cdot h_{f, k}^{\circ}\right)-\left(x_{C_{4}, f i}+x_{C O, f i}+x_{C O_{2}, f i}\right) \cdot h_{f, C O_{2}}^{\circ} \\
& -\left(2 \cdot x_{C_{4}, f i}+x_{H_{2}, f i}+x_{H_{2} O, f i}\right) \cdot h_{f, H_{2} \mathrm{O}}^{\circ}-x_{N_{2}, f i} \cdot h_{f, N_{2}}^{\circ}
\end{aligned}
$$

\subsubsection{Numerical solution scheme}

Among the different numerical solution methods, e.g. finite difference, finite volume, and finite element, finite difference scheme is chosen for solving the heat transfer equations because of the simplicity and straightforwardness of this method in orthogonal grids.

The schematic of the 2-D cross section of a repeat element and the numbering scheme for the nodes are shown in Figure 3.7. As it can be seen from this figure, the repeat element has $\mathrm{m} \times \mathrm{s}$ nodes. The number of nodes, i.e. $\mathrm{m}$ and $\mathrm{s}$, must be decided after conducting a grid independence analysis. 


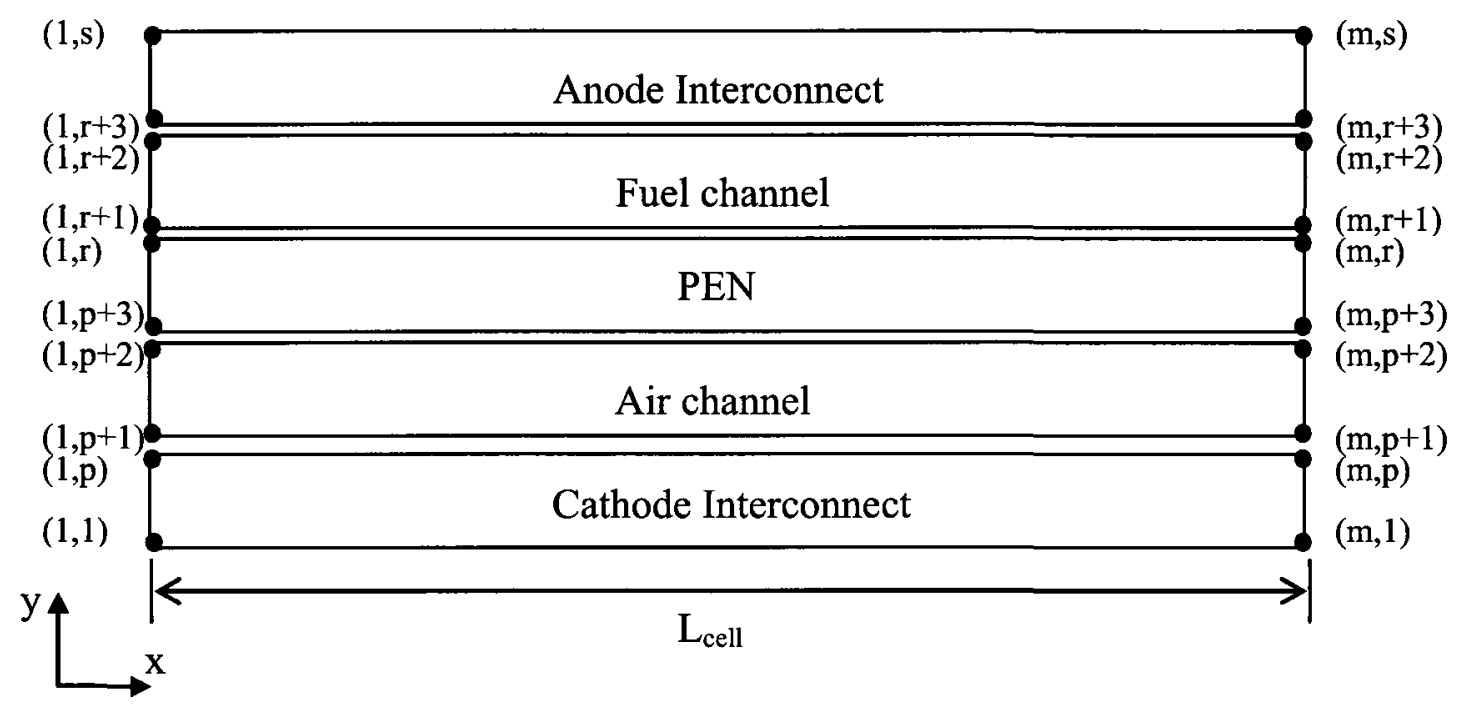

Figure 3.7: Numbering scheme for finite difference solution of the repeat element of the SOFC.

The length of the cell, and the thicknesses of cathode interconnect, PEN, and anode interconnect are divided into $\mathrm{m}-1, \mathrm{p}-1, \mathrm{r}-\mathrm{p}-3$, and s-r-3 parts. The related equations are given as

$$
\begin{aligned}
& L_{c e l l}=(m-1) \cdot \Delta x \\
& t_{c i}=(p-1) \cdot \Delta y_{1} \\
& t_{p e n}=(r-p-3) \cdot \Delta y_{2} \\
& t_{a i}=(s-r-3) \cdot \Delta y_{3}
\end{aligned}
$$

The continuity equations (3.79)-(3.84) and (3.87)-(3.88) take the following forms as shown below: 


$$
\begin{aligned}
& \left(\dot{n}_{C H_{4}}^{\prime \prime}\right)_{i+1, r+1}=\left(\dot{n}_{C H_{4}}^{\prime \prime}\right)_{i, r+1}+\Delta x \cdot\left(\frac{-\dot{r}_{s t r}^{\prime \prime}}{t_{f c}}\right)_{i} \\
& \left(\dot{n}_{H_{2}}^{\prime \prime}\right)_{i+1, r+1}=\left(\dot{n}_{H_{2}}^{\prime \prime}\right)_{i, r+1}+\Delta x \cdot\left(\frac{3 \dot{r}_{s t r}^{\prime \prime}}{t_{f c}}+\Delta \dot{n}_{w g s}^{\prime \prime \prime}-\frac{\dot{r}_{e l}^{\prime \prime}}{t_{f c}}\right)_{i} \\
& \left(\dot{n}_{C O}^{\prime \prime}\right)_{i+1, r+1}=\left(\dot{n}_{c O}^{\prime \prime}\right)_{i, r+1}+\Delta x \cdot\left(\frac{\dot{r}_{s t r}^{\prime \prime}}{t_{f c}}-\Delta \dot{n}_{w g s}^{\prime \prime \prime}\right)_{i} \\
& \left(\dot{n}_{C O_{2}}^{\prime \prime}\right)_{i+1, r+1}=\left(\dot{n}_{C O_{2}}^{\prime \prime}\right)_{i, r+1}+\Delta x \cdot\left(\Delta \dot{n}_{w g s}^{\prime \prime \prime}\right)_{i} \\
& \left(\dot{n}_{H_{2} \mathrm{O}}^{\prime \prime}\right)_{i+1, r+1}=\left(\dot{n}_{H_{2} \mathrm{O}}^{\prime \prime}\right)_{i, r+1}+\Delta x \cdot\left(\frac{-\dot{r}_{s t r}^{\prime \prime}}{t_{f c}}-\Delta \dot{n}_{w g s}^{\prime \prime \prime}+\frac{\dot{r}_{e l}^{\prime \prime}}{t_{f c}}\right)_{i} \\
& \left(\dot{n}_{N_{2}}^{\prime \prime}\right)_{i+1, r+1}=\left(\dot{n}_{N_{2}}^{\prime \prime}\right)_{i, r+1} \\
& \left(\dot{n}_{O_{2}}^{\prime \prime}\right)_{i+1, p+1}=\left(\dot{n}_{O_{2}}^{\prime \prime}\right)_{i, p+1}+\Delta x \cdot\left(\frac{-\dot{r}_{e l}^{\prime \prime} / 2}{t_{a c}}\right) \\
& \left(\dot{n}_{N_{2}}^{n}\right)_{i+1, p+1}=\left(\dot{n}_{N_{2}}^{\prime \prime}\right)_{i, p+1}
\end{aligned}
$$

An implicit finite different scheme is used for the solution of the heat transfer equations. Unlike explicit method, this method is unconditionally stable. The space derivative is discretized at the $n+1$ time level using central-difference approximation. For example,

$$
\left.\frac{\partial^{2} T}{\partial x^{2}}\right|_{i, j, n+1}=\frac{T_{i-1, j}^{n+1}-2 \cdot T_{i, j}^{n+1}+T_{i+1, j}^{n+1}}{(\Delta x)^{2}}+o\left[(\Delta x)^{2}\right]
$$


The time derivative is discretized using backward finite difference approximation as follows:

$$
\left.\frac{\partial T}{\partial t}\right|_{i, j, n+1}=\frac{T_{i, j}^{n+1}-T_{i, j}^{n}}{\Delta t}+o(\Delta t)
$$

The finite difference equations for the boundary conditions are taken as second order accurate. The equations are derived by considering an imaginary node outside the control volume and eliminating this node between the general equation for interior nodes and the boundary equation. The details of this approach may be found in the book by Ozisik [110]. As an example, finite difference equations for cathode interconnect and air channel are given below.

For cathode interconnect, Eqn. (3.89) can be written as

$$
\frac{T_{i, j}^{n+1}-T_{i, j}^{n}}{\Delta t}=\alpha_{c i} \cdot\left(\frac{T_{i-1, j}^{n+1}-2 \cdot T_{i, j}^{n+1}+T_{i+1, j}^{n+1}}{\Delta x^{2}}+\frac{T_{i, j-1}^{n+1}-2 \cdot T_{i, j}^{n+1}+T_{i, j+1}^{n+1}}{\Delta y 1^{2}}\right)
$$

Eqn. (3.119) can be shown as 
$\left(1+2 F o_{x, c i}+2 F o_{y 1, c i}\right) \cdot T_{i, j}^{n+1}-F o_{x, c i} \cdot T_{i-1, j}^{n+1}-F o_{x, c i} \cdot T_{i+1, j}^{n+1}-F o_{y 1, c i} \cdot T_{i, j-1}^{n+1}-F o_{y 1, c i} \cdot T_{i, j+1}^{n+1}=T_{i, j}^{n}$

where

$$
\begin{aligned}
& F o_{x, c i}=\frac{\alpha_{c i} \cdot \Delta t}{\Delta x^{2}} \\
& F o_{y 1, c i}=\frac{\alpha_{c i} \cdot \Delta t}{\Delta y 1^{2}}
\end{aligned}
$$

Equation (3.120) is valid for interior nodes from $i=2$ to $m-1$ and $j=2$ to $p-1$.

The cathode interconnect has three adiabatic boundary conditions, as shown in Equations (3.89a) and (3.89b). For the interior nodes of these boundary conditions, $T_{0, j}^{n+1}=T_{2, j}^{n+1}$, $T_{m+1, j}^{n+1}=T_{m-1, j}^{n+1}$, and $T_{i, 0}^{n+1}=T_{i, 2}^{n+1}$ should be replaced in Equation (3.120), which takes the form as shown below:

$$
\begin{aligned}
& \left(1+2 F o_{x, c i}+2 F o_{y 1, c i}\right) \cdot T_{1, j}^{n+1}-2 F o_{x, c i} \cdot T_{2, j}^{n+1}-F o_{y 1, c i} \cdot T_{1, j-1}^{n+1}-F o_{y 1, c i} \cdot T_{1, j+1}^{n+1}=T_{1, j}^{n} \\
& \left(1+2 F o_{x, c i}+2 F o_{y 1, c i}\right) \cdot T_{m, j}^{n+1}-2 F o_{x, c i} \cdot T_{m-1, j}^{n+1}-F o_{y 1, c i} \cdot T_{m, j-1}^{n+1}-F o_{y 1, c i} \cdot T_{m, j+1}^{n+1}=T_{m, j}^{n} \\
& \left(1+2 F o_{x, c i}+2 F o_{y 1, c i}\right) \cdot T_{i, 1}^{n+1}-F o_{x, c i} \cdot T_{i-1,1}^{n+1}-F o_{x, c i} \cdot T_{i+1,1}^{n+1}-2 F o_{y 1, c i} \cdot T_{i, 2}^{n+1}=T_{i, 1}^{n}
\end{aligned}
$$


In the above equations, Equations (3.121), (3.122), and (3.123) represent the interior nodes of the boundaries $\mathrm{i}=1, \mathrm{i}=\mathrm{m}$, and $\mathrm{j}=1$, respectively.

For the interior nodes of the boundary condition shown in the Equation $(3.89 \mathrm{c})$, the finite difference equation, Equation (3.124), can be found by eliminating the imaginary node between the equation for interior nodes, Equation (3.124a) and that for boundary condition, Equation (3.124b). Equation (3.124) represent the boundary condition for $j=p$.

$$
\begin{aligned}
&\left(1+2 F o_{x, c i}+2 F o_{y 1, c i}\right) \cdot T_{i, p}^{n+1}-F o_{x, c i} \cdot T_{i-1, p}^{n+1}-F o_{x, c i} \cdot T_{i+1, p}^{n+1}-F o_{y 1, c i} \cdot T_{i, p-1}^{n+1}-F o_{y 1, c i} \cdot T_{i, p+1 i}^{n+1}=T_{i, p}^{n} \\
&-T_{i, p+1 i}^{n+1}+T_{i, p-1}^{n+1}= \frac{2 B i_{c, a} \cdot w_{\text {gas }}}{w_{\text {solid }}} \cdot\left(T_{i, p}^{n+1}-T_{i, p+1}^{n+1}\right)+\frac{2 B i_{r, 1} \cdot w_{\text {gas }}}{w_{\text {solid }}} \cdot\left(T_{i, p}^{n+1}-T_{i, p+3}^{n+1}\right) \\
&+\frac{2 \Delta y 1}{t_{a c}} \cdot\left(1-\frac{w_{\text {gas }}}{w_{\text {solid }}}\right) \cdot\left(T_{i, p}^{n+1}-T_{i, p+3}^{n+1}\right)
\end{aligned}
$$

where

$$
\begin{aligned}
& B i_{c, a}=\frac{h_{c, a} \cdot \Delta y 1}{k_{c i}} \\
& B i_{r, 1}=\frac{h_{r 1} \cdot \Delta y 1}{k_{c i}}
\end{aligned}
$$




$$
\begin{aligned}
& {\left[\begin{array}{l}
1+2 F o_{x, c i}+2 F o_{y 1, c i}+F o_{y 1, c i} \cdot \frac{2 B i_{c, a} \cdot w_{g a s}}{w_{s o l i d}}+ \\
\left.F o_{y 1, c i} \cdot \frac{2 B i_{r, 1} \cdot w_{g a s}}{w_{s o l i d}}+F o_{y 1, c i} \cdot \frac{2 \Delta y 1}{t_{a c}} \cdot\left(1-\frac{w_{g a s}}{w_{\text {solid }}}\right)\right] \cdot T_{i, p}^{n+1}-F o_{x, c i} \cdot T_{i-1, p}^{n+1}
\end{array}\right.} \\
& -F o_{x, c i} \cdot T_{i+1, p}^{n+1}-2 F o_{y 1, c i} \cdot T_{i, p-1}^{n+1}-F o_{y 1, c i} \cdot \frac{2 B i_{c, a} \cdot w_{g a s}}{w_{\text {solid }}} \cdot T_{i, p+1}^{n+1} \\
& -\left[F o_{y 1, c i} \cdot \frac{2 B i_{r, 1} \cdot w_{g a s}}{w_{s o l i d}}+F o_{y 1, c i} \cdot \frac{2 \Delta y 1}{t_{a c}} \cdot\left(1-\frac{w_{g a s}}{w_{\text {solid }}}\right)\right] \cdot T_{i, p+3}^{n+1}=T_{i, p}^{n}
\end{aligned}
$$

There are also four finite difference equations for the corners of the cathode interconnect, which are shown in Equations (3.125)-(3.128). These equations are derived by solving the finite difference equations for the relevant boundary conditions.

$$
\begin{aligned}
& \left(1+2 F o_{x, c i}+2 F o_{y 1, c i}\right) \cdot T_{1,1}^{n+1}-2 F o_{x, c i} \cdot T_{2,1}^{n+1}-2 F o_{y 1, c i} \cdot T_{1,2}^{n+1}=T_{1,1}^{n} \\
& \left(1+2 F o_{x, c i}+2 F o_{y 1, c i}\right) \cdot T_{m, 1}^{n+1}-2 F o_{x, c i} \cdot T_{m-1,1}^{n+1}-2 F o_{y 1, c i} \cdot T_{m, 2}^{n+1}=T_{m, 1}^{n} \\
& {\left[1+2 F o_{x, c i}+2 F o_{y 1, c i}+F o_{y 1, c i} \cdot \frac{2 B i_{c, a} \cdot w_{\text {gas }}}{w_{\text {solid }}}+\right.} \\
& \left.F o_{y 1, c i} \cdot \frac{2 B i_{r, 1} \cdot w_{g a s}}{w_{\text {solid }}}+F o_{y 1, c i} \cdot \frac{2 \Delta y 1}{t_{a c}} \cdot\left(1-\frac{w_{\text {gas }}}{w_{\text {solid }}}\right)\right] \cdot T_{1, p}^{n+1} \\
& -2 F o_{x, c i} \cdot T_{2, p}^{n+1}-2 F o_{y 1, c i} \cdot T_{1, p-1}^{n+1}-F o_{y 1, c i} \cdot \frac{2 B i_{c, a} \cdot w_{g a s}}{w_{\text {solid }}} \cdot T_{1, p+1}^{n+1} \\
& -\left[F o_{y 1, c i} \cdot \frac{2 B i_{r, 1} \cdot w_{g a s}}{w_{\text {solid }}}+F o_{y 1, c i} \cdot \frac{2 \Delta y 1}{t_{a c}} \cdot\left(1-\frac{w_{\text {gas }}}{w_{\text {solid }}}\right)\right] \cdot T_{1, p+3}^{n+1}=T_{1, p}^{n}
\end{aligned}
$$




$$
\begin{aligned}
& {\left[\begin{array}{l}
1+2 F o_{x, c i}+2 F o_{y 1, c i}+F o_{y 1, c i} \cdot \frac{2 B i_{c, a} \cdot w_{\text {gas }}}{w_{\text {solid }}}+ \\
\left.F o_{y 1, c i} \cdot \frac{2 B i_{r, 1} \cdot w_{g a s}}{w_{\text {solid }}}+F o_{y 1, c i} \cdot \frac{2 \Delta y 1}{t_{a c}} \cdot\left(1-\frac{w_{\text {gas }}}{w_{\text {solid }}}\right)\right] \cdot T_{m, p}^{n+1}-2 F o_{x, c i} \cdot T_{m-1, p}^{n+1}
\end{array}\right.} \\
& -2 F o_{y 1, c i} \cdot T_{m, p-1}^{n+1}-F o_{y 1, c i} \cdot \frac{2 B i_{c, a} \cdot w_{\text {gas }}}{w_{\text {solid }}} \cdot T_{m, p+1}^{n+1} \\
& -\left[F o_{y 1, c i} \cdot \frac{2 B i_{r, 1} \cdot w_{\text {gas }}}{w_{\text {solid }}}+F o_{y 1, c i} \cdot \frac{2 \Delta y 1}{t_{a c}} \cdot\left(1-\frac{w_{\text {gas }}}{w_{\text {solid }}}\right)\right] \cdot T_{m, p+3}^{n+1}=T_{m, p}^{n}
\end{aligned}
$$

Equations (3.125)-(3.128) represent the corners $(1,1),(\mathrm{m}, 1),(1, \mathrm{p})$, and $(\mathrm{m}, \mathrm{p})$, respectively.

The set of equations representing the heat diffusion equations for the nodes of the cathode interconnect are given in the above Eqns. (3.119)-(3.128). In a similar way, finite difference equations for the PEN and the anode interconnect can be written.

For the air channel, Equation (3.90) can be written as

$$
\begin{aligned}
& \rho_{a c} \cdot c_{p, a c} \cdot\left(\frac{T_{i, p+1}^{n+1}-T_{i, p+1}^{n}}{\Delta t}\right)+\frac{\left(\dot{n}_{O_{2}}^{\prime \prime} \cdot \bar{h}_{O_{2}}\right)_{i}-\left(\dot{n}_{O_{2}}^{\prime \prime} \cdot \bar{h}_{O_{2}}\right)_{i-1}+\left(\dot{n}_{N_{2}}^{\prime \prime} \cdot \bar{h}_{N_{2}}\right)_{i}-\left(\dot{n}_{N_{2}}^{\prime \prime} \cdot \bar{h}_{N_{2}}\right)_{i-1}}{\Delta x}= \\
& \frac{h_{c, a}\left(T_{i, p+3}^{n+1}-T_{i, p+1}^{n+1}\right)+h_{c, a}\left(T_{i, p}^{n+1}-T_{i, p+1}^{n+1}\right)}{t_{a c}}-\frac{\left(\dot{r}_{e l}^{\prime \prime} \cdot \bar{h}_{O_{2}}\right)_{i} \cdot w_{\text {solid }}}{2 \cdot w_{\text {gas }} \cdot t_{a c}}
\end{aligned}
$$


The change of enthalpy for oxygen and nitrogen can be written as shown in Equations (3.129b) and (3.129c), respectively.

$$
\begin{aligned}
& \left(\dot{n}_{O_{2}}^{\prime \prime} \cdot \bar{h}_{O_{2}}\right)_{i}-\left(\dot{n}_{O_{2}}^{\prime \prime} \cdot \bar{h}_{O_{2}}\right)_{i-1}=\left(\dot{n}_{O_{2}}^{\prime \prime}\right)_{i-1} \cdot\left(\bar{h}_{O_{2}, i}-\bar{h}_{O_{2}, i-1}\right)-\left(\Delta \dot{n}_{O_{2}}^{\prime \prime} \cdot \bar{h}_{O_{2}}\right)_{i} \\
& \left(\dot{n}_{N_{2}}^{\prime \prime} \cdot \bar{h}_{N_{2}}\right)_{i}-\left(\dot{n}_{N_{2}}^{\prime \prime} \cdot \bar{h}_{N_{2}}\right)_{i-1}=\left(\dot{n}_{N_{2}}^{\prime \prime}\right)_{i-1} \cdot\left(\bar{h}_{N_{2}, i}-\bar{h}_{N_{2}, i-1}\right)
\end{aligned}
$$

Here, we rewrite Equations (3.129b) and (3.129c) by introducing average specific heat that is a function of the average temperature between two consecutive nodes to get stable results from the code.

$$
\begin{aligned}
& \left(\dot{n}_{O_{2}}^{\prime \prime} \cdot \bar{h}_{O_{2}}\right)_{i}-\left(\dot{n}_{O_{2}}^{\prime \prime} \cdot \bar{h}_{O_{2}}\right)_{i-1}=\left(\dot{n}_{O_{2}}^{\prime \prime}\right)_{i-1} \cdot \bar{c}_{p, O_{2, a v e}}\left(T_{i, p+1}^{n+1}-T_{i-1, p+1}^{n+1}\right)-\left(\Delta \dot{n}_{O_{2}}^{\prime \prime} \cdot \bar{h}_{O_{2}}\right)_{i} \\
& \left(\dot{n}_{N_{2}}^{\prime \prime} \cdot \bar{h}_{N_{2}}\right)_{i}-\left(\dot{n}_{N_{2}}^{\prime \prime} \cdot \bar{h}_{N_{2}}\right)_{i-1}=\left(\dot{n}_{N_{2}}^{\prime \prime}\right)_{i-1} \cdot \bar{c}_{p, N_{2, a v e}}\left(T_{i, p+1}^{n+1}-T_{i-1, p+1}^{n+1}\right)
\end{aligned}
$$

If we put Eqs (3.129d) and (3.129e) into Equation (3.129a), we obtain

$$
\begin{aligned}
& \rho_{a c} \cdot c_{p, a c} \cdot\left(\frac{T_{i, p+1}^{n+1}-T_{i, p+1}^{n}}{\Delta t}\right)+\frac{\left(\dot{n}_{O_{2}}^{\prime \prime}\right)_{i-1} \cdot \bar{c}_{p, O_{2, a v e}}\left(T_{i, p+1}^{n+1}-T_{i-1, p+1}^{n+1}\right)}{\Delta x}-\frac{\left(\Delta \dot{n}_{O_{2}}^{\prime \prime} \cdot \bar{h}_{O_{2}}\right)_{i}}{\Delta x} \\
& +\frac{\left(\dot{n}_{N_{2}}^{\prime \prime}\right)_{i-1} \cdot \bar{c}_{p, N_{2, a v e}}\left(T_{i, p+1}^{n+1}-T_{i-1, p+1}^{n+1}\right)}{\Delta x}= \\
& \frac{h_{c, a}\left(T_{i, p+3}^{n+1}-T_{i, p+1}^{n+1}\right)+h_{c, a}\left(T_{i, p}^{n+1}-T_{i, p+1}^{n+1}\right)}{t_{a c}}-\frac{\left(\dot{r}_{e l}^{n} \cdot \bar{h}_{O_{2}}\right)_{i} \cdot w_{\text {solid }}}{2 \cdot w_{\text {gas }} \cdot t_{a c}}
\end{aligned}
$$


Here, the third term in the left hand side and the second term in the right hand side are equal to each other. Hence, Equation (3.129f) simplify to Equation (3.129g).

$$
\begin{aligned}
& \rho_{a c} \cdot c_{p, a c} \cdot\left(\frac{T_{i, p+1}^{n+1}-T_{i, p+1}^{n}}{\Delta t}\right)+\frac{\left(\dot{n}_{O_{2}}^{\prime \prime}\right)_{i-1} \cdot \bar{c}_{p, O_{2, a v e}}\left(T_{i, p+1}^{n+1}-T_{i-1, p+1}^{n+1}\right)}{\Delta x} \\
& +\frac{\left(\dot{n}_{N_{2}}^{\prime \prime}\right)_{i-1} \cdot \bar{c}_{p, N_{2, a v e}}\left(T_{i, p+1}^{n+1}-T_{i-1, p+1}^{n+1}\right)}{\Delta x}=\frac{h_{c, a}\left(T_{i, p+3}^{n+1}-T_{i, p+1}^{n+1}\right)+h_{c, a}\left(T_{i, p}^{n+1}-T_{i, p+1}^{n+1}\right)}{t_{a c}}
\end{aligned}
$$

If we rearrange Equation $(3.129 \mathrm{~g}$ ), we obtain the finite difference equation for the air channel which is valid from $i=2$ to $i=m$.

$$
\begin{aligned}
& \left(\frac{\rho_{a c} \cdot c_{p, a c}}{\Delta t}+\frac{\left(\dot{n}_{O_{2}}^{\prime \prime}\right)_{i-1} \cdot \bar{c}_{p, O_{2, a v e}}+\left(\dot{n}_{N_{2}}^{\prime \prime}\right)_{i-1} \cdot \bar{c}_{p, N_{2, a v e}}}{\Delta x}+\frac{2 h_{c, a}}{t_{a c}}\right) \cdot T_{i, p+1}^{n+1} \\
& -\left(\frac{\left(\dot{n}_{O_{2}}^{\prime \prime}\right)_{i-1} \cdot \bar{c}_{p, O_{2, a v e}}+\left(\dot{n}_{N_{2}}^{\prime \prime}\right)_{i-1} \cdot \bar{c}_{p, N_{2, a v e}}}{\Delta x}\right) \cdot T_{i-1, p+1}^{n+1} \\
& -\frac{h_{c, a} \cdot T_{i, p+3}^{n+1}}{t_{a c}}-\frac{h_{c, a} \cdot T_{i, p}^{n+1}}{t_{a c}}=\frac{\rho_{a c} \cdot c_{p, a c}}{\Delta t} \cdot T_{i, p+1}^{n}
\end{aligned}
$$

The finite difference equation for the fuel channel may be written in a similar way.

The set of equations are linearized by using the 'lagging properties by one time step' method [110]. Then, these equations are solved by Gauss Elimination Method. The 
calculations continue until the solid temperature reaches a certain value for the heat-up period and the system reaches steady state for start-up period.

\subsection{System Level Modeling}

In this section, the modeling of several integrated SOFC systems using energy and exergy analyses are presented. The performances of these systems are assessed calculating several parameters such as electrical efficiency, fuel utilization, power to heat ratio, and exergetic efficiency. Firstly, a SOFC and gas turbine based cogeneration system is modeled to investigate the exergetic performance of the system and determine the locations and magnitudes of the exergy destructions in the system and exergy losses to the environment. Secondly, a SOFC and biomass gasification system is modeled thermodynamically to study the effect of operating temperature level of the SOFC on its performance. Finally, a detailed modeling of a SOFC and biomass gasification system is done to study the effect of gasification agent on the performance of the overall system and calculate the exergy destructions and losses.

\subsubsection{Energy analysis}

In energy analysis, a system is divided into several control volumes and laws of thermodynamics are applied to these control volumes to find the thermodynamic properties of the states of the system, and work and heat interactions within the system.

For a control volume, continuity equation, energy balance (first law of thermodynamics)

and entropy balance (second law of thermodynamics) are shown in Equations (3.130)- 
(3.132). For steady state steady flow processes, terms in the left hand side of these equations become zero.

$$
\begin{aligned}
& \frac{d m_{C V}}{d t}=\sum \dot{m}_{i}-\sum \dot{m}_{e} \\
& \frac{d E_{C V}}{d t}=\dot{Q}_{C V}-\dot{W}_{C V}+\sum \dot{m}_{i}\left(h_{i}+\frac{u_{i}^{2}}{2}+g \cdot z_{i}\right)-\sum \dot{m}_{e}\left(h_{e}+\frac{u_{e}^{2}}{2}+g \cdot z_{e}\right) \\
& \frac{d S_{C V}}{d t}=\sum_{j} \frac{\dot{Q}_{j}}{T_{j}}+\sum_{i} \dot{m}_{i} \cdot s_{i}-\sum_{e} \dot{m}_{e} \cdot s_{e}+\dot{S}_{g e n}
\end{aligned}
$$

For some components, such as pump, turbine, compressor, and blower, we define isentropic efficiencies. For example, isentropic efficiency of a turbine, which is shown in Equation (3.133), compares the actual turbine power to the power that would be obtained in an isentropic expansion. Isentropic efficiency of a compressor, which is shown in Equation (3.134), compares the actual power input to the power that would be required in an isentropic compression. Isentropic efficiencies of other components may be defined similarly. For isentropic cases, the first term and the last term of the right hand side of Equation (3.132) (second law of thermodynamics) are equal to zero.

$$
\begin{aligned}
& \eta_{s t}=\frac{\dot{W}_{c v}}{\left(\dot{W}_{c V}\right)_{s}} \\
& \eta_{s c}=\frac{\left(\dot{W}_{c v}\right)_{s}}{\dot{W}_{c v}}
\end{aligned}
$$


Some performance assessment parameters related to energy analyses are electrical efficiency, fuel utilization efficiency, and power-to-heat ratio of the system. Electrical efficiency, which is shown in Equation (3.135), is the ratio of the net power output of the plant to the heating value of the fuel. Fuel utilization efficiency, which is shown in Equation (3.136), compares the total amount of energy produced (heat and work) to the lower heating value of the fuel. Power-to-heat ratio, as shown in Equation (3.137), compares the net power output of the system to the change of enthalpy rate of the process.

$$
\begin{aligned}
& \eta_{e l}=\frac{\left(\dot{W}_{\text {net }}\right)_{\text {plant }}}{\dot{n}_{\text {fuel }} \cdot L H V} \\
& \text { FUE }=\frac{\left(\dot{W}_{\text {net }}\right)_{\text {plant }}+\Delta \dot{H}_{\text {process }}}{\dot{n}_{\text {fuel }} \cdot L H V} \\
& \text { PHR }=\frac{\left(\dot{W}_{\text {net }}\right)_{\text {plant }}}{\Delta \dot{H}_{\text {process }}}
\end{aligned}
$$

\subsubsection{Exergy analysis}

Exergy is defined as the maximum work that may be achieved by bringing a system into equilibrium (mechanical, thermal and chemical) with its environment. At this condition, the pressure, temperature, and chemical potentials of the system become equal to those of the environment, which is also called dead state. Unlike energy, exergy is not generally conserved but destroyed by irreversibilities within a system. These irreversibilities may be classified as internal and external irreversibilities. Main sources of internal 
irreversibilities are friction, expansion, mixing and chemical reaction. External irreversibilities arise due to heat transfer through a finite temperature difference. Exergy is lost when the energy associated with a material or energy stream is rejected to the environment.

Exergy balance can be derived by combining first and second laws of thermodynamics [111]. The steady state form of control volume exergy balance may be given as

$$
0=\sum_{j}\left(1-\frac{T_{0}}{T_{j}}\right) \cdot \dot{Q}_{j}-\dot{W}_{c v}+\sum_{i} \dot{n}_{i} \cdot e x_{i}-\sum_{e} \dot{n}_{e} \cdot e x_{e}-\dot{E} x_{D}
$$

In Equation (3.138), ex represents the specific molar exergy. The components of specific exergy are discussed below. $\dot{E} x_{D}$ represents the exergy destruction rate in the control volume. Exergy losses are included in the fourth term of Equation (3.138).

If we neglect the magnetic, electrical, nuclear, kinetic and potential effects, there are mainly two types of exergy: pyhsical and chemical. The first one measures the amount of work when the system comes into thermal $\left(\mathrm{T}=\mathrm{T}_{0}\right)$ and mechanical $\left(\mathrm{P}=\mathrm{P}_{0}\right)$ equilibrium. This condition is called as restricted dead state. Chemical exergy gives the amount of work when the system is brought from restricted dead state to dead state. As discussed earlier, at dead state, in addition to the thermal and mechanical equilibrium, the system is also at chemical equilibrium $\left(\mu=\mu_{\mathrm{o}}\right)$. 
The physical flow exergy for simple, compressible pure substances is given as

$$
e x^{P H}=\left(h-h_{o}\right)-T_{o}\left(s-s_{o}\right)
$$

Chemical exergy may be calculated using the tables available in the literature, e.g. [112], or using the following formulas. Equations (3.140), (3.141), and (3.142) represent water, ideal gas mixture for the case when all the gas species appear in the environment, and ideal gas mixture for the general case, respectively.

$$
\begin{aligned}
& e x^{C H}=\bar{R} \cdot T_{o} \cdot \ln \frac{P_{g}\left(T_{o}\right)}{x_{o, H_{2} O(g)} \cdot P_{o}} \\
& e x^{C H}=\bar{R} \cdot T_{o} \cdot \sum x_{k} \cdot \ln \frac{x_{o, k}}{x_{k}} \\
& e x^{C H}=\sum x_{k} \bar{e} x_{k}^{C H}+\bar{R} \cdot T_{o} \cdot \sum x_{k} \cdot \ln x_{k}
\end{aligned}
$$

For a hydrocarbon fuel, $\mathrm{C}_{a} \mathrm{H}_{b}$, chemical exergy of the fuel may be given as

$$
\begin{aligned}
e^{\mathrm{CH}}= & {\left[\bar{h}_{\mathrm{F}}+\left(\mathrm{a}+\frac{\mathrm{b}}{4}\right) \cdot \overline{\mathrm{h}}_{\mathrm{O}_{2}}-\mathrm{a} \cdot \overline{\mathrm{h}}_{\mathrm{CO}_{2}}-\frac{\mathrm{b}}{2} \cdot \bar{h}_{\mathrm{H}_{2} \mathrm{O}(\mathrm{g})}\right]\left(\mathrm{T}_{\mathrm{O}}, \mathrm{P}_{\mathrm{o}}\right) } \\
& -\mathrm{T}_{\mathrm{o}} \cdot\left[\overline{\mathrm{s}}_{\mathrm{F}}+\left(\mathrm{a}+\frac{\mathrm{b}}{4}\right) \cdot \overline{\mathrm{s}}_{\mathrm{O}_{2}}-\mathrm{a} \cdot \overline{\mathrm{s}}_{\mathrm{CO}_{2}}-\frac{\mathrm{b}}{2} \cdot \overline{\mathrm{s}}_{\mathrm{H}_{2} \mathrm{O}(\mathrm{g})}\right]\left(\mathrm{T}_{0}, \mathrm{P}_{\mathrm{O}}\right) \\
& +\overline{\mathrm{R}} \cdot \mathrm{T}_{\mathrm{o}} \cdot \ln \left[\frac{\left(\mathrm{x}_{\mathrm{O}, \mathrm{O}_{2}}\right)^{\mathrm{a} \mathrm{b} / 4}}{\left(\mathrm{x}_{\mathrm{O}, \mathrm{CO}_{2}}\right)^{\mathrm{a}} \cdot\left(\mathrm{x}_{\mathrm{O}, \mathrm{H}_{2} \mathrm{O}(\mathrm{g})}\right)^{\mathrm{b} / 2}}\right]
\end{aligned}
$$


In the book by Szargut [112], such correlations for different fuels may also be found.

The exergy destruction rate in a component may be compared to the exergy rate of the fuel provided to the overall system as follows:

$$
y_{D}=\frac{\dot{E} x_{D}}{\dot{E} x_{F}}
$$

The exergy destruction rate of a component may be compared to the total exergy destruction rate within the system as follows:

$$
y_{D}^{*}=\frac{\dot{E} x_{D}}{\dot{E} x_{D, t o t}}
$$

The exergy loss ratio is defined similarly by comparing the exergy loss rate to the exergy rate of the fuel provided to the overall system.

$$
y_{L}=\frac{\dot{E} x_{L}}{\dot{E} x_{F}}
$$

In defining the exergetic efficiency, it is necessary to identify both a product and a fuel for the thermodynamic system being analyzed. The product represents the desired output 
produced by the system. The fuel represents the resources expended to generate the product. Exergetic efficiency of a component or system may be given as

$$
\varepsilon=\frac{\dot{E} x_{P}}{\dot{E} x_{F}}=1-\frac{\dot{E} x_{D}+\dot{E} x_{L}}{\dot{E} x_{F}}
$$

Exergetic efficiency of the system can also be defined in terms of exergy destruction ratio and exergy loss ratio.

$$
\varepsilon=1-\sum y_{D}-\sum y_{L}
$$

\subsubsection{Modeling approaches and equations of the systems studied}

In this section, modeling approaches and equations of the systems studied are given. These systems are: a SOFC and gas turbine based cogeneration system and two SOFC and biomass gasification systems.

\subsubsection{SOFC and gas turbine based cogeneration system}

In this study, a SOFC and gas turbine based cogeneration system is analyzed. In the analysis, exergy balances are applied to the control volumes enclosing the components of the system to calculate the exergy destructions and losses.

A schematic of this system is shown in Figure 3.8. The operation principle of this system is as follows: Fuel and air compressors increase the pressure of fuel and air, respectively, 
according to the operating pressure level of the SOFC. There is always an amount of unutilized fuel in the SOFC exit which depends on the operation variables of the cell. This fuel is burned in a combustor to increase the temperature of the fuel cell exit. The burned gas mixture enters the gas turbine to generate power for compensating the power requirement of the compressors. The gas mixture leaving the gas turbine provides heat for increasing the temperature of the fuel and air compressor exits according to the SOFC inlet temperature requirement. The remaining enthalpy of the gas mixture is used to provide heat to generate steam in the heat recovery steam generator (HRSG).

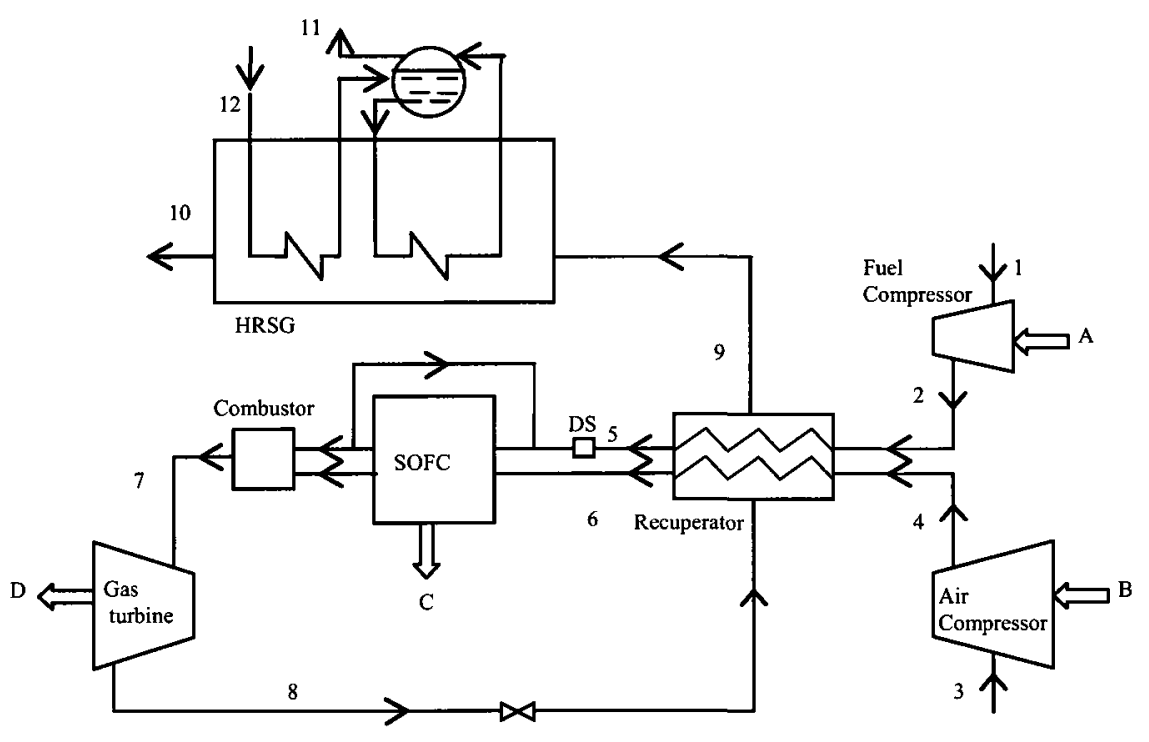

Figure 3.8: A SOFC and gas turbine based cogeneration system.

Energy and exergy balances are applied to the control volumes enclosing the components of the system. The main assumptions made in the analyses are given below: 
- The system operates at steady state.

- Kinetic and potential energy effects are ignored.

- Ideal gas principles apply for the gases.

- Complete combustion occurs in the combustor.

- All the steam export from the system returns as condensate.

- Blow down requirements and deaerator vent flows of HRSG are not taken into account.

- Heat losses to the environment from the components are ignored except HRSG.

- Pressure drops along the components are ignored except HRSG.

- Gas mixture at the fuel channel exit is at chemical equilibrium.

The thermodynamic model of a DIR-SOFC including the carbon deposition considerations, which is discussed in Sections 3.5 and 3.6, is used to model the fuel cell. This model gives the output parameters for a single cell with a given active surface area. Using this model, the input and output power of all the devices are first calculated for a single cell. According to the desired net electrical power output of the system, the required number of cells is then computed.

For the exergy analysis of the system, the following steps are applied:

- The physical and chemical exergy flow rates are calculated.

- The system is divided into several control volumes.

- The exergy destruction rates for each control volume are calculated.

- The exergy losses are calculated. 
- The ratios related to the exergy destructions and losses are calculated.

- The exergetic efficiency of the system is found.

Selection of the control volumes and exergy balances are shown in Table 3.4.

Table 3.4: Exergy balances for the control volumes of the system.

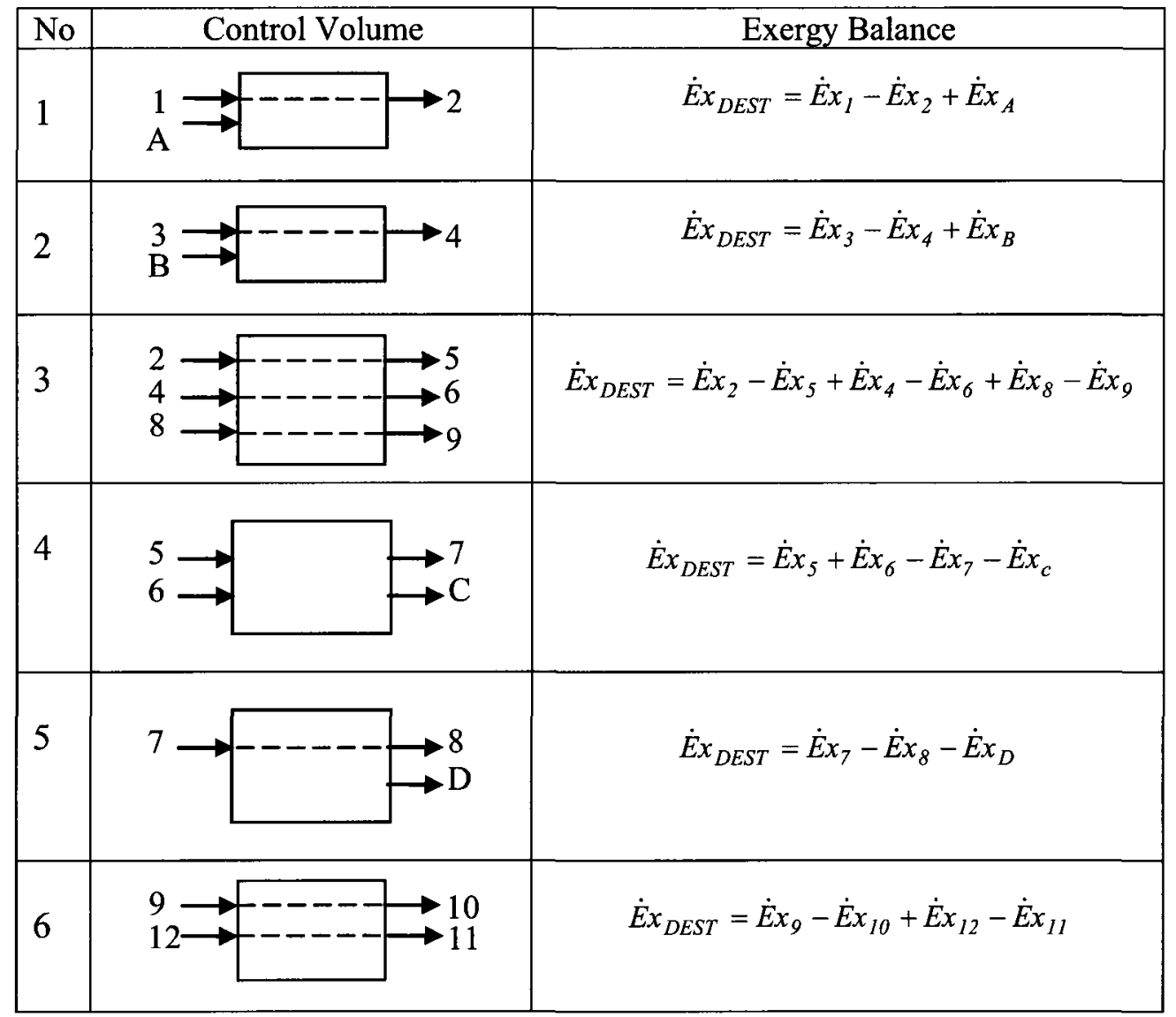

\subsubsection{SOFC and biomass gasification system - Study I}

In this study, an integrated SOFC and biomass gasification system is modeled thermodynamically. The system studied consists of a downdraft gasifier operating with 
air, a hot-gas cleanup system and a SOFC, as shown in Figure 2.4. The operation principle of the system is as follows. Syngas is produced from biomass gasification. This gas is cleaned and fed to the SOFC where power is produced. It should be noted that the auxiliary components such as blowers are neglected in this study because this study only focuses on the performance of the SOFC rather than the overall system.

Using the ultimate analysis of biomass, one can represent the biomass material as $\mathrm{C}_{\mathrm{x}} \mathrm{H}_{\mathrm{y}} \mathrm{O}_{\mathrm{z}}$. The air gasification of biomass may be given as

$$
\begin{aligned}
& C_{x} \mathrm{H}_{y} \mathrm{O}_{z}+m \mathrm{H}_{2} \mathrm{O}+\lambda \mathrm{O}_{2}+3.76 \lambda \mathrm{N}_{2} \rightarrow \\
& \alpha_{1} \mathrm{CH}_{4}+\alpha_{2} \mathrm{H}_{2}+\alpha_{3} \mathrm{CO}+\alpha_{4} \mathrm{CO}_{2}+\alpha_{5} \mathrm{H}_{2} \mathrm{O}+3.76 \lambda \mathrm{N}_{2}
\end{aligned}
$$

We know the moisture content in the biomass, $M C$, from the ultimate analysis. $M C$ can be shown as follows:

$$
M C=\frac{\dot{m}_{\mathrm{H}_{2} \mathrm{O}(l)}}{\dot{m}_{\mathrm{H}_{2} \mathrm{O}(l)}+\dot{m}_{C_{x} \mathrm{H}_{y} \mathrm{O} z}}
$$

Equation (3.150) can be written in terms of molar flow rates as

$$
M C=\frac{\dot{n}_{\mathrm{H}_{2} \mathrm{O}(I)} \cdot M_{\mathrm{H}_{2} \mathrm{O}(l)}}{\dot{n}_{\mathrm{H}_{2} \mathrm{O}(l)} \cdot M_{\mathrm{H}_{2} \mathrm{O}(l)}+\dot{n}_{C_{x} \mathrm{H}_{y} \mathrm{O}} \cdot M_{C_{x} \mathrm{H}_{y} \mathrm{O}_{z}}}
$$


If we divide the numerator and denominator by $\dot{n}_{d r y b i o m a s s}$, we obtain

$$
M C=\frac{m \cdot M_{H_{2} O(l)}}{m \cdot M_{H_{2} O(l)}+M_{C_{x} H_{y} O_{z}}}
$$

Rearranging Equation (3.152), we can write $m$ as

$$
m=\frac{M C \cdot M_{C_{x} \mathrm{H}_{y} \mathrm{O}_{z}}}{(1-M C) \cdot M_{\mathrm{H}_{2} \mathrm{O}(l)}}
$$

There are several reactions occurring during gasification process. Some key reactions can be given as

$$
\begin{aligned}
& \mathrm{C}+2 \mathrm{H}_{2} \leftrightarrow \mathrm{CH}_{4} \\
& \mathrm{C}+\mathrm{H}_{2} \mathrm{O} \leftrightarrow \mathrm{CO}+\mathrm{H}_{2} \\
& \mathrm{C}+\mathrm{CO}_{2} \leftrightarrow 2 \mathrm{CO}
\end{aligned}
$$

Equations (3.155) and the reverse of Equation (3.156) can be combined to obtain water gas shift reaction.

The exit gas composition of the gasifier can be found by solving the set of equations consisting of atom balances, Equations (3.157)-(3.159), chemical equilibrium relations, 
Equations (3.160)-(3.161) and the energy balance around the control volume enclosing the biomass gasifier, Equation (3.162).

$$
\begin{aligned}
& x=\alpha_{1}+\alpha_{3}+\alpha_{4} \\
& y+2 m=4 \alpha_{1}+2 \alpha_{2}+2 \alpha_{5} \\
& z+m+2 \lambda=\alpha_{3}+2 \alpha_{4}+\alpha_{5} \\
& K_{w g s}=\exp \left[-\Delta \bar{g}_{w g s}^{\circ} / R T\right]=\frac{x_{\mathrm{CO}_{2}} \cdot x_{\mathrm{H}_{2}}}{x_{\mathrm{CO}} \cdot x_{\mathrm{H}_{2} \mathrm{O}}} \\
& K_{m}=\exp \left[-\Delta \bar{g}_{m}^{\circ} / R T\right]=\frac{x_{\mathrm{CH}_{4}}}{x_{\mathrm{H}_{2}}{ }^{2}} \cdot\left(\frac{P}{P_{o}}\right)^{-1} \\
& \bar{h}_{f, C_{\mathrm{X}} \mathrm{H}_{y} \mathrm{O}_{z}}^{\circ}+m \cdot \bar{h}_{f, \mathrm{H}_{2} \mathrm{O}}^{\circ}+\lambda \cdot\left(\bar{h}_{\mathrm{O}_{2}}^{\circ}+3.76 \bar{h}_{\mathrm{N}_{2}}^{\circ}\right)= \\
& \alpha_{1} \bar{h}_{\mathrm{CH}_{4}}^{\circ}+\alpha_{2} \bar{h}_{\mathrm{H}_{2}}^{\circ}+\alpha_{3} \bar{h}_{\mathrm{CO}}^{\circ}+\alpha_{4} \bar{h}_{\mathrm{CO}_{2}}^{\circ}+\alpha_{5} \bar{h}_{\mathrm{H}_{2} \mathrm{O}}^{\circ}+3.76 \lambda \bar{h}_{\mathrm{N}_{2}}^{\circ}
\end{aligned}
$$

The enthalpy of formation of the dry biomass can be calculated using

$$
\bar{h}_{C_{x} H_{y} O_{z}}=x \bar{h}_{C O_{2}}+(y / 2) \cdot \bar{h}_{H_{2} O_{(l)}}+H H V_{m} \cdot M_{C_{x} H_{y} O_{z}}
$$

where higher heating value can be calculated using the Dulong's formula

$$
H H V_{m}=338.3 \cdot C+1443 \cdot(H-O / 8)+94.2 \cdot S
$$

where $\mathrm{C}, \mathrm{H}, \mathrm{O}$, and $\mathrm{S}$ are the weight percentages in the dry biomass which is given in the ultimate analysis. 
In this study, the thermodynamic model of DIR-SOFC taking into account the carbon deposition problem, as discussed in Sections 3.5 and 3.6, is used for SOFC modeling.

\subsubsection{SOFC and biomass gasification system - Study II}

In this study, an integrated SOFC and biomass gasification system is modeled. For this purpose, energy and exergy analyses are applied to the control volumes enclosing the components of the system. Different gasification agents, e.g. air, enriched oxygen and steam, are considered in the modeling. Performance assessment parameters for the systems are calculated.

A schematic of the integrated biomass gasification and SOFC system is shown in Figure 3.9. In this system, biomass enters the dryer to bring its moisture content to a level acceptable by the gasifier. According to the gasification agent, one of the following substances enters the gasifier: air, enriched oxygen or steam. The gas produced by gasification, which is called syngas, has high amounts of tar, sulphur and other contaminants which may cause degradation in SOFC. Due to this fact, a gas cleanup should be used to clean the syngas according to the SOFC impurity levels. In this study, a hot gas cleanup is chosen. The cleaned syngas enters the SOFC, where electricity is produced. To prevent the carbon deposition, anode recirculation ratio is adjusted. The depleted fuel and air streams enter the afterburner to burn the unused fuel and increase the temperature of the depleted gas streams leaving the SOFC. The burned gas is used to increase the temperature of air supplied by the blower to the SOFC temperature level. 
The same gas stream supplies heat to the steam generator, and then to the gasifier in the case of steam gasification. Finally, the same gas stream supplies heat to the dryer and it is emitted to the atmosphere.

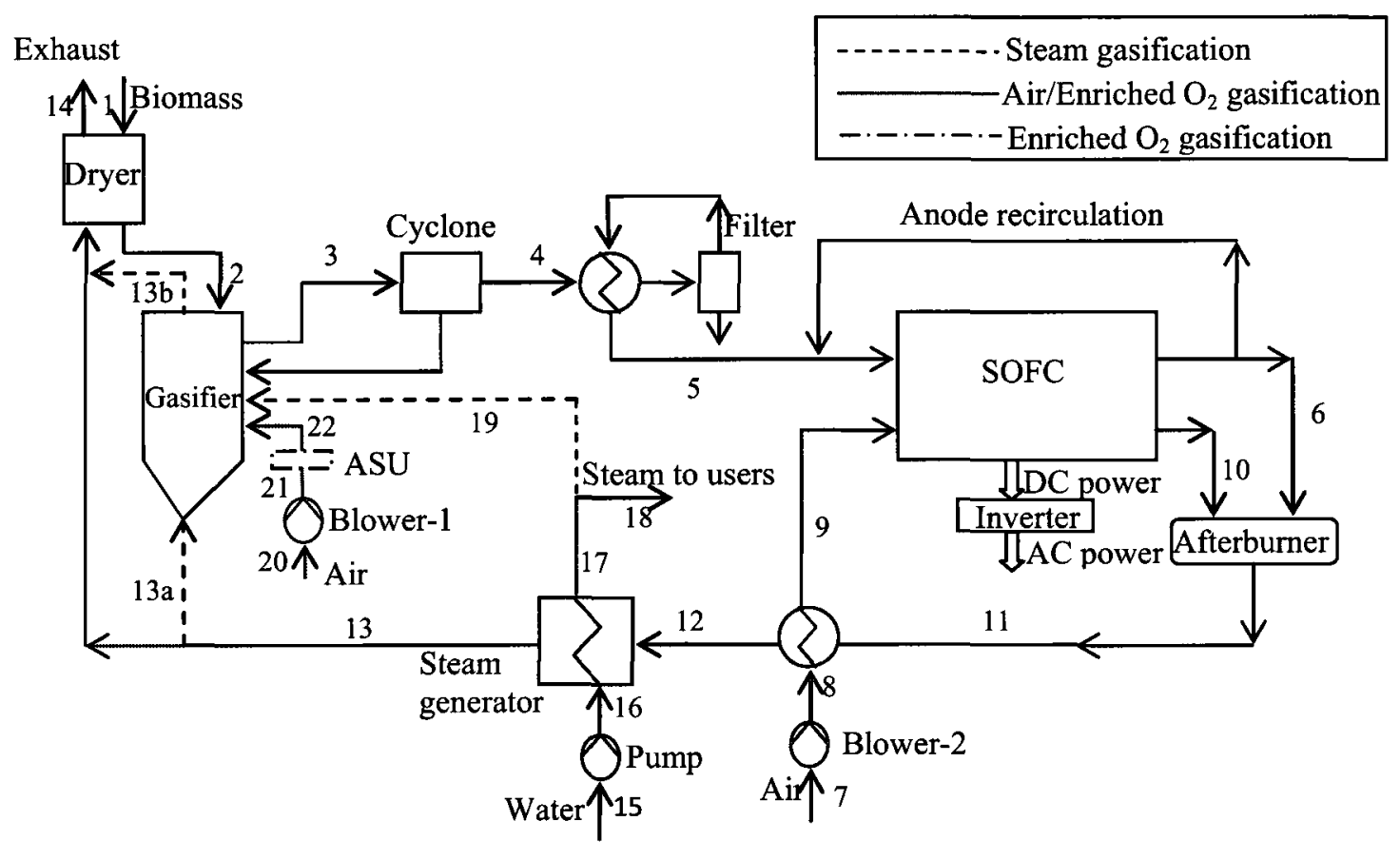

Figure 3.9: Integrated biomass gasification and SOFC systems

A number is given to each state. In Figure 3.9, the states 20 and 22 are valid for both the air and enriched oxygen gasification cases. The state 21 is only valid for enriched oxygen gasification case. The states $13 \mathrm{a}, 13 \mathrm{~b}$, and 19 are only valid for the steam gasification case. The differences in configurations are represented with different dashed lines, which are labelled on this figure. 
The main approach in the modeling is as follows. The syngas composition is first calculated. Then, using this composition and other SOFC operating parameters, the quasi 2-D transient SOFC code that is discussed in Section 3.7 is run. This code gives us the molar flow rate at the inlet and exit of gas channels, power output, and temperature at the exit of gas channels for a single cell. According to the power requirement of the SOFC, the number of SOFC stacks that must be used in this system is found. Then, using the output data from the gasifier and SOFC models, the molar flow rate of dry biomass is calculated. Using this molar flow rate and applying energy balances to the remaining components, the enthalpy flow rate of all states, work input to the blowers and pump, if applicable, are calculated.

The main assumptions in this model are as follows:

- The system operates at steady state

- Kinetic and potential energy effects are ignored.

- Ideal gas principles apply for the gases.

- The syngas produced by the gasifier is at chemical equilibrium

- The impurities such as tar, sulphur, ammonia are not considered in the calculations.

- Heat losses from the components are neglected.

- High temperature blower for anode recirculation is not shown in the figure and its work input is neglected.

- All of the steam export returns as condensate.

- Complete combustion occurs in the combustor. 
As an example, the modeling equations for the steam gasification case are given below.

The chemical equation in the dryer may be shown as follows

$C_{x} H_{y} O_{z}+m_{1} H_{2} O_{(l)} \rightarrow C_{x} H_{y} O_{z}+m_{2} H_{2} O_{(l)}+\left(m_{1}-m_{2}\right) H_{2} O_{(v)}$

The gasification reaction may be given as

$$
\begin{aligned}
& C_{x} H_{y} O_{z}+m_{2} H_{2} O_{(l)}+\left(m_{1}-m_{2}\right) H_{2} O_{(v)}+\lambda H_{2} O_{(v)}+q_{\text {added }} \rightarrow \\
& \alpha_{1} \mathrm{CH}_{4}+\alpha_{2} \mathrm{H}_{2}+\alpha_{3} \mathrm{CO}+\alpha_{4} \mathrm{CO}_{2}+\alpha_{5} \mathrm{H}_{2} \mathrm{O}
\end{aligned}
$$

Here, we fix $\lambda$, hence there are six unknowns, which are: $\alpha_{1}, \alpha_{2}, \alpha_{3}, \alpha_{4}, \alpha_{5}$, and $q_{\text {added }}$. We need six equations to find these unknowns. These equations are 3 atom balances, Equations (3.167)-(3.169), two chemical equilibrium relations (water-gas shift reaction, Equation (3.160), and methanation reaction, Equation (3.161)), and the energy balance around the control volume enclosing the gasifier, Equation (3.170).

$$
\begin{aligned}
& x=\alpha_{1}+\alpha_{3}+\alpha_{4} \\
& y+2 m_{1}+2 \lambda=4 \alpha_{1}+2 \alpha_{2}+2 \alpha_{5} \\
& z+m_{1}+\lambda=\alpha_{3}+2 \alpha_{4}+\alpha_{5} \\
& \bar{h}_{2, C_{x} \mathrm{H}_{y} \mathrm{O}_{2}}^{\circ}+m_{2} \cdot \bar{h}_{2, \mathrm{H}_{2} \mathrm{O}(l)}^{\circ}+\left(m_{1}-m_{2}\right) \cdot \bar{h}_{2, \mathrm{H}_{2} \mathrm{O}(v)}^{\circ}+\lambda \cdot \bar{h}_{19, \mathrm{H}_{2} \mathrm{O}(v)}^{\circ}+q_{\text {added }}= \\
& \alpha_{1} \bar{h}_{3, \mathrm{CH}_{4}}^{\circ}+\alpha_{2} \bar{h}_{3, \mathrm{H}_{2}}^{\circ}+\alpha_{3} \bar{h}_{3, \mathrm{CO}}^{\circ}+\alpha_{4} \bar{h}_{3, \mathrm{CO}_{2}}^{\circ}+\alpha_{5} \bar{h}_{3, \mathrm{H}_{2} \mathrm{O}}^{\circ}
\end{aligned}
$$


For SOFC model, the code for the transient heat transfer model is run several times to obtain a desired fuel utilization for a given cell geometry, cell voltage, Reynolds number and excess air coefficient. Using this code, output for a single cell is obtained. For this output, number of stacks needed for the system can be calculated as follows

$n_{\text {stack }}=\frac{\dot{W}_{\text {req, SOFC }}}{w_{\text {SOFC }} \cdot n_{\text {cps }}}$

We should take the closest integer higher than the value obtained by Equation (3.171). Then, power output of SOFC, molar flow rate of gas species at the fuel and air channels inlets and exits can be calculated for the total amount of stacks calculated.

At this point, we can calculate the molar flow rate dry biomass entering the system using

$$
\dot{n}_{C_{x} H_{y} O_{z}}=\frac{\sum_{k=1}^{5} \dot{n}_{k, f c . \text { inlet }}}{\alpha_{1}+\alpha_{2}+\alpha_{3}+\alpha_{4}+\alpha_{5}}
$$

If we consider complete combustion in the afterburner, the chemical reaction occurring in the afterburner may be given as

$$
\begin{aligned}
& \dot{n}_{6, \mathrm{CH}_{4}} \mathrm{CH}_{4}+\dot{n}_{6, \mathrm{H}_{2}} \mathrm{H}_{2}+\dot{n}_{6, \mathrm{CO}} \mathrm{CO}+\dot{n}_{6, \mathrm{CO}_{2}} \mathrm{CO}_{2}+\dot{n}_{6, \mathrm{H}_{2} \mathrm{O}} \mathrm{H}_{2} \mathrm{O}+\dot{n}_{6, \mathrm{~N}_{2}} \mathrm{~N}_{2}+\dot{n}_{10, \mathrm{O}_{2}} \mathrm{O}_{2}+\dot{n}_{10, \mathrm{~N}_{2}} \mathrm{~N}_{2} \rightarrow \\
& \dot{n}_{11, \mathrm{CO}_{2}} \mathrm{CO}_{2}+\dot{n}_{11, \mathrm{H}_{2} \mathrm{O}} \mathrm{H}_{2} \mathrm{O}+\dot{n}_{11, \mathrm{O}_{2}} \mathrm{O}_{2}+\dot{n}_{11, \mathrm{~N}_{2}} \mathrm{~N}_{2}
\end{aligned}
$$


The molar flow rates of gas species at states 6 and 10 are known from the SOFC model. We can calculate the molar flow rates of gas species at state 11 using the atom balances, Equations (3.174)-(3.177), and the enthalpy flow rate of this state can be found using an energy balance around the control volume enclosing the afterburner, Equation (3.178).

$$
\begin{aligned}
& \dot{n}_{11, \mathrm{CO}_{2}}=\dot{n}_{6, \mathrm{CH}_{4}}+\dot{n}_{6, \mathrm{CO}}+\dot{n}_{6, \mathrm{CO}_{2}} \\
& \dot{n}_{11, \mathrm{H}_{2} \mathrm{O}}=2 \cdot \dot{n}_{6, \mathrm{CH}_{4}}+\dot{n}_{6, \mathrm{H}_{2}}+\dot{n}_{6, \mathrm{H}_{2} \mathrm{O}} \\
& \dot{n}_{11, \mathrm{O}_{2}}=\dot{n}_{6, \mathrm{CO}} / 2+\dot{n}_{6, \mathrm{CO}_{2}}+\dot{n}_{6, \mathrm{H}_{2} \mathrm{O}} / 2+\dot{n}_{10, \mathrm{O}_{2}}-\dot{n}_{11, \mathrm{CO}_{2}}-\dot{n}_{11, \mathrm{H}_{2} \mathrm{O}} / 2 \\
& \dot{n}_{11, \mathrm{~N}_{2}}=\dot{n}_{6, \mathrm{~N}_{2}}+\dot{n}_{10, \mathrm{~N}_{2}} \\
& \dot{H}_{11}=\sum_{k=1}^{6}\left(\dot{n}_{6, k} \cdot \bar{h}_{6, k}\right)+\sum_{l=1}^{2}\left(\dot{n}_{10, l} \cdot \bar{h}_{10, l}\right)
\end{aligned}
$$

where $\mathrm{k}$ denotes $\mathrm{CH}_{4}, \mathrm{H}_{2}, \mathrm{CO}, \mathrm{CO}_{2}, \mathrm{H}_{2} \mathrm{O}$, and $\mathrm{N}_{2}$; whereas 1 denotes $\mathrm{O}_{2}$ and $\mathrm{N}_{2}$.

The specific enthalpy of state 8 may be written as

$$
\bar{h}_{8}=\bar{h}_{7}+\frac{\left(P_{8}-P_{7}\right) \cdot M_{\text {air }}}{\rho_{\text {air }} \cdot \eta_{\text {blower }}}
$$

Specific work input to blower may be given as

$$
\dot{W}_{\text {blower }}=\left(\dot{n}_{9, O_{2}}+\dot{n}_{9, N_{2}}\right) \cdot\left(\bar{h}_{8}-\bar{h}_{7}\right)
$$


From an energy balance around the control volume enclosing the heat exchanger, enthalpy flow rate of state 12 may be found as follows:

$$
\dot{H}_{12}=\dot{H}_{11}+\sum_{l=1}^{2}\left(\dot{n}_{8, l} \cdot \bar{h}_{8, l}\right)-\sum_{l=1}^{2}\left(\dot{n}_{9, l} \cdot \bar{h}_{9, l}\right)
$$

From an energy balance around the control volume enclosing the dryer, enthalpy flow rate of state $13 \mathrm{~b}$ may be found as follows:

$$
\begin{aligned}
& \dot{H}_{13 b}=\sum_{m=1}^{4}\left(\dot{n}_{11, m} \cdot \bar{h}_{14, m}\right)+ \\
& \dot{n}_{C_{x} \mathrm{H}_{y} \mathrm{O}_{z}} \cdot\left(\bar{h}_{2, C_{x} \mathrm{H}_{y} \mathrm{O}_{z}}+m_{2} \cdot \bar{h}_{2, H_{2} \mathrm{O}(l)}+\left(m_{1}-m_{2}\right) \cdot \bar{h}_{2, H_{2} \mathrm{O}(\mathrm{V})}-\bar{h}_{1, C_{x} \mathrm{H}_{y} \mathrm{O}_{z}}-m_{1} \cdot \bar{h}_{1, \mathrm{H}_{2} \mathrm{O}(I)}\right)
\end{aligned}
$$

where $\mathrm{m}$ denotes $\mathrm{CO}_{2}, \mathrm{H}_{2} \mathrm{O}, \mathrm{O}_{2}$ and $\mathrm{N}_{2}$.

The specific enthalpy for state 16 may be written as

$$
\bar{h}_{16}=\bar{h}_{15}+\frac{\nu_{15} \cdot\left(P_{16}-P_{15}\right) \cdot M_{H_{2} O}}{\eta_{\text {pump }}}
$$

At this point, we can calculate the total heat added to the gasifier as follows:

$$
\dot{Q}_{\text {added }}=q_{\text {added }} \cdot \dot{n}_{C_{x} H_{y} \mathrm{O}_{z}}
$$


Enthalpy flow rate of state 13a can be calculated as follows:

$$
\dot{H}_{13 a}=\dot{H}_{13 b}+\dot{Q}_{a d d e d}
$$

From an energy balance around the control volume enclosing the steam generator, the molar flow rate of steam generated can be found as follows:

$\dot{n}_{17}=\frac{\dot{H}_{12}-\dot{H}_{13 a}}{\bar{h}_{17}-\bar{h}_{16}}$

Work input to pump may be given as

$\dot{W}_{\text {pump }}=\dot{n}_{17} \cdot\left(\bar{h}_{16}-\bar{h}_{15}\right)$

Change of enthalpy flow rate of the process may be shown as

$$
\Delta \dot{H}_{\text {process }}=\left(\dot{n}_{17}-\dot{n}_{C_{x} H_{y} O_{z}} \cdot \lambda\right) \cdot\left(\bar{h}_{18}-\bar{h}_{15}\right)
$$

Net electrical power output of the system may be given as

$$
\dot{W}_{\text {net }}=n_{\text {stack }} \cdot n_{c p s} \cdot w_{\text {SOFC }} \cdot \eta_{\text {inv }}-\dot{W}_{\text {blower }}-\dot{W}_{\text {pump }}
$$


Electrical efficiency, fuel utilization efficiency, and power-to-heat ratio may be calculated using Equations (3.190)-(3.192), respectively.

$$
\begin{aligned}
& \eta_{e l}=\frac{\dot{W}_{\text {net }}}{\dot{n}_{C_{x} H_{y} \mathrm{O}_{z}} \cdot\left(L H V+m_{1} \cdot \bar{h}_{f g}\right)} \\
& F U E=\frac{\dot{W}_{\text {net }}+\Delta \dot{H}_{\text {process }}}{\dot{n}_{C_{x} H_{y} O_{z}} \cdot\left(L H V+m_{1} \cdot \bar{h}_{f g}\right)} \\
& P H R=\frac{\dot{W}_{\text {net }}}{\Delta \dot{H}_{\text {process }}}
\end{aligned}
$$

Exergetic efficiency of the system may be defined as

$$
\varepsilon=\frac{\dot{W}_{\text {net }}+\Delta \dot{E} x_{\text {process }}}{\dot{E} x_{c h, C_{x} H_{y} \mathrm{O}_{z}}+\dot{n}_{15} \cdot \bar{e}_{c h, \mathrm{H}_{2} \mathrm{O}(l)}}
$$

Here, $\dot{E} x_{c h, C_{x} H_{y} O_{z}}$ can be found using the correlation given by Szargut [112]. The correlation is modified for this study as follows:

$$
\dot{E} x_{c h, C_{x} H_{y} O_{z}}=\beta \cdot\left[\dot{n}_{C_{x} H_{y} O_{z}} \cdot\left(L H V+m_{1} \cdot \bar{h}_{f g}\right)\right]
$$

where $\beta$ is defined for solid $\mathrm{C}, \mathrm{H}, \mathrm{O}, \mathrm{N}$ compounds (for $\mathrm{O} / \mathrm{C}<2$ ) as [112]: 


$$
\beta=\frac{1.044+0.016 \cdot H / C-0.3493 \cdot O / C \cdot(1+0.0531 \cdot H / C)+0.0493 \cdot N / C}{1-0.4124 \cdot 0 / C}
$$

The change of exergetic rate of process may be given as

$$
\Delta \dot{E} x_{\text {process }}=\left(\dot{n}_{17}-\dot{n}_{C_{x} H_{y} O_{z}} \cdot \lambda\right) \cdot\left(e x_{18}-e x_{15}\right)
$$

\subsection{Summary}

Several SOFC models are developed in cell, stack, and system levels. These include a thermodynamic model, a carbon deposition model, a quasi 2-D transient heat transfer model, and system level models.

The thermodynamic model developed in this study may be summarized as follows: In the first part of the model, using the principles of thermodynamics, mathematical manipulations and definitions of some fuel cell related parameters such as fuel utilization ratio, fuel channel equilibrium exit gas composition is derived in terms of extents of chemical reactions and molar flow rate of gas species at the fuel channel inlet. Then using chemical equilibrium equations and the relation between the electric current and the molar flow rate of hydrogen that is utilized, exit gas composition of the fuel channel exit is found. In the second part of the model, air utilization ratio which measures the amount of excess air that should be sent to the air channel to carry away the unutilized heat in the fuel cell is calculated for an insulated fuel cell and a controlled fuel inlet and exit gas temperature. Hence, air channel inlet and exit gas composition, Nernst voltage, 
polarizations and work output of the fuel cell are derived in terms of air utilization ratio. Using the first law of thermodynamics for the control volume enclosing the fuel cell, this ratio is calculated. After finding this ratio, fuel cell output parameters, such as cell voltage, work output of the cell, and electrical efficiency of the cell are found.

The thermodynamic model is improved by adding the carbon deposition. The chemical composition of gases at a point close to the fuel channel inlet at which the local fuel utilization is approximately zero are found. It is assumed that only steam reforming and water gas shift reactions occur at this point, which are at chemical equilibrium. Two methods are developed to investigate the carbon deposition possibility. In the first method, carbon deposition boundaries are formed and shown in $\mathrm{C}-\mathrm{H}-\mathrm{O}$ triangular phase diagrams. In this diagram, each gas composition corresponds to a point. If that point is above the boundary (towards the $\mathrm{C}$ vertex), then there is carbon deposition in the system. In the other case, there is no risk of carbon deposition from the viewpoint of thermodynamics. In the second method, carbon activities of the reactions that are the most possible ones for the formation of carbon are calculated. If the carbon activities at the inlet and exit of the fuel channel are both less than 1, there is no carbon deposition risk; in the other case there is carbon deposition.

A transient heat transfer model is developed for simulating the heat-up and start-up behaviour of a SOFC. All the heat transfer mechanisms, i.e. conduction, convection, and radiation, and all the polarization modes, i.e. ohmic, activation, and concentration, are included in this model. In modeling, the heat transfer equations and chemical and 
electrochemical relations are applied to the control volumes of a repeat element of a planar SOFC. These control volumes are anode interconnect, fuel channel, PEN, air channel, and cathode interconnect. For numerical solution, finite difference scheme is used and a code in Matlab is written. In this model, cell voltage, Reynolds number at the fuel channel inlet, and excess air coefficient are the main input parameters. Heat-up and start-up time, fuel utilization ratio, current density, temperature and molar gas composition distributions, power output, and electrical efficiency of the cell are the main output parameters.

In system level modeling, energy and exergy analyses are applied to several conceptual integrated SOFC systems. These systems include an integrated SOFC and gas turbine system and two SOFC and biomass gasification system. In the energy analysis, continuity equation, first law of thermodynamics, and second law of thermodynamics, where applicable, are applied to the control volumes enclosing the components of these systems. As a result of energy analysis, performance assessment parameters such as electrical efficiency, fuel utilization efficiency, and power-to-heat ratio are calculated. In the exergy analysis, components of the exergy flow rates, which are physical and chemical exergies, are first calculated. Then, exergy balances are applied to the control volumes to calculate the exergy destructions within the components. Exergy losses to the environment are also found. Exergetic performance of the systems are assessed through ratios related to the exergy destructions and losses, and the exergetic efficiency of the integrated system. 


\section{CHAPTER 4}

\section{RESULTS AND DISCUSSION}

\subsection{Introduction}

In this chapter, validation of the models discussed in Chapter 3, and results and discussion of several case studies conducted using these models are presented. These models are: the thermodynamic, carbon deposition, transient heat transfer, and system level models.

\subsection{Thermodynamics and Electrochemistry of SOFC}

In this section, Nernst voltage for a SOFC operating with pure hydrogen is first calculated for different fuel utilization and air utilization ratios. Then, polarizations and specific exergy destruction are calculated for a hydrogen fed IT-SOFC. The results are shown and discussed in this section.

Based on Winkler's model [93], which is considered one of the key models in thermodynamic modeling of SOFC, and Equation (3.10), the variation of Nernst voltage in terms of temperature and fuel and air utilization ratios are found, and shown in Figure 4.1. It may be seen from Figure 4.1a that as more fuel is utilized, the Nernst voltage decreases since partial pressure of hydrogen at the fuel channel exit decreases. However, it may not be said that a fuel cell should be operated with low fuel utilization because electrical efficiency of the system becomes higher with high fuel utilization. Lower air 
utilization means higher air flow rate at the air channel inlet. Figure $4.1 \mathrm{~b}$ shows that choosing low air utilization makes the Nernst voltage higher. However, system cost increases if molar flow rate of air at the cathode inlet increases. Hence, thermodynamic and economic considerations should be taken into account together in deciding the optimum parameters.

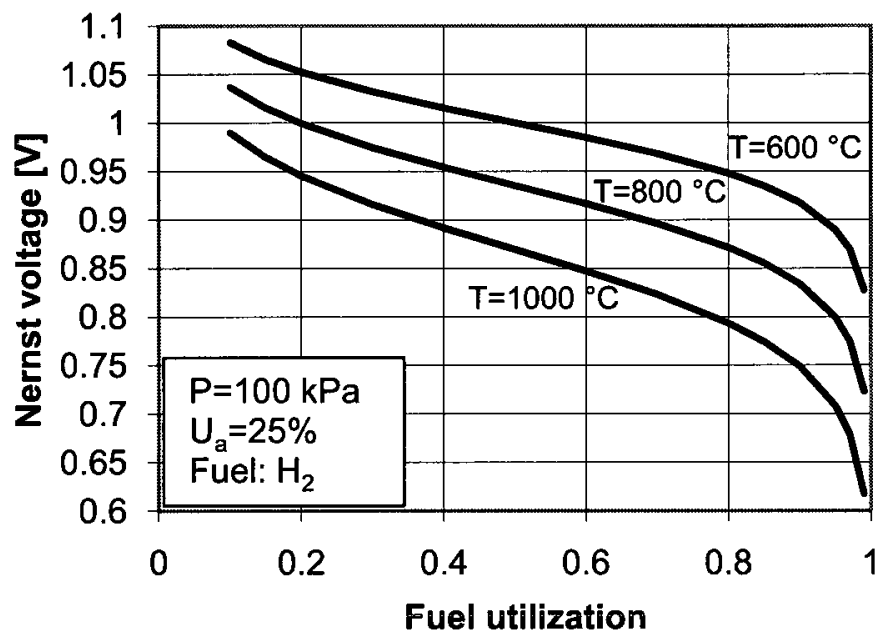

(a)

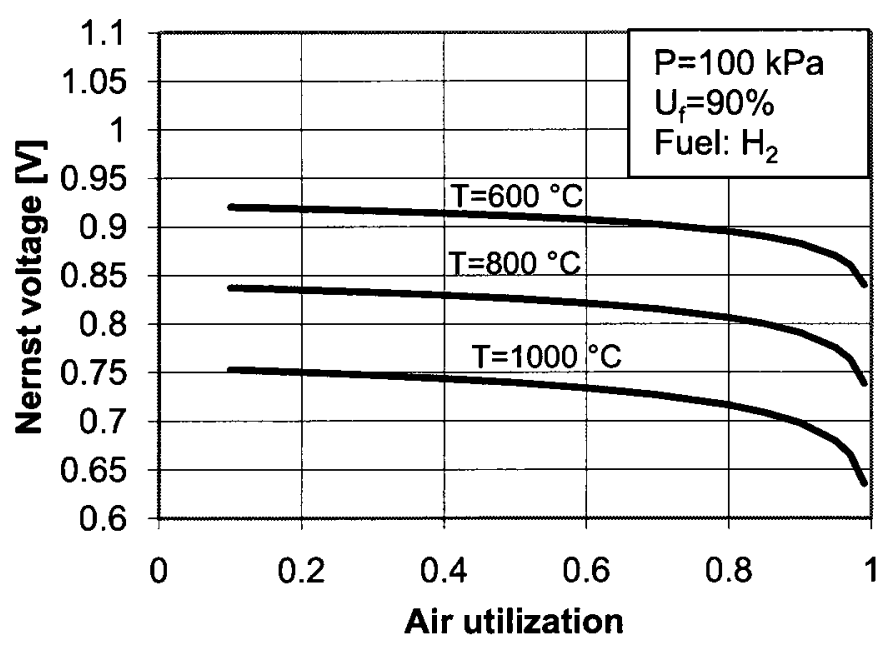

(b)

Figure 4.1: Effect of (a) fuel utilization and temperature, (b) air utilization and temperature, on Nernst voltage. 
The contribution of different polarizations and total polarization, and specific exergy destruction for an IT-SOFC is shown in Figure 4.2. As it can be seen from this figure, ohmic polarization has the highest share among the polarizations although the electrolyte thickness is chosen thin enough for an anode-supported SOFC. Activation polarization of cathode follows ohmic polarization due to having lower exchange current density than anode. Concentration polarization of cathode has the least contribution. It can also be seen from this figure that specific exergy destruction changes between 0 and $25 \mathrm{~kJ} / \mathrm{mol}$ of utilized hydrogen for the given data.

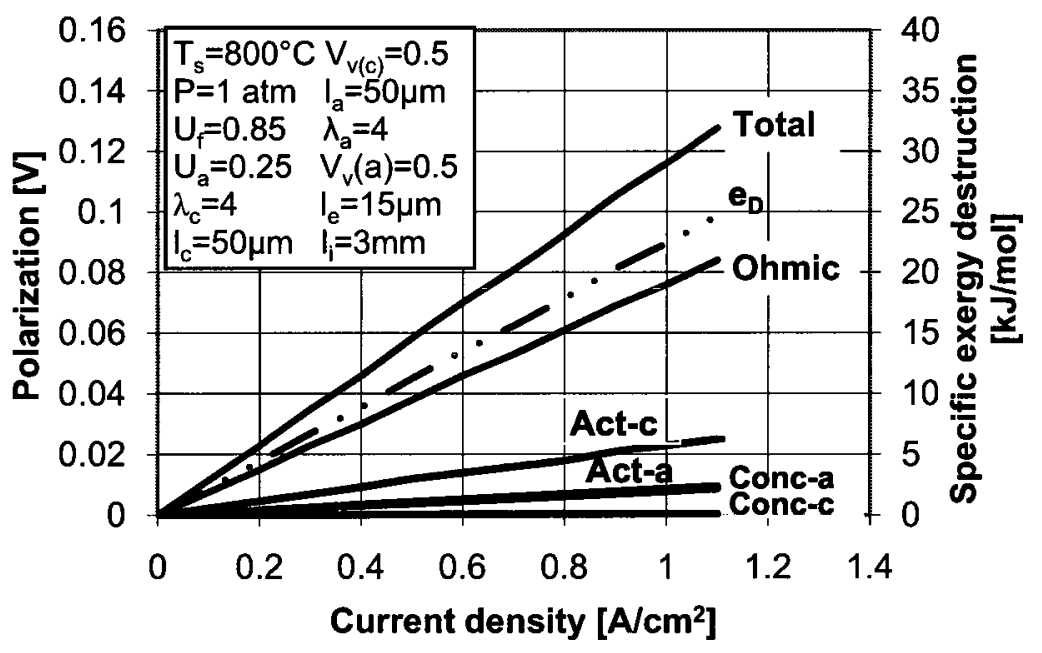

Figure 4.2: Contribution of different polarizations and specific exergy destruction for a hydrogen fuelled SOFC.

\subsection{Thermodynamic Modeling of Direct Internal Reforming SOFCs Operating With}

\section{Syngas}

In this section, the validation of the thermodynamic model of DIR-SOFC operating with syngas, which is discussed in Section 3.5 , is first presented. Then, a case study is 
conducted using this model. Effect of recirculation ratio and fuel utilization on cell voltage, power output, air utilization ratio, and electrical efficiency of the cell are assessed.

\subsubsection{Model validation}

The experimental studies for DIR-SOFC lack in the literature in terms of usage of different fuels, and information on the input parameters used for the experiments in the existing papers are not clearly defined. In the present model, taking the channel inlet and exit temperatures different, taking the fuel cell as insulated, and using a syngas make it difficult to find data for comparison purpose from literature. However, experimental data with methane as fuel presented by Tao et al. [113] are used for comparison with the model results as given in Table 4.1. It is seen that the difference is in the range of $\pm 12 \%$ for the voltage and $\pm 8 \%$ for the power output. This difference is mainly due to the assumptions made for the model.

Table 4.1: Comparison of the model developed with the experimental data*

\begin{tabular}{|l|l|l|l|l|}
\hline $\begin{array}{l}\text { Current } \\
\text { density } \\
\left(\mathrm{A} / \mathrm{cm}^{2}\right)\end{array}$ & $\begin{array}{l}\text { Cell voltage } \\
\text { of the } \\
\text { model }(\mathrm{V})\end{array}$ & $\begin{array}{l}\text { Cell voltage of } \\
\text { the experiment } \\
(\mathrm{V})\end{array}$ & $\begin{array}{l}\text { Power density of } \\
\text { the model } \\
\left(\mathrm{W} / \mathrm{cm}^{2}\right)\end{array}$ & $\begin{array}{l}\text { Power density of } \\
\text { the experiment } \\
\left(\mathrm{W} / \mathrm{cm}^{2}\right)\end{array}$ \\
\hline 0.1 & 0.83 & 0.86 & 0.083 & 0.082 \\
\hline 0.2 & 0.794 & 0.76 & 0.159 & 0.15 \\
\hline 0.3 & 0.753 & 0.68 & 0.226 & 0.21 \\
\hline 0.4 & 0.705 & 0.62 & 0.282 & 0.26 \\
\hline 0.5 & 0.639 & 0.57 & 0.319 & 0.295 \\
\hline 0.6 & 0.57 & 0.52 & 0.342 & 0.315 \\
\hline
\end{tabular}




\subsubsection{Case study}

As a case study, a typical gas mixture obtained from a pyrolysis process is used as the fuel. In dry basis, the composition of this mixture is as follows [114]: $21 \% \mathrm{CH}_{4}, 40 \% \mathrm{H}_{2}$, $20 \% \mathrm{CO}, 18 \% \mathrm{CO}_{2}$, and $1 \% \mathrm{~N}_{2}$. Other fixed input parameters are shown in Table 4.2. Among them, exchange current density depends on temperature and material. For the temperature used in this study and common SOFC materials, these values are obtained from the literature [115]. Effective diffusivity through the anode and cathode mainly depends on material thickness and temperature. In this study, the cell is assumed to be an anode-supported cell and suitable values are chosen according the data given by Singhal and Kendall [10].

Table 4.2: Input values that are fixed throughout the study.

\begin{tabular}{|l|l|}
\hline Input & Value \\
\hline Temperature of the exit $\left(T_{z}\right)$ & $850^{\circ} \mathrm{C}$ \\
\hline Temperature difference between exit and inlet $(\Delta T)$ & $100^{\circ} \mathrm{C}$ \\
\hline Pressure of the cell $\left(P_{\text {cell }}\right)$ & $100 \mathrm{kPa}$ \\
\hline Active surface area $(A)$ & $100 \mathrm{~cm}^{2}$ \\
\hline Exchange current density of anode $\left(i_{o a}\right)$ & $0.65 \mathrm{~A} / \mathrm{cm}^{2}$ \\
\hline Exchange current density of cathode $\left(i_{o c}\right)$ & $0.25 \mathrm{~A} / \mathrm{cm}^{2}$ \\
\hline Effective gaseous diffusivity through the anode $\left(D_{a e f f}\right)$ & $0.2 \mathrm{~cm}^{2} / \mathrm{s}$ \\
\hline Effective gaseous diffusivity through the cathode $\left(D_{c e f f}\right)$ & $0.05 \mathrm{~cm}^{2} / \mathrm{s}$ \\
\hline Thickness of anode $\left(\mathrm{L}_{\mathrm{a}}\right)$ & $500 \mu \mathrm{m}$ \\
\hline Thickness of electrolyte $\left(\mathrm{L}_{\mathrm{e}}\right)$ & $10 \mu \mathrm{m}$ \\
\hline Thickness of cathode $\left(\mathrm{L}_{\mathrm{c}}\right)$ & $50 \mu \mathrm{m}$ \\
\hline
\end{tabular}

Fuel utilization ratio, recirculation ratio, and current density are chosen as varying input parameters. Current density is taken in a range from 0.1 to a close value to its maximum value. Recirculation ratio is taken as $0.1,0.2$, and 0.3 . When the effect of fuel utilization 
is investigated, it is fixed at 0.2 . Fuel utilization ratio is taken as $0.65,0.75$, and 0.85 . When the effect of recirculation ratio is investigated, it is fixed at 0.85 . The results of these parametric studies are presented in the following subsections.

\subsubsection{Effect of recirculation ratio}

The recirculation ratio adjusts the steam to carbon ratio of fuel entering the fuel channel, which is very critical to prevent carbon deposition at the anode catalyst. In this section, the effect of this ratio on the performance of the system is investigated and the results are shown in Figures 4.3-4.6.

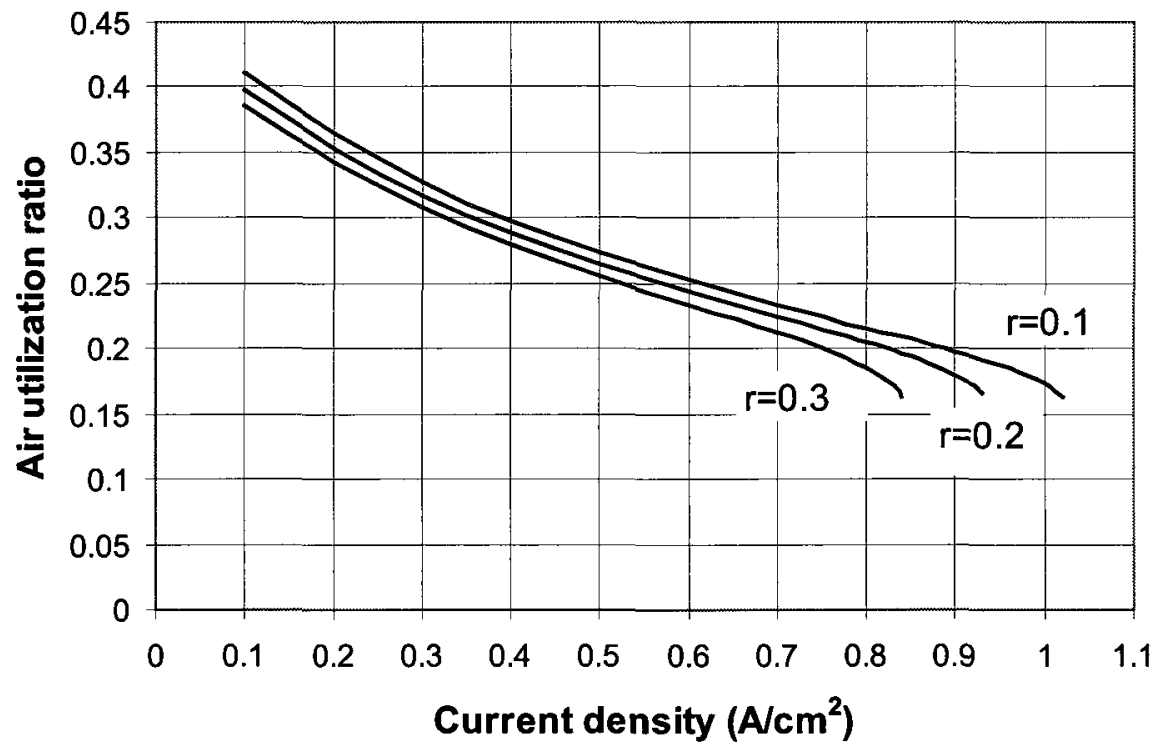

Figure 4.3: Effect of recirculation ratio and current density on air utilization ratio for fuel utilization ratio of 0.85 . 


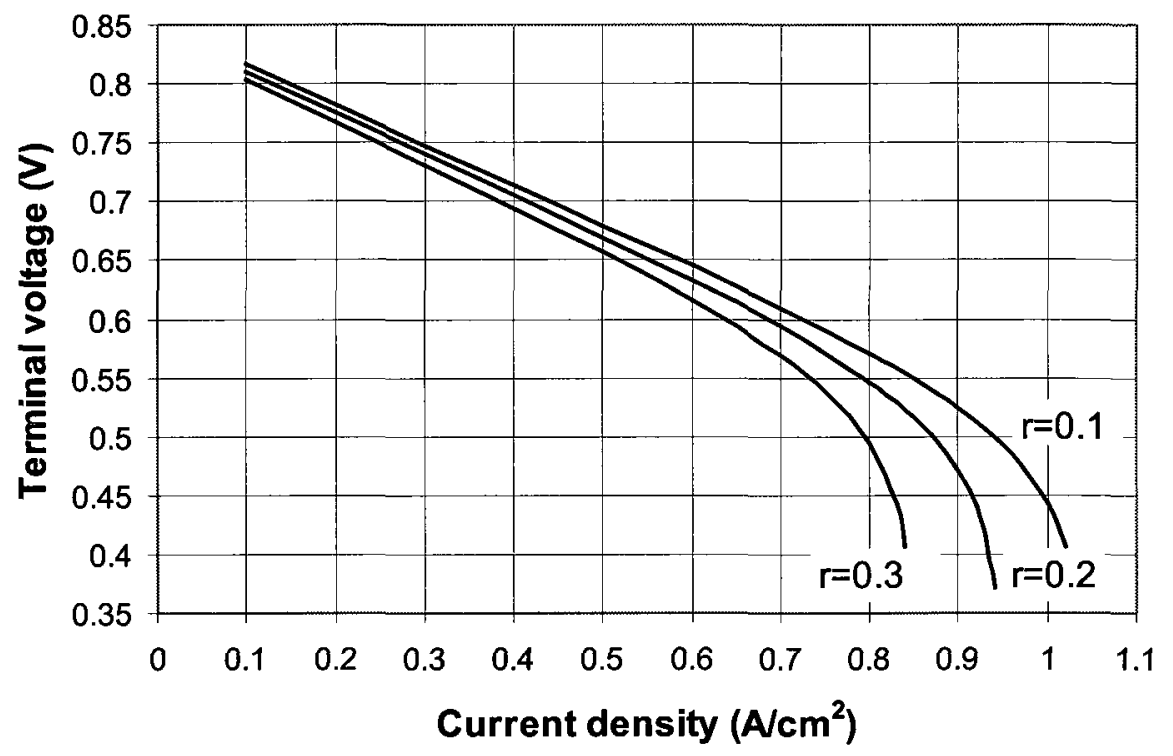

Figure 4.4: Effect of recirculation ratio and current density on terminal voltage for fuel utilization ratio of 0.85 .

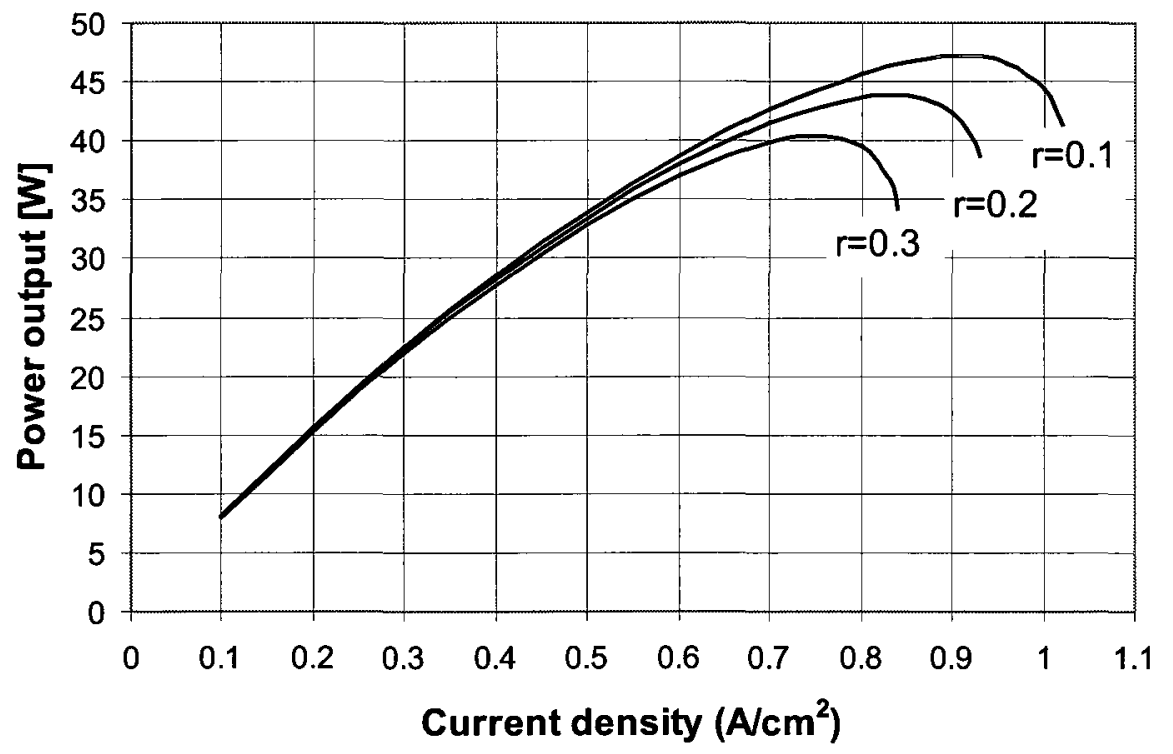

Figure 4.5: Effect of recirculation ratio and current density on power output for fuel utilization ratio of 0.85 . 


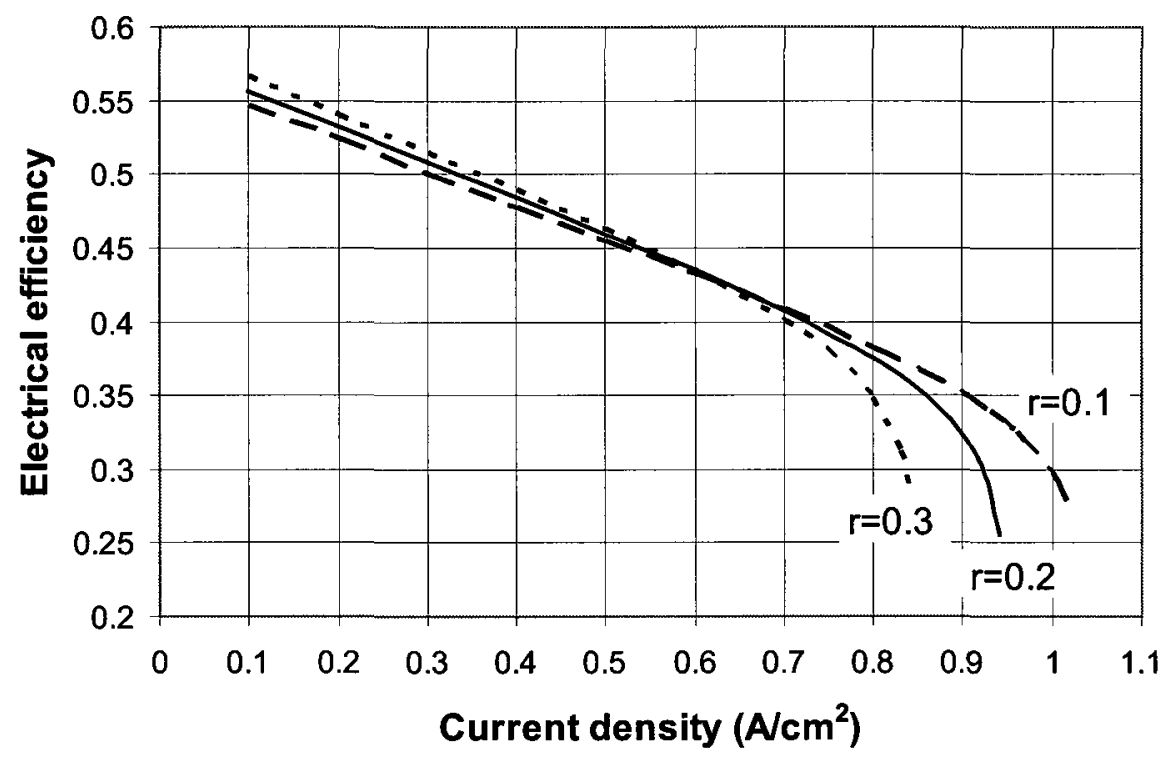

Figure 4.6: Effect of recirculation ratio and current density on electrical efficiency for fuel utilization ratio of 0.85 .

It may be observed from Figures 4.3-4.6 that effect of recirculation ratio is not very significant for low current densities. For high current densities, as recirculation ratio increases, mass flow rate of fuel, air utilization ratio, cell voltage, power output, and electrical efficiency of the cell decrease. Having a lower air utilization ratio means higher mass flow rate of air entering from the cathode section, which in turn increases the operation cost of the system. However, the mass flow rate of fuel decreases in this condition, which decreases the operation cost.

\subsubsection{Effect of fuel utilization}

There is always some amount of unutilized hydrogen in the exit stream of a fuel cell and that the degree of utilization of hydrogen is determined by the fuel utilization ratio. Figures 4.7-4.10 show the effect of fuel utilization ratio on the output parameters. 


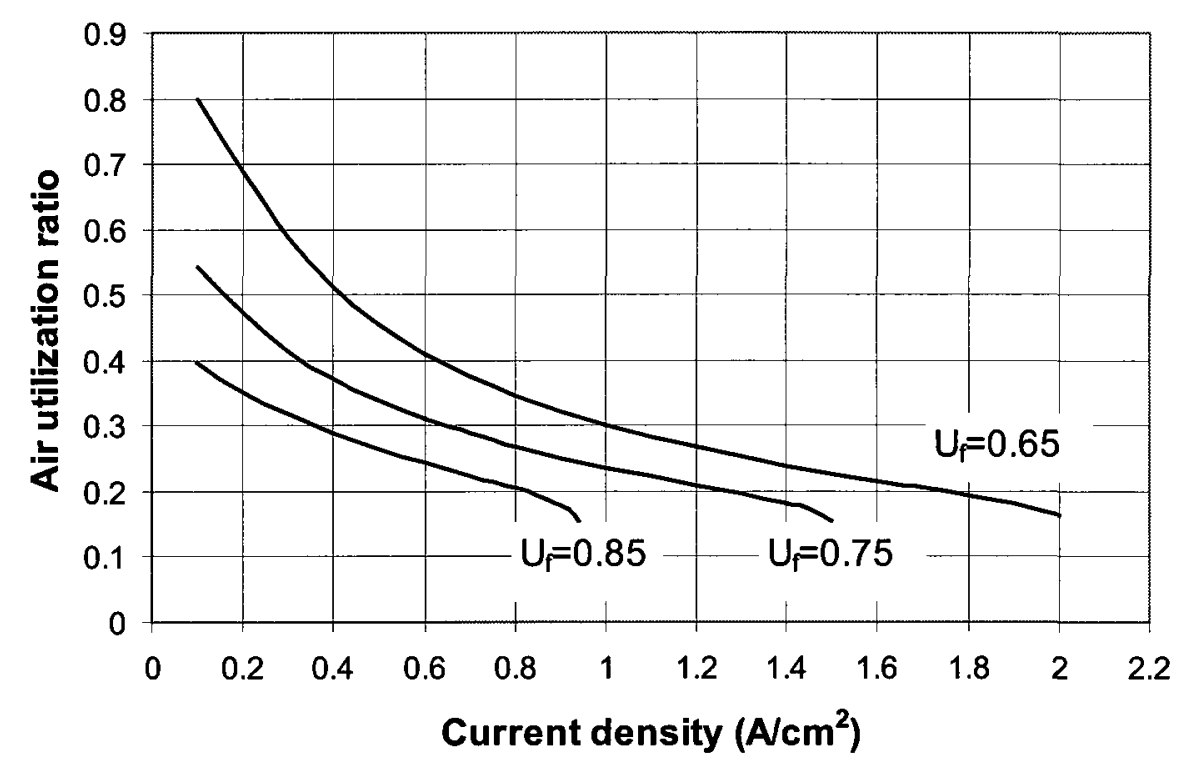

Figure 4.7: Effect of fuel utilization ratio and current density on air utilization ratio for recirculation ratio of 0.2 .

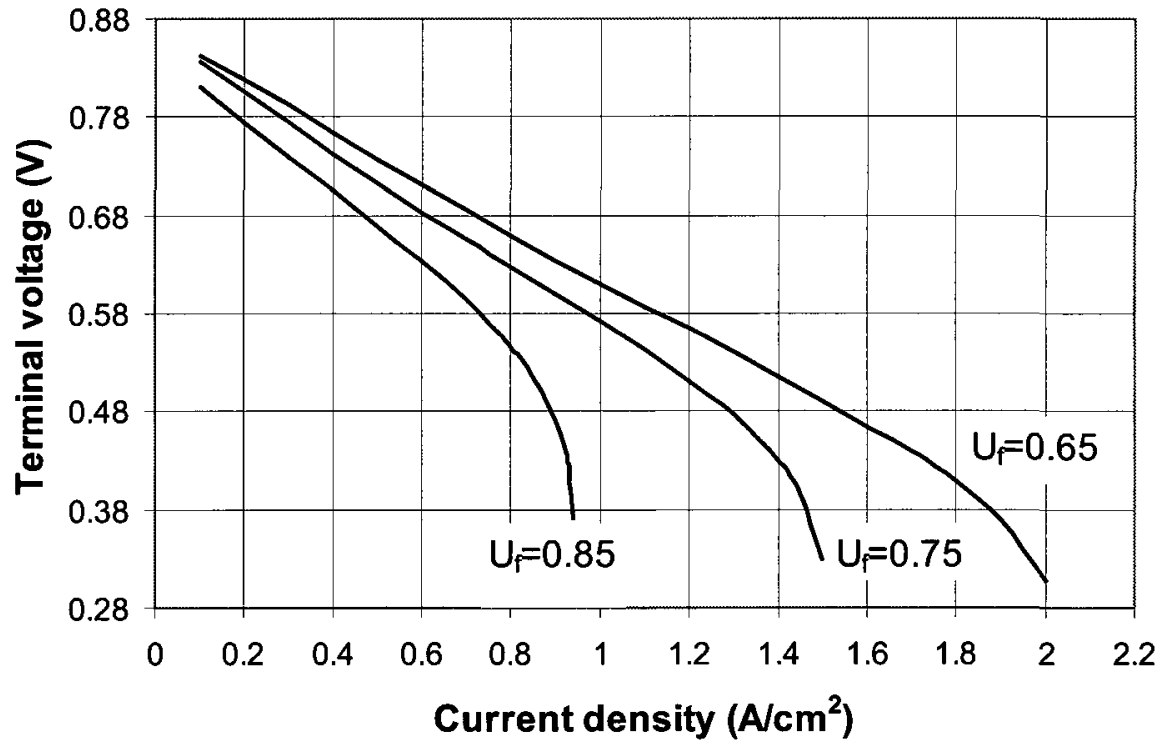

Figure 4.8: Effect of fuel utilization ratio and current density on terminal voltage for recirculation ratio of 0.2 . 


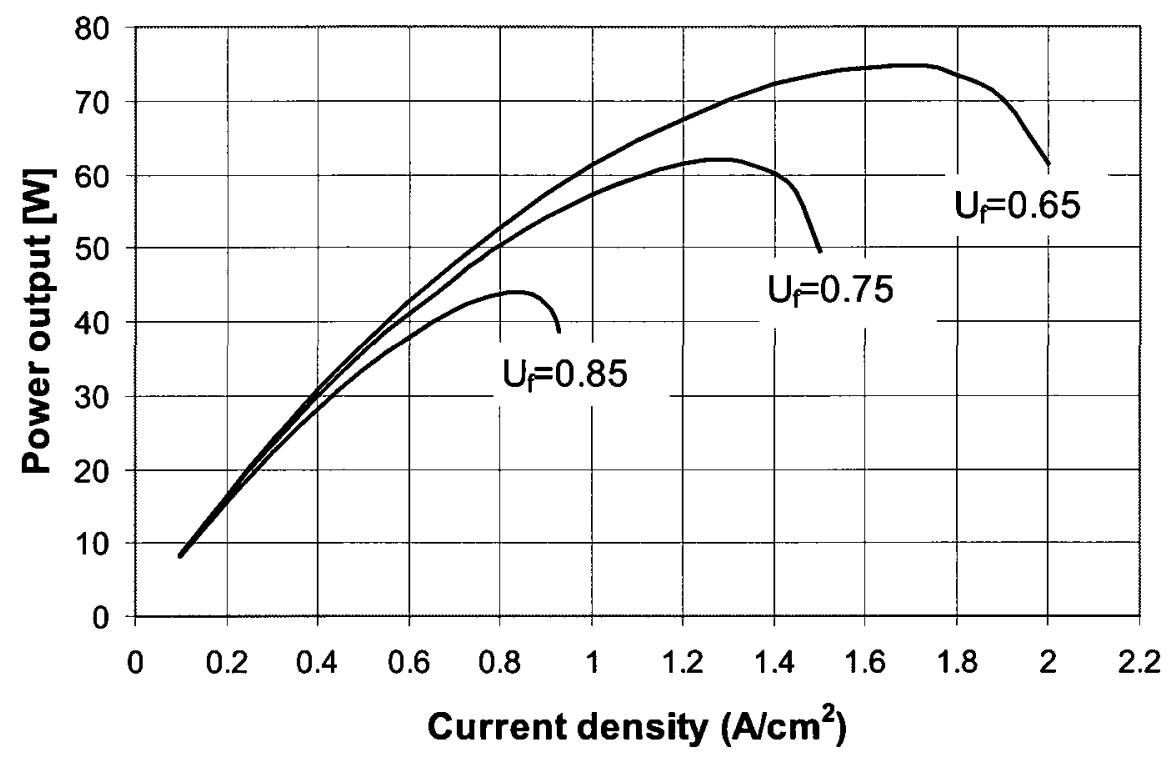

Figure 4.9: Effect of fuel utilization ratio and current density on power output for recirculation ratio of 0.2 .

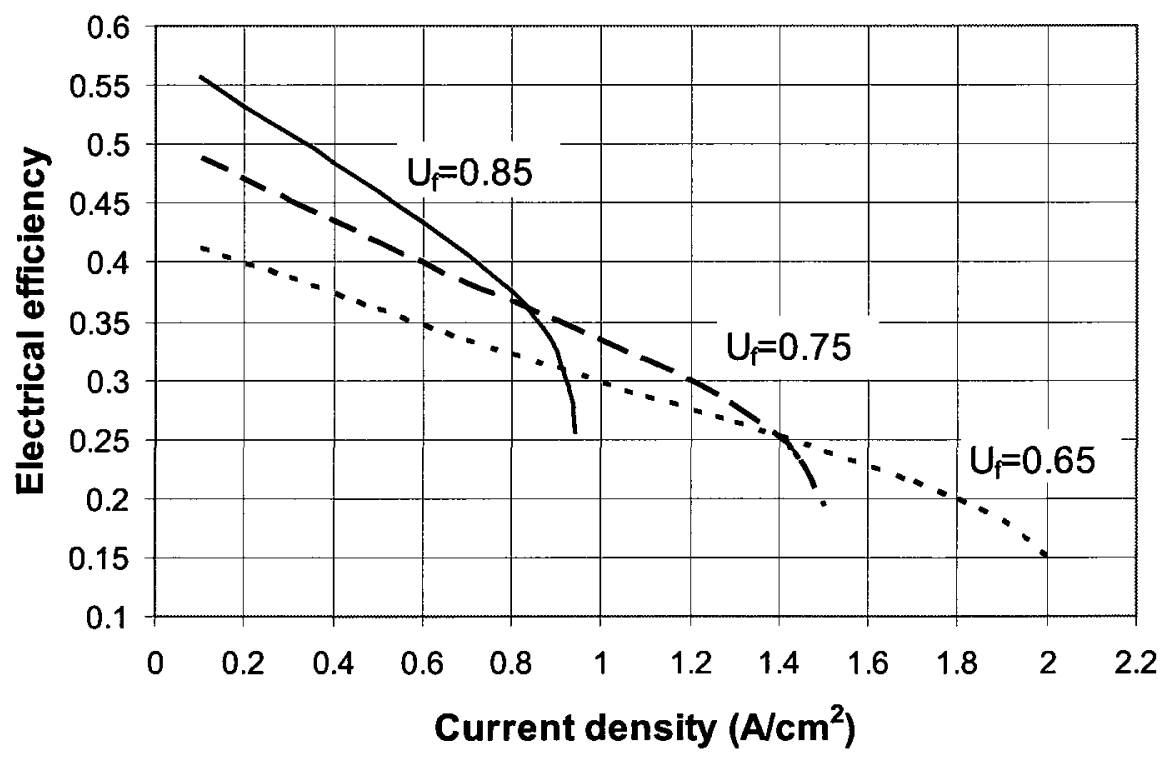

Figure 4.10: Effect of fuel utilization ratio and current density on electrical efficiency for recirculation ratio of 0.2 . 
It may be observed from Figures $4.7-4.10$ that a wider range of current density may be selected for lower fuel utilization ratios. As fuel utilization ratio increases, mass flow rate of fuel, air utilization ratio, terminal voltage, and power output of the cell decrease; whereas electrical efficiency of the cell increases. It may be considered controversial to have low power output and high electrical efficiency at the same time. This is due to the fact that less mass flow rate of fuel is required for higher fuel utilization ratios. Hence, it is seen that increasing the fuel utilization ratio improves the system thermodynamically and decreases the cost of fuel, but also increases the cost of the air flow entering the cathode section.

\subsection{Carbon Deposition Modeling in Direct Internal Reforming SOFCs}

In this section, results and discussion of the carbon deposition model that is presented in Section 3.6 are given. The carbon deposition boundaries for different temperature levels are first found. Effects of recirculation ratio and temperature level on the carbon deposition are then discussed for a SOFC operating with different fuels: methane and a gas mixture obtained from pyrolysis. Finally, effect of chemical composition of gases obtained from biomass gasification on carbon deposition is investigated.

\subsubsection{Carbon deposition boundary}

$\mathrm{C}, \mathrm{H}$, and $\mathrm{O}$ atom ratios are calculated at $100 \mathrm{kPa}$ for the temperature range between 800

$\mathrm{K}-1400 \mathrm{~K}$ using the method discussed in Section 3.6.1 and the results are shown in Figure 4.11. As it can be interpreted from this figure, for higher temperature, carbon deposition region becomes smaller, which means the number of $\mathrm{C}-\mathrm{H}-\mathrm{O}$ systems that may 
cause carbon deposition reduce. At $800 \mathrm{~K}$, at $\mathrm{C}-\mathrm{O}$ axis where $\mathrm{H}$ ratio is zero, $\mathrm{C}$ and $\mathrm{O}$ ratios become $34.5 \%$ and $65.5 \%$; at $\mathrm{C}-\mathrm{H}$ axis where $\mathrm{O}$ ratio is zero, $\mathrm{C}$ and $\mathrm{H}$ ratios become $13.3 \%$ and $86.7 \%$, respectively. At $1400 \mathrm{~K}$, at $\mathrm{C}-\mathrm{O}$ axis where $\mathrm{H}$ ratio is zero, $\mathrm{C}$ and $\mathrm{O}$ ratios become $50 \%$ and $50 \%$; at $\mathrm{C}-\mathrm{H}$ axis where $\mathrm{O}$ ratio is zero, $\mathrm{C}$ and $\mathrm{H}$ ratios become $1.5 \%$ and $98.5 \%$, respectively.

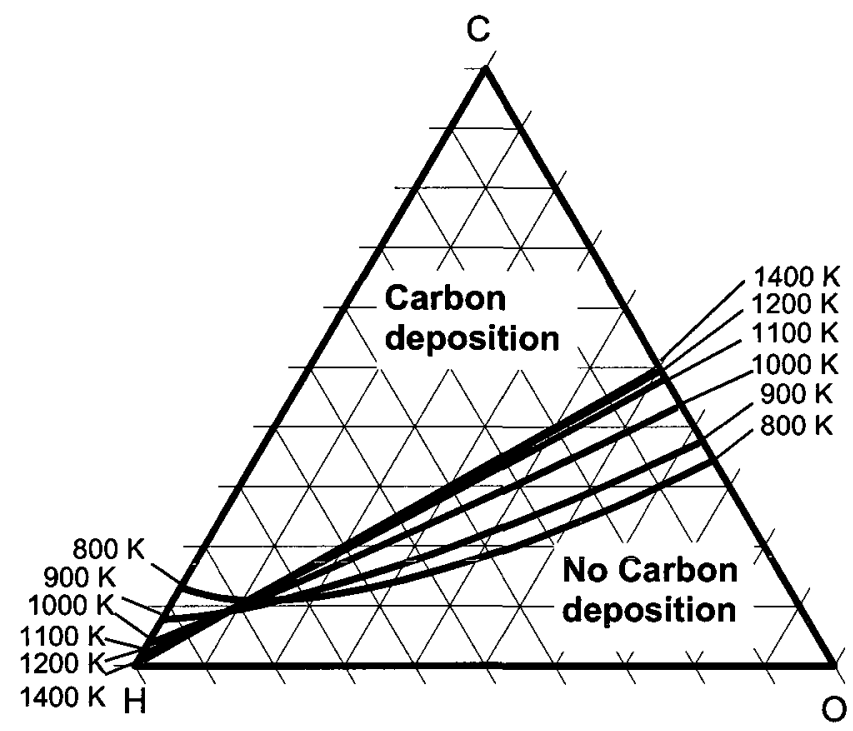

Figure 4.11: Carbon deposition boundary of C-H-O systems at $100 \mathrm{kPa}$.

\subsubsection{Effect of temperature level}

In calculations, three temperature levels are considered to represent different types of SOFC. These are $800 \mathrm{~K}$ (inlet) $-900 \mathrm{~K}$ (exit), $950 \mathrm{~K}$ (inlet) $-1050 \mathrm{~K}$ (exit), $1100 \mathrm{~K}$ (inlet) - $1200 \mathrm{~K}$ (exit), which represent LT-SOFC, IT-SOFC, and HT-SOFC, respectively. A temperature difference of $100 \mathrm{~K}$ is assumed in each case considering the cooling necessity and thermomechanical considerations of the fuel cell. The fuel is taken 
as methane and then a gas mixture which is produced from a pyrolysis process. In all calculations, the pressure of the cell is taken as $100 \mathrm{kPa}$, and the active surface area is taken as $100 \mathrm{~cm}^{2}$. It is found that the carbon activity at the exit is always lower than the inlet for the operating data that is considered in this study. Since the possibility of carbon deposition is more severe at the inlet than the exit, only the results obtained for the inlet condition are shown in the following subsections.

\subsubsection{Fuel as methane}

When pure methane is used as a fuel in a DIR-SOFC, water is needed to initiate and continue the steam reforming reaction. If we do not want to use any external water source, some part of the depleted fuel at the exit should be recirculated since the water content at the exit is high due to the electrochemical reaction. However, it should be noted that we still need some external water for start-up operation for a short time for this case.

The effects of recirculation for LT-SOFC, IT-SOFC, and HT-SOFC are shown in Figures 4.12 through 4.14. These figures show how the composition of a gas at equilibrium approaches the carbon deposition boundary as the recirculation ratio increases. As it may be seen from these figures, less recirculation is needed as the temperature level increases. The recirculation ratios of $0.7,0.5$, and 0.4 are needed for LT-SOFC, IT-SOFC, and HTSOFC, respectively, at a fuel utilization ratio of 0.85 , to prevent the carbon deposition problem. 


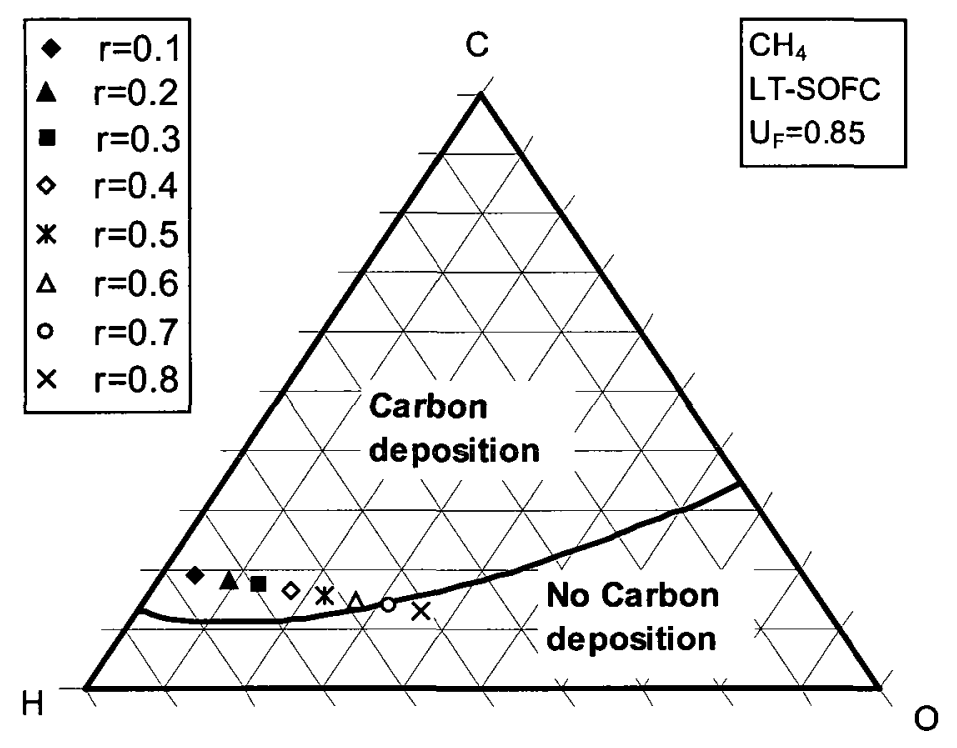

Figure 4.12: C-H-O diagram of a LT-SOFC operating with methane.

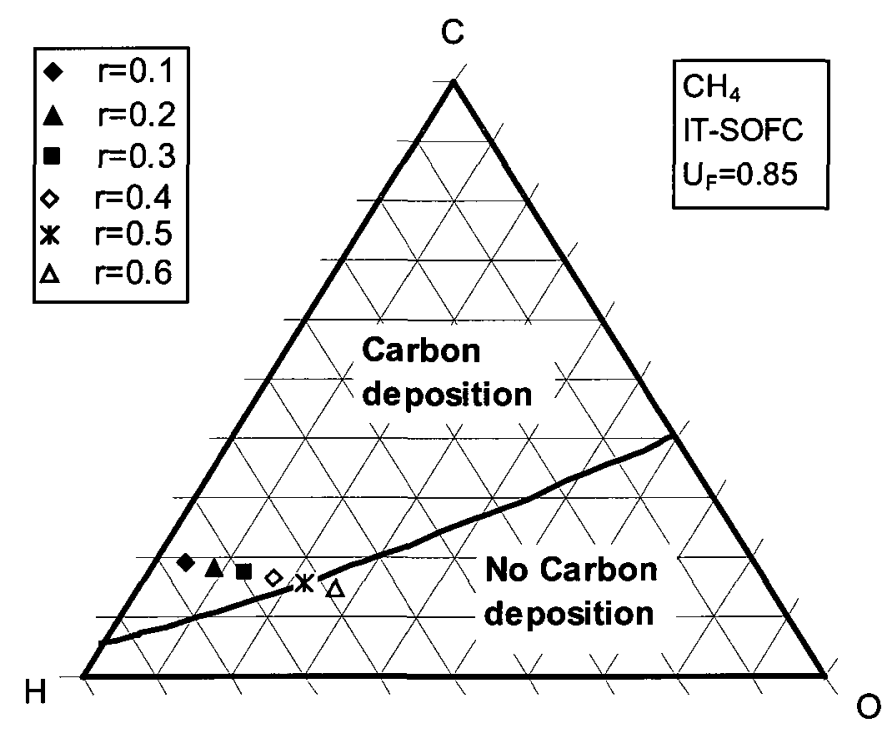

Figure 4.13: $\mathrm{C}-\mathrm{H}-\mathrm{O}$ diagram of an IT-SOFC operating with methane. 


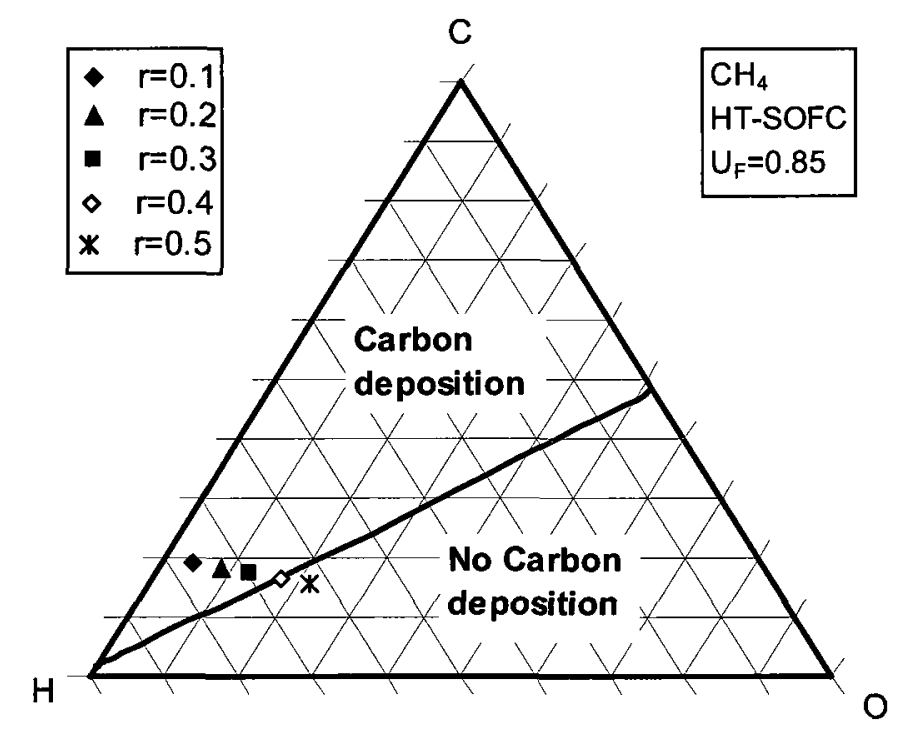

Figure 4.14: C-H-O diagram of a HT-SOFC operating with methane.

At the carbon deposition boundary, the gas mixture is at equilibrium with solid carbon. In equilibrium, the activity of pure solids is defined to be equal to one. Above the boundary, the carbon activity is greater than one; and below the boundary, the carbon activity is less than one. The carbon activity for LT-SOFC, IT-SOFC, and HT-SOFC at different fuel utilization ratios are calculated; and these results are shown in Figures 4.15-4.17. In these figures, the dashed line shows the carbon deposition boundaries. It may be interpreted from these figures that as the fuel utilization ratio increases, carbon activity decreases. In addition, although the carbon activity is the highest for HT-SOFC at low recirculation ratios, the change of carbon activity with recirculation ratio is more than others; hence, less recirculation is needed to obtain the no-carbon deposition conditions. 


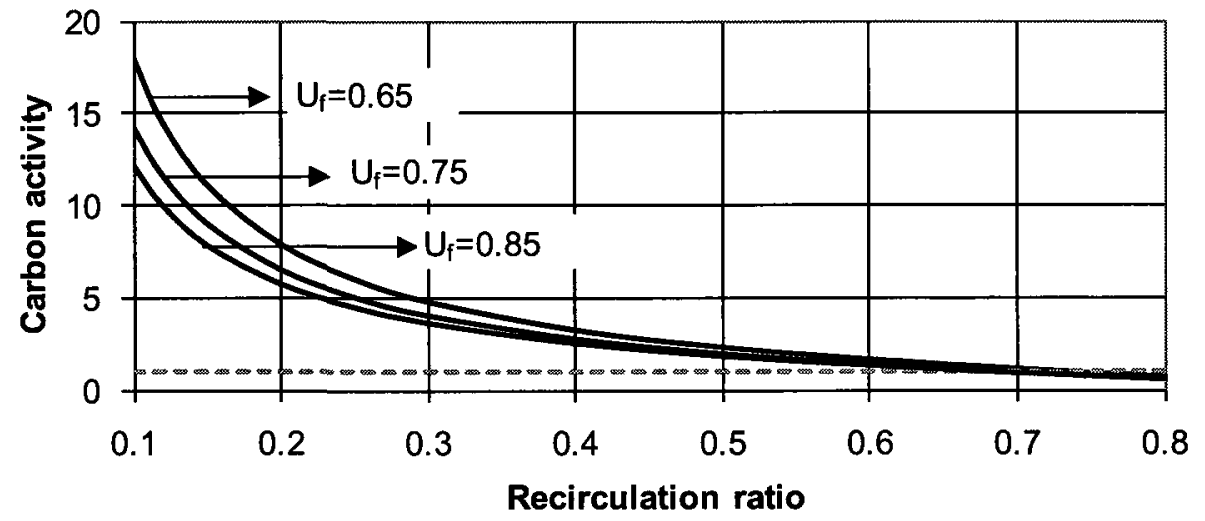

Figure 4.15: Carbon activity at the inlet for a LT-SOFC operating with methane.

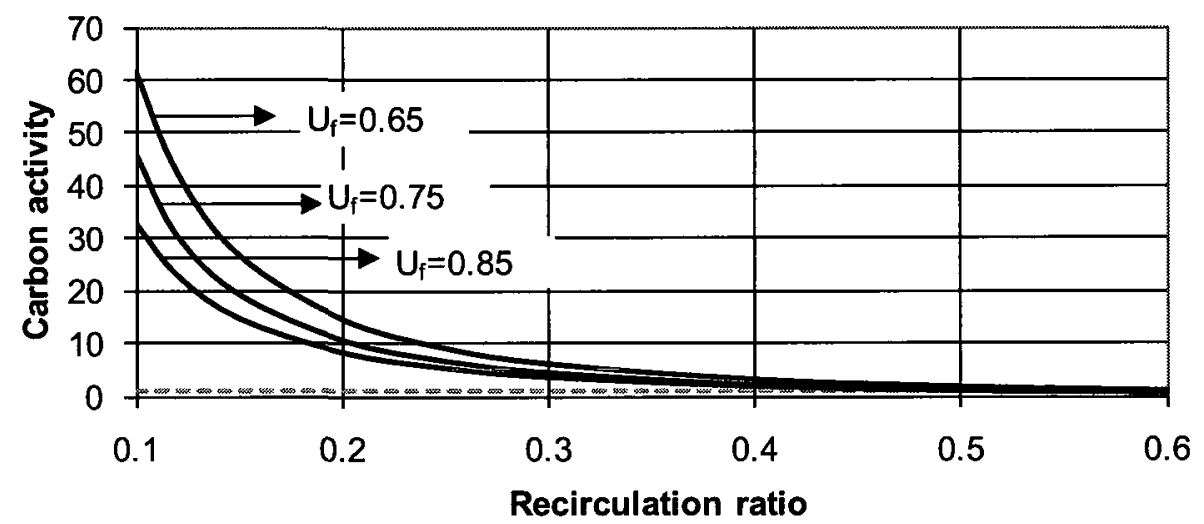

Figure 4.16: Carbon activity at the inlet for an IT-SOFC operating with methane.

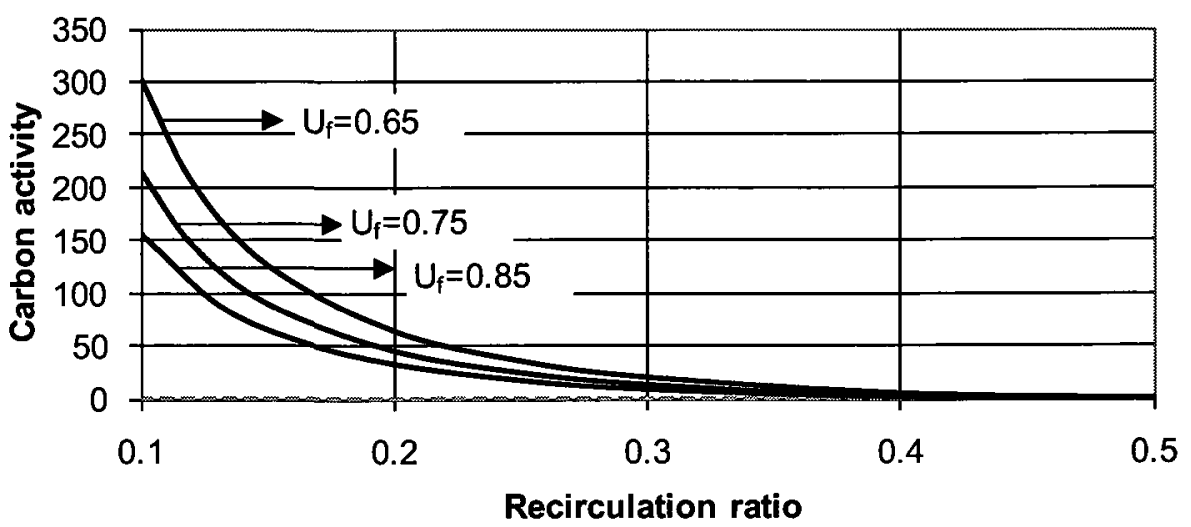

Figure 4.17: Carbon activity at the inlet for a HT-SOFC operating with methane. 
It was shown in Section 4.3 that a recirculation ratio which is sufficiently low enough to prevent carbon deposition should be chosen to have the maximum thermodynamic performance. Due to this fact, the minimum recirculation ratio for different temperature levels and fuel utilization ratios are calculated and shown in Figure 4.18. It can be seen from this figure that as the fuel utilization ratio changes between 0.5 and 0.85 , minimum recirculation ratio changes between 0.78 and $0.68,0.65$ and 0.51 , and 0.55 and 0.4 for LT-SOFC, IT-SOFC and HT-SOFC, respectively.

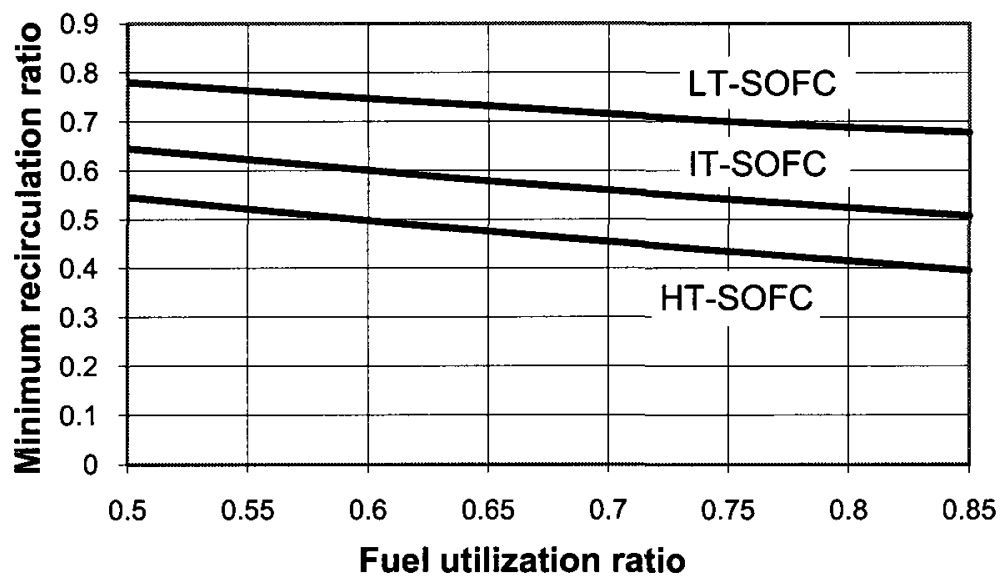

Figure 4.18: Minimum recirculation ratio for preventing the carbon deposition for a SOFC operating with methane.

\subsubsection{Fuel as gas mixture obtained from pyrolysis}

In Section 4.3, the performance of a SOFC operating with a gas mixture produced from a pyrolysis process is discussed. In this section, carbon deposition possibility when using the same gas mixture is investigated. The results of the carbon deposition modeling are shown in Figures 4.19-4.22 for a LT-SOFC and an IT-SOFC. 


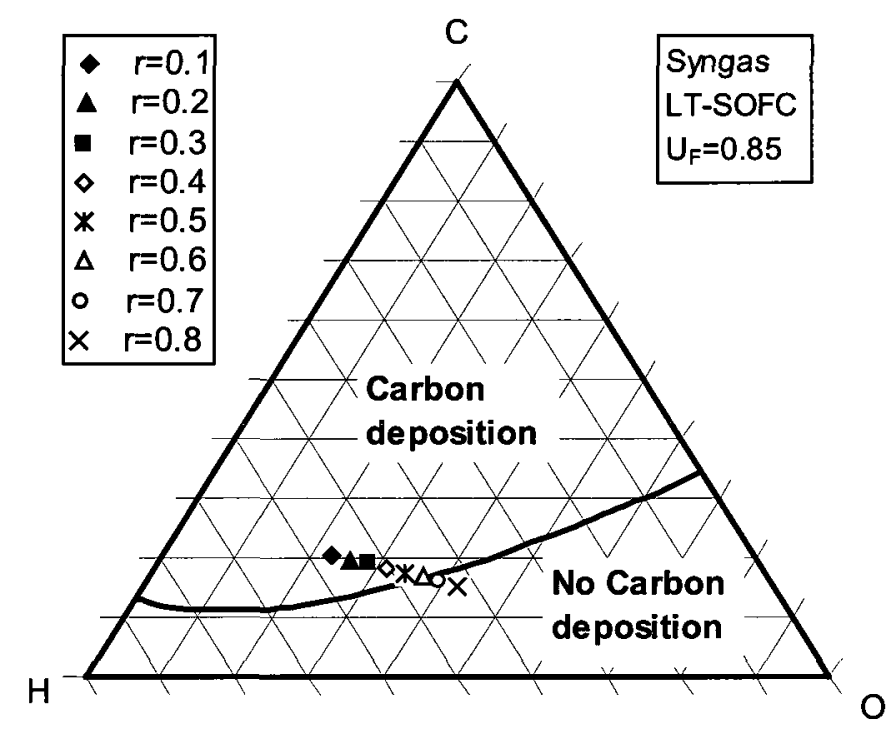

Figure 4.19: $\mathrm{C}-\mathrm{H}-\mathrm{O}$ diagram of a LT-SOFC operating with a gas mixture produced from pyrolysis.

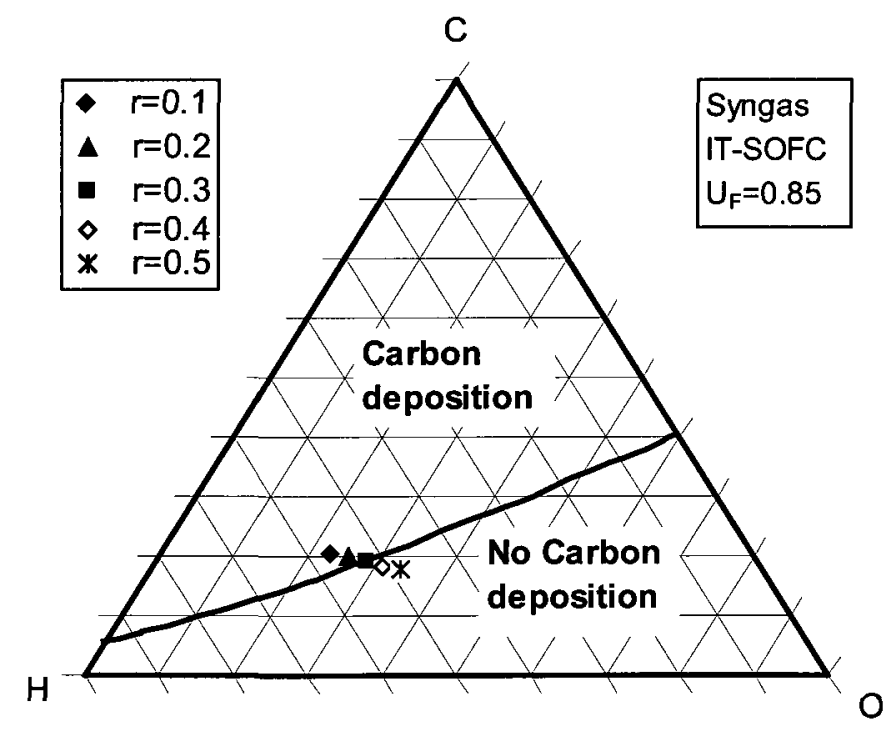

Figure 4.20: $\mathrm{C}-\mathrm{H}-\mathrm{O}$ diagram of an IT-SOFC operating with a gas mixture produced from pyrolysis. 


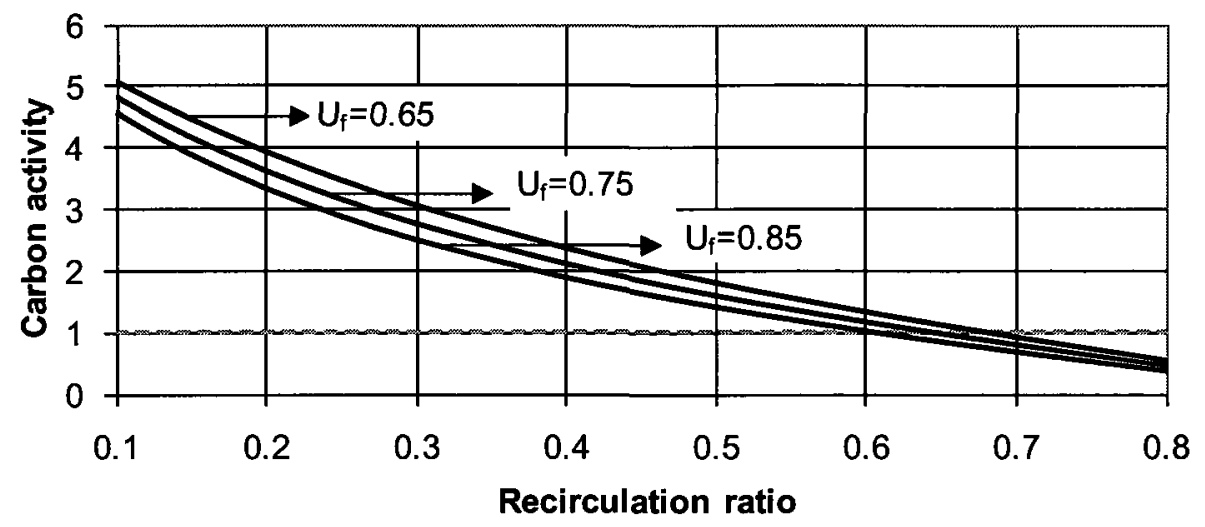

Figure 4.21: Carbon activity at the inlet for a LT-SOFC operating with a gas mixture produced from pyrolysis.

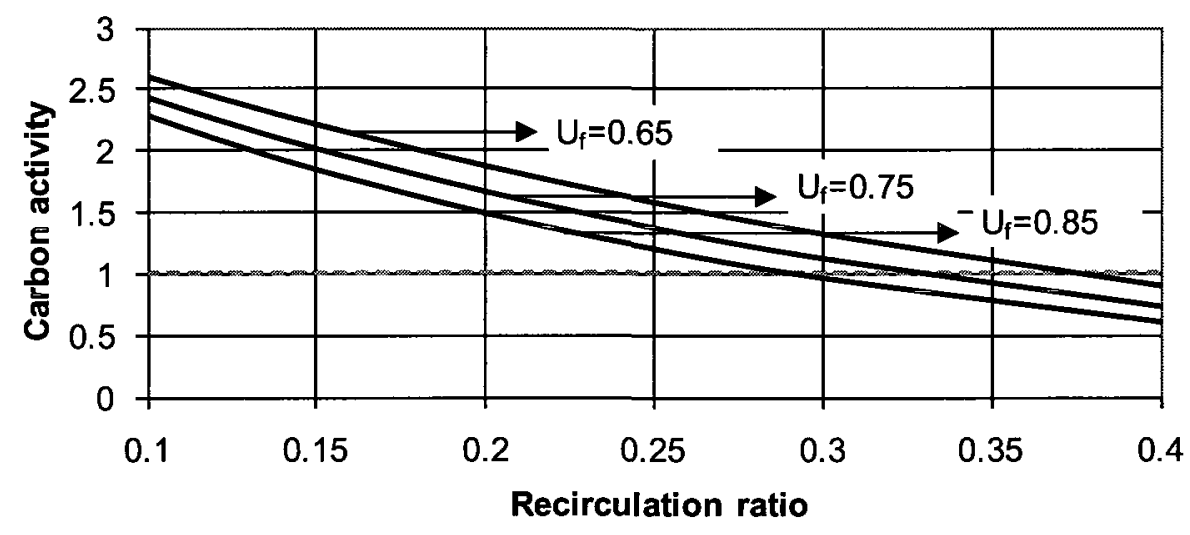

Figure 4.22: Carbon activity at the inlet for an IT-SOFC operating with a gas mixture produced from pyrolysis.

Figures 4.19-4.22 show similar trends of those for methane. At the fuel utilization ratio of 0.85 , it is found that, approximately, a recirculation ratio of 0.6 and 0.3 are needed for LT-SOFC and IT-SOFC, respectively. In addition, carbon activities and their change with recirculation are found to be lower than those for methane at low recirculation ratios. The 
results for HT-SOFC are not shown in these figures since less than $10 \%$ of recirculation is needed to prevent carbon deposition at the fuel utilization ratios of 0.65 to 0.85 .

The minimum recirculation ratio needed for LT-SOFC, IT-SOFC and HT-SOFC are shown in Figure 4.23. The results show that as the fuel utilization ratio changes between 0.5 and 0.85 , minimum recirculation ratio changes between 0.75 and $0.62,0.46$ and 0.3 , and 0.13 and 0.07 for LT-SOFC, IT-SOFC, and HT-SOFC, respectively.

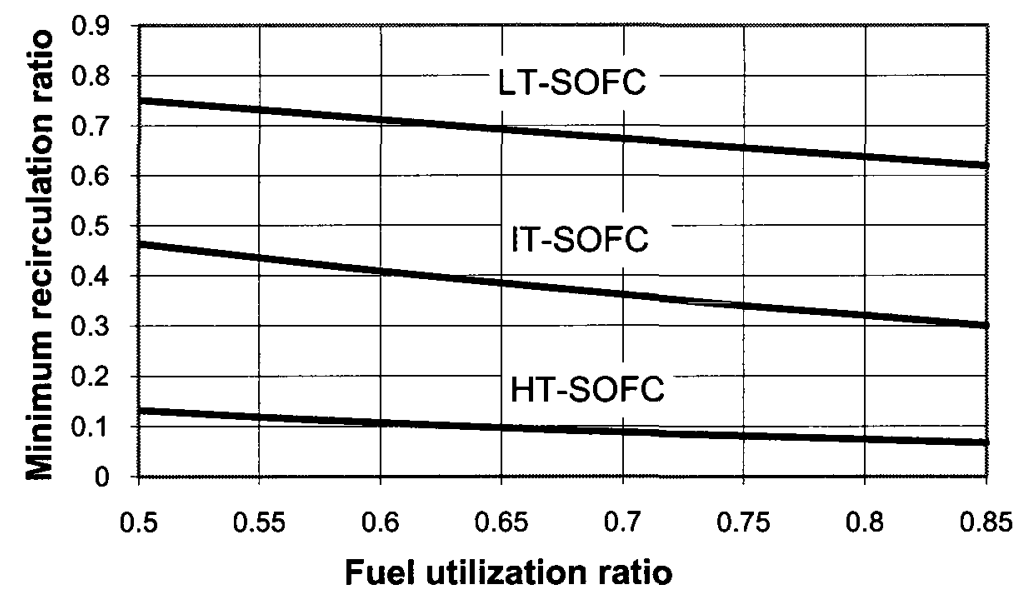

Figure 4.23: Minimum recirculation ratio for preventing the carbon deposition for a SOFC operating with a gas mixture produced from pyrolysis.

\subsubsection{Effect of chemical composition of gases from biomass gasification}

In this study, an atmospheric SOFC is assumed to operate with dry and cleaned syngas consisting of $\mathrm{CH}_{4}, \mathrm{CO}_{2}, \mathrm{CO}, \mathrm{H}_{2} \mathrm{O}, \mathrm{H}_{2}$, and $\mathrm{N}_{2}$. In calculations, typical gas compositions obtained from different gasifiers are considered, which are shown in Table 4.3. The inlet 
and exit gas temperatures are assumed as $750{ }^{\circ} \mathrm{C}$ and $850^{\circ} \mathrm{C}$, respectively. Active surface area of the cell is taken as $100 \mathrm{~cm}^{2}$. It is also assumed that the cell is manufactured as anode-supported with the following thicknesses: $500 \mu \mathrm{m}$ anode, $10 \mu \mathrm{m}$ electrolyte, and $50 \mu \mathrm{m}$ cathode. The effect of recirculation ratio on the carbon deposition possibility is investigated, and the performance of the SOFC is assessed for the no-carbon deposition conditions.

Table 4.3: Typical product gas composition from different gasifiers.

\begin{tabular}{|l|c|c|c|c|c|c|}
\hline & $\begin{array}{l}\text { Fluid } \\
\text { bed, air }\end{array}$ & $\begin{array}{l}\text { Updraft, } \\
\text { air }\end{array}$ & $\begin{array}{l}\text { Downdraft, } \\
\text { air }\end{array}$ & $\begin{array}{l}\text { Downdraft, } \\
\mathrm{O}_{2}\end{array}$ & $\begin{array}{l}\text { Multi-solid } \\
\text { Fluid Bed }\end{array}$ & $\begin{array}{l}\text { Twin Fluid } \\
\text { bed }\end{array}$ \\
\hline $\mathrm{H}_{2}$ & $9 \%$ & $11 \%$ & $17 \%$ & $32 \%$ & $15 \%$ & $31 \%$ \\
\hline $\mathrm{CO}$ & $14 \%$ & $24 \%$ & $21 \%$ & $48 \%$ & $47 \%$ & $48 \%$ \\
\hline $\mathrm{CO}_{2}$ & $20 \%$ & $9 \%$ & $13 \%$ & $15 \%$ & $15 \%$ & $0 \%$ \\
\hline $\mathrm{CH}_{4}$ & $7 \%$ & $3 \%$ & $1 \%$ & $2 \%$ & $23 \%$ & $21 \%$ \\
\hline $\mathrm{N}_{2}$ & $50 \%$ & $53 \%$ & $48 \%$ & $3 \%$ & $0 \%$ & $0 \%$ \\
\hline
\end{tabular}

First, the recirculation ratio that prevents the carbon deposition problem is determined. From Table 4.4 and Figures 4.24 and 4.25, it may be interpreted that there is no carbon deposition for the lowest recirculation ratio that we considered in this study, i.e. $r=0.1$, for the SOFC operating with the gases produced from the following gasification systems: air blown fluid bed, air blown updraft bed, air-blown downdraft bed, and oxygen blown downdraft bed. For the multi-solid fluid bed and twin fluid bed, a recirculation ratio of 0.3 is needed to prevent carbon deposition at the fuel cell. 
Table 4.4: Carbon activities of the syngases produced from different gasifiers.

\begin{tabular}{|c|c|c|c|c|c|c|}
\hline & $\begin{array}{l}\text { Fluid } \\
\text { bed, air }\end{array}$ & $\begin{array}{l}\text { Updraft, } \\
\text { air }\end{array}$ & $\begin{array}{l}\text { Downdraft, } \\
\text { air }\end{array}$ & $\begin{array}{l}\text { Downdraft, } \\
\mathrm{O}_{2}\end{array}$ & $\begin{array}{l}\text { Multi-solid } \\
\text { Fluid Bed }\end{array}$ & $\begin{array}{l}\text { Twin } \\
\text { Fluid bed }\end{array}$ \\
\hline $\mathrm{r}=0.1$ & 0.244 & 0.438 & 0.209 & 0.673 & 3.061 & 6.744 \\
\hline $\mathrm{r}=0.2$ & -- & -- & -- & -- & 1.234 & 1.976 \\
\hline $\mathrm{r}=0.3$ & -- & -- & -- & -- & 0.610 & 0.765 \\
\hline
\end{tabular}

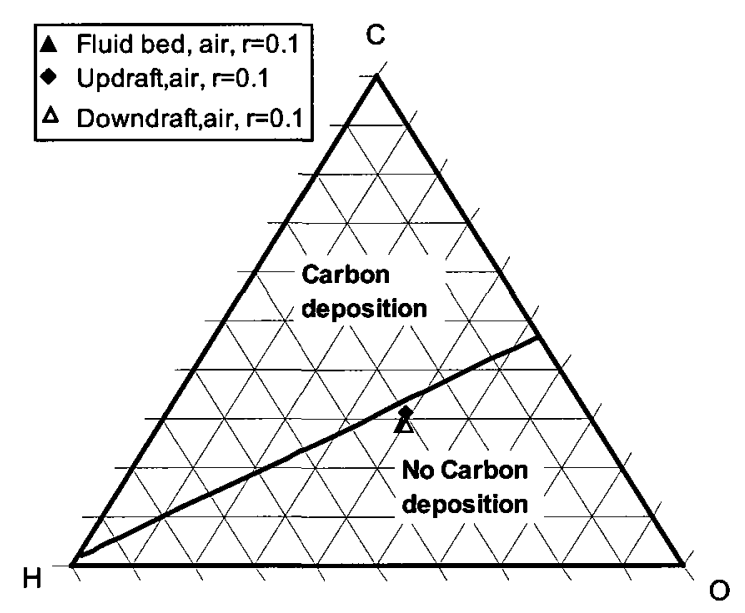

Figure 4.24: C-H-O diagram for determining the carbon deposition possibility for fluid bed-air, updraft-air, and downdraft-air.

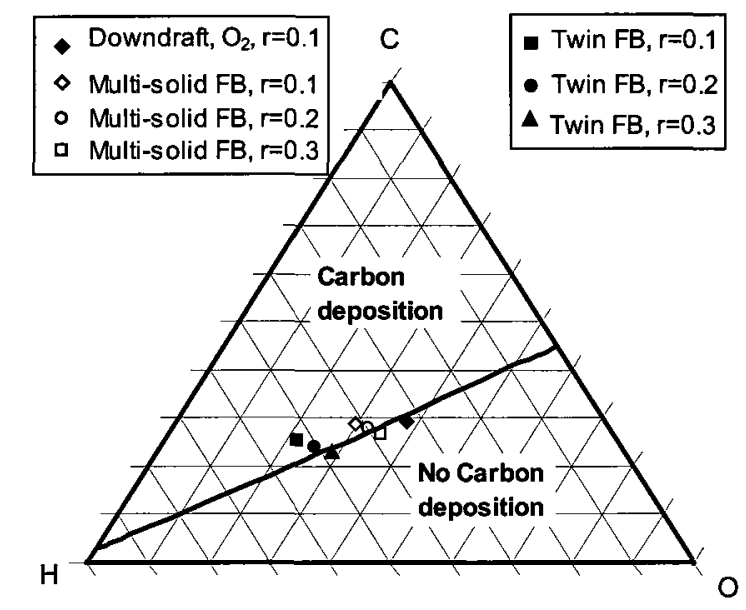

Figure 4.25: C-H-O diagram for determining the carbon deposition possibility for downdraft $-\mathrm{O}_{2}$, multi-solid fluid bed, and twin fluid bed. 
The performance of the SOFC operating with gases produced from different gasifiers with the recirculation ratio that ensures no-carbon deposition conditions is also evaluated. The results are shown in Figures 4.26-4.29.

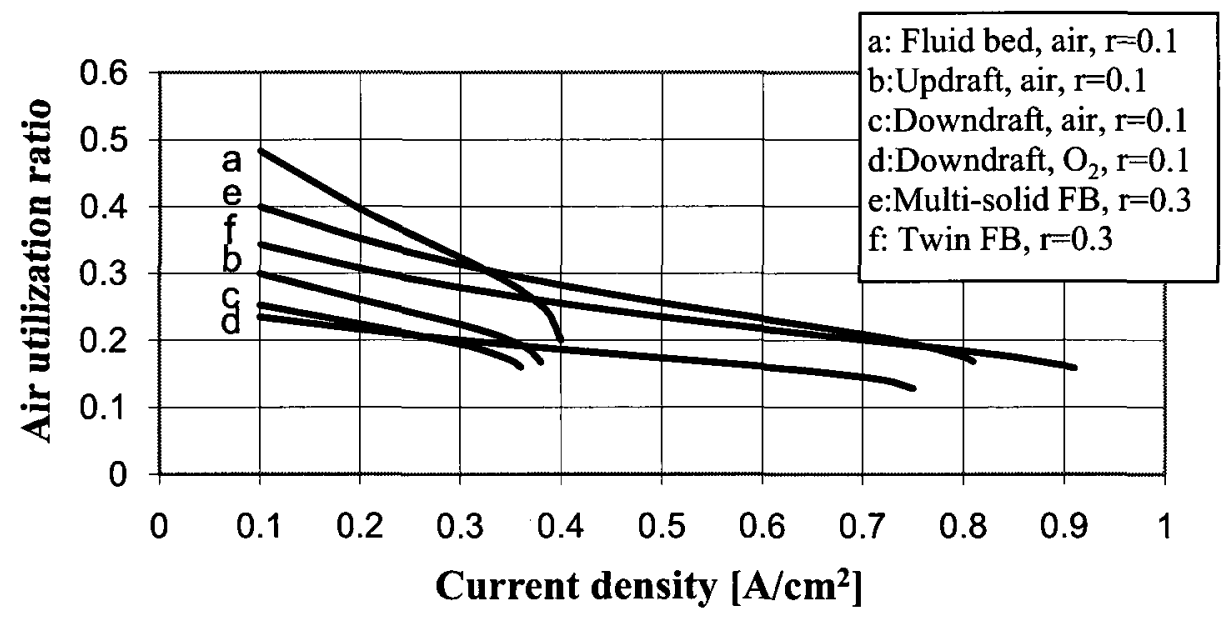

Figure 4.26: Effect of gasifier type on the air utilization ratio.

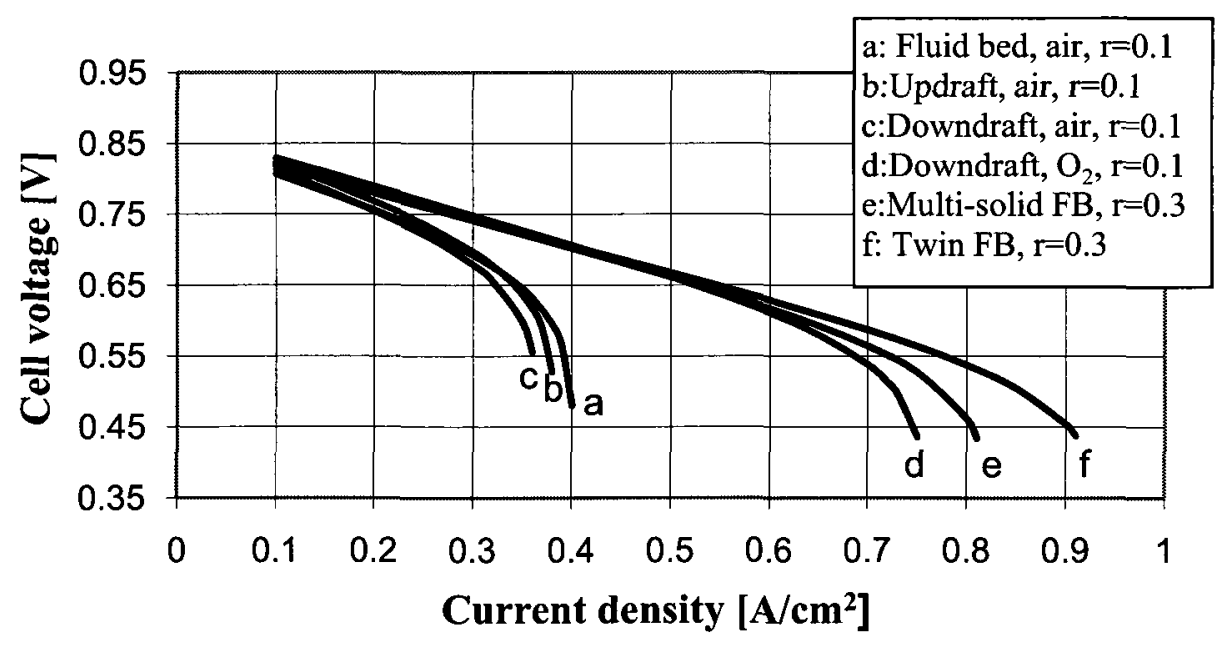

Figure 4.27: Effect of gasifier type on the cell voltage. 


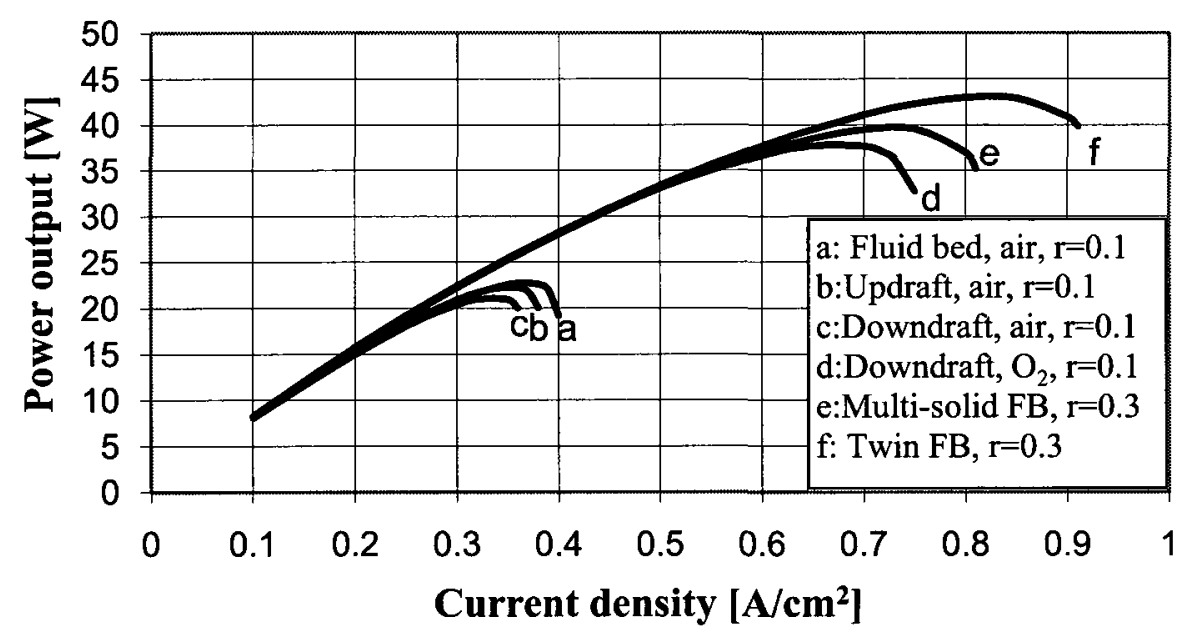

Figure 4.28: Effect of gasifier type on the power output.

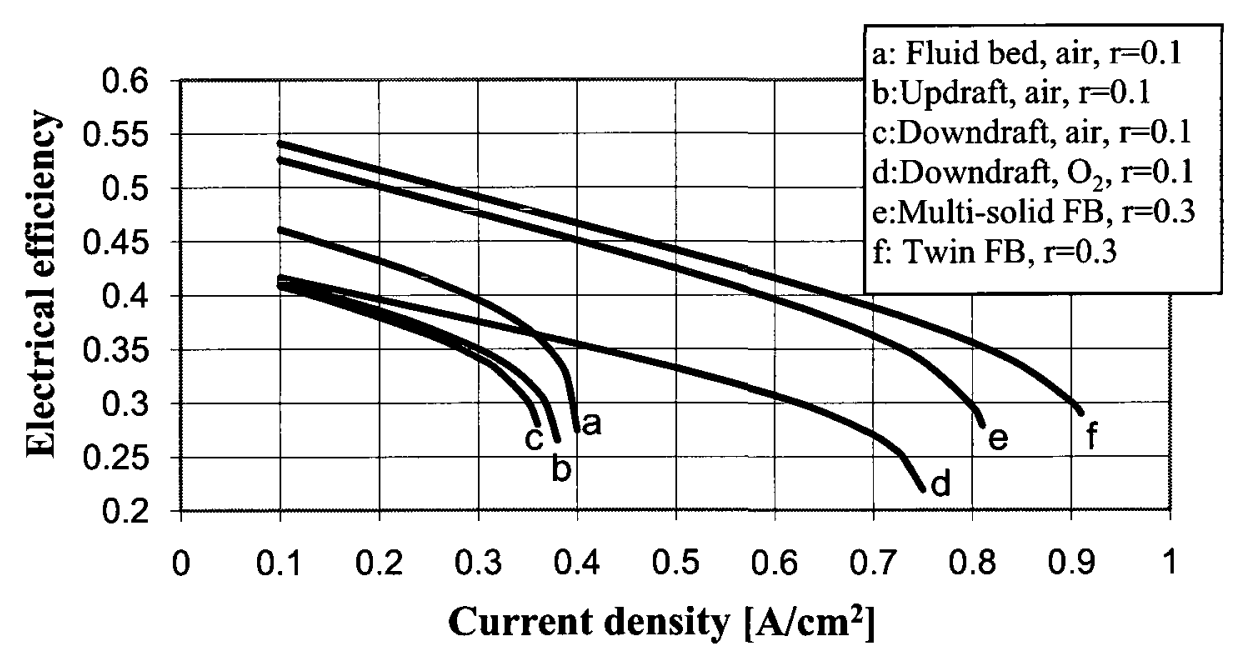

Figure 4.29: Effect of gasifier type on the electrical efficiency.

The results shown in Figures 4.26-4.29 are compared for the common current density conditions for the different cases. It may be seen from Figure 4.26 that fluid bed case has 
the highest air utilization; whereas oxygen blown downdraft bed case has the lowest. This means that higher mass flow rate of air should be sent through the air channel for oxygen blown draft bed case. Figures 4.27 and 4.28 show that cell voltage and power output are almost same for low current density conditions. However, as current density increases, air blown downdraft, multi-solid fluidized bed, and twin fluidized bed cases become higher than the remaining cases. The most important result of the study is the comparison of the electrical efficiencies, which is shown in Figure 4.29. According to this figure, twin fluid bed case has the highest electrical efficiency, and the multi-solid fluid bed case follows it. Air-blown downdraft and updraft options cases have the lowest electrical efficiencies.

\subsection{Transient Heat Transfer Modeling of SOFC}

In this section, validation of the transient heat transfer model discussed in Section 3.7 and the results of the case studies applied to this model are presented and discussed. Two case studies are conducted: a SOFC operating with humidified hydrogen and a DIR-SOFC operating with a gas mixture.

\subsubsection{Validation}

For validating the model, the results of the benchmark test, which was conducted in a workshop organized by International Energy Agency in 1994 [107], is used. In this benchmark test, nine institutions modeled planar SOFC with the same operating data. These institutions are: KFA-Julich (Germany), ISTIC, University of Genova (Italy), ECN Petten (Holland), Riso, National Laboratory (Denmark), Eniricerche (Italy), Dornier

(Germany), Statoil (Norway), Ife-Kjeller (Norway), and Siemens (Germany). There were 
two benchmark tests: benchmark test- 1 and benchmark test- 2 . In the first test, a SOFC operating with $90 \% \mathrm{H}_{2}$ and $10 \% \mathrm{H}_{2} \mathrm{O}$ was modeled. In the second test, a DIR-SOFC operating with $17.1 \% \mathrm{CH}_{4}, 26.26 \% \mathrm{H}_{2}, 2.94 \% \mathrm{CO}, 4.36 \% \mathrm{CO}_{2}$, and $49.34 \% \mathrm{H}_{2} \mathrm{O}$ was modeled. The main assumption used in the test was to accept each of the polarizations in the anode and cathode as equal to the ohmic loss of the electrolyte. These models were developed under steady-state conditions. The input data for the benchmark tests are given in Table 4.5. In another study, Braun [108] developed a steady state model using the same input data and assumptions with the benchmark test.

Table 4.5: Input data used in the benchmark tests.

\begin{tabular}{|l|l|}
\hline Cell geometry & $100 \times 100$ \\
\hline Active area [mm $\left.{ }^{2}\right]$ & $50 \times 10^{-6}$ \\
Anode thickness [m] & $50 \times 10^{-6}$ \\
Cathode thickness [m] & $150 \times 10^{-6}$ \\
Electrolyte thickness [m] & 3 \\
Channel width [mm] & 1 \\
Channel height [mm] & 2.42 \\
Rib width [mm] & 2.5 \\
Total thickness (with ribs) [mm] & \\
\hline Operating parameters & 1173 \\
\hline Temperature at the fuel channel inlet [K] & 1173 \\
Temperature at the air channel inlet [K] & 100 \\
Pressure of the cell [kPa] & 7 \\
Excess air coefficient & 0.85 \\
Fuel utilization & 3000 \\
Mean current density [A/m $\left.{ }^{2}\right]$ & $21 \% \mathrm{O}_{2}, 79 \% \mathrm{~N}_{2}$ \\
Gas composition at the air channel inlet & $90 \% \mathrm{H}_{2}, 10 \% \mathrm{H}_{2} \mathrm{O}(\mathrm{Test} 1)$ \\
Gas composition at the fuel channel inlet & $17.1 \% \mathrm{CH}_{4}, 26.26 \% \mathrm{H}_{2}, 2.94 \% \mathrm{CO}$, \\
& $4.36 \% \mathrm{CO}_{2}$, and $49.34 \% \mathrm{H}_{2} \mathrm{O}(\mathrm{Test} 2)$ \\
\hline
\end{tabular}

Source: Achenbach [107]. 
In this study two models, using different assumptions, have been developed for a co-flow and counter-flow SOFC. A transient heat transfer model was first developed using the same assumption for polarizations as the benchmark tests. This model is called ModelV1. In the second model, the assumption used in Model-V1 is altered in that different analytical equations are considered for ohmic, activation and concentration polarizations, as given in Chapter 3.3. This model is called Model-V2. There are some differences in the input and output parameters of this model and the benchmark test. Unlike the input parameters used in the benchmark test, fuel utilization and mean current density are taken as output parameters, but the cell voltage and Reynolds number are taken as input parameters in the present models. Since the results of the benchmark tests are given in steady state condition, the model is validated for this condition.

\subsubsection{Case studies}

For case studies, the same operating conditions with the benchmark tests are selected for comparison purpose. Transient and steady state behaviors of the SOFC are investigated.

\subsubsection{Case study-1: SOFC operating with humidified hydrogen}

The transient heat transfer model is simulated for the benchmark test-1 conditions [107]. A nodal analysis is first carried out to find the number of nodes that will make the results independent from the grid size. Then, the results are validated using those from the benchmark test and Braun's thesis. Heat-up and start-up simulations are done to find the change of output parameters with time. Finally, several parametric studies including the

effect of mass flow rate of air at the heat-up stage, Reynolds number, excess air 
coefficient, current density, and thicknesses of air and fuel channels on the output parameters are investigated.

\subsection{Nodal Analysis}

A nodal analysis is first carried out to find the number of nodes that will make the results independent from the grid size. In Figures 4.30-4.32, some of the results for the nodal analysis for the heat-up period are given. In these figures, 15 nodes in y direction are taken and number of nodes in $\mathrm{x}$ direction is varied. Mass flow rate of air is taken as $0.0712 \mathrm{~g} / \mathrm{s}$ and $\Delta \mathrm{t}$ is taken as $1 \mathrm{~s}$. From these figures, we can see that considering 375 nodes is sufficient to obtain grid-independent results. It should be noted that since the final temperature distribution of heat-up stage is used as the initial temperature distribution of the start-up stage, the number of nodes considered for heat-up and start-up stages should be equal to each other. In other words, if we find that the number of nodes for the start-up stage that will make the results independent from the grid size is higher than those for the heat-up stage, then the number of nodes for the heat-up stage should be adjusted accordingly. Effect of $\Delta t$ and $\Delta y$ on the results is also investigated. It is found that they do not have a significant effect on the results.

A nodal analysis is done for the start-up period of the co-flow humidified hydrogen fed SOFC for the Model-V1. The Reynolds number is taken as 0.67 to obtain consistent results with the benchmark test- 1 for the given fuel utilization and the average current density. Some of the results for the start-up period are given in Figures 4.33-4.35. It can be seen from these figures that current density distribution is more sensitive to the grid 
size. From these figures, it is found that we should take the number of nodes in the spatial domain as 750 nodes. Hence, the calculations are done for both of the stages, i.e. heat-up and start-up stages, for this number of nodes.

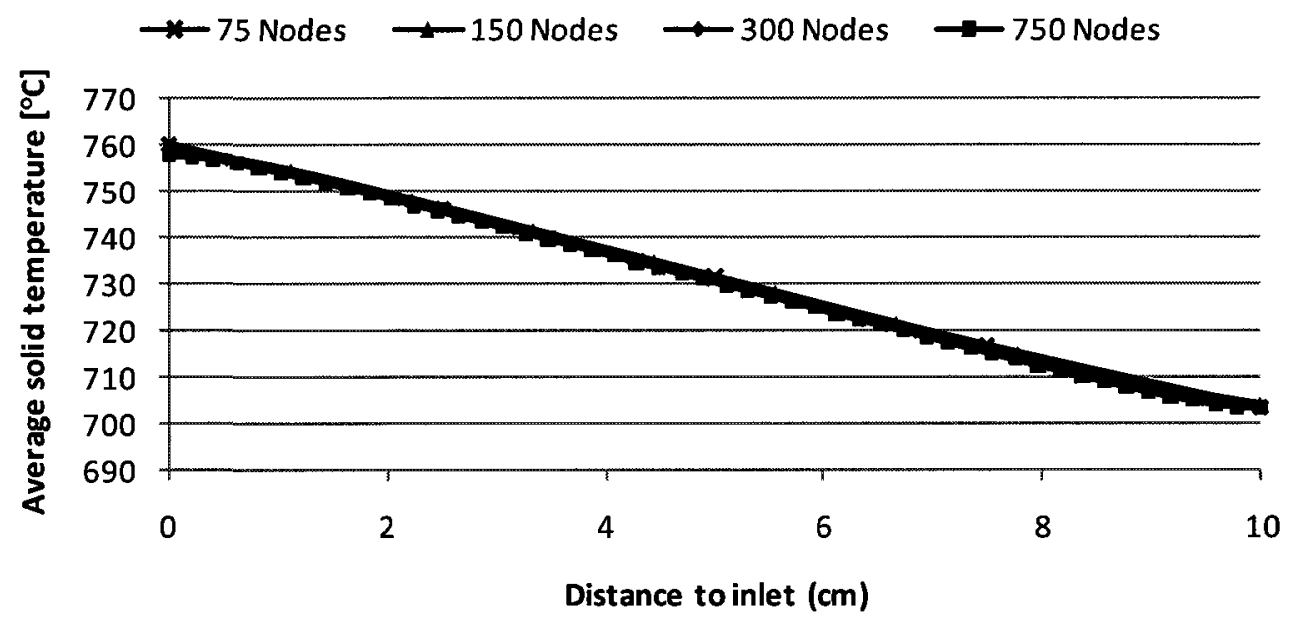

Figure 4.30: Sensitivity of number of nodes in the spatial domain to average solid temperature.

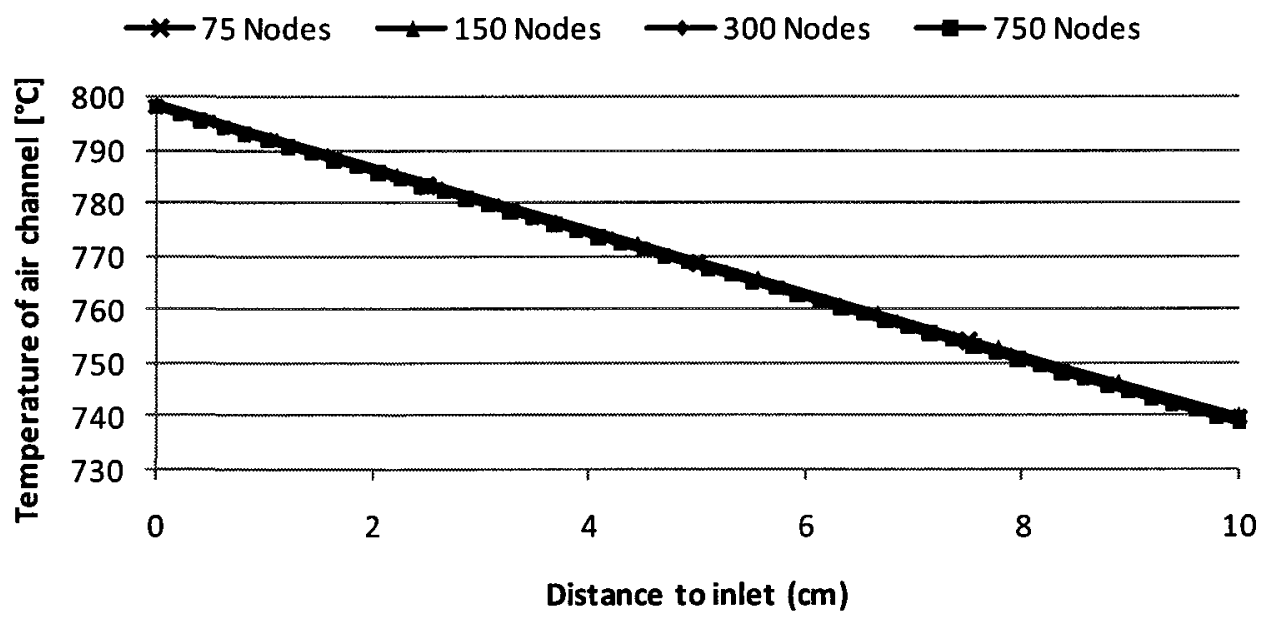

Figure 4.31: Sensitivity of number of nodes in the spatial domain to temperature of air channel. 


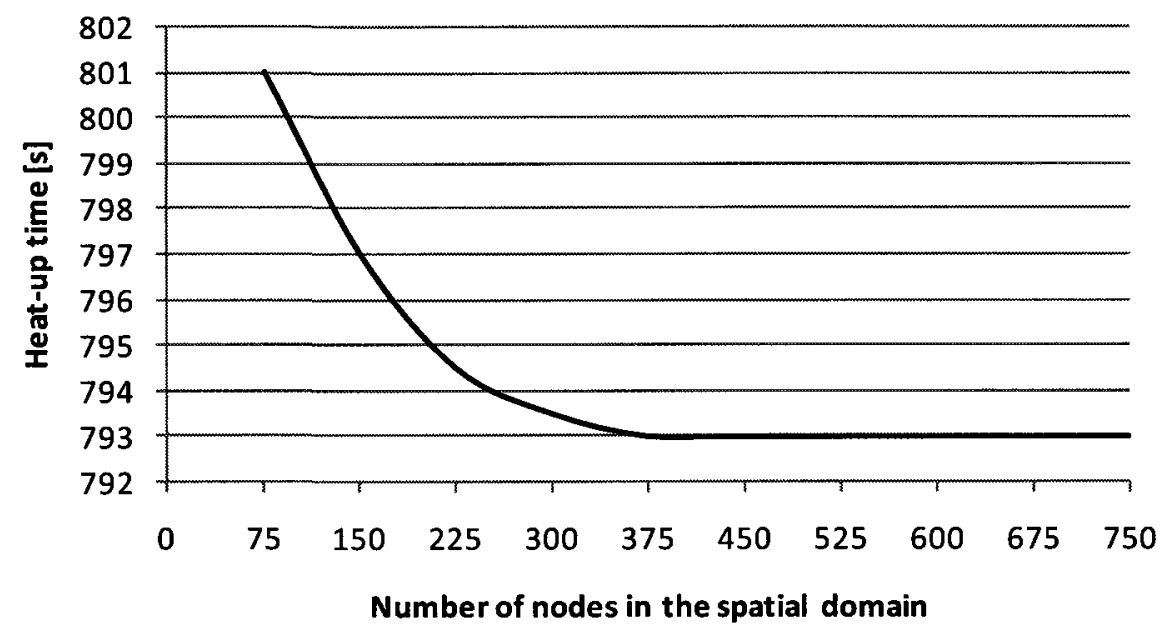

Figure 4.32: Sensitivity of number of nodes in the spatial domain to the heat-up time.

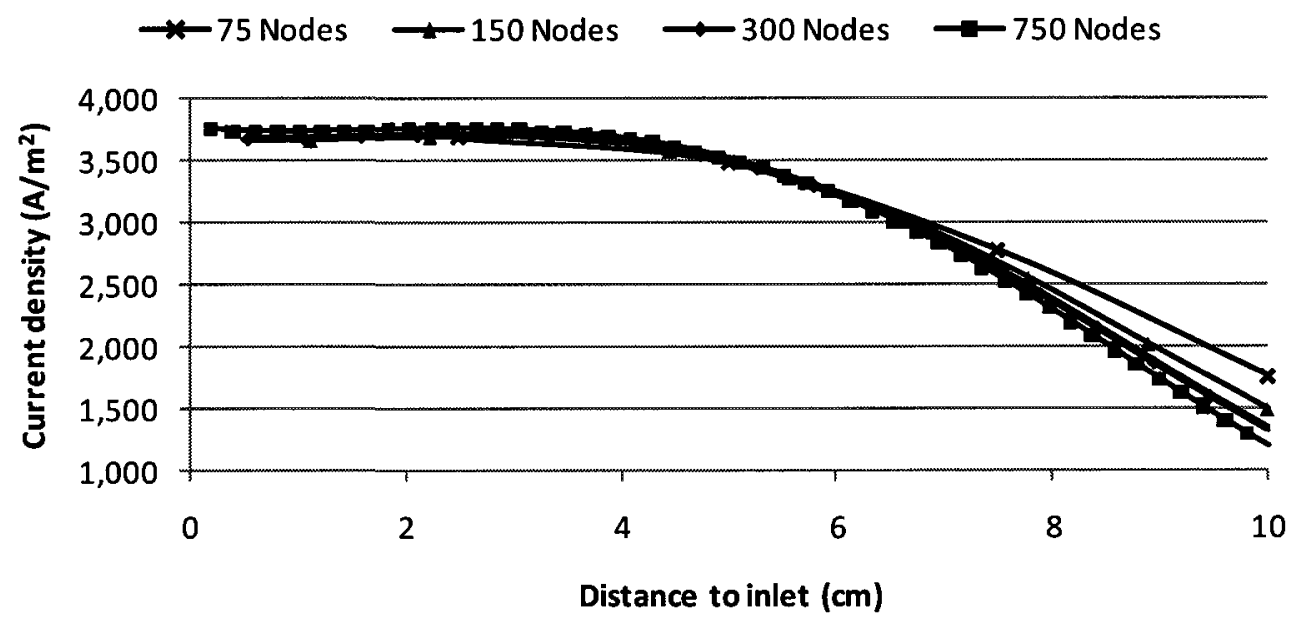

Figure 4.33: Sensitivity of nodes in spatial domain to current density. 


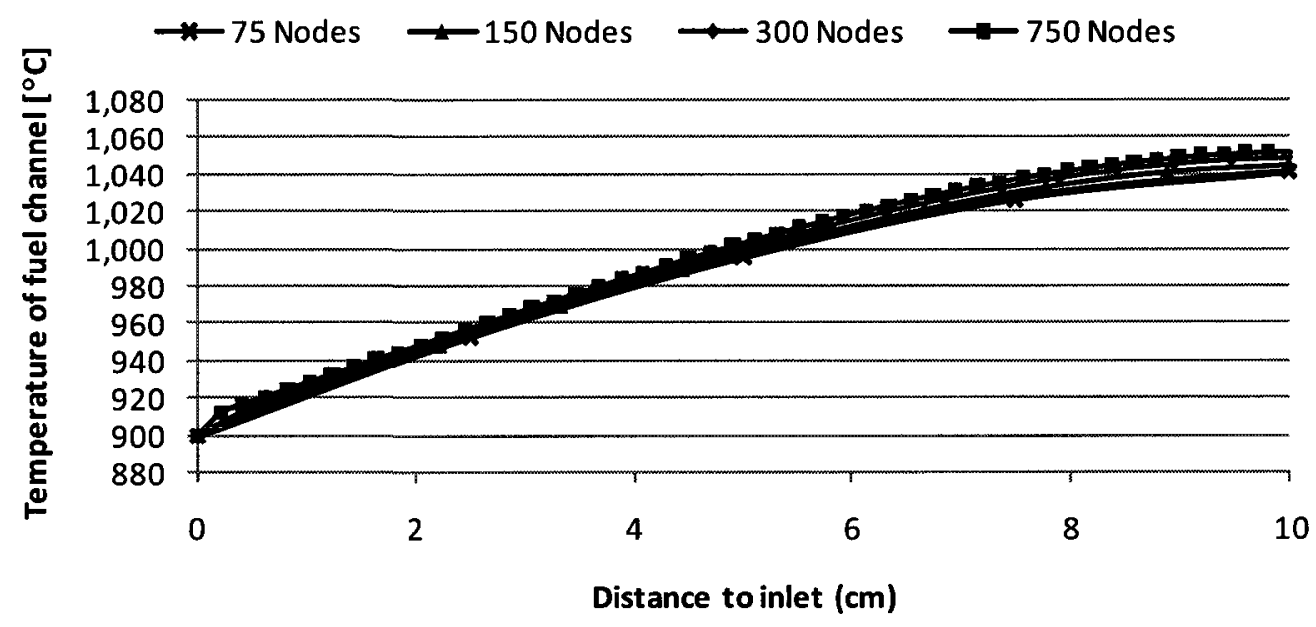

Figure 4.34: Sensitivity of nodes in spatial domain to temperature of fuel channel.

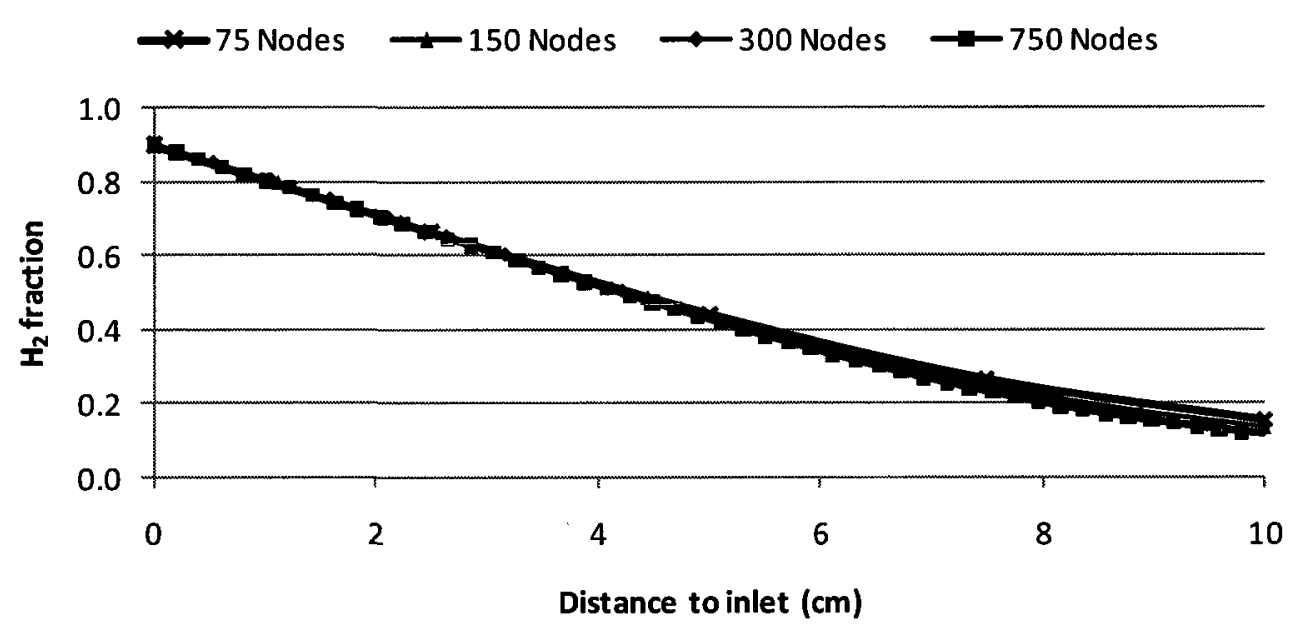

Figure 4.35: Sensitivity of nodes in spatial domain to molar fraction of hydrogen.

\subsection{Validation}

For validating the present models, the input parameters were first calibrated. As discussed before, cell voltage is considered as an input parameter in the present models and not in the benchmark tests. The results for the cell voltage for the benchmark test- 1 are given in 
Table 4.6. From these results, the cell voltage was chosen as $0.7 \mathrm{~V}$ for the co-flow and 0.71 for the counter-flow case. Average current density and fuel utilization are input parameters in the benchmark tests and their values are as $0.3 \mathrm{~A} / \mathrm{cm}^{2}$ and 0.85 , respectively. To get results closer to these values, the Reynolds number is found to be 0.67 in Model-V1. The same value for Reynolds number is used in Model-V2.

Table 4.6: Cell voltage for the benchmark test-1.

\begin{tabular}{|l|l|l|}
\hline Company/Institution & Co-flow [V] & Counter-flow [V] \\
\hline Dornier, D & 0.684 & 0.689 \\
\hline ECN Petten, NL & 0.704 & N.A. \\
\hline Eniricerche, I & 0.722 & 0.730 \\
\hline Inst. For Energiteknikk Kjeller, N & 0.71 & 0.71 \\
\hline KFA-Julich, D & 0.706 & 0.712 \\
\hline Siemens, D & 0.712 & 0.716 \\
\hline Statoil, N & 0.702 & 0.709 \\
\hline Riso, DK & 0.7034 & 0.7101 \\
\hline
\end{tabular}

Source: Achenbach [107].

Maximum and minimum values for the current density, solid temperature and air and fuel channel outlet temperatures are given in Tables 4.7- 4.9, respectively. From Table 4.7, it can be seen that the current density, found by different companies and institutions, is between $1020 \mathrm{~A} / \mathrm{m}^{2}$ and $3956 \mathrm{~A} / \mathrm{m}^{2}$ for the co-flow case, and $1080 \mathrm{~A} / \mathrm{m}^{2}$ and $8970 \mathrm{~A} / \mathrm{m}^{2}$ for the counter-flow case. It can be seen from this table that the results for Model-V1 are between these values. When we take the average of the maximum and minimum current densities found by the companies and institutions that participated in the benchmark test, and compare these average values with the results of Model-V1, it was found that the 
relative error for the maximum current density is $0.78 \%$ and $3.02 \%$, and that for the minimum current density is $7.22 \%$ and $2.64 \%$ for co-flow and counter-flow cases, respectively. The same procedure is followed for the solid temperature and air and fuel channel outlet temperatures, which are given in Tables 4.8 and 4.9 , respectively. It was found that only the maximum solid temperature for the counter-flow case is not in the range given in Table 4.8. It is $0.57 \%$ lower than the bottom limit for the maximum solid temperature. This result is mainly due to the difference in modeling between Model-V1 and the benchmark test. In Model-V1 for counter-flow configuration, the outlet temperature for the fuel channel and the inlet temperature for the air channel are fixed to obtain a uniform temperature distribution. The inlet temperature of the fuel channel and the outlet temperature for the air channel were calculated. However, it is not clear how the inlet and outlet temperatures for the gas channels were calculated in the models by the companies and institutions that participated in the benchmark test. For Model-V1, it was found that the relative error for the maximum solid temperature is $1.74 \%$ and $2.00 \%$, and that for the minimum solid temperature it is $2.29 \%$ and $0.59 \%$ for co-flow and counterflow cases, respectively. For the same model, the results show that the relative error for the air channel outlet temperature is $1.40 \%$ and $2.26 \%$, and that for the fuel channel outlet temperature is $1.58 \%$ and $1.14 \%$ for the co-flow and counter-flow cases, respectively. It should be noted in the comparison of air and fuel channel outlet temperatures with Model-V1, the results of Siemens are neglected. It is understood from Table 4.9 that Siemens chose inlet temperatures of air and fuel channels as $900{ }^{\circ} \mathrm{C}$ for the counter-flow case, which is not the case in the models developed by the author or the other institutions and companies. 
Table 4.7: Validation of maximum and minimum values of current density.

\begin{tabular}{|l|l|l|}
\hline Company/Institution & $\begin{array}{c}\text { Co-flow } \\
(\mathrm{max} / \mathrm{min})\left(\mathrm{A} / \mathrm{m}^{2}\right)\end{array}$ & $\begin{array}{c}\text { Counter-flow } \\
(\mathrm{max} / \mathrm{min})\left(\mathrm{A} / \mathrm{m}^{2}\right)\end{array}$ \\
\hline Dornier, D & $3636 / 1686$ & $7192 / 1297$ \\
\hline ECN Petten, NL & $3614 / 1211$ & N.A. \\
\hline Eniricerche, I & $3840 / 1020$ & $8970 / 1080$ \\
\hline Inst. For Energiteknikk Kjeller, N & $3933 / 1191$ & $7862 / 1113$ \\
\hline KFA-Julich, D & $3725 / 1237$ & $7910 / 1163$ \\
\hline Siemens, D & $3863 / 1236$ & $8513 / 1135$ \\
\hline Statoil, N & $3956 / 1366$ & $7391 / 1235$ \\
\hline Riso, DK & $3739 / 1296$ & $7107 / 1187$ \\
\hline Braun's Thesis & $3799 / 1211$ & $7393 / 1152$ \\
\hline Model-V1 & $3760 / 1187$ & $7564 / 1202$ \\
\hline Model-V2 & $5175 / 1175$ & $5530 / 1586$ \\
\hline
\end{tabular}

Source (data for company/institution): Achenbach [107].

Table 4.8: Validation of maximum and minimum values of solid temperature.

\begin{tabular}{|l|l|l|}
\hline Company/Institution & $\begin{array}{c}\text { Co-flow } \\
(\mathrm{max} / \mathrm{min})\left({ }^{\circ} \mathrm{C}\right)\end{array}$ & $\begin{array}{c}\text { Counter-flow } \\
(\mathrm{max} / \mathrm{min})\left({ }^{\circ} \mathrm{C}\right)\end{array}$ \\
\hline Dornier, D & $1070 / 928$ & $1085 / 914$ \\
\hline ECN Petten, NL & $1082 / 899$ & N.A. \\
\hline Eniricerche, I & $1069 / 916$ & $1083 / 906$ \\
\hline Inst. For Energiteknikk Kjeller, N & $1058 / 930$ & $1084 / 912$ \\
\hline KFA-Julich, D & $1059 / 913$ & $1073 / 906$ \\
\hline Siemens, D & $1049 / 909$ & $1062 / 904$ \\
\hline Statoil, N & $1098 / 970$ & $1082 / 913$ \\
\hline Riso, DK & $1061 / 924$ & $1075 / 910$ \\
\hline Braun's Thesis & $1059 / 924$ & $1073 / 910$ \\
\hline Model-V1 & $1049 / 903$ & $1056 / 904$ \\
\hline Model-V2 & $1043 / 907$ & $1054 / 906$ \\
\hline Soure $(d-f o r c t$
\end{tabular}

Source (data for company/institution): Achenbach [107]. 
Table 4.9: Validation of air and fuel channel outlet temperatures.

\begin{tabular}{|l|l|l|}
\hline Company/Institution & $\begin{array}{c}\text { Co-flow } \\
\text { (air/fuel) }\left({ }^{\circ} \mathrm{C}\right)\end{array}$ & $\begin{array}{c}\text { Counter-flow } \\
\text { (air/fuel) }\left({ }^{\circ} \mathrm{C}\right)\end{array}$ \\
\hline Dornier, D & $1068 / 1070$ & $1080 / 914$ \\
\hline ECN Petten, NL & $1082 / 1082$ & N.A. \\
\hline Eniricerche, I & $1068 / 1068$ & $1080 / 906$ \\
\hline Inst. For Energiteknikk Kjeller, N & $1055 / 1058$ & $1073 / 912$ \\
\hline KFA-Julich, D & $1059 / 1059$ & $1070 / 906$ \\
\hline Siemens, D & $1048 / 1048$ & $1061 / 1064$ \\
\hline Statoil, N & $1067 / 1067$ & $1082 / 914$ \\
\hline Riso, DK & $1059 / 1061$ & $1070 / 910$ \\
\hline Braun's Thesis & $1058 / 1059$ & $1068 / 910$ \\
\hline Model-V1 & $1048 / 1047$ & $1051 / 900$ \\
\hline Model-V2 & $1042 / 1043$ & $1051 / 900$ \\
\hline
\end{tabular}

Source (data for company/institution): Achenbach [107].

When the results for Model-V2 are checked from Tables 4.7-4.9, it is seen that except for the current density distribution, the results are comparable with the results of the benchmark test and Model-V1. The difference in the results for current density distribution between Model-V1 and Model-V2 is as expected since the models in the benchmark tests were developed using an assumption on polarizations, as discussed in Section 4.5.1. However, this assumption is not valid today. Detailed correlations have been published on the activation and concentration polarizations in the literature, e.g. [99, 116]. However, the temperature distribution is still comparable for Model-V2 with the benchmark test-1. For example, for Model-V2, the relative error for the maximum solid temperature is found to be $2.32 \%$ and $2.19 \%$, and for the minimum solid temperature it is $1.84 \%$ and $0.37 \%$ for co-flow and counter-flow cases, respectively. Also, for this model, the results show that the relative error for the air channel outlet temperature is 
$1.98 \%$ and $2.26 \%$, and that for the fuel channel outlet temperature is $1.97 \%$ and $1.14 \%$ for the co-flow and counter-flow cases, respectively.

The distributions of current density, fuel channel temperature, and molar hydrogen fraction in the fuel channel, found by using Model-V1 and Model-V2 for the co-flow case, are also validated with the data published by ECN, which is an institute that participated in the benchmark test. This validation is shown in Figures 4.36-4.38. The distributions for the counter-flow case, found by the companies participated in the benchmark test, are not available in the literature, but the distributions found by using the present models, are added to these figures for comparison. As can be seen from Figure 4.36, current density trends for Model-V1, and the model developed by ECN, are similar except that the current density for Model-V1 is slightly higher at the first half of the cell. Model-V2 has a different trend for both co-flow and counter-flow cases because of the different correlations for activation and concentration polarizations in this model. However, when we calculate the average current densities for the Model-V1 and ModelV2, it is found that the values are very comparable with the average current density of the model developed by ECN, which is $0.3 \mathrm{~A} / \mathrm{cm}^{2}$. The average current densities for the coflow case are $0.304 \mathrm{~A} / \mathrm{cm}^{2}$ and $0.294 \mathrm{~A} / \mathrm{cm}^{2}$ for the Model-V1 and Model-V2, respectively; whereas, those for the counter-flow case are $0.299 \mathrm{~A} / \mathrm{cm}^{2}$ and $0.301 \mathrm{~A} / \mathrm{cm}^{2}$ for the Model-V1 and Model-V2, respectively. When we compare the temperature distribution in the fuel channel found by the Model-V1 and Model-V2 with the results of ECN, as shown in Figure 4.37, it can be seen that the trends are similar. The temperature at the fuel channel exit is found to be higher for ECN. However, when we check the 
Table 4.9, it may be seen this temperature is comparatively higher for ECN than for that of the other companies and institutions. From Figure 4.38, it can be seen that molar composition of hydrogen has almost the same trend with ECN.

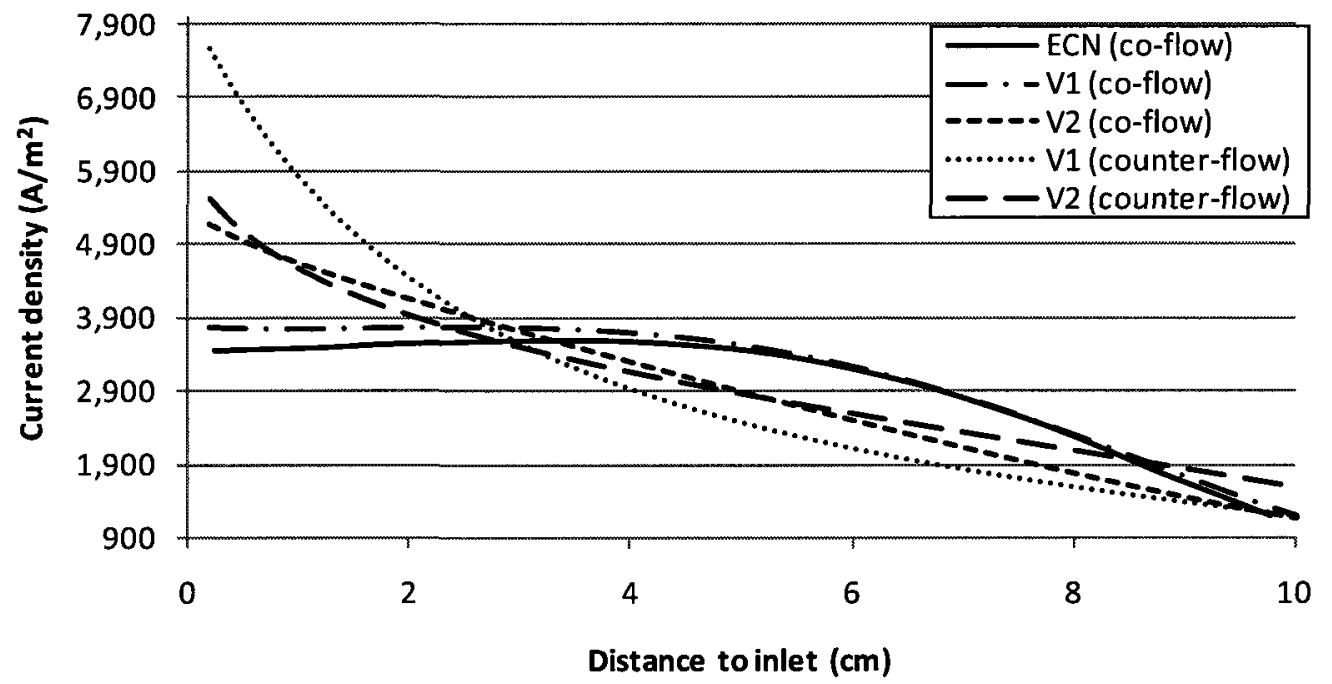

Figure 4.36: Comparison of current density distribution found using the Model-V1 and Model-V2 with the benchmark test (ECN's data [107]).

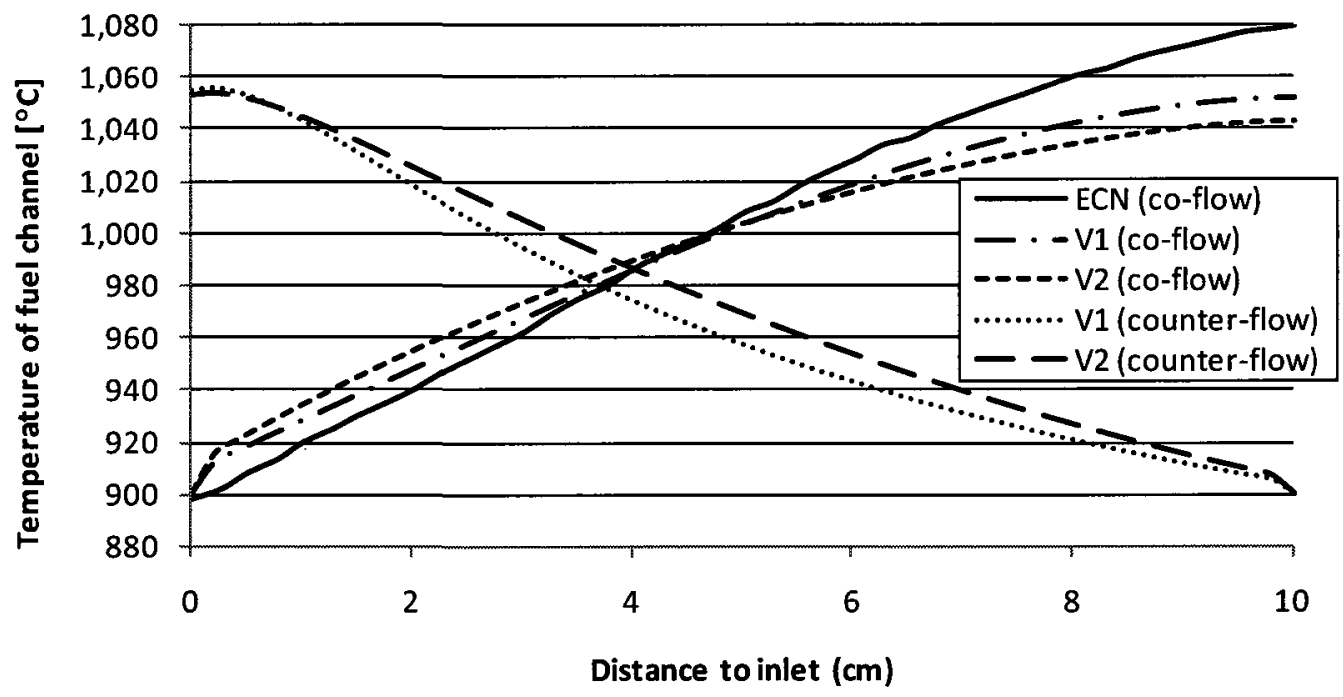

Figure 4.37: Comparison of temperature distribution in the fuel channel found using the present the Model-V1 and Model-V2 with the benchmark test (ECN's data [107]). 


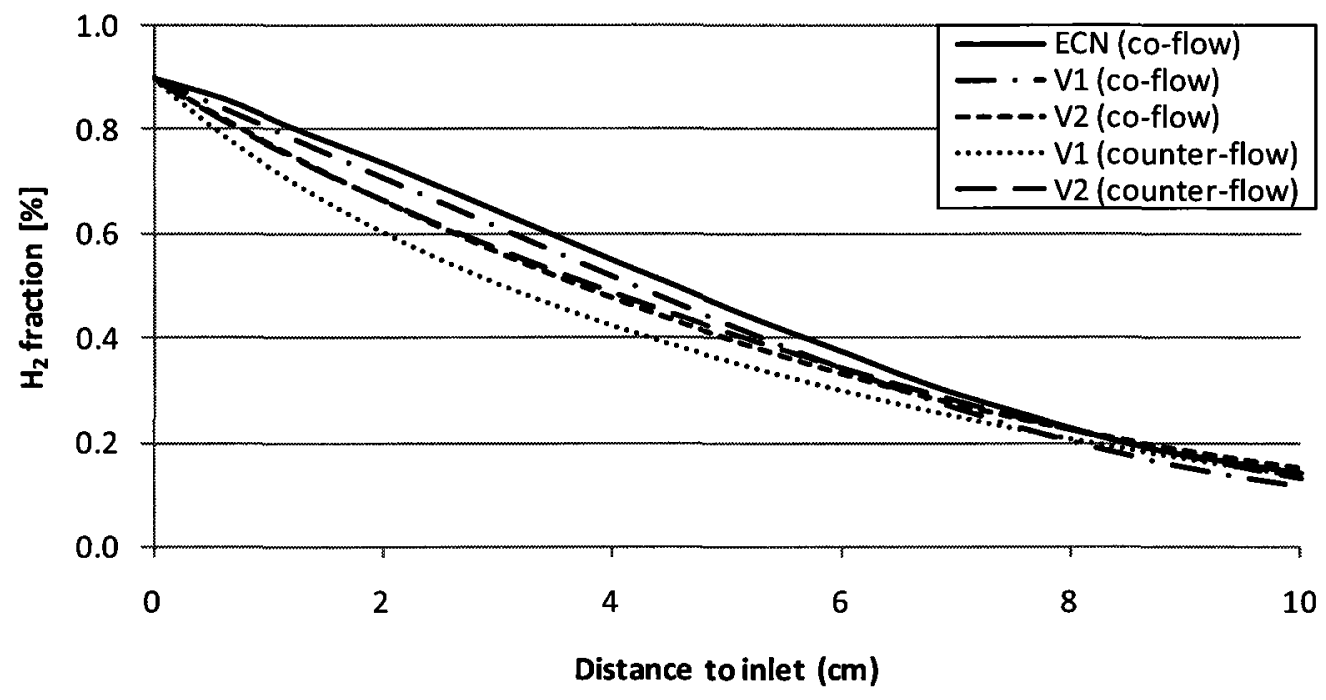

Figure 4.38: Comparison of molar hydrogen fraction distribution in the fuel channel found using the Model-V1 and Model-V2 with the benchmark test (ECN's data [107]).

\subsection{Transient behavior of the cell}

Heat-up and start-up simulations give the change of temperature, fuel utilization, average current density, electrical efficiency, power density, and molar fraction of hydrogen with time. These simulations are conducted for both co-flow and counter-flow cases.

In Figures 4.39 and 4.40, temperature distributions for the co-flow case for Model-V2 are given for the heat-up and start-up stages, respectively. In the heat-up period, temperature at the air channel inlet is controlled due to thermomechanical considerations. This temperature increases by $100{ }^{\circ} \mathrm{C}$ more than the minimum solid temperature at each time step. At this stage, forced convection at the air channel, natural convection at the fuel channel, radiation and conduction between the solid parts affect the temperature distribution. The heat-up period ends when the minimum solid temperature reaches a 
prescribed value which is chosen as $700{ }^{\circ} \mathrm{C}$ in this study. At this temperature, the resistivity of the electrolyte, hence the ohmic polarization becomes low enough to produce meaningful amount of power. In Figure 4.39, we can see that the temperature drops in $\mathrm{x}$ and $\mathrm{y}$ directions at the end of heat-up period, i.e. $\mathrm{t}=794 \mathrm{~s}$, are approximately $5.5^{\circ} \mathrm{C} / \mathrm{cm}$ and $11.2{ }^{\circ} \mathrm{C} / \mathrm{cm}$ for an air flow rate of $0.0712 \mathrm{~g} / \mathrm{s}$. In the start-up period, the temperatures at the air and fuel channel inlets are fixed. There is a temperature rise through the channel length because of the heat generation due to polarizations; however some of this heat is carried away by the excess air sent through the air channel. The temperature gradients in $\mathrm{x}$ and $\mathrm{y}$ directions at the end of the start-up period are approximately $13{ }^{\circ} \mathrm{C} / \mathrm{cm}$ and $2.9^{\circ} \mathrm{C} / \mathrm{cm}$, respectively, as shown in Figure 4.40 .

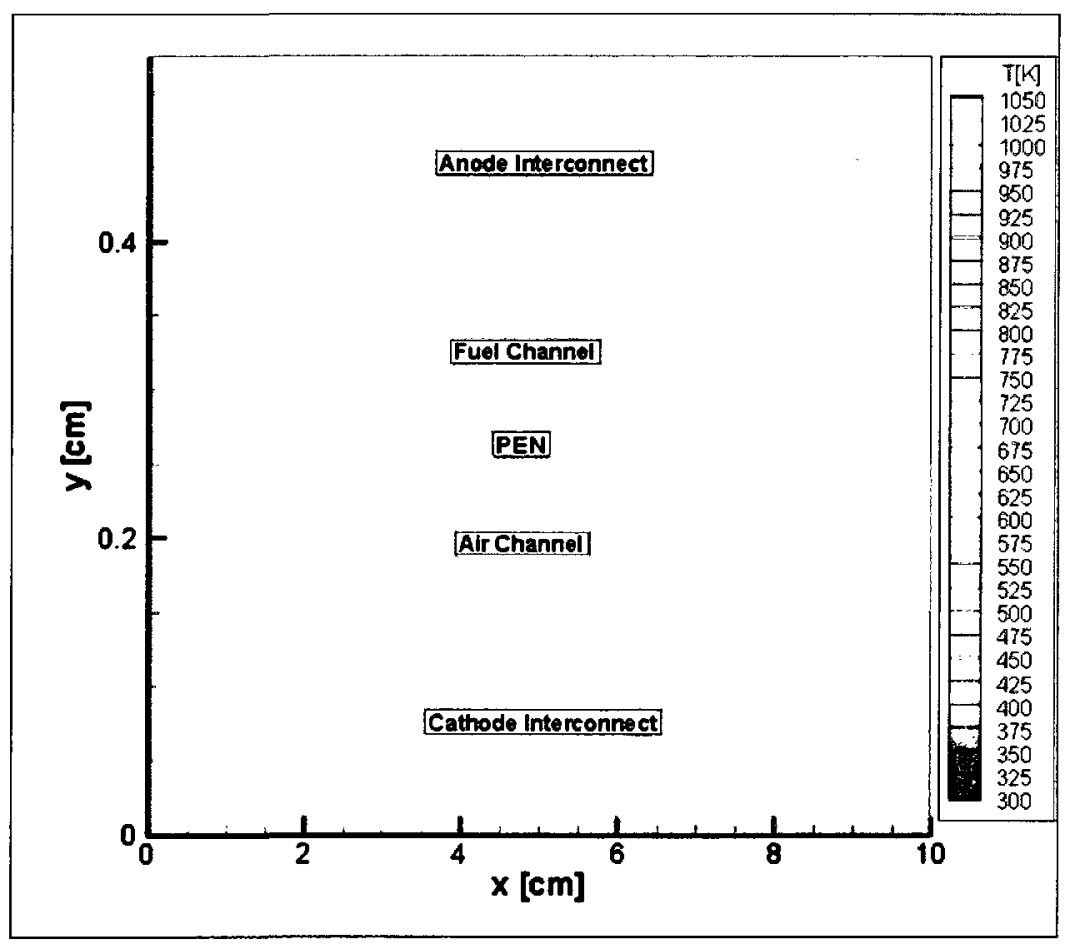

(a) $\mathrm{t}=132 \mathrm{~s}$ 


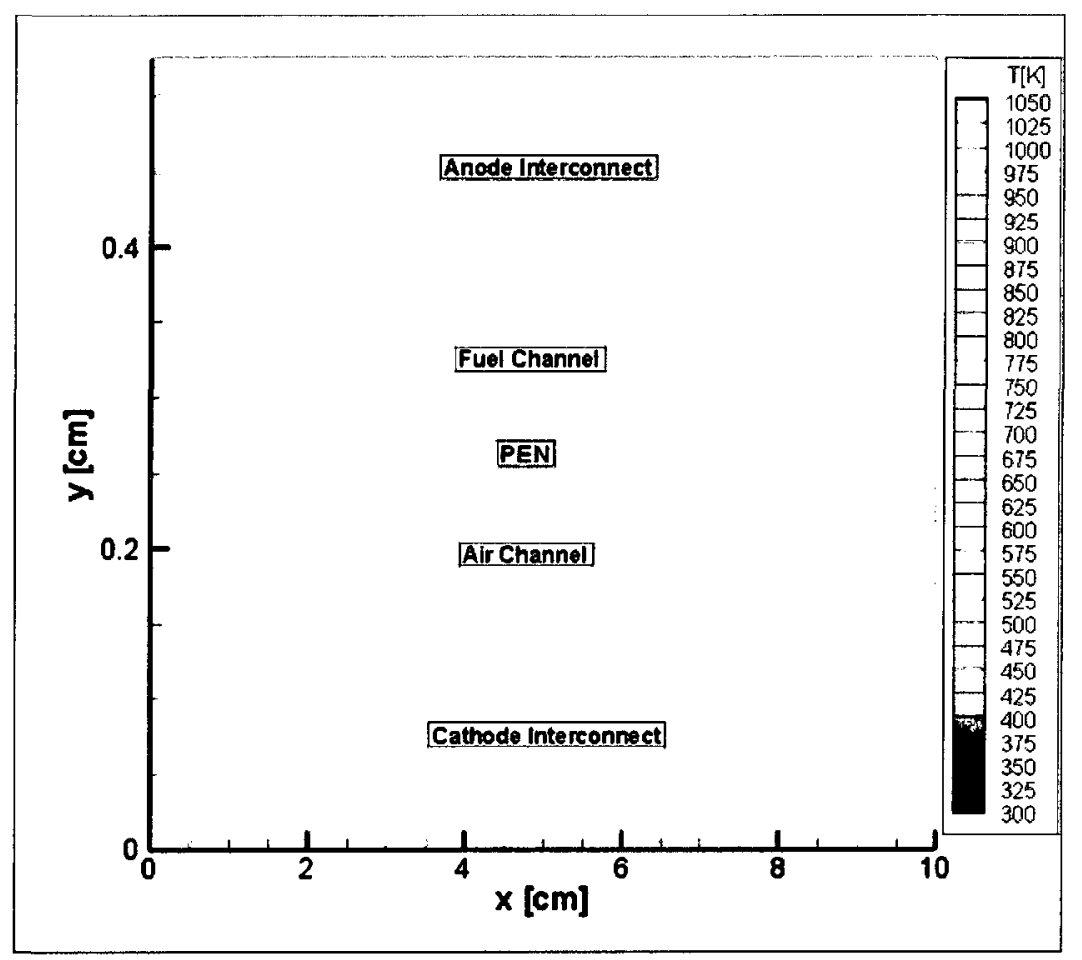

(b) $t=265 \mathrm{~s}$

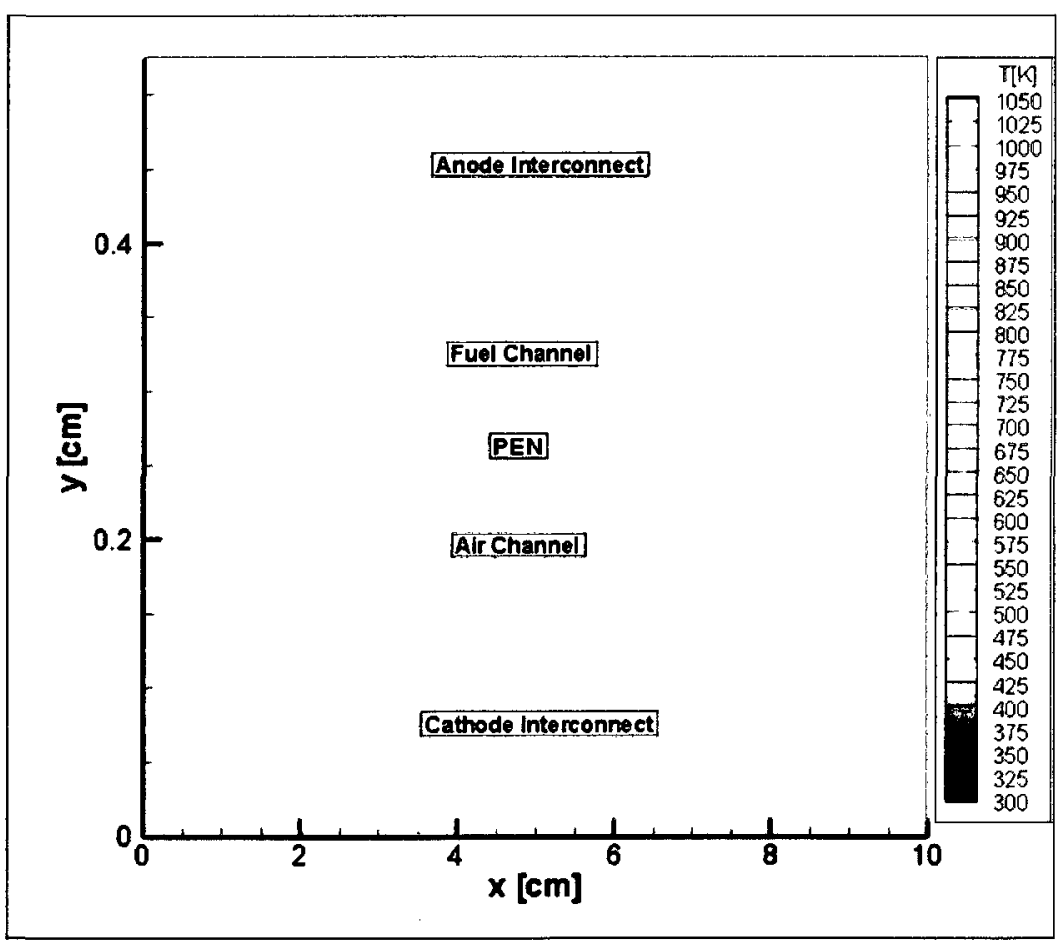

(c) $\mathrm{t}=397 \mathrm{~s}$ 


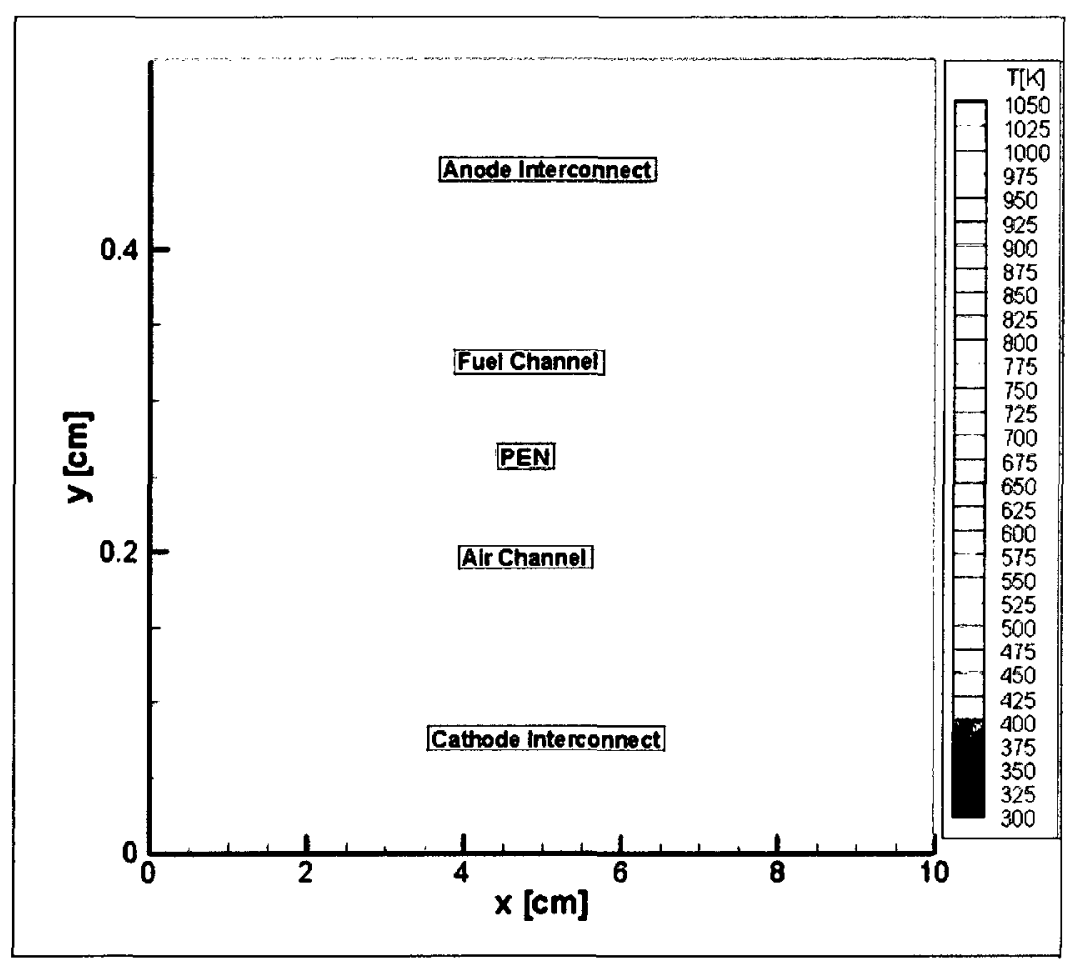

(d) $t=529 \mathrm{~s}$

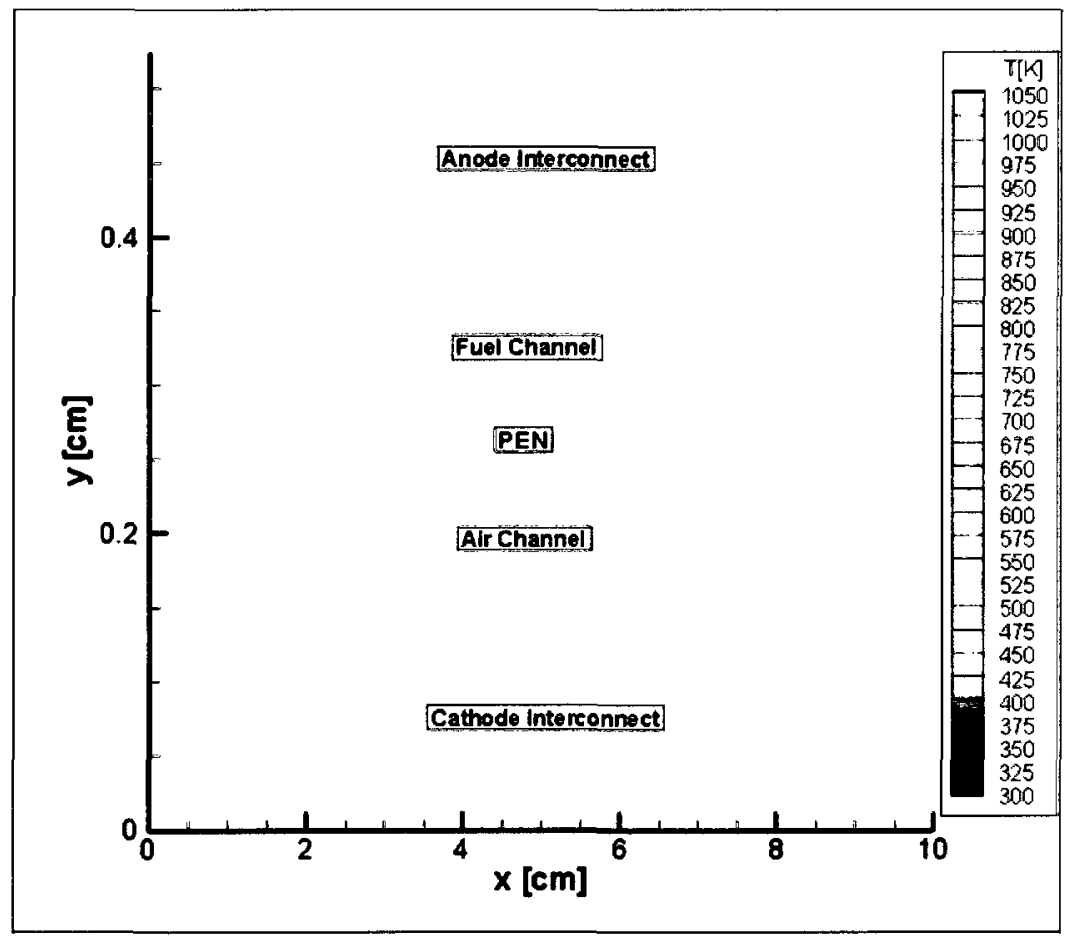

(e) $\mathrm{t}=662 \mathrm{~s}$ 


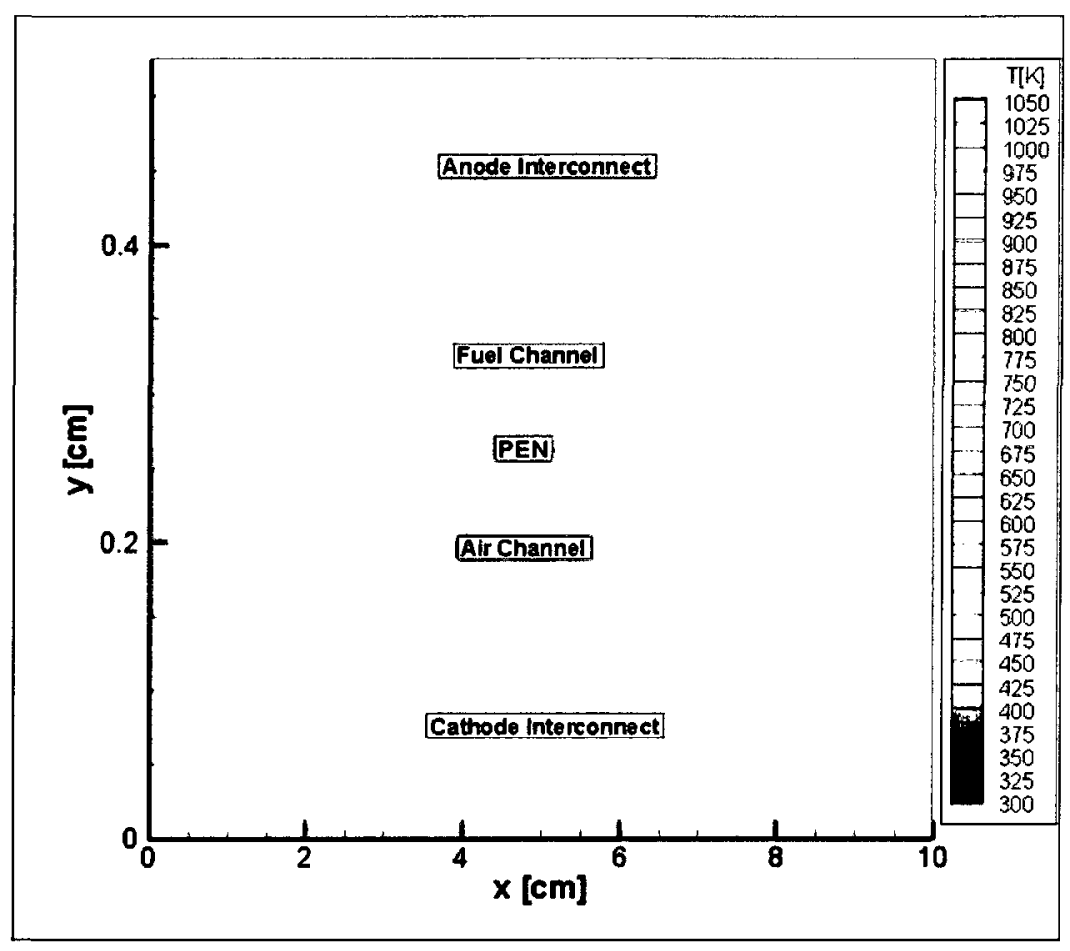

(f) $t=794 s$

Figure 4.39: 2-D temperature distributions during heat-up period (co-flow).

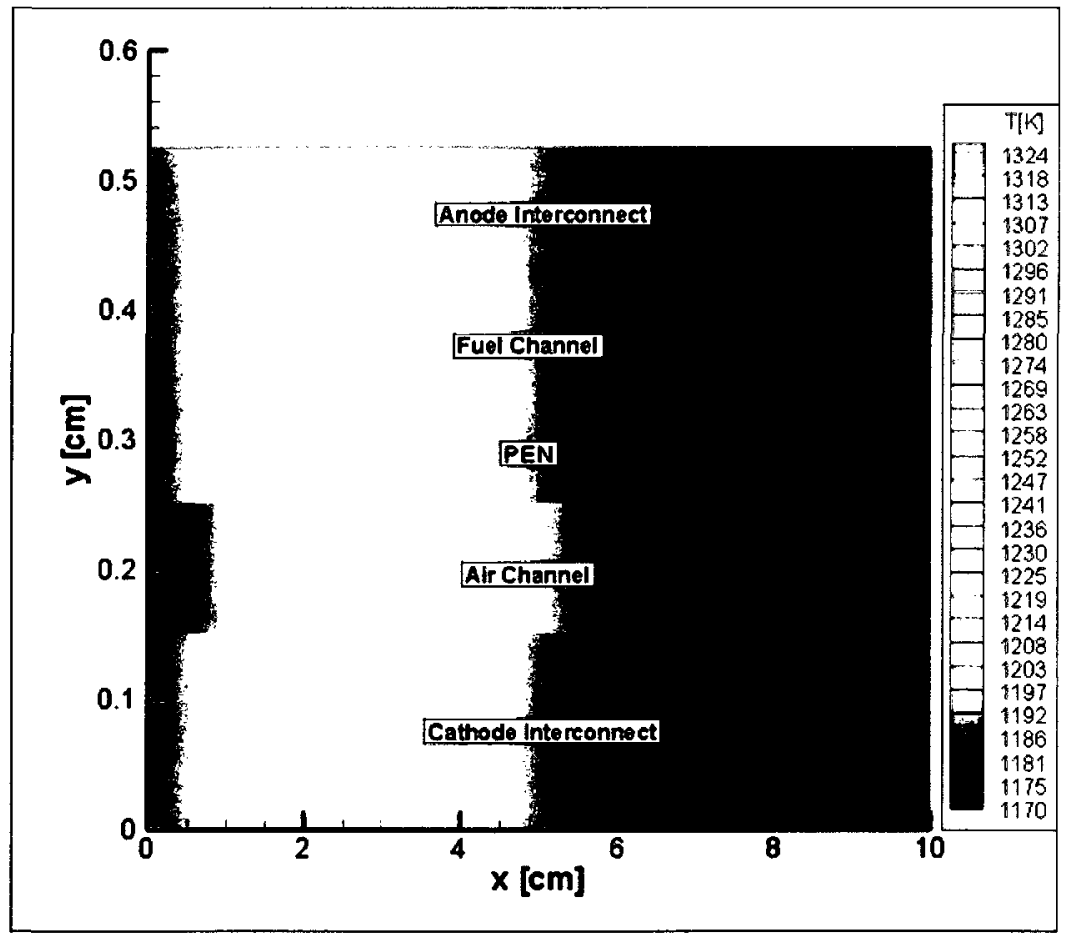

(a) $\mathrm{t}=1253 \mathrm{~s}$ 


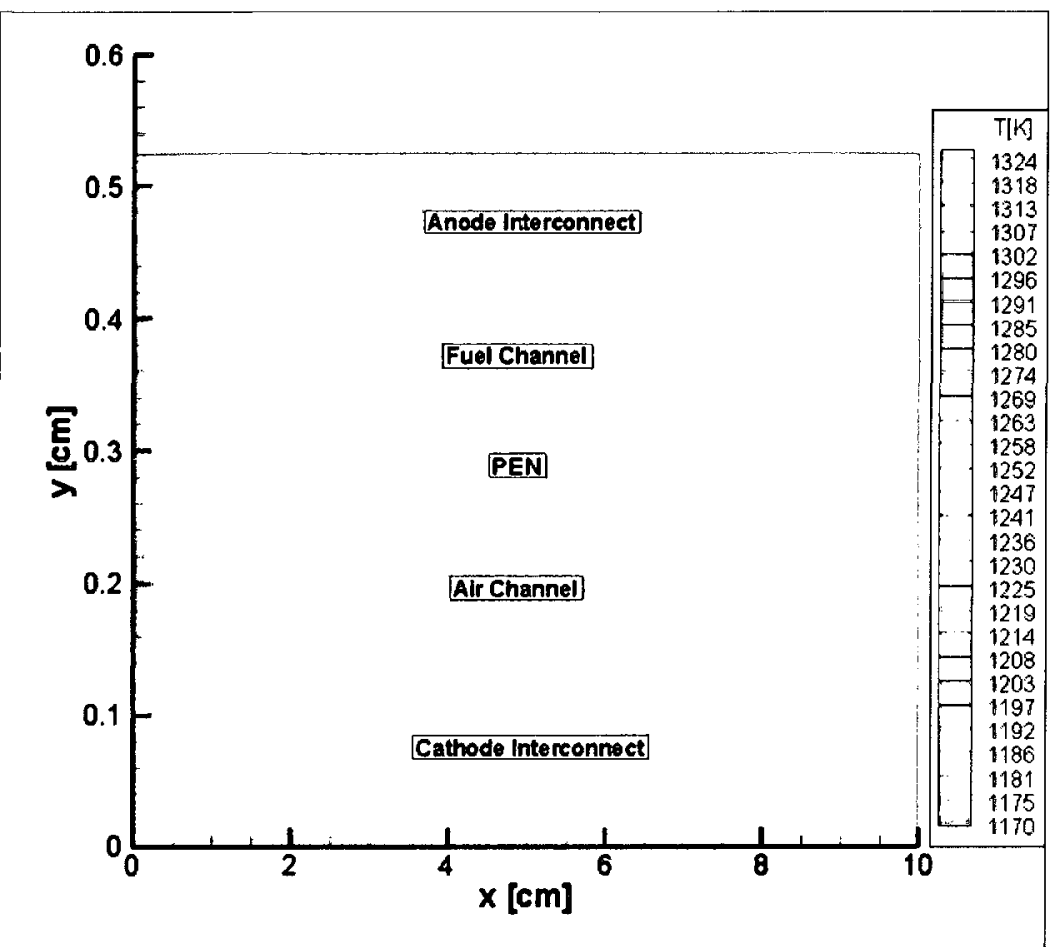

(b) $\mathrm{t}=1503 \mathrm{~s}$

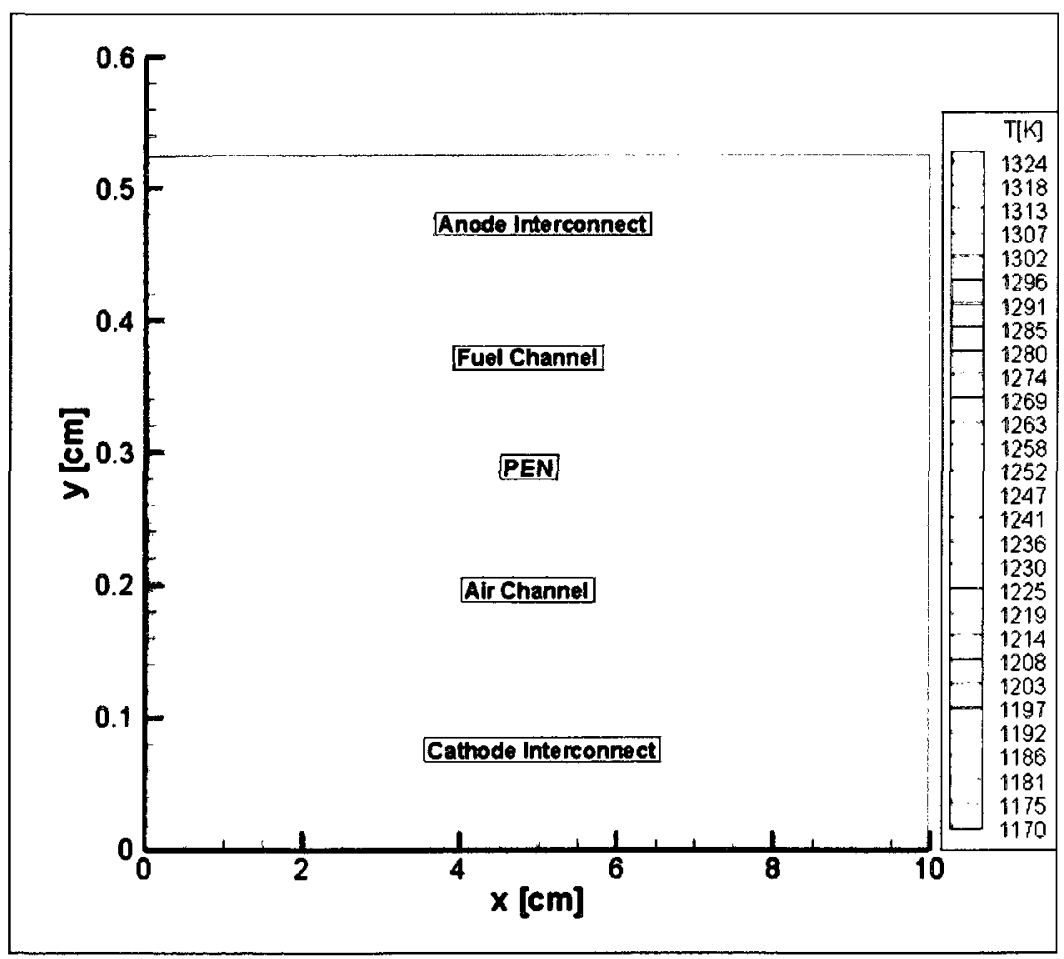

(c) $t=1753 \mathrm{~s}$ 


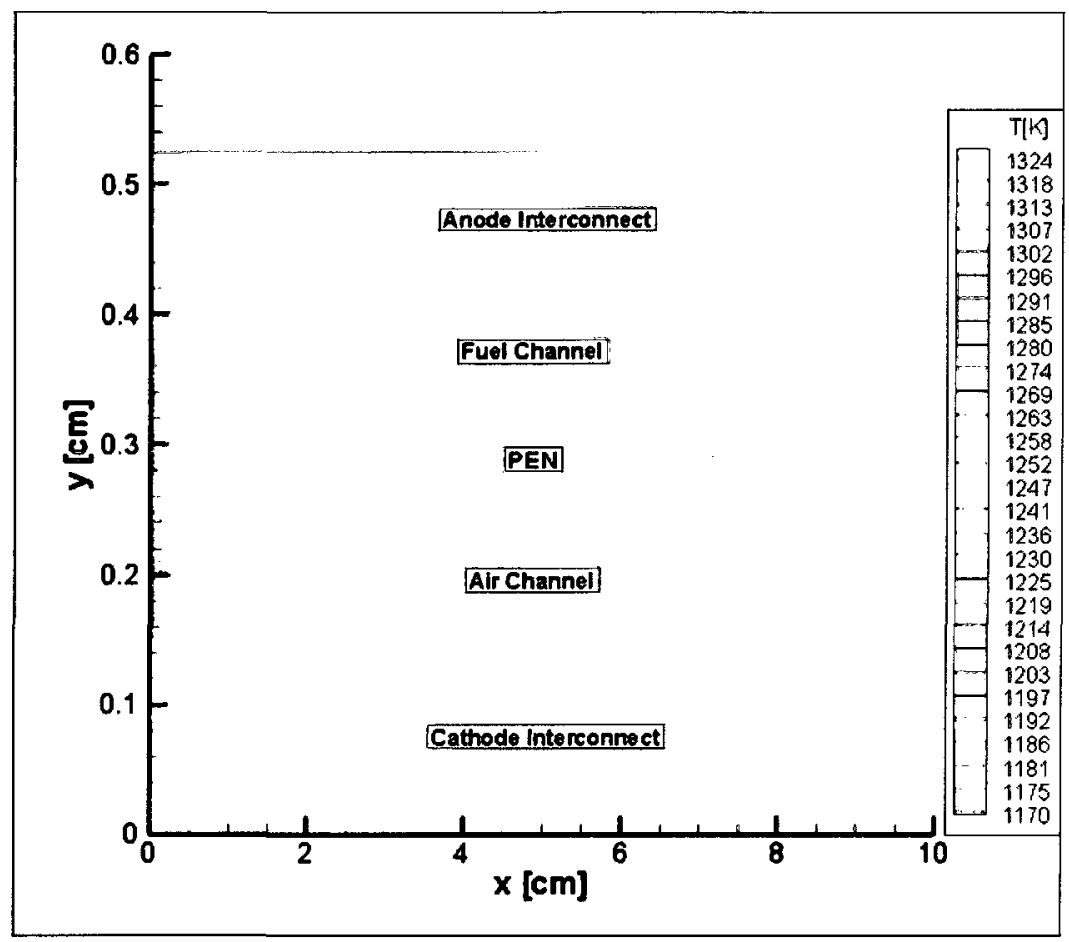

(d) $\mathrm{t}=2003 \mathrm{~s}$

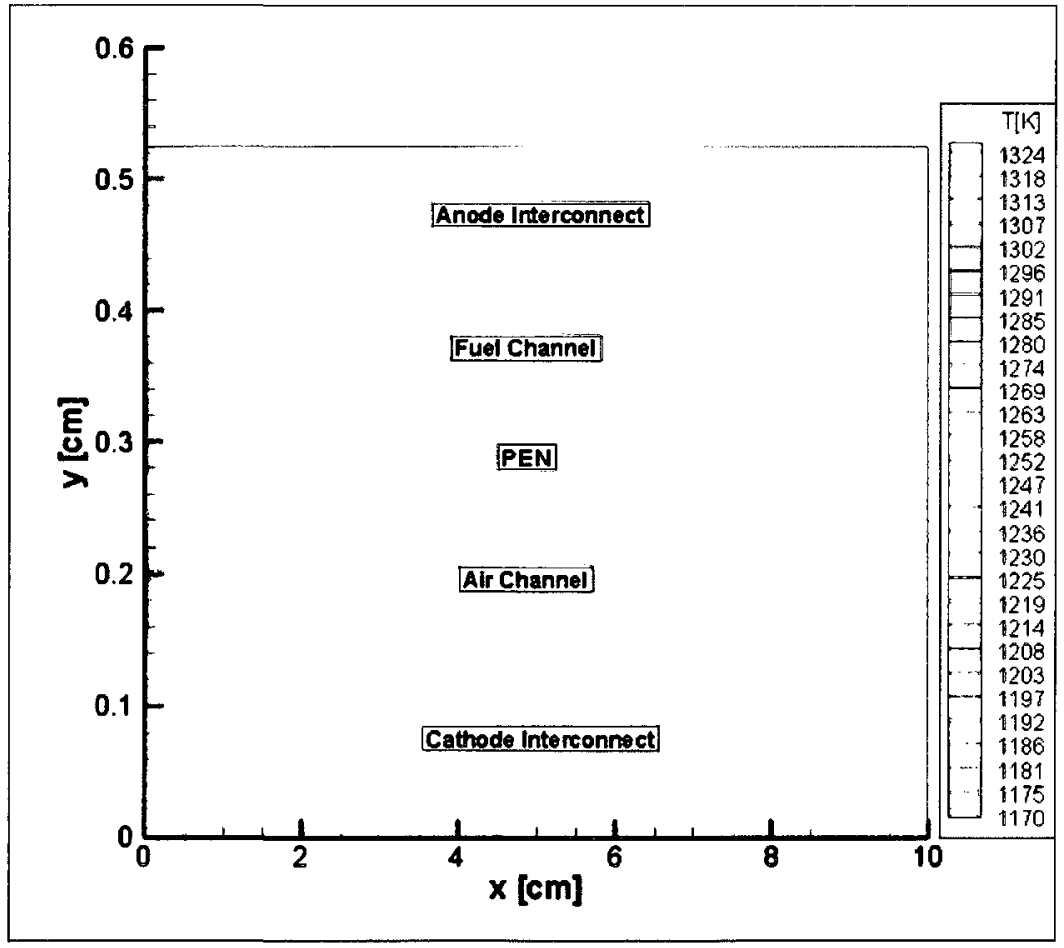

(e) $t=2503 \mathrm{~s}$ 


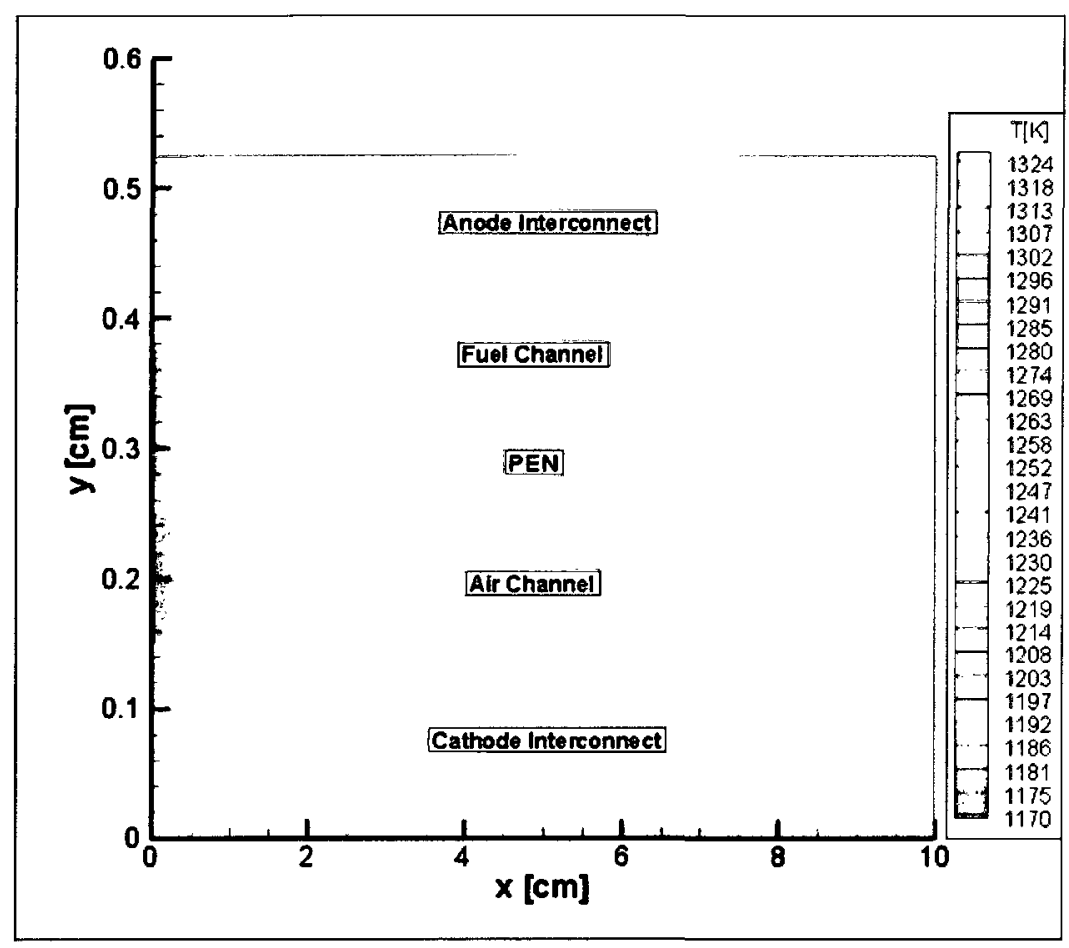

(f) $\mathrm{t}=4143 \mathrm{~s}$

Figure 4.40: 2-D temperature distributions during start-up period (co-flow).

Figures 4.41 and 4.42 show the temperature profiles of the counter-flow case for ModelV2 for several times for the heat-up and start-up stages, respectively. In the counter-flow case, air is sent through the opposite side of the cell compared to the co-flow case. Hence, the temperature distribution shown in the Figure 4.41 is symmetrical to that shown in the Figure 4.39. The temperature gradients in the $\mathrm{x}$ and $\mathrm{y}$ directions at the end of the start-up period are approximately $14.6^{\circ} \mathrm{C} / \mathrm{cm}$ and $1.25^{\circ} \mathrm{C} / \mathrm{cm}$, respectively, as can be seen from Figure 4.42. 


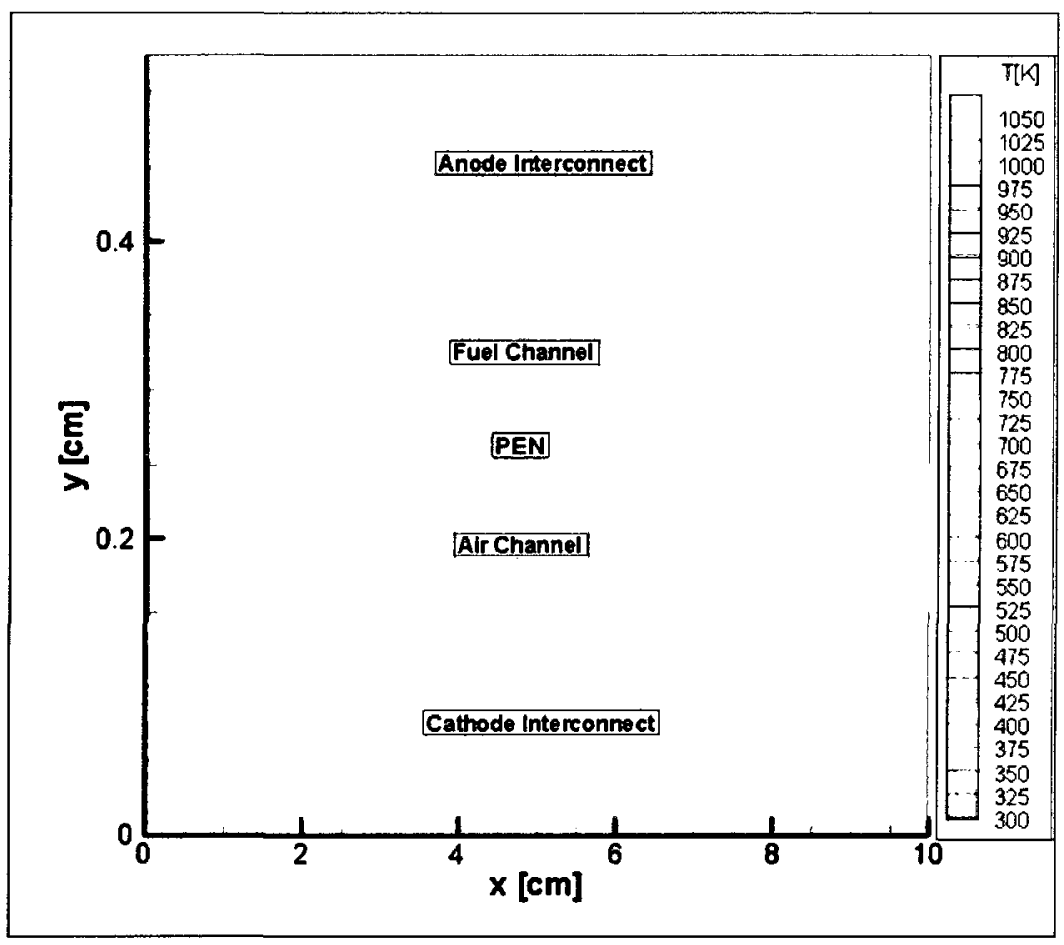

(a) $\mathrm{t}=132 \mathrm{~s}$

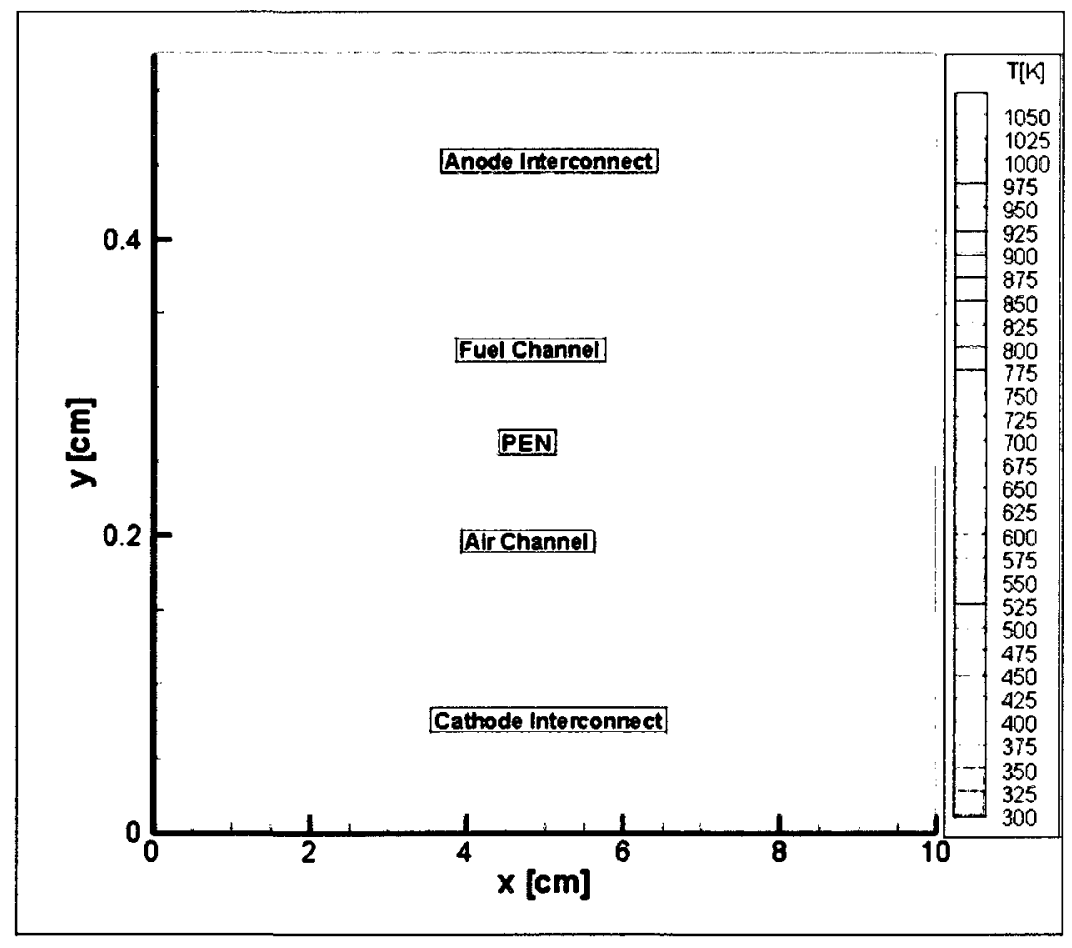

(b) $t=265 \mathrm{~s}$ 


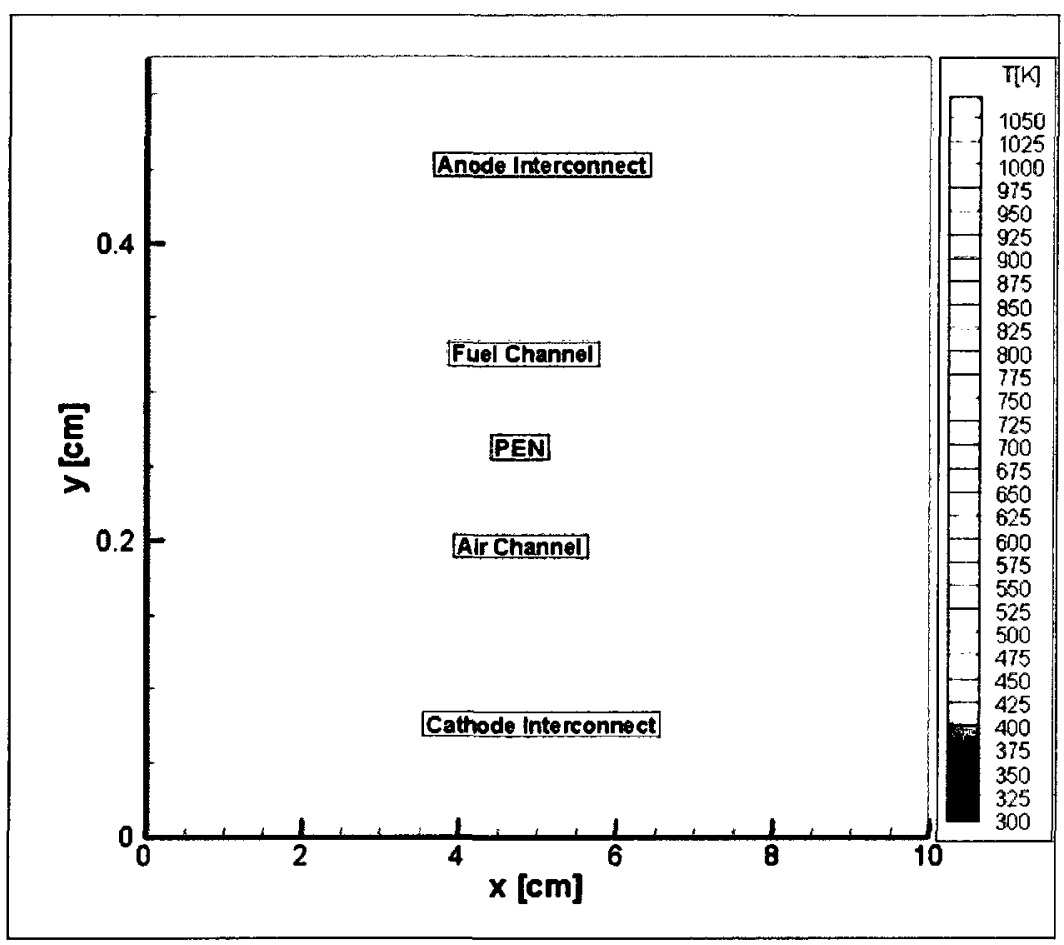

(c) $t=397 \mathrm{~s}$

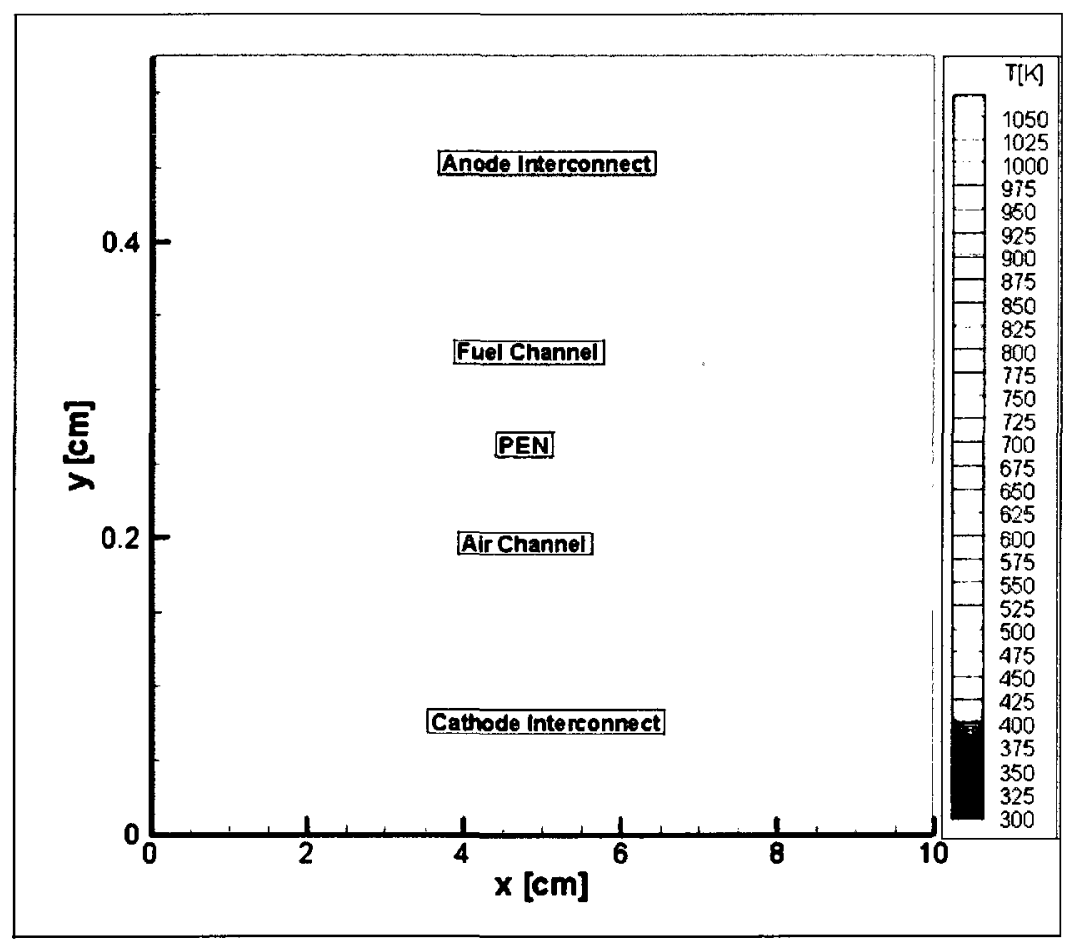

(d) $\mathrm{t}=529 \mathrm{~s}$ 


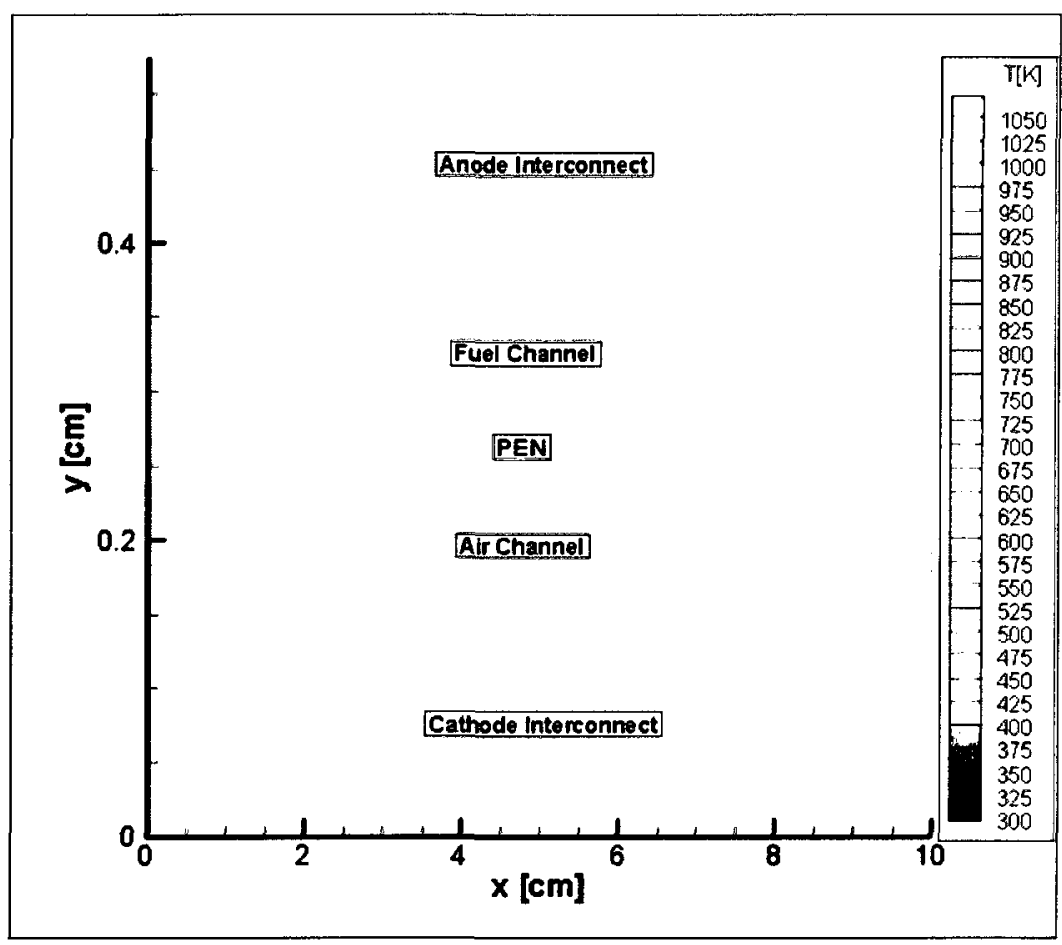

(e) $t=662 \mathrm{~s}$

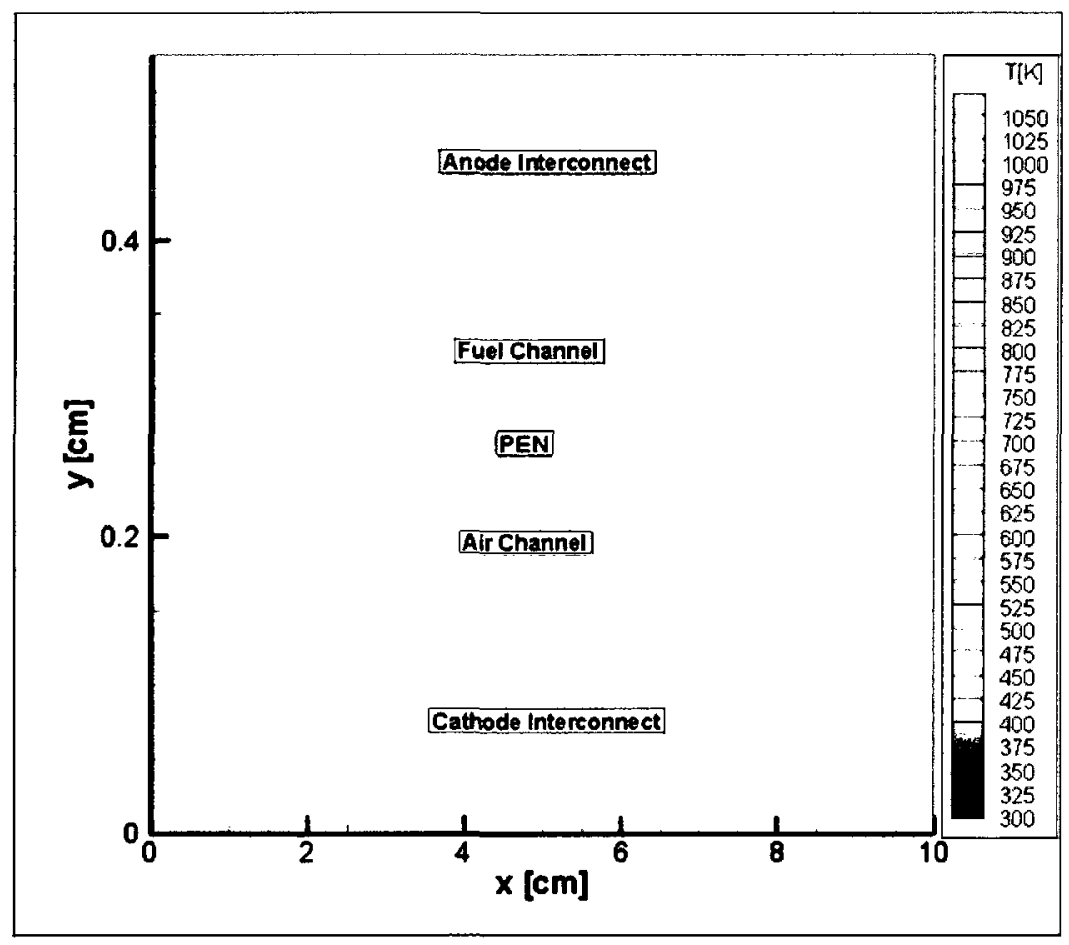

(f) $t=794 s$

Figure 4.41: 2-D temperature distributions during heat-up period (counter-flow). 


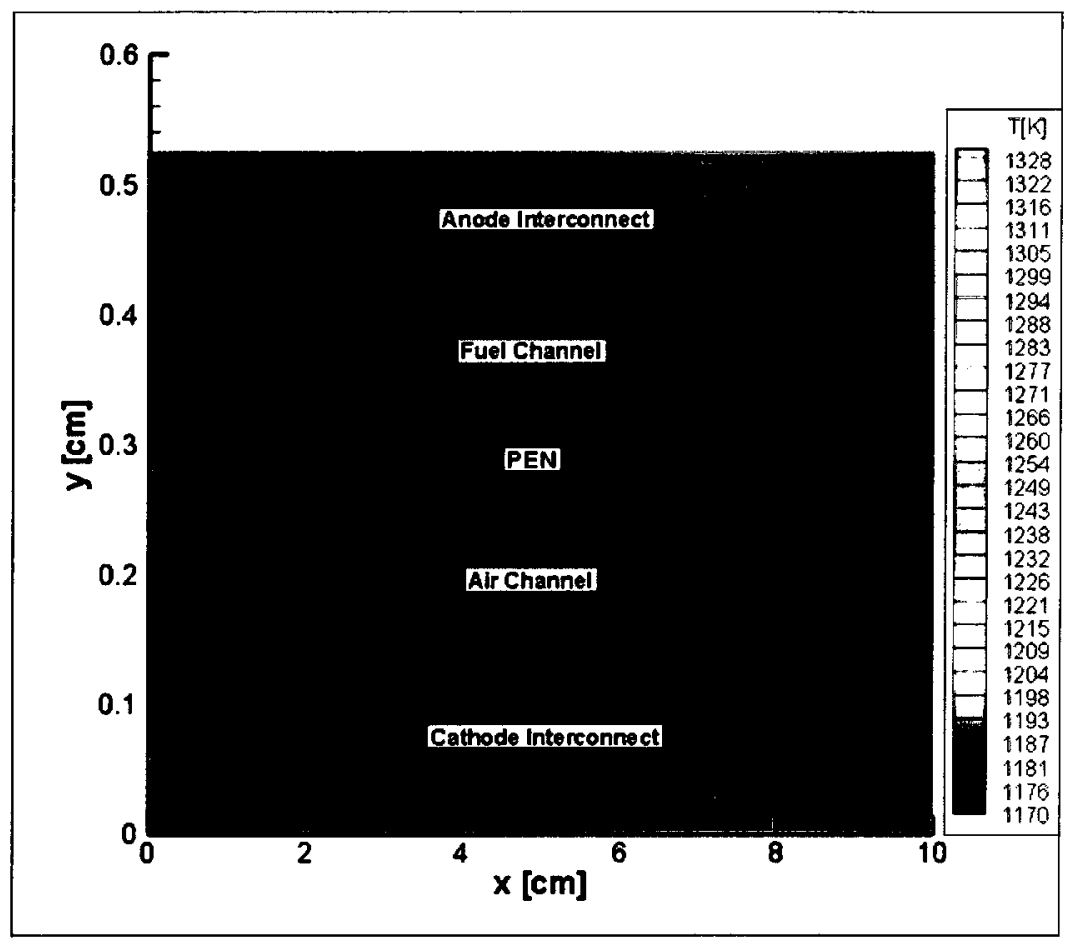

(a) $\mathrm{t}=1253 \mathrm{~s}$

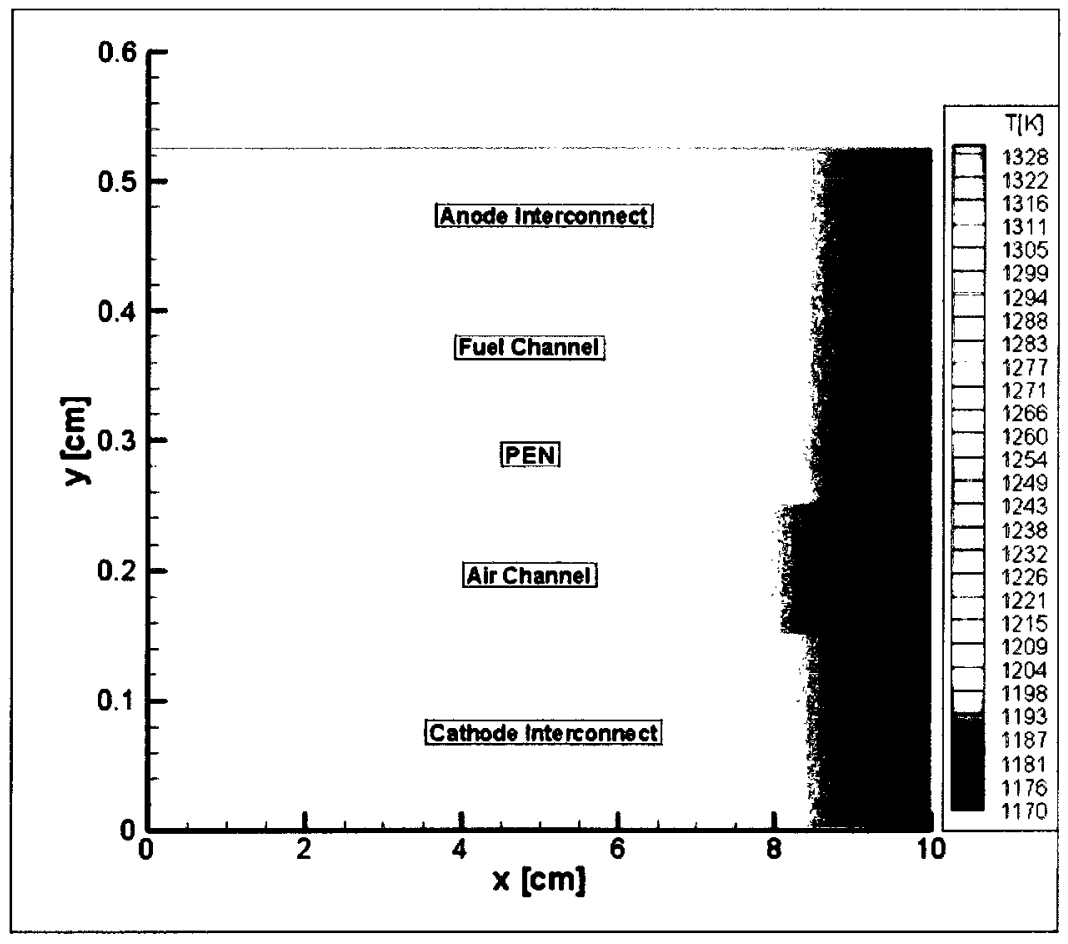

(b) $\mathrm{t}=1503 \mathrm{~s}$ 


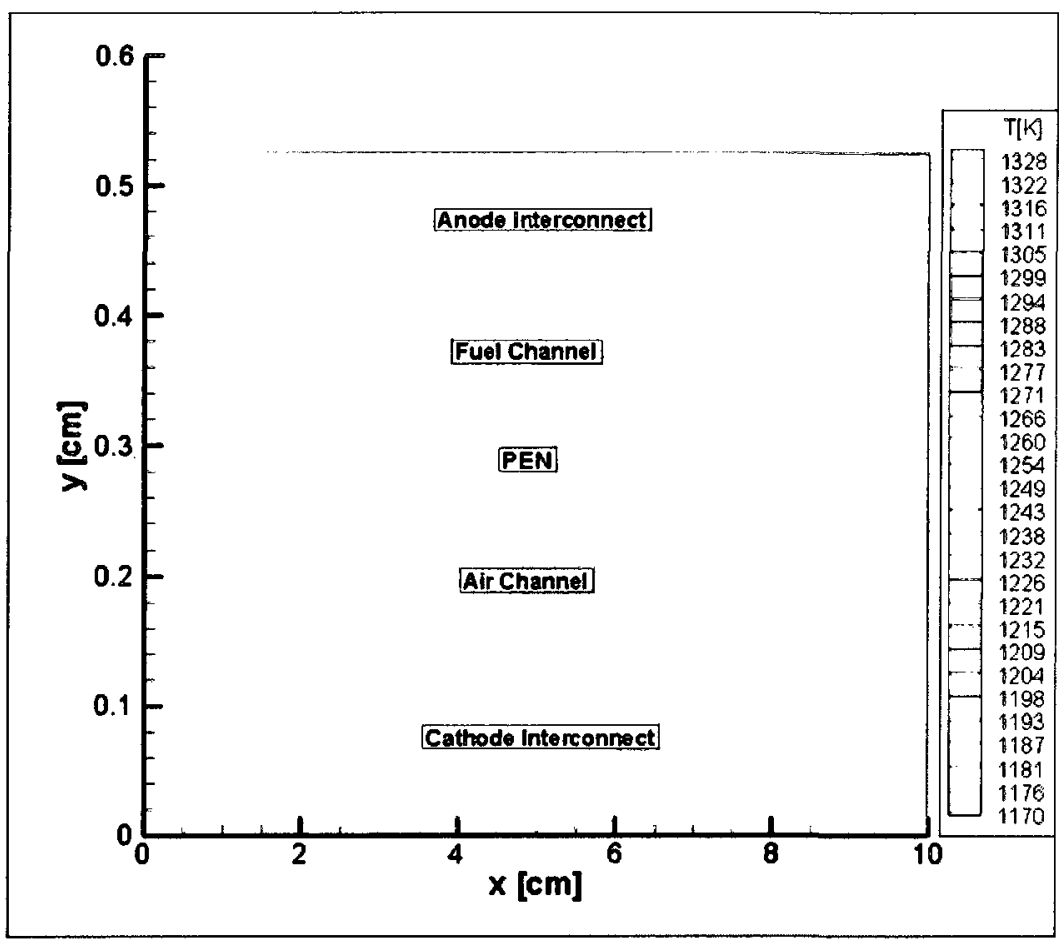

(c) $t=1753 \mathrm{~s}$

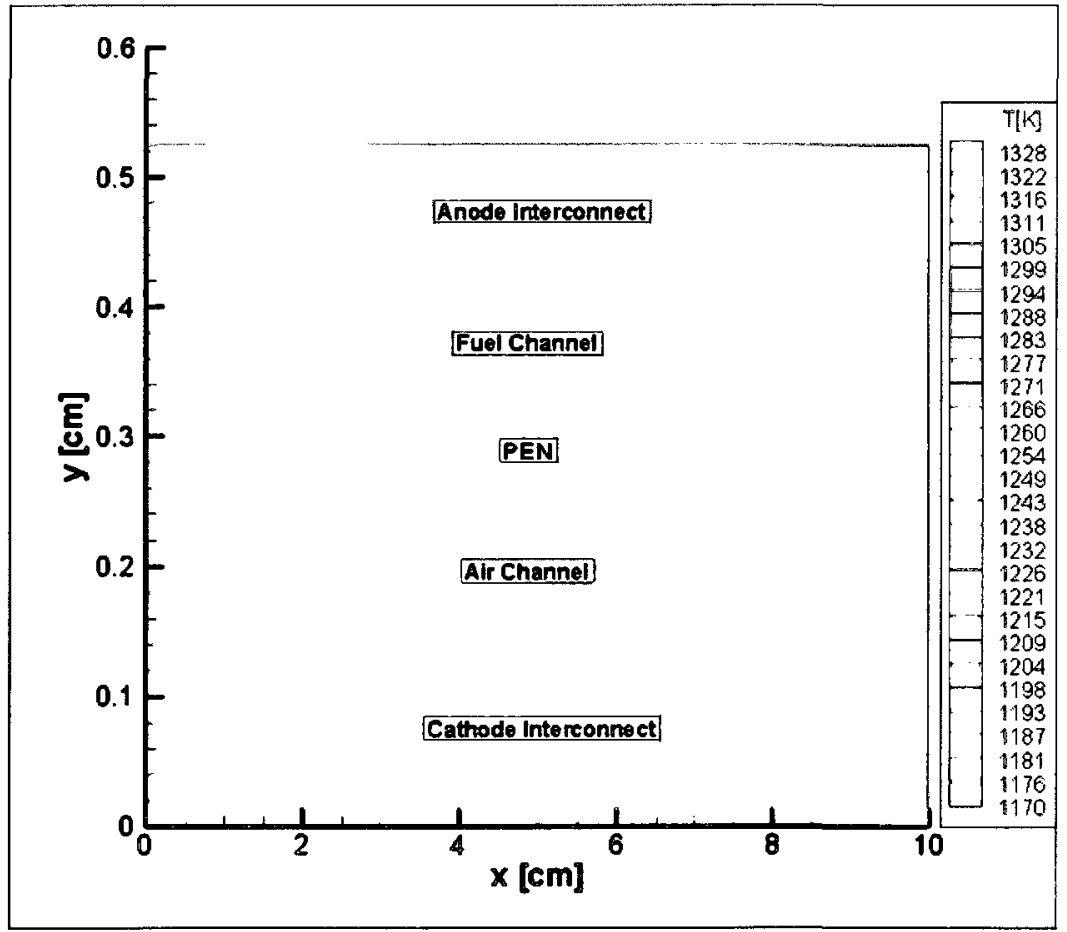

(d) $t=2003 \mathrm{~s}$ 


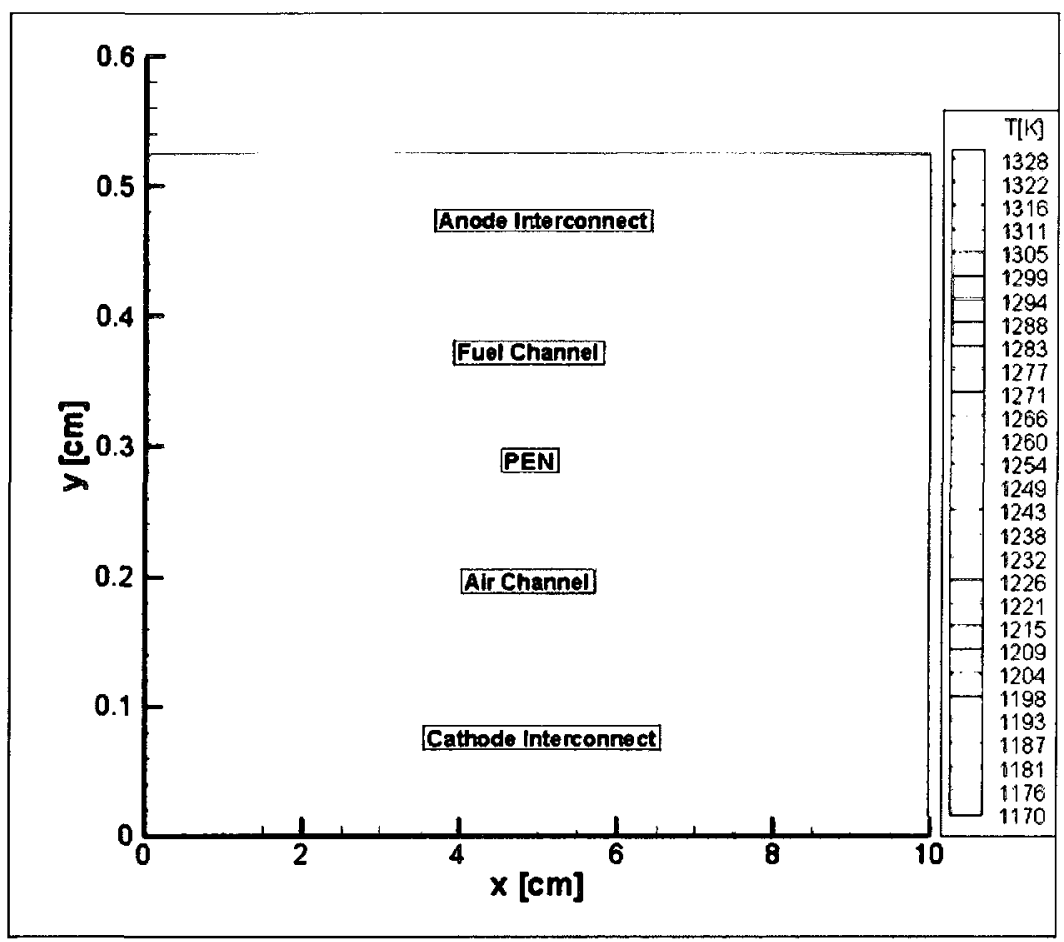

(e) $t=2503 \mathrm{~s}$

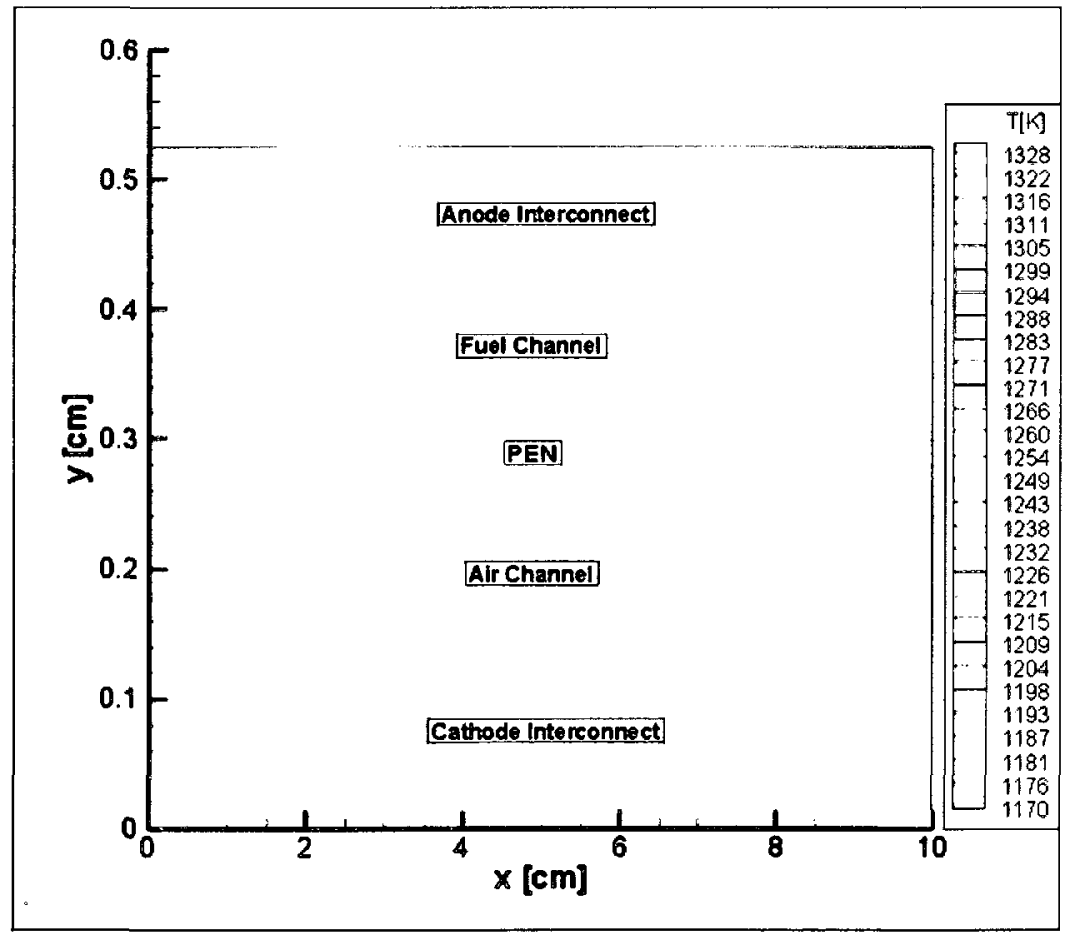

(f) $\mathrm{t}=4233 \mathrm{~s}$

Figun 4 A A8: 2-D temperature distributions during start-up period (counter-flow). 
The Figures 4.43-4.46 show how the average solid temperature, air channel outlet temperature, fuel channel inlet/outlet temperature, fuel utilization, average current density, electrical efficiency, power density, and molar fraction of hydrogen change with time. As it can be seen from Figures $4.43 \mathrm{a}-4.43 \mathrm{c}$, there is nearly a linear relation between temperature and time for the heat-up period, which takes 794s. As start-up period starts, the temperature increases gradually until the system reaches steady state condition. The SOFC reaches this condition at $4143 \mathrm{~s}$ and $4233 \mathrm{~s}$ for the co-flow and counter-flow configuration, respectively. At this condition, the absolute temperature difference between two consecutive times is less than $10^{-4}$. However it can be seen from these figures that after $2500 \mathrm{~s}$, there is not a significant change in the output parameters for both of the configurations. It can be followed from Figures 4.44 and 4.45 that the output parameters are zero in the heat-up period since there is no flow in the fuel channel. For the co-flow case, during the start-up period, average current density, fuel utilization, power density and electrical efficiency increase from 0.19 to $0.3 \mathrm{~A} / \mathrm{cm}^{2}, 0.53$ to 0.83 , 0.13 to $0.21 \mathrm{~W} / \mathrm{cm}^{2}$, and 0.29 to 0.47 , respectively. The molar flow rate of hydrogen at the exit of the fuel channel is higher at the beginning of the start-up period compared to the steady state condition, as can be seen from Figures $4.46 \mathrm{a}$ and $4.46 \mathrm{~b}$. It is higher because of the higher fuel utilization which is due to the lower operating temperature at the beginning of the start-up period. Figures 4.43-4.46 show that the transient behaviors for co- and counter-flow configurations do not differ significantly. They have similar trend but the counter-flow configuration takes slightly more time to reach the steady state condition, as discussed above. 


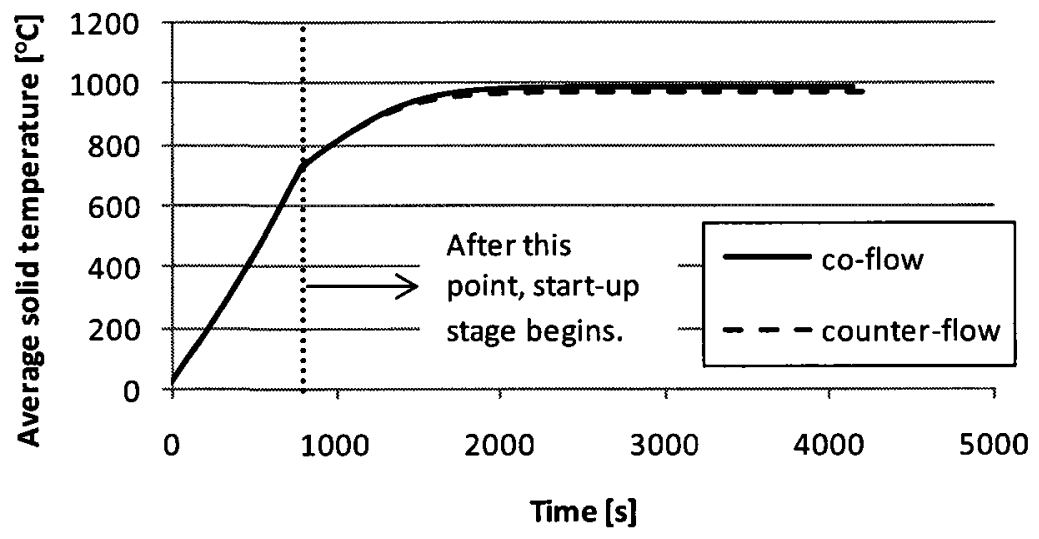

(a)

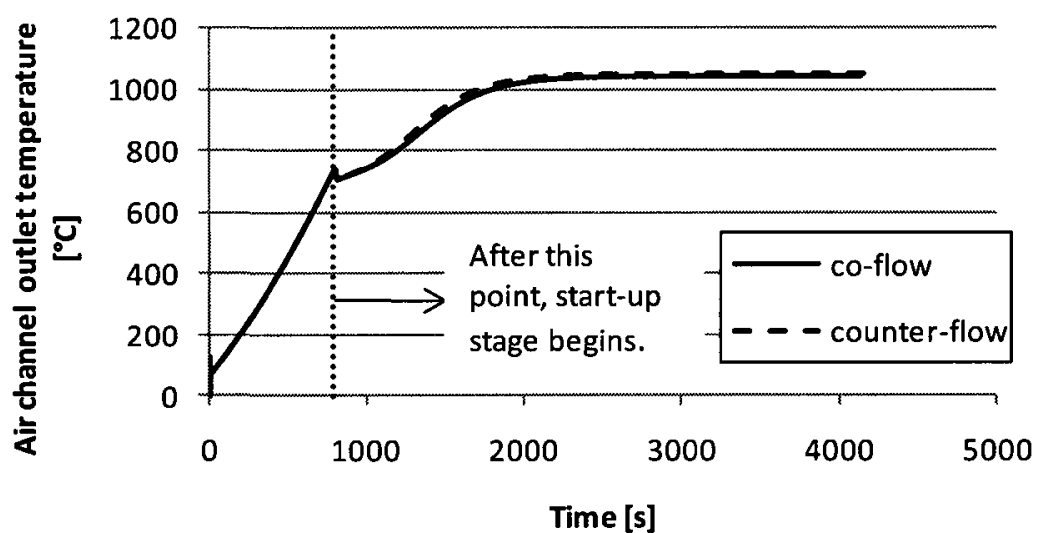

(b)

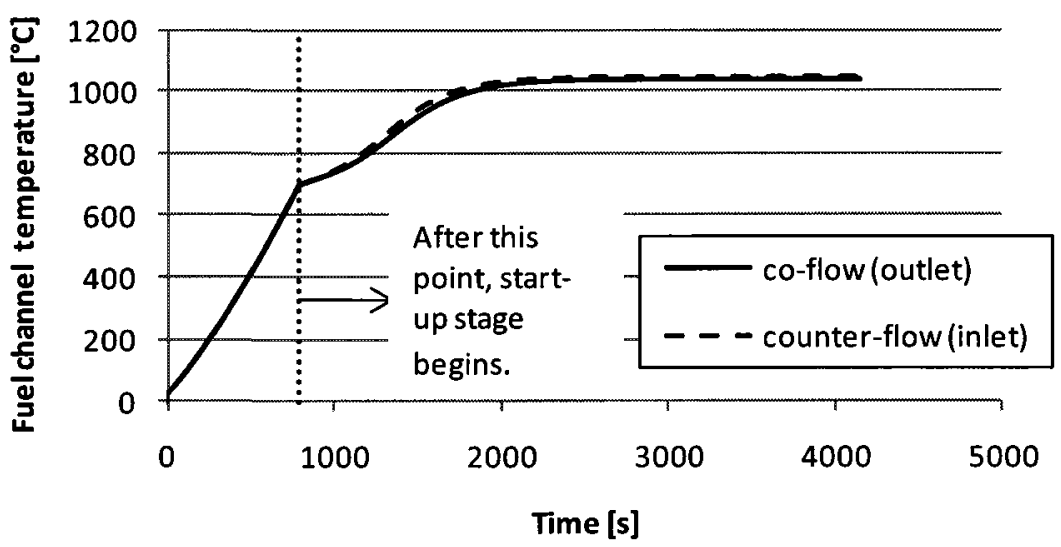

(c)

Figure 4.43: Transient behavior of SOFC fueled with humidified hydrogen: (a) average solid temperature, (b) air channel outlet temperature, (c) fuel channel temperature. 


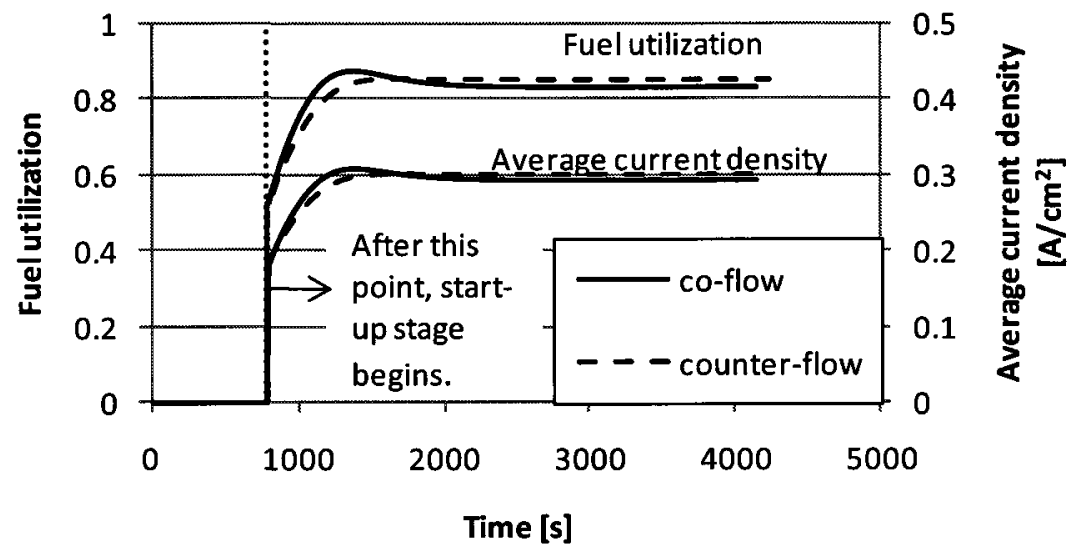

Figure 4.44: Change of fuel utilization and current density with time for the SOFC fueled with humidified hydrogen.

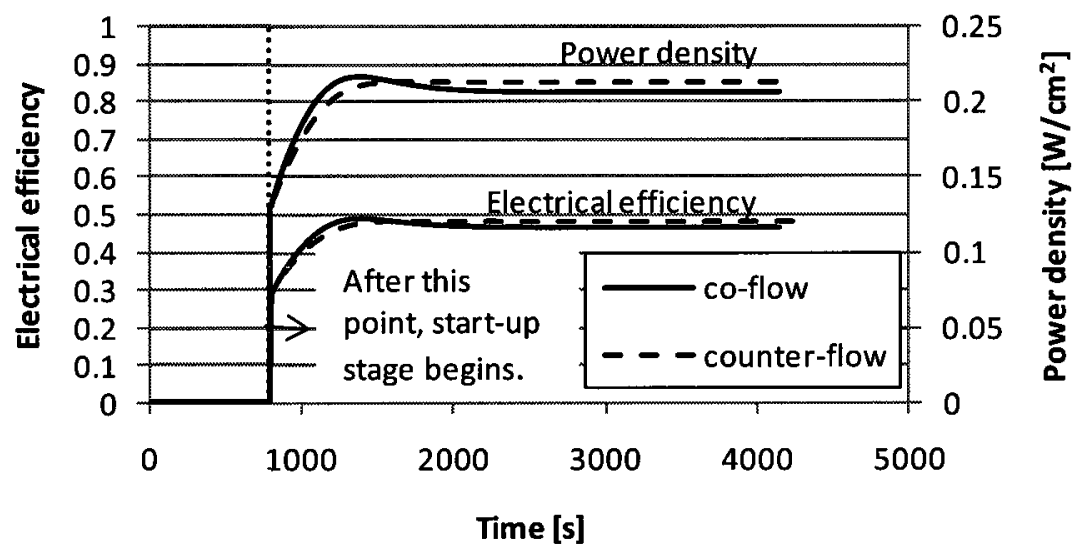

Figure 4.45: Change of electrical efficiency and power density with time for the SOFC fueled with humidified hydrogen.

\subsection{Parametric studies}

Several parametric studies are conducted. These studies include the effect of mass flow rate of air at the heat-up stage on the heat-up time, and the effect of Reynolds number, excess air coefficient, current density, and channel geometry on the output parameters such as fuel utilization, average current density, electrical efficiency, and power density. 


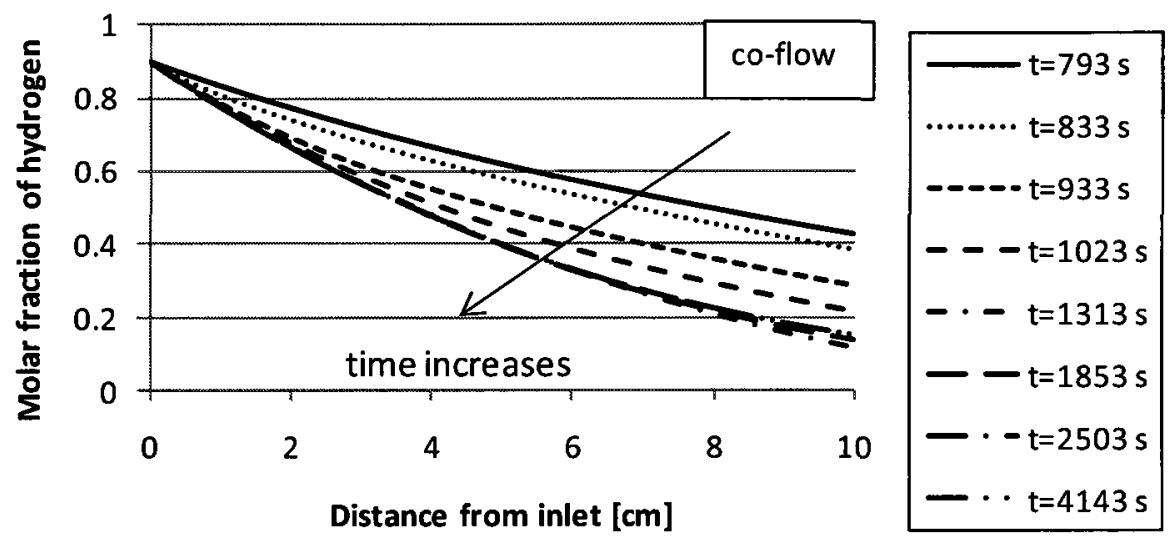

(a)

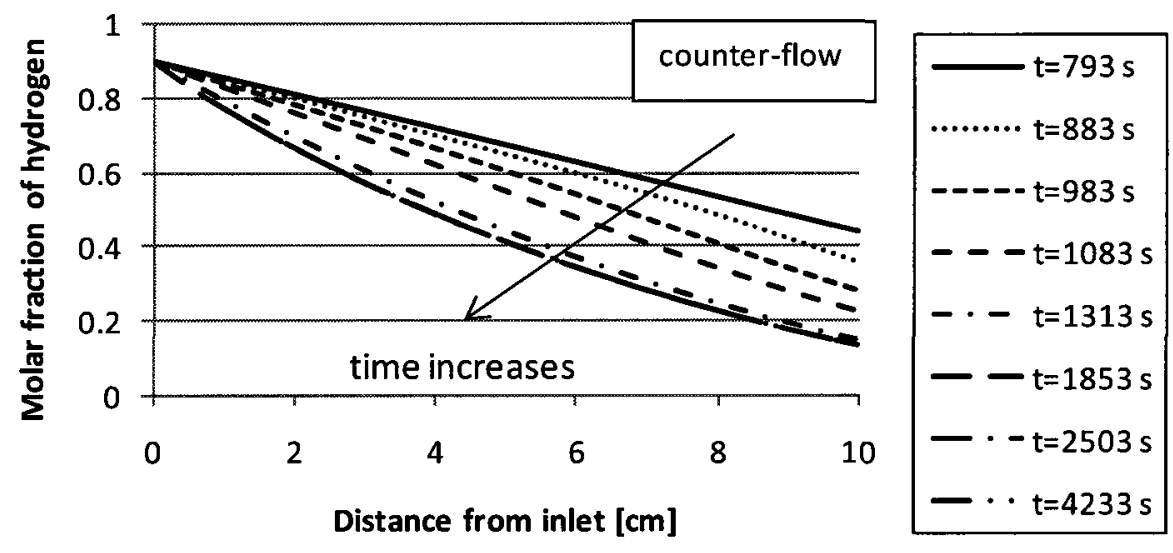

(b)

Figure 4.46: Change of molar fraction of hydrogen with time for the SOFC fueled with humidified hydrogen for (a) co-flow case, (b) counter-flow case.

In the base model, the heat-up time is calculated as $794 \mathrm{~s}$ for a mass flow rate per cross section of the air channel of $2.373 \mathrm{~g} / \mathrm{s} \cdot \mathrm{cm}^{2}$. For different mass flow rate of air, the heat-up time is investigated and the results are shown in Figure 4.47. As it can been seen from 
this figure, as the mass flow rate of air increases, the heat-up time decreases rapidly, and then it decreases gradually. In general, heat-up period should be minimized since there is no power production in this period. In addition, a rapid heat-up is generally required for power generation technologies and crucial for some applications such as portable applications. This figure shows that as the mass flow rate of air increases, heat-up time decreases. This result is as expected because sending more hot air increases the temperature at each time step, thus the fuel cell reaches the prescribed temperature quicker. However, increasing this mass flow rate causes an increase in the blower power requirement, which in turn decreases the electrical efficiency of the system. In addition, the operation cost increases. Due to this fact, mass flow rate of air should be selected after an optimization study according to the purpose of application area.

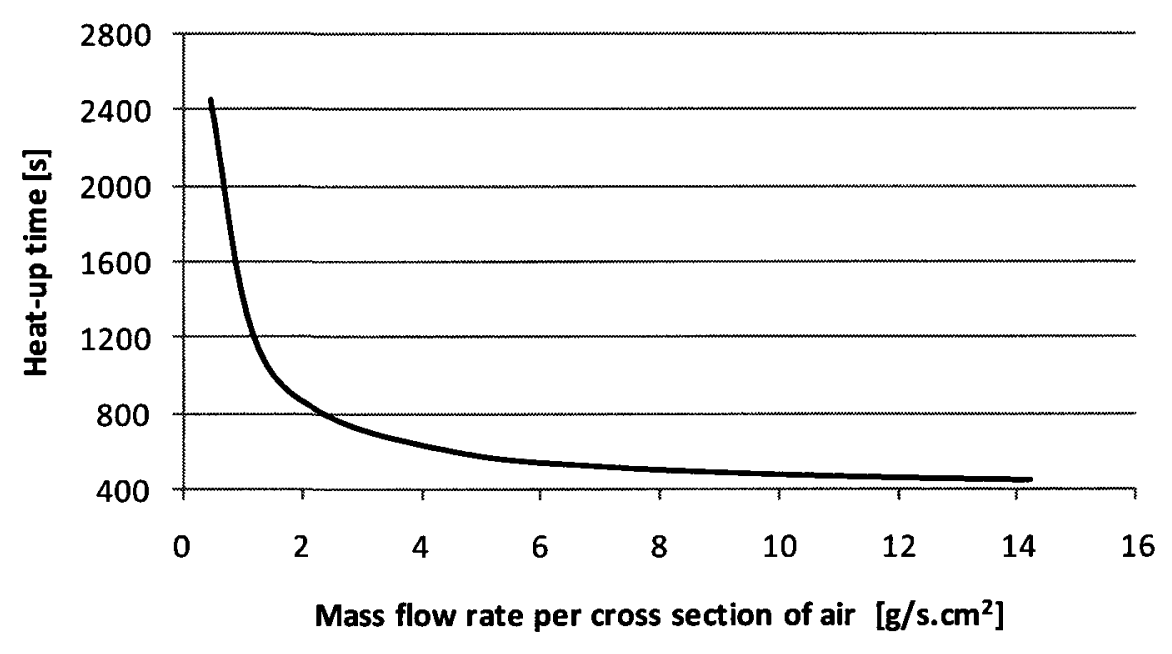

Figure 4.47: Effect of mass flow rate of air at the heat-up stage on the heat-up time. 
Figures 4.48 and 4.49 show the effect of the Reynolds number on the output parameters. Reynolds number is directly proportional to the mass flow rate of the fuel. This flow rate is shown on the second horizontal axis of these figures. As it can be seen from these figures, Reynolds number should be greater than a certain value to get any meaningful results. If we choose this number very low, the code written in Matlab might give us imaginary numbers as the output. From Figure 4.48, we see that as Reynolds number increases, fuel utilization decreases, whereas average current density increases, which can be explained as follows: As the Reynolds number increase, molar flow rate of hydrogen and molar flow rate of hydrogen that is utilized increase, which in turn increases the average current density. However, since the increase in molar flow rate of hydrogen is more than the molar flow rate of hydrogen utilized, fuel utilization decreases. Power density has the same trend with current density, as shown in Figure 4.49, because the cell voltage is assumed to be constant in the modeling. It can be shown easily that electrical efficiency is directly proportional to the fuel utilization; hence it has the same trend with fuel utilization as shown in the same figure. These figures also show that counter-flow configuration has a better performance, e.g. electrical efficiency, for low Reynolds numbers that we obtain meaningful amount of fuel utilization, e.g. fuel utilization of 0.85 . For example, for Reynolds number 0.67 , electrical efficiency is $46.5 \%$ and $48.3 \%$, for coflow and counter-flow configurations, respectively. 


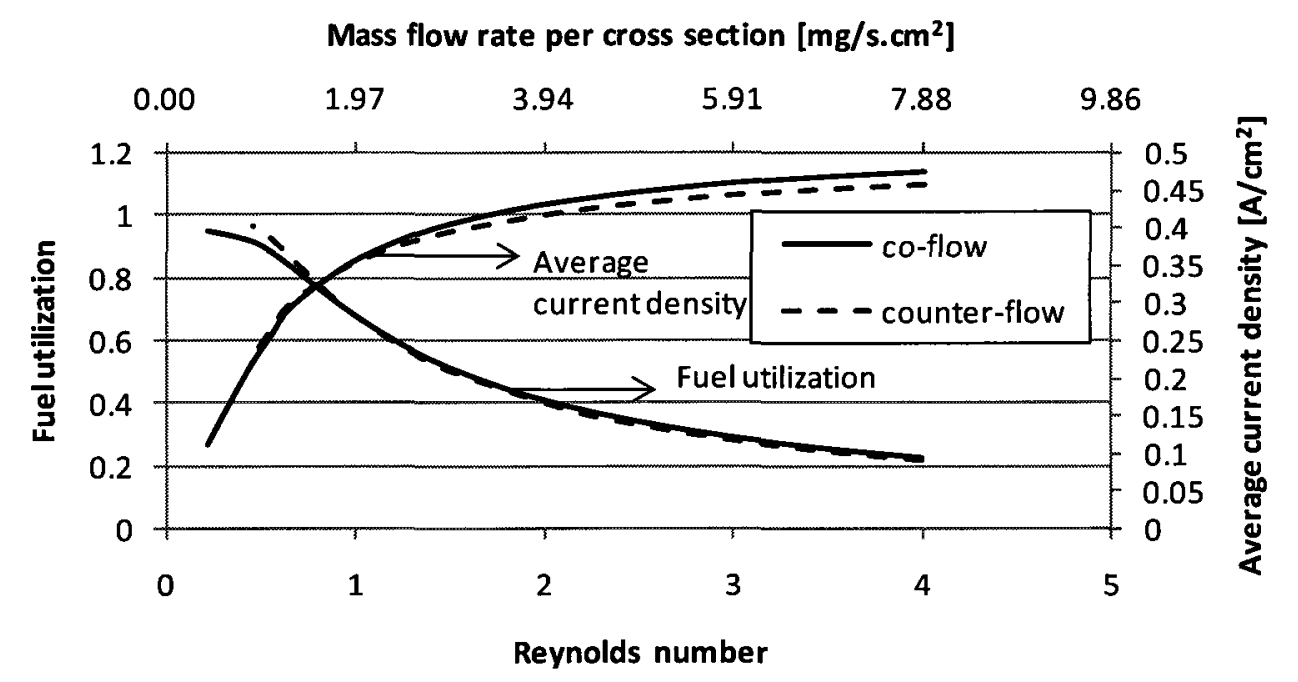

Figure 4.48: Effect of Reynolds number on the fuel utilization and average current density.

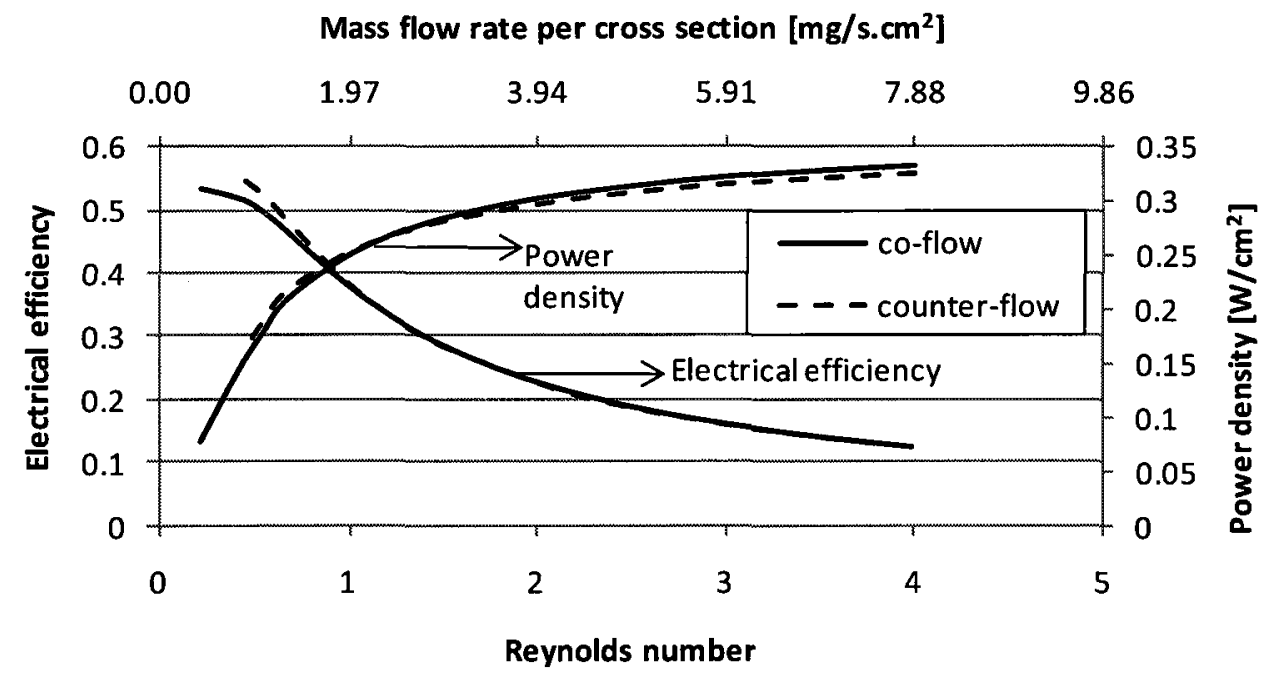

Figure 4.49: Effect of Reynolds number on the electrical efficiency and power density.

Excess air coefficient, which controls the mass flow rate of air at the inlet of the air channel, is an important operating variable because it controls the current density, the 
temperature of the fuel cell, which in turn affects the performance of the cell. If less amount of air is sent through the air channel, the temperature of the cell is increased, as shown in Figure 4.50. Therefore, the excess air coefficient should be carefully selected not to cause a thermo-mechanical problem. Figures 4.51 and 4.52 show that taking the excess air coefficient high provides higher performance of the cell. This performance increase can be explained as follows: As the excess air coefficient increases, temperature of the fuel cell decreases. This decrease causes an increase in the Nernst voltage, and decrease in the activation and concentration polarizations, as discussed in sections 4.1 and 4.2. Hence, the current density and the performance of the cell increase. However, the blower power requirement and the operation cost also increase with an increase in the excess air coefficient. In addition, higher exit temperature from the channels, which necessitates lower excess air coefficient, is generally required for the integrated SOFC systems. Hence, an optimum excess air coefficient should be selected depending on the application and taking into account the performance and economics. When we compare the co-flow and counter-flow configurations, Figure 4.52 shows that for the excess air coefficient up to 9 , counter-flow configuration has a higher electrical efficiency. If we take the excess air coefficient higher than 9, co-flow configuration has a higher electrical efficiency.

A SOFC can operate at different cell voltage or average current density. The effect of average current density and Reynolds number on the performance of the system is studied and the results are shown in Figures 4.53-4.56. The results show that taking the Reynolds number high enables a higher operating range of the fuel cell. However, for a 
given current density, cell voltage is lower, whereas fuel utilization and electrical efficiency are higher for lower Reynolds number. The results also show that counter-flow has slightly better performance compared to co-flow configuration.

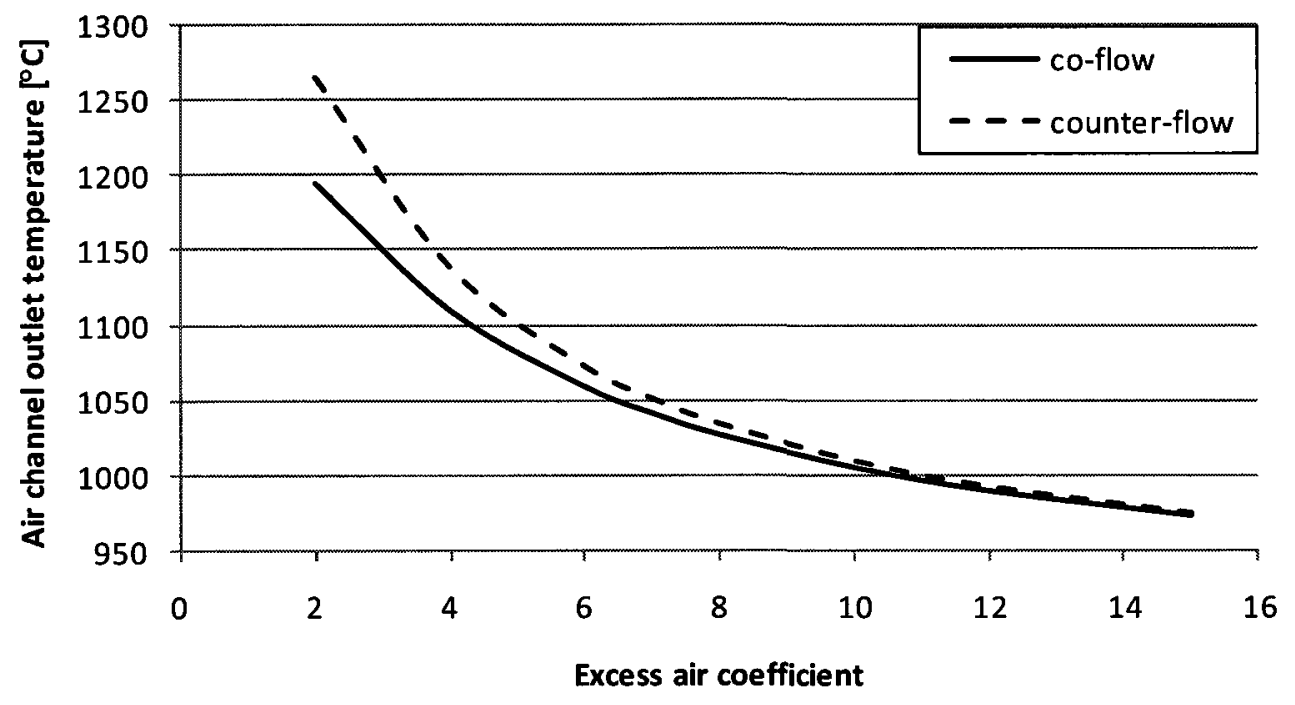

Figure 4.50: Effect of excess air coefficient on the air channel outlet temperature.

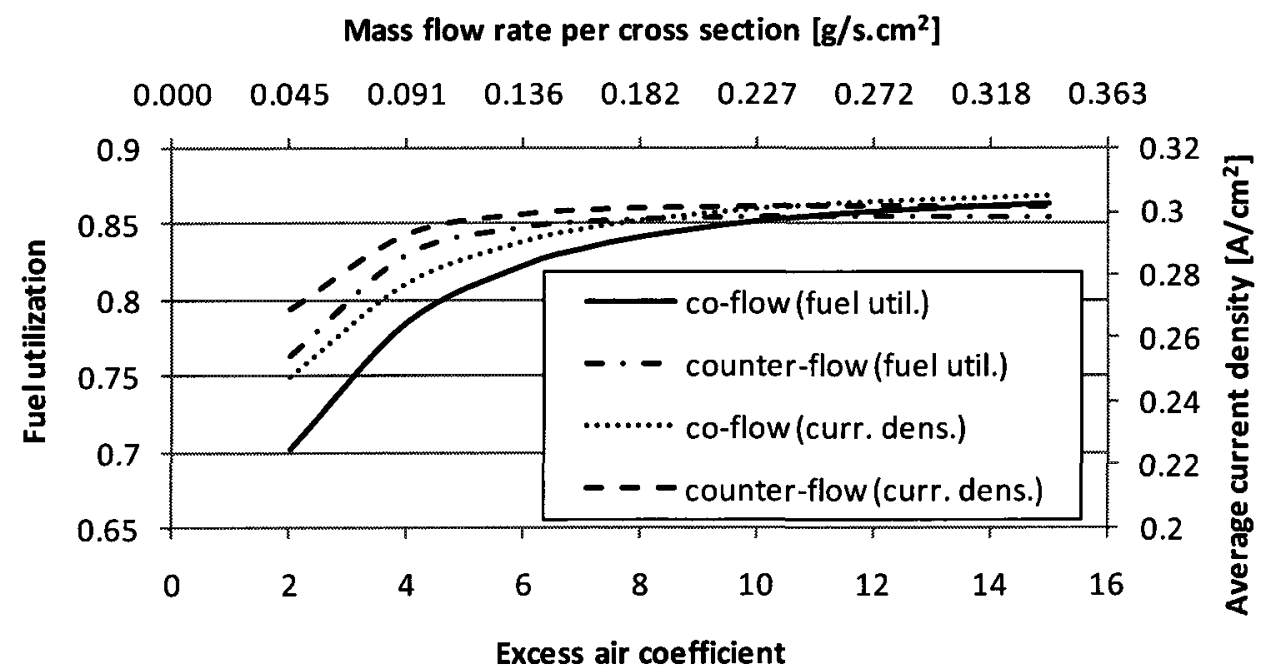

Figure 4.51: Effect of excess air coefficient on the fuel utilization and average current density. 


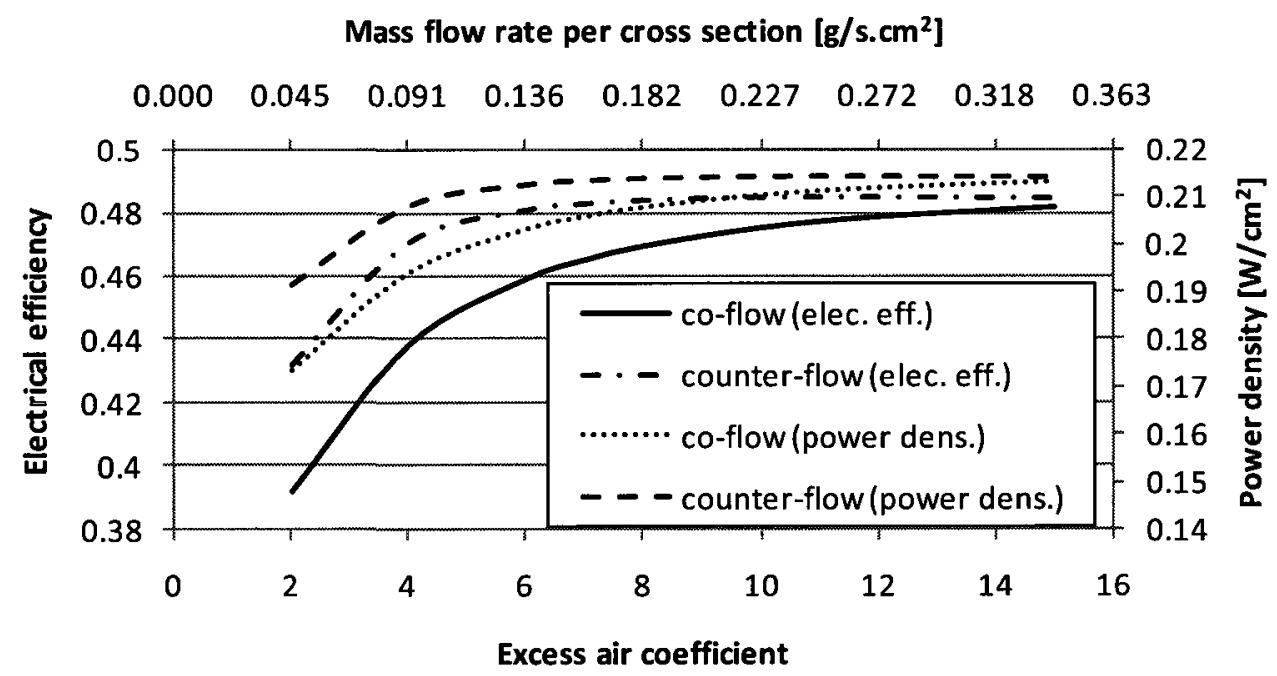

Figure 4.52: Effect of excess air coefficient on the electrical efficiency and power density.

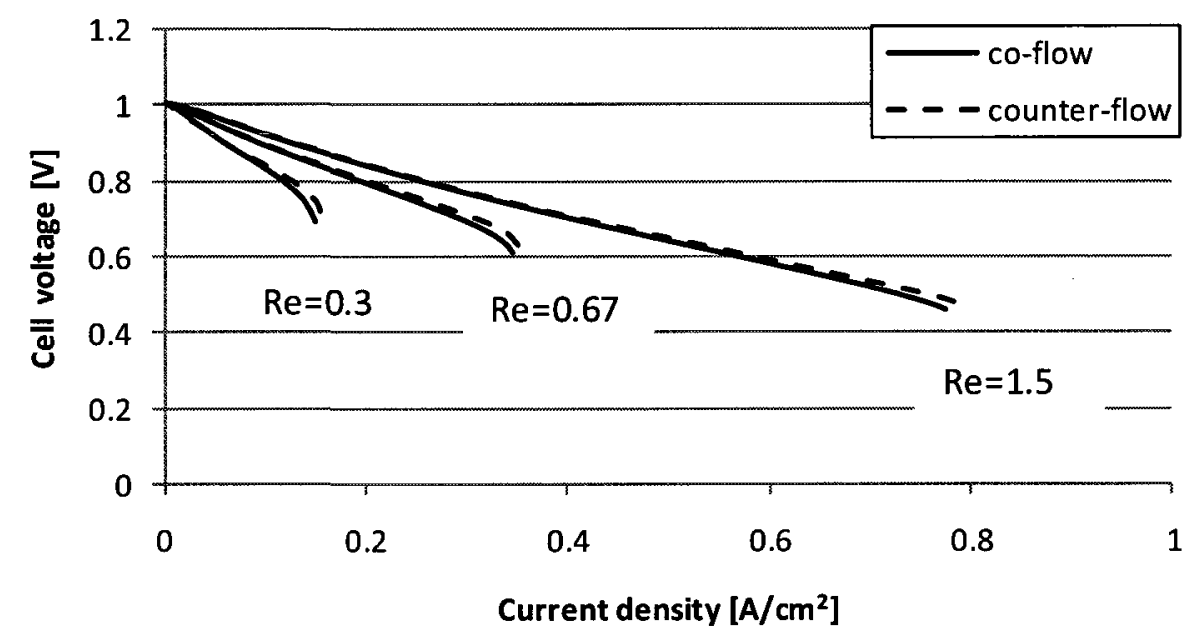

Figure 4.53: Effect of current density and Reynolds number on cell voltage. 


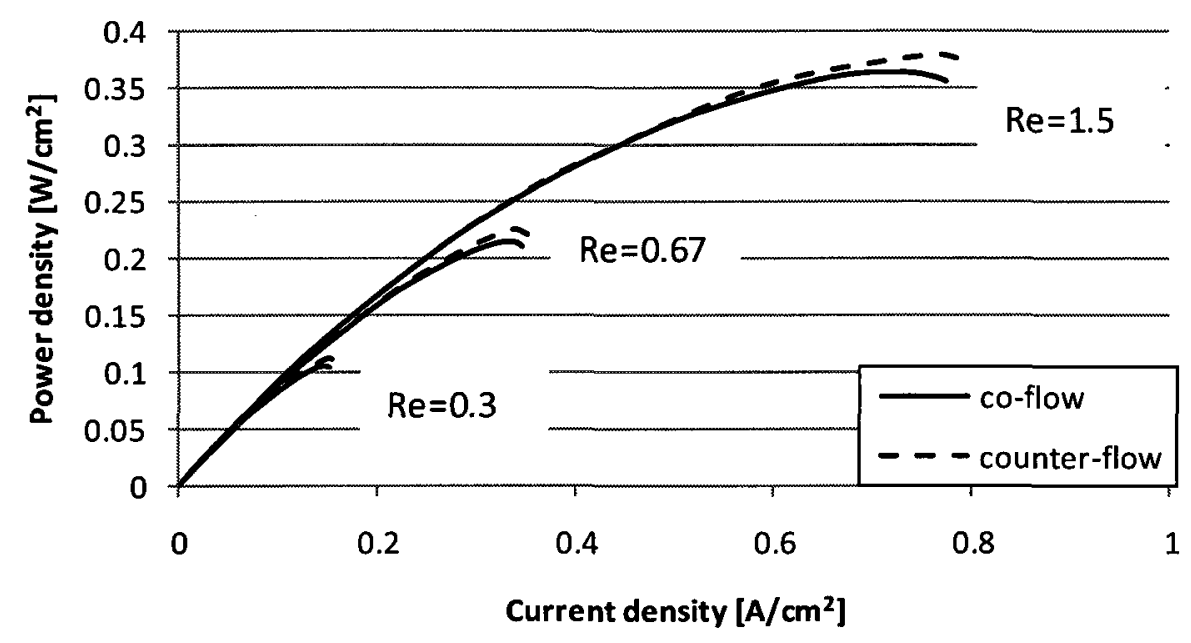

Figure 4.54: Effect of current density and Reynolds number on power density.

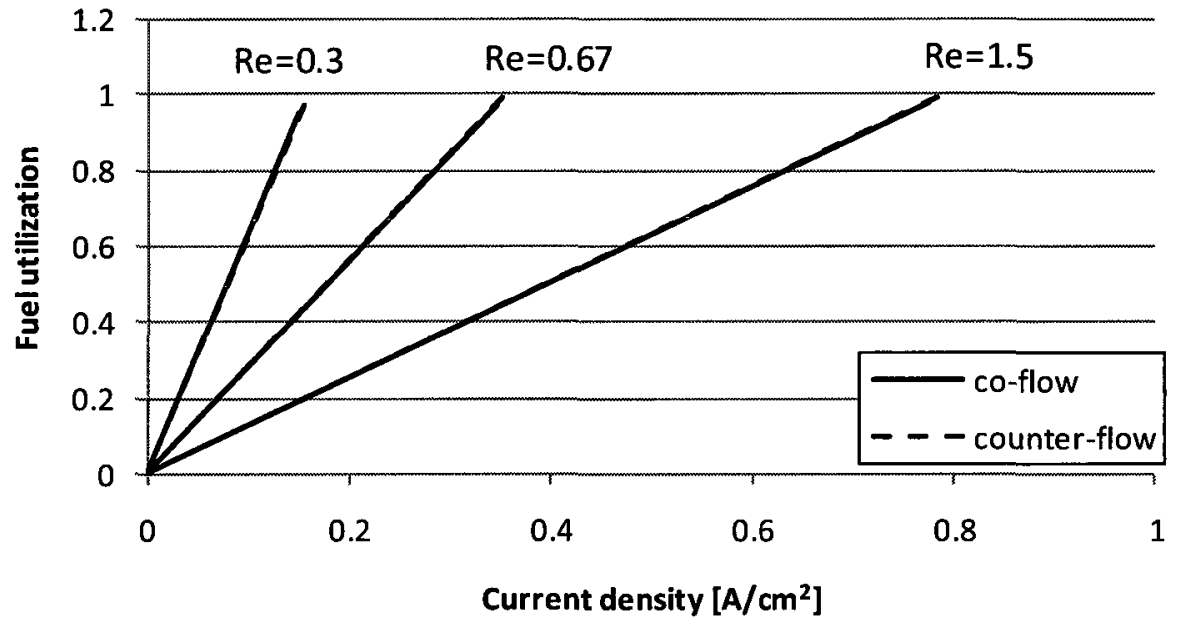

Figure 4.55: Effect of current density and Reynolds number on fuel utilization.

The effect of the thickness of the gas channels on the performance of the cell is investigated as the last parametric study, and the results are shown in Figure 4.57 and 4.58. In these results, the Reynolds number is fixed at 0.67 . As it can be seen from these figures, fuel utilization and electrical efficiency decrease whereas average current density 
and power density increase with an increase in the gas channel thickness. This can be explained as follows: Since the Reynolds number is fixed, as the channel thickness increases, mass flow rate of the fuel increases, which decreases the fuel utilization. The other parameters change accordingly as discussed before.

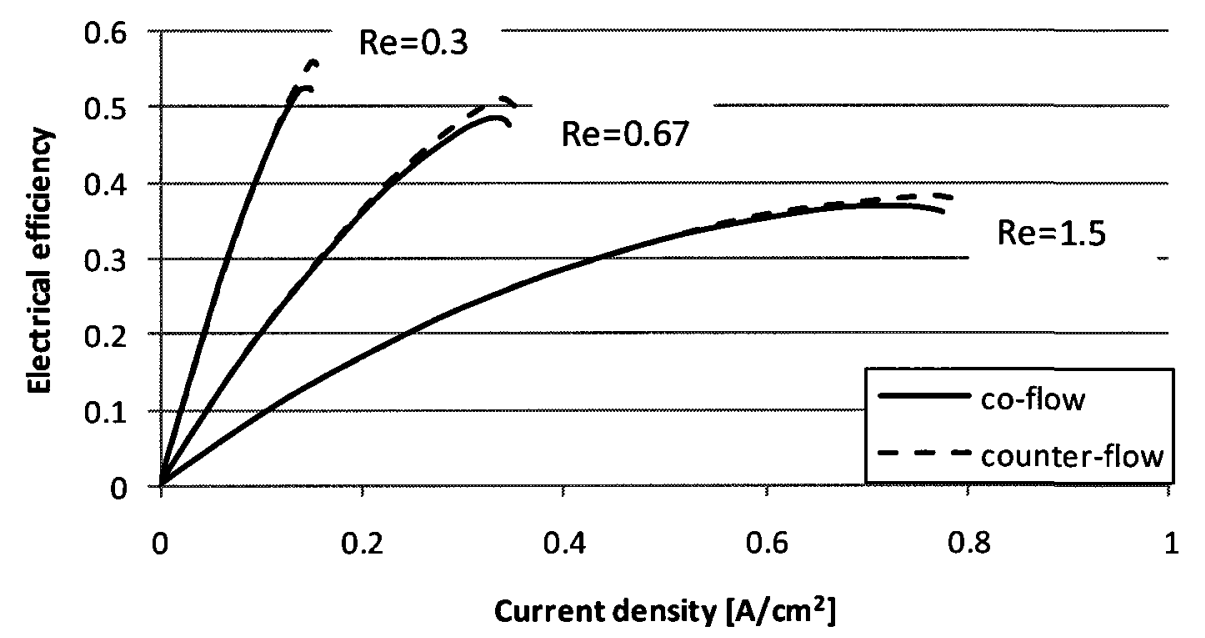

Figure 4.56: Effect of current density and Reynolds number on electrical efficiency.

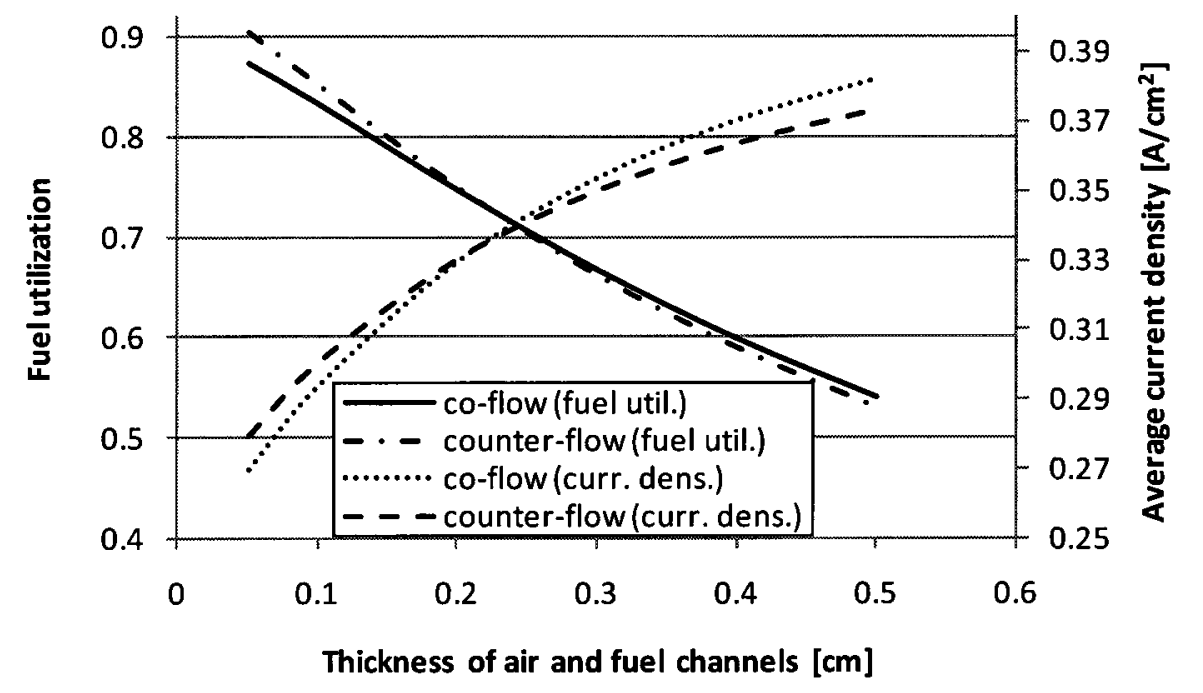

Figure 4.57: Effect of thickness of air and fuel channels on fuel utilization and average current density. 


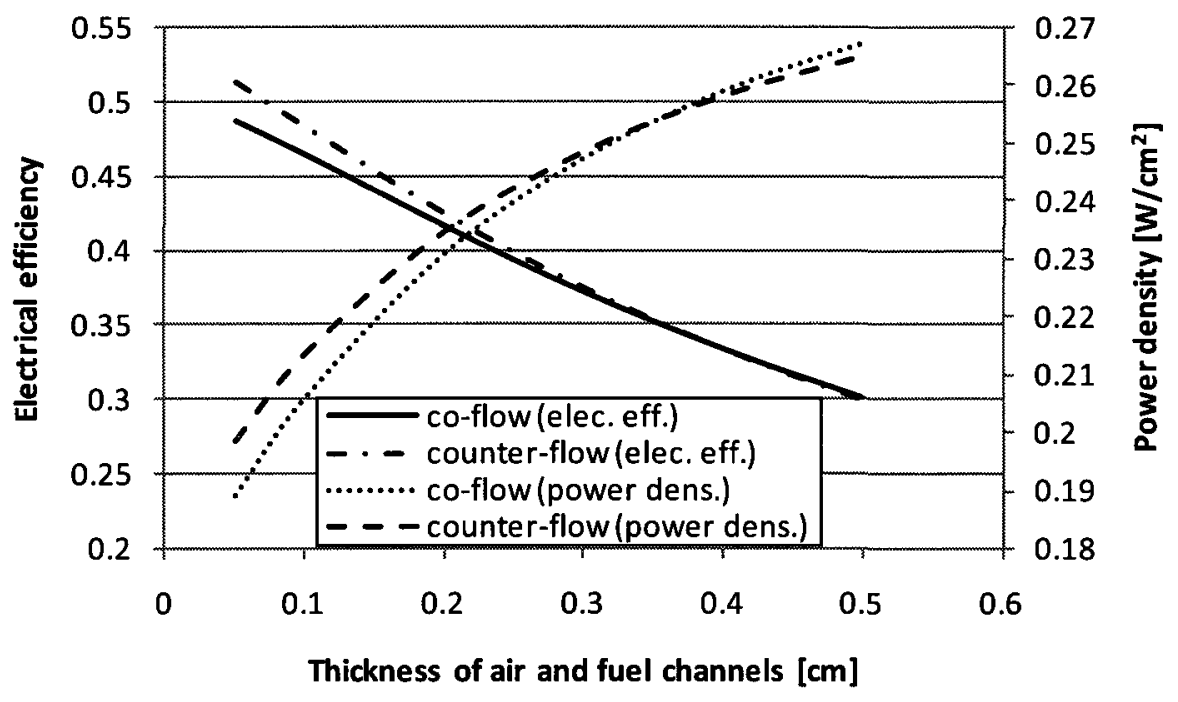

Figure 4.58: Effect of thickness of air and fuel channels on electrical efficiency and power density.

\subsubsection{Case study-2: DIR-SOFC operating with a gas mixture}

In this study, benchmark test-2 conditions, which are given in Table 4.5, are used as the input data for the transient heat transfer model of the DIR-SOFC operating with a gas mixture consisting of $\mathrm{CH}_{4}, \mathrm{H}_{2}, \mathrm{CO}, \mathrm{CO}_{2}, \mathrm{H}_{2} \mathrm{O}$, and $\mathrm{N}_{2}$. As in the case of case study-1, the input parameters of the model are adjusted to obtain the given average current density and fuel utilization. In the first part of this study, the model is validated with the results of the benchmark test- 2 and Braun's thesis for the steady-state condition. In the second part of this study, the transient behaviour of the system is studied for co-flow and counterflow configurations.

\subsection{Model validation}

In the benchmark test-2, the results are shown for fuel utilization of 0.85 and an average current density of $0.3 \mathrm{~A} / \mathrm{cm}^{2}$. Since these two parameters are output parameters in the 
model developed by the author, Reynolds number is altered until we get results that are close enough to these two parameters. As in the case of case study-1, two models are developed. In the first model, the same polarization assumption is used as the benchmark test and this model is named Model-V1. In the second model, correlations for the polarizations are used and this model is named Model-V2. For the co-flow configuration, in the Model-V1, Reynolds number is found to be 1.85 , which gives fuel utilization of 0.85 and average current density of $0.318 \mathrm{~A} / \mathrm{cm}^{2}$. For the same configuration in ModelV2, Reynolds number is found to be 2 , which gives fuel utilization of 0.85 and average current density of $0.346 \mathrm{~A} / \mathrm{cm}^{2}$. For the counter-flow configuration, in the Model-V1 and Model-V2, Reynolds number is found to be 1.7, which gives fuel utilization of 0.85 and average current density of $0.3 \mathrm{~A} / \mathrm{cm}^{2}$.

The validation of the co-flow configuration for the Model-V1 and Model-V2 are given in Table 4.10. As the cell voltage is an input parameter in the model developed, a value between the maximum and minimum values of the cell voltage from the models conducted in the benchmark test- 2 is taken, as shown in this table. From this table, it can be seen that the results for the Model-V1 of the co-flow case is between the maximum and minimum values found by the companies and institutions participated in the benchmark test- 2 except the power. The result for power has a relative error of $3.37 \%$ and $5.76 \%$ with the maximum and minimum value of it, respectively, given by the participants of the benchmark test-2. For Model-V2 of the co-flow case, the maximum current density is slightly higher than the maximum value of the benchmark test because of the assumption on the polarizations done in this model. 
Table 4.10: Validation of the Model-V1 and Model-V2 of the co-flow configuration with the benchmark test-2 and Braun's model.

\begin{tabular}{|c|c|c|c|c|c|}
\hline \multirow{2}{*}{\multicolumn{2}{|c|}{ Parameter }} & \multirow{2}{*}{\multicolumn{4}{|c|}{ Co-flow }} \\
\hline & & & & & \\
\hline \multirow{2}{*}{ Voltage (V) } & Max & $\begin{array}{l}\text { Benchmark }^{1} \\
0.65\end{array}$ & \multirow{2}{*}{$\begin{array}{l}\text { Braun's model }^{2} \\
0.65\end{array}$} & \multirow{2}{*}{$\begin{array}{l}\text { Model- } \\
\mathrm{V1}^{3} \\
0.65\end{array}$} & \multirow{2}{*}{$\begin{array}{l}\text { Model- } \\
\text { V2 } \\
0.65\end{array}$} \\
\hline & Min & 0.63 & & & \\
\hline \multirow[t]{2}{*}{ Power (W) } & Max & 19.47 & \multirow[t]{2}{*}{19.49} & \multirow[t]{2}{*}{20.15} & \multirow[t]{2}{*}{21.92} \\
\hline & Min & 18.99 & & & \\
\hline \multirow[t]{2}{*}{ Efficiency (\%) } & Max & \multirow[t]{2}{*}{ N/A } & \multirow[t]{2}{*}{49.8} & \multirow[t]{2}{*}{49.5} & \multirow[t]{2}{*}{49.8} \\
\hline & Min & & & & \\
\hline \multirow[t]{3}{*}{ Current density $\left(\mathrm{A} / \mathrm{m}^{2}\right)$} & & $\operatorname{Max} / \operatorname{Min}$ & & & \\
\hline & Max & $3665 / 3040$ & 3457 & 3599 & 4484 \\
\hline & Min & $2508 / 1748$ & 2149 & 2161 & 1738 \\
\hline \multirow[t]{3}{*}{ Solid temperature $(\mathrm{C})$} & & Max/Min & & & \\
\hline & Max & $1034 / 1021$ & 1020 & 1025 & 1023 \\
\hline & Min & $862 / 847$ & 845 & 853 & 858 \\
\hline \multirow[t]{3}{*}{ Outlet gas temperature $(\mathrm{C})$} & & $\mathrm{Max} / \mathrm{Min}$ & & & \\
\hline & Air & $1026 / 1016$ & 1014 & 1022 & 1022 \\
\hline & Fuel & $1026 / 1021$ & 1019 & 1024 & 1023 \\
\hline
\end{tabular}

${ }^{1}$ Data shows the results from the benchmark test. Data are taken from Braun's thesis [108].

${ }^{2}$ Data shows the results from the Braun's model. Data are taken from Braun's thesis [108].

${ }^{3}$ Data shows the results from the present model that uses the same assumption with the benchmark test.

${ }^{4}$ Data shows the results from the present model that uses the different assumption for polarizations.

The validation of the counter-flow configuration for the Model-V1 and Model-V2 is given in Table 4.11. When we check the results from this table, we see that the results for Model-V1 are slightly lower than the values given for the benchmark test. This difference is mainly due to the methodology applied in the modeling. As discussed before, in the model developed by the author, outlet of fuel channel temperature and inlet of air channel are considered fixed; whereas it is unknown what kind of an assumption is done in the model used in the benchmark test. In spite of this assumption, the relative errors for Model-V1 for power, maximum current density, minimum current density, maximum solid temperature, minimum solid temperature, exit temperature of air channel and exit temperature of fuel channel are $0.99 \%, 2.30 \%, 4.72 \%, 2.91 \%, 0.11 \%, 3.67 \%$ and $0.67 \%$, 
respectively. The results for Model-V2 are almost same with the Model-V1 except the maximum and minimum values of current density. This difference is due to the difference on the assumption on polarizations between these two models. However, the average current densities for these two models are same, which are equal to $0.3 \mathrm{~A} / \mathrm{cm}^{2}$.

Table 4.11: Validation of the Model-V1 and Model-V2 of the counter-flow configuration with the benchmark test-2 and Braun's model.

\begin{tabular}{|c|c|c|c|c|c|}
\hline \multirow{2}{*}{\multicolumn{2}{|c|}{ Parameter }} & \multirow{2}{*}{\multicolumn{4}{|c|}{ Counter-flow }} \\
\hline & & & & & \\
\hline \multirow{2}{*}{ Voltage (V) } & $\operatorname{Max}$ & $\begin{array}{l}\text { Benchmark }^{1} \\
0.692\end{array}$ & \multirow{2}{*}{$\begin{array}{l}\text { Braun's model }^{2} \\
0.693 \\
\end{array}$} & \multirow{2}{*}{$\begin{array}{l}\text { Model- } \\
\text { V1 } \\
0.69\end{array}$} & \multirow{2}{*}{$\begin{array}{l}\text { Model- } \\
\text { V2 } \\
0.69\end{array}$} \\
\hline & Min & 0.680 & & & \\
\hline \multirow[t]{2}{*}{ Power (W) } & Max & 20.76 & \multirow[t]{2}{*}{20.78} & \multirow[t]{2}{*}{20.2} & \multirow[t]{2}{*}{20.2} \\
\hline & Min & 20.40 & & & \\
\hline \multicolumn{2}{|l|}{ Efficiency (\%) } & N/A & 53.1 & 52.7 & 52.6 \\
\hline \multirow{3}{*}{$\begin{array}{l}\text { Current density } \\
\left(\mathrm{A} / \mathrm{m}^{2}\right)\end{array}$} & & Max/Min & & & \\
\hline & Max & $6554 / 5330$ & 5395 & 5210 & 4437 \\
\hline & Min & $1332 / 994$ & 1260 & 1272 & 1692 \\
\hline \multirow{3}{*}{$\begin{array}{l}\text { Solid temperature } \\
\left.{ }^{\circ} \mathrm{C}\right)\end{array}$} & & Max/Min & & & \\
\hline & Max & $1089 / 1062$ & 1058 & 1032 & 1033 \\
\hline & Min & $915 / 906$ & 912 & 907 & 909 \\
\hline \multirow{3}{*}{$\begin{array}{l}\text { Outlet gas } \\
\text { temperature }(\mathrm{C})\end{array}$} & & Max/Min & & & \\
\hline & Air & $1028 / 1018$ & 1014 & 982 & 981 \\
\hline & Fuel & $915 / 906$ & 914 & 900 & 900 \\
\hline
\end{tabular}

Data shows the results from the benchmark test. Data are taken from Braun's thesis [108].

${ }^{2}$ Data shows the results from the Braun's model. Data are taken from Braun's thesis [108].

${ }^{3}$ Data shows the results from the present model that uses the same assumption with the benchmark test.

${ }^{4}$ Data shows the results from the present model that uses the different assumption for polarizations.

The results for the distribution of the output parameters through the channel length could not be accessed for the benchmark test. However, those results from Braun's thesis for the co-flow configuration are used for validation of the distribution of average solid temperature and current density. It can be seen from the Figures 4.59 and 4.60 that, these distributions for Model-V1 and Braun's thesis have the same trends. The current density distribution for Model-V2 is different, which is discussed below. 


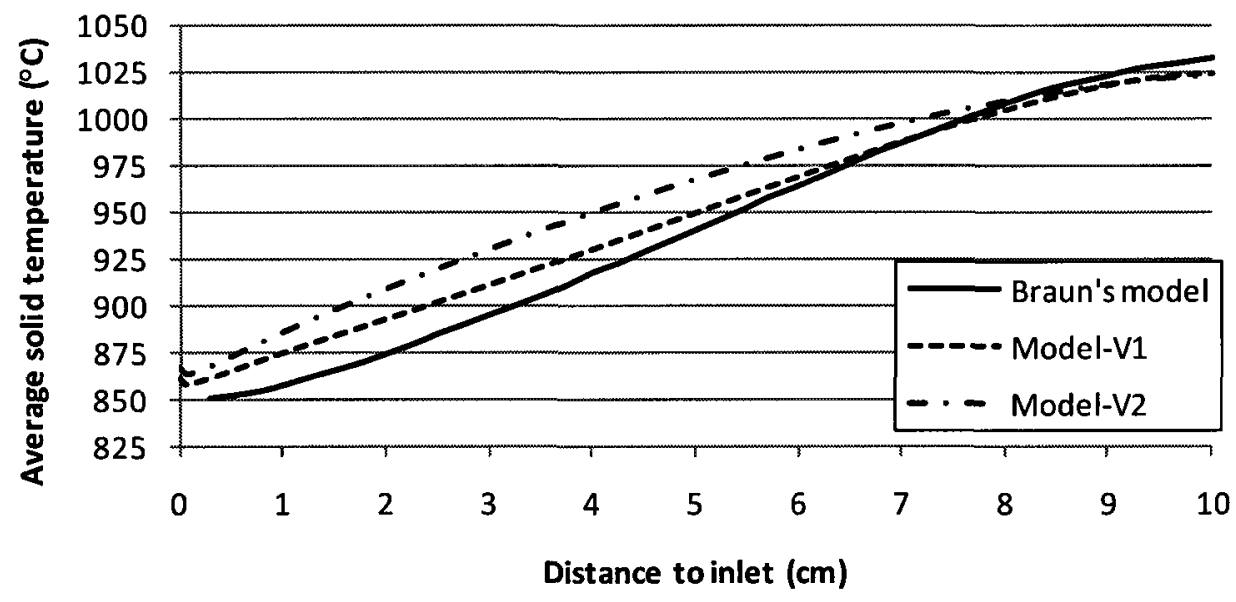

Figure 4.59: Validation for the distribution of the average solid temperature.

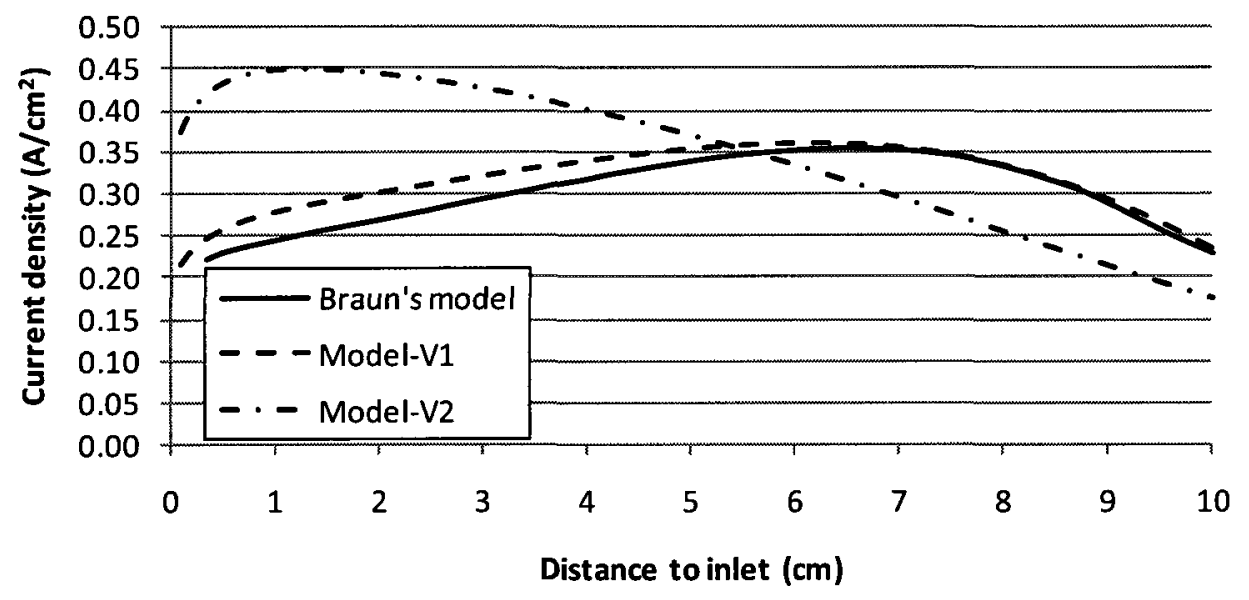

Figure 4.60: Validation for the distribution of the current density.

In the case study, the results show that the current density distribution of Model-V1 and Model-V2 have different trend. However, the average current densities of these models are very close to each other. Since the current density is found by solving the relation between the Nernst voltage and the voltage losses, i.e. the polarizations, the change of 
these voltages through the channel length is investigated. The results are given for the coflow configuration and shown in Figures 4.61 and 4.62 for the Model-V1 and Model-V2, respectively. From these figures, it can be seen that the Nernst voltage and the total amount of polarizations have the same trend. However, the individual or the combinations of the individual polarizations have different trends. From these trends, it can be considered that the nature of the equations considered for polarizations are responsible for the different current density distribution between Model-V1 and ModelV2. For example, for ohmic polarization, this polarization is directly proportional to the current density; whereas for activation and concentration polarizations, these polarizations are trigonometric and logarithmic functions of current density, respectively.

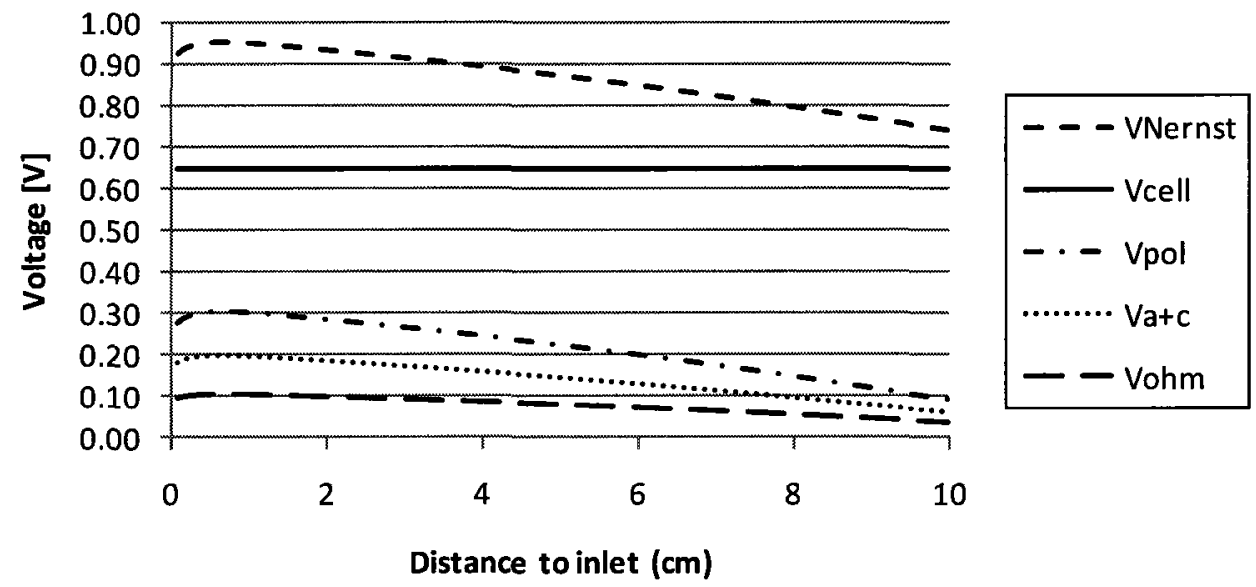

Figure 4.61: Change of voltage for co-flow configuration of Model-V1. 


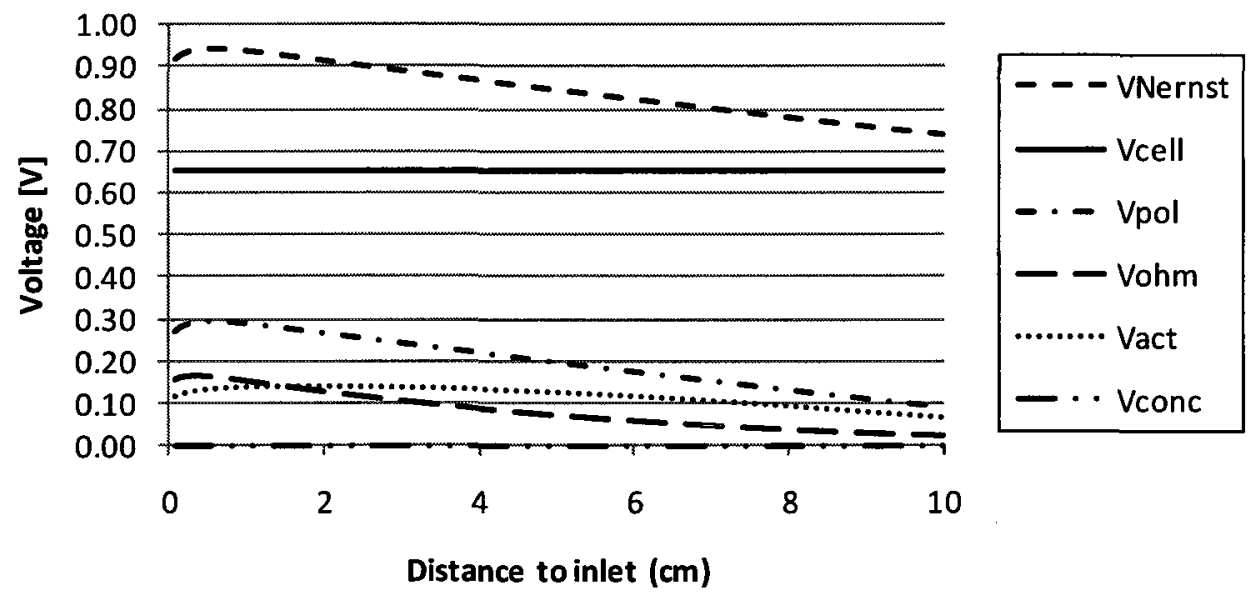

Figure 4.62: Change of voltage for co-flow configuration of Model-V2.

\subsection{Transient behavior of the cell}

After validating the model, the co-flow and counter-flow simulations are carried out for the same cell voltage and fuel utilization, which are chosen as $0.69 \mathrm{~V}$ and 0.85 , respectively. The 2-D temperature distributions are found for several time steps for both of the configurations and the transient behavior of the cell is investigated.

Figure 4.63 shows the temperature distributions for the co-flow configuration at different time steps during the start-up period. The temperature distribution at the heat-up period is same as the humidified hydrogen case; hence it is not shown again in this section. As can be followed from this figure, there is a temperature rise with time due to fixing the inlet temperature of air and fuel channels at a higher temperature than the temperature of the cell at the end of heat-up period. The temperature at the $\mathrm{x}$ direction drops suddenly due to the endothermic steam reforming reaction and then increases through the channel due to exothermic electrochemical and water-gas shift reactions. For this configuration, the cell 
reaches steady state condition at 4433 s. At this time, the temperature gradients of the solid part in the $\mathrm{x}$ and $\mathrm{y}$ directions are approximately $15.6{ }^{\circ} \mathrm{C} / \mathrm{cm}$ and $1.03{ }^{\circ} \mathrm{C} / \mathrm{cm}$, respectively. The temperature distribution for several time steps for the counter-flow configuration is shown in Figure 4.64. As can be seen from this figure, temperature reaches a higher value at the steady state condition for this configuration compared to coflow configuration. At this time, the temperature gradients of the solid part in the $\mathrm{x}$ and $\mathrm{y}$ directions are approximately $7.48{ }^{\circ} \mathrm{C} / \mathrm{cm}$ and $1.01{ }^{\circ} \mathrm{C} / \mathrm{cm}$, respectively. As illustration, the temperature gradients of the solid structure at the flow direction for co- and counterflow configurations are shown in Figure 4.65. The effect of steam reforming reaction, which causes a sudden change in the temperature gradient at the inlet of the SOFC, can be clearly seen in this figure.

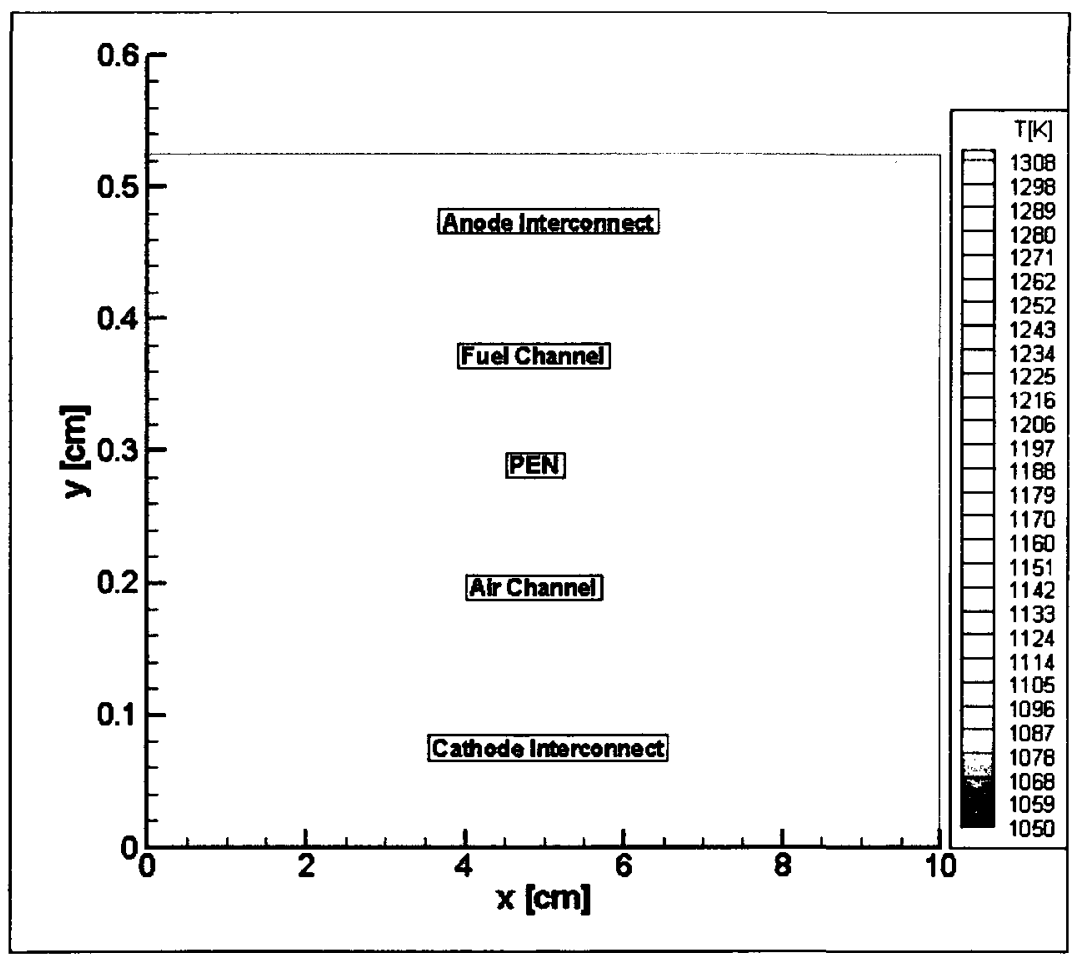

(a) $\mathrm{t}=1253 \mathrm{~s}$ 


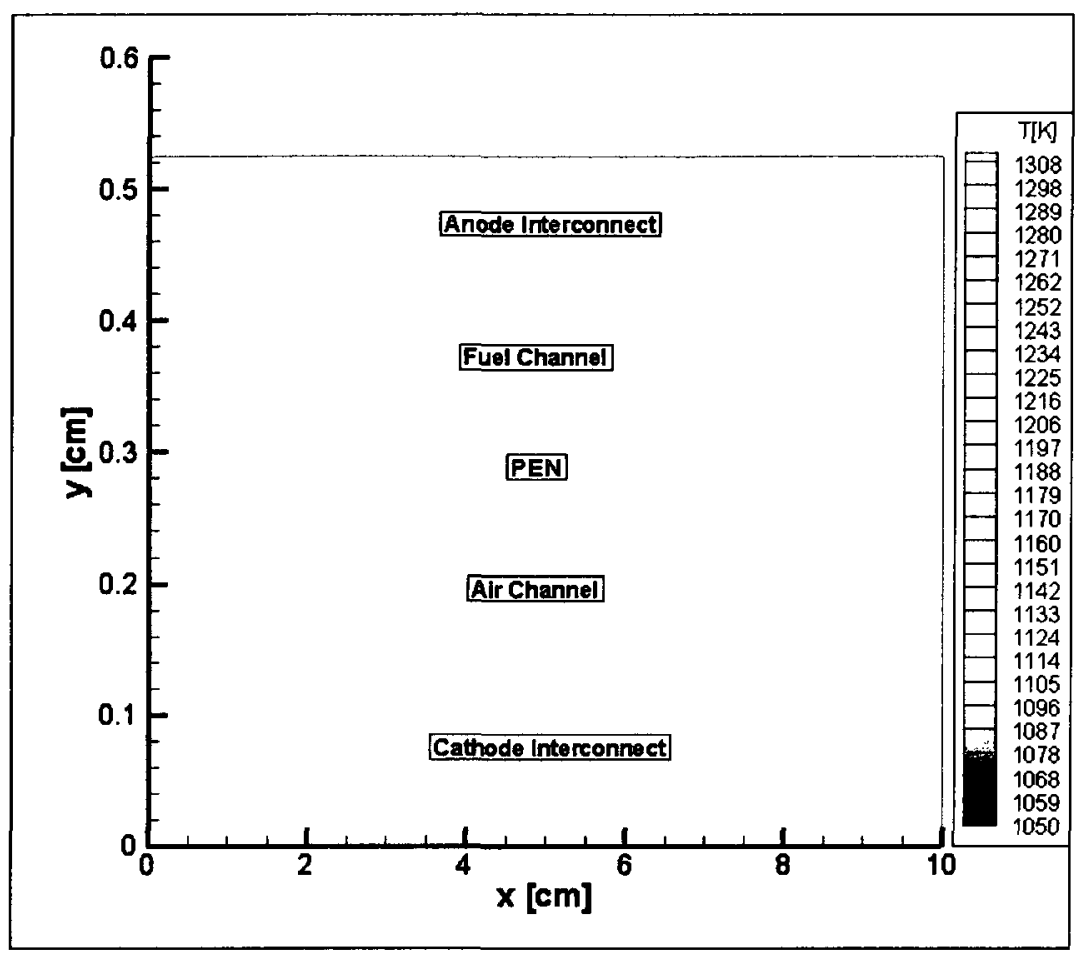

(b) $\mathrm{t}=1513 \mathrm{~s}$

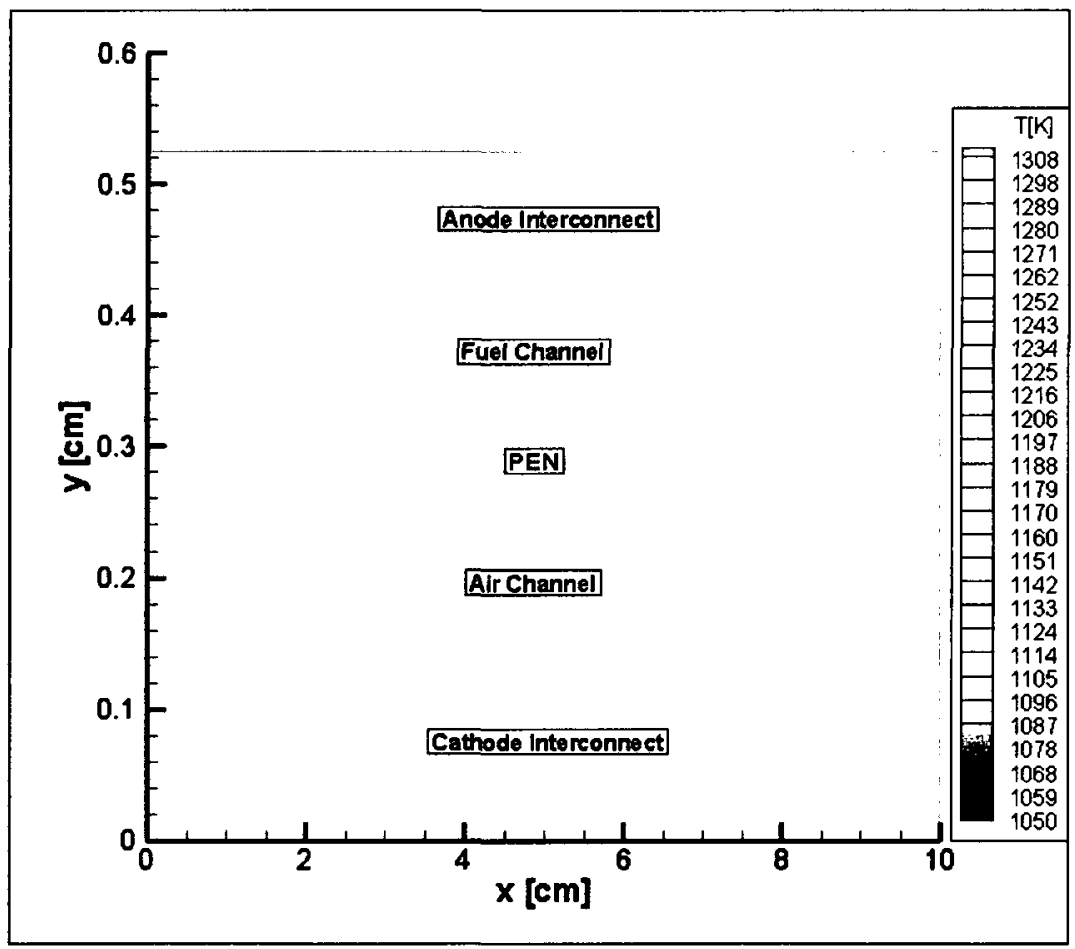

(c) $\mathrm{t}=1753 \mathrm{~s}$ 


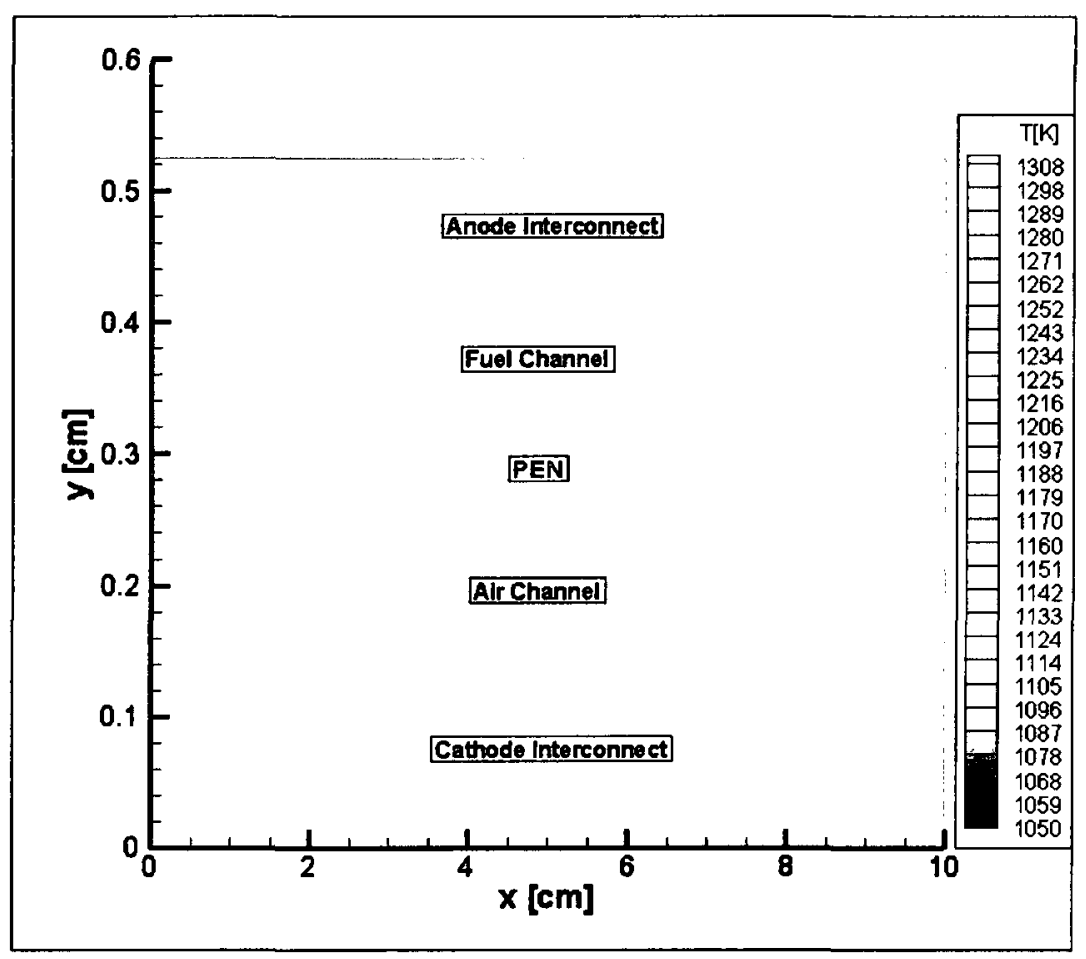

(d) $t=2013 \mathrm{~s}$

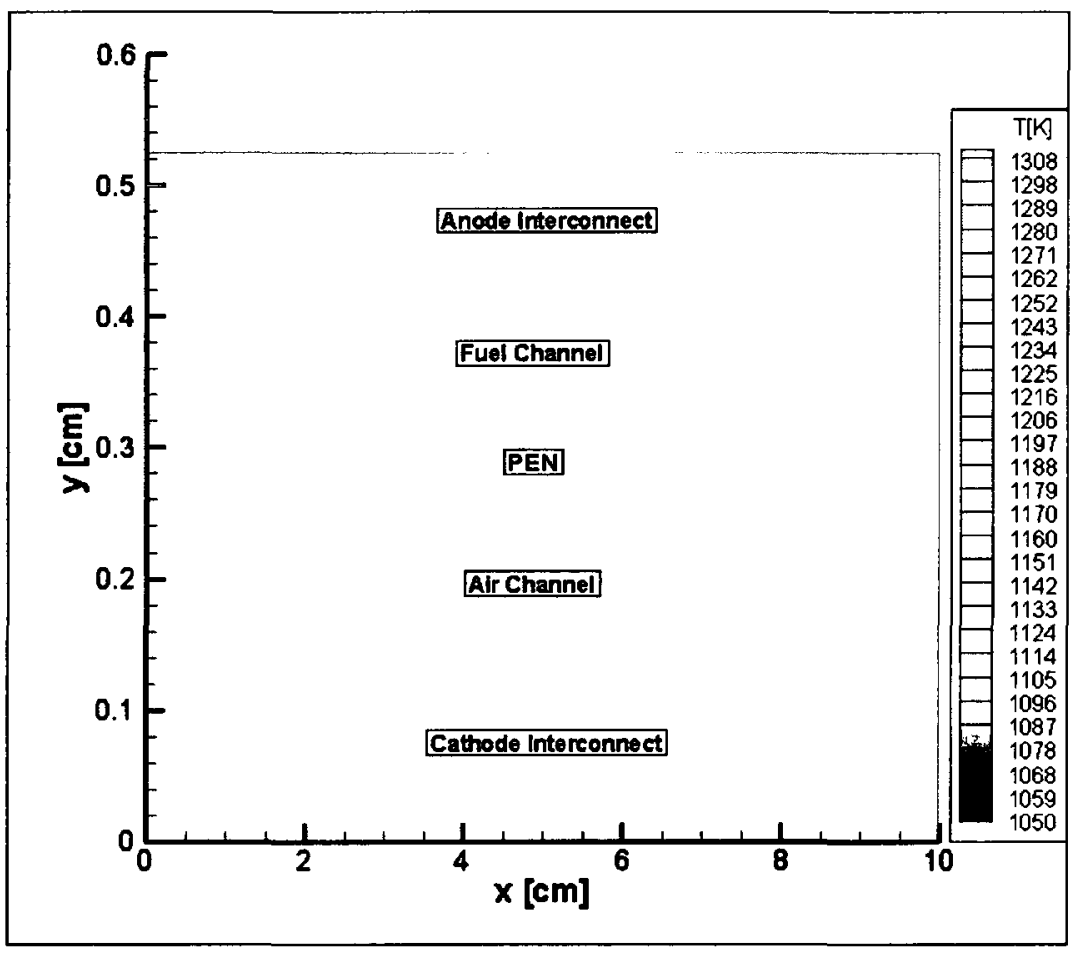

(e) $t=2513 \mathrm{~s}$ 


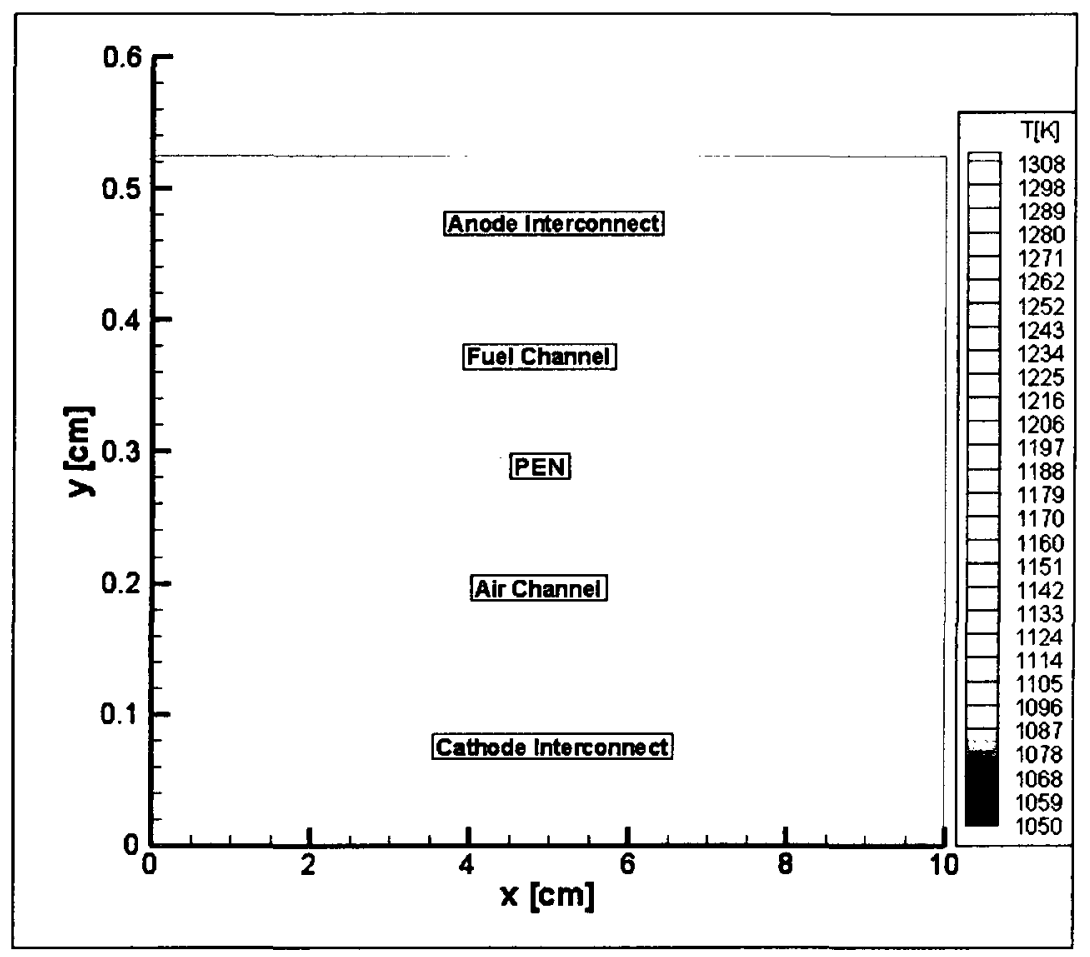

(f) $t=4433 \mathrm{~s}$

Figure 4.63: 2-D temperature distributions for co-flow SOFC at different time steps.

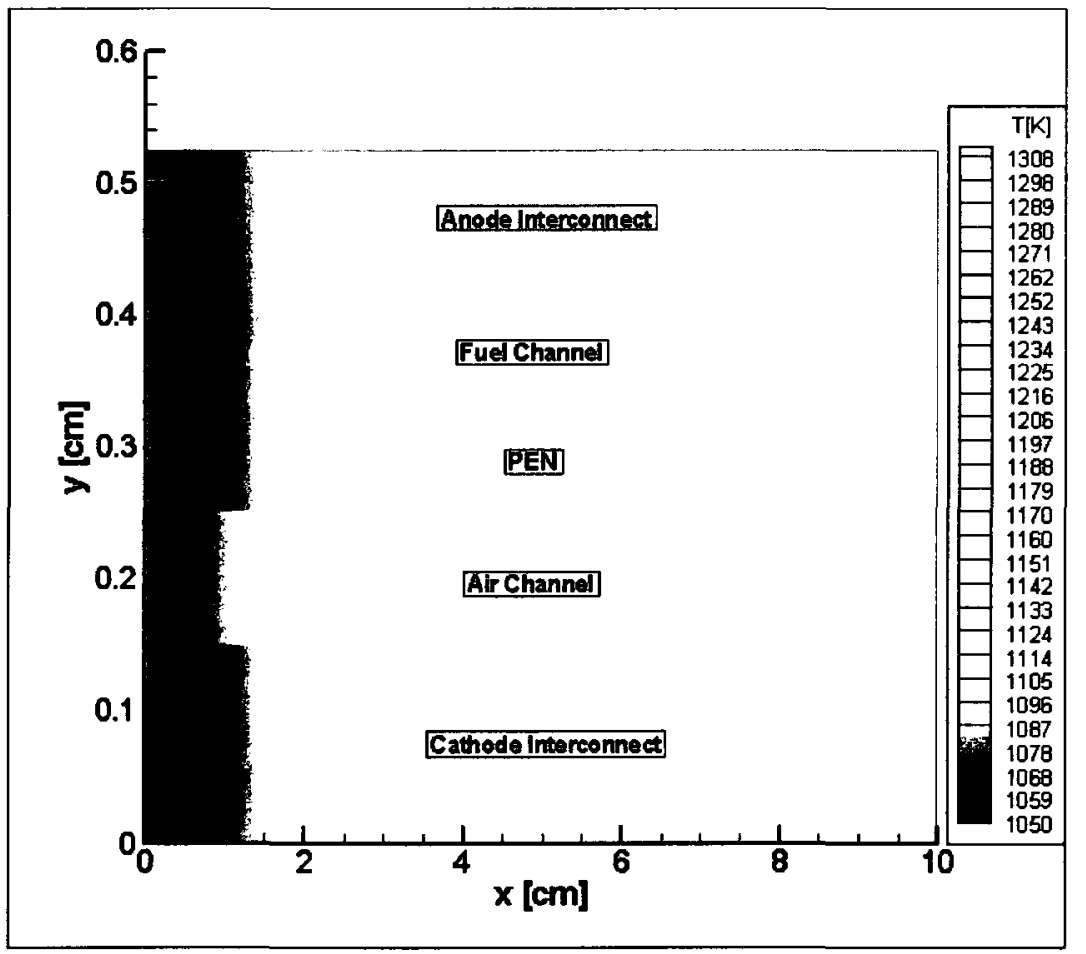

(a) $\mathrm{t}=1253 \mathrm{~s}$ 


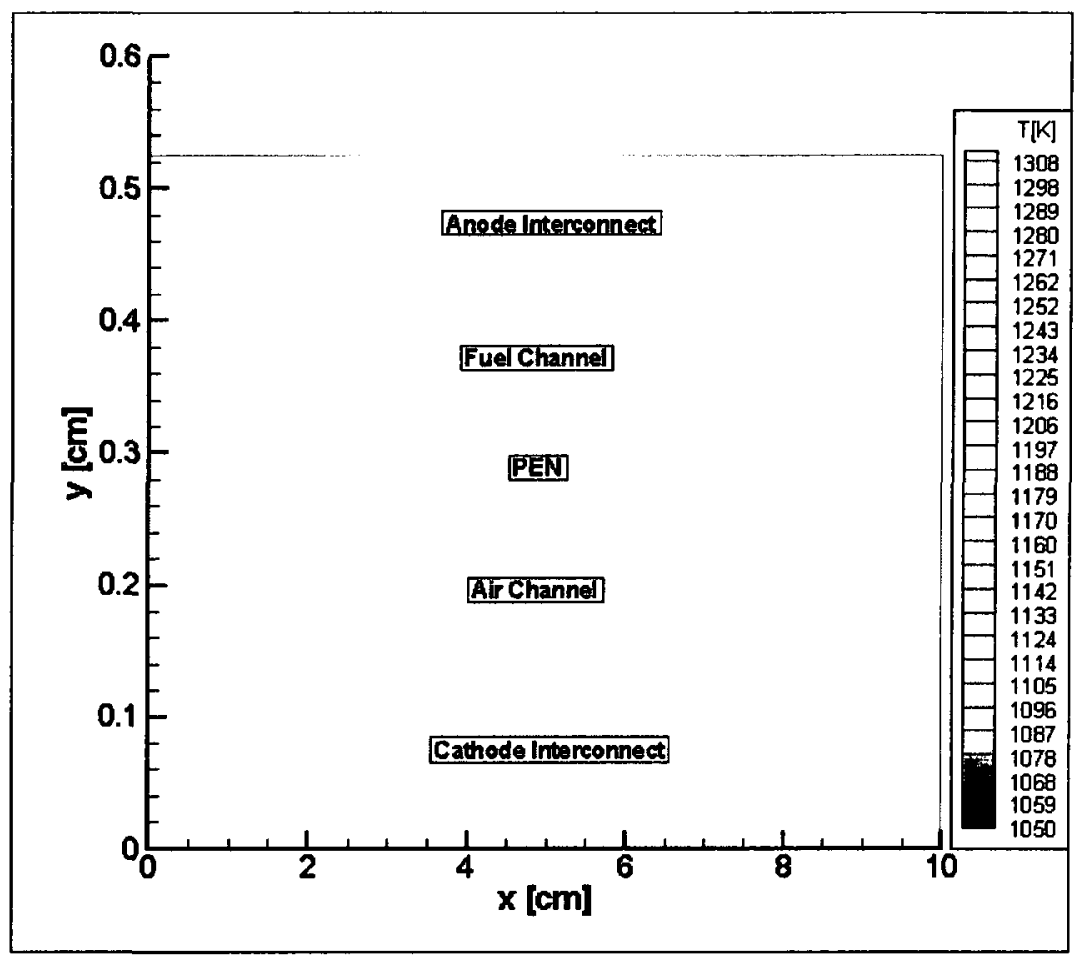

(b) $t=1513 \mathrm{~s}$

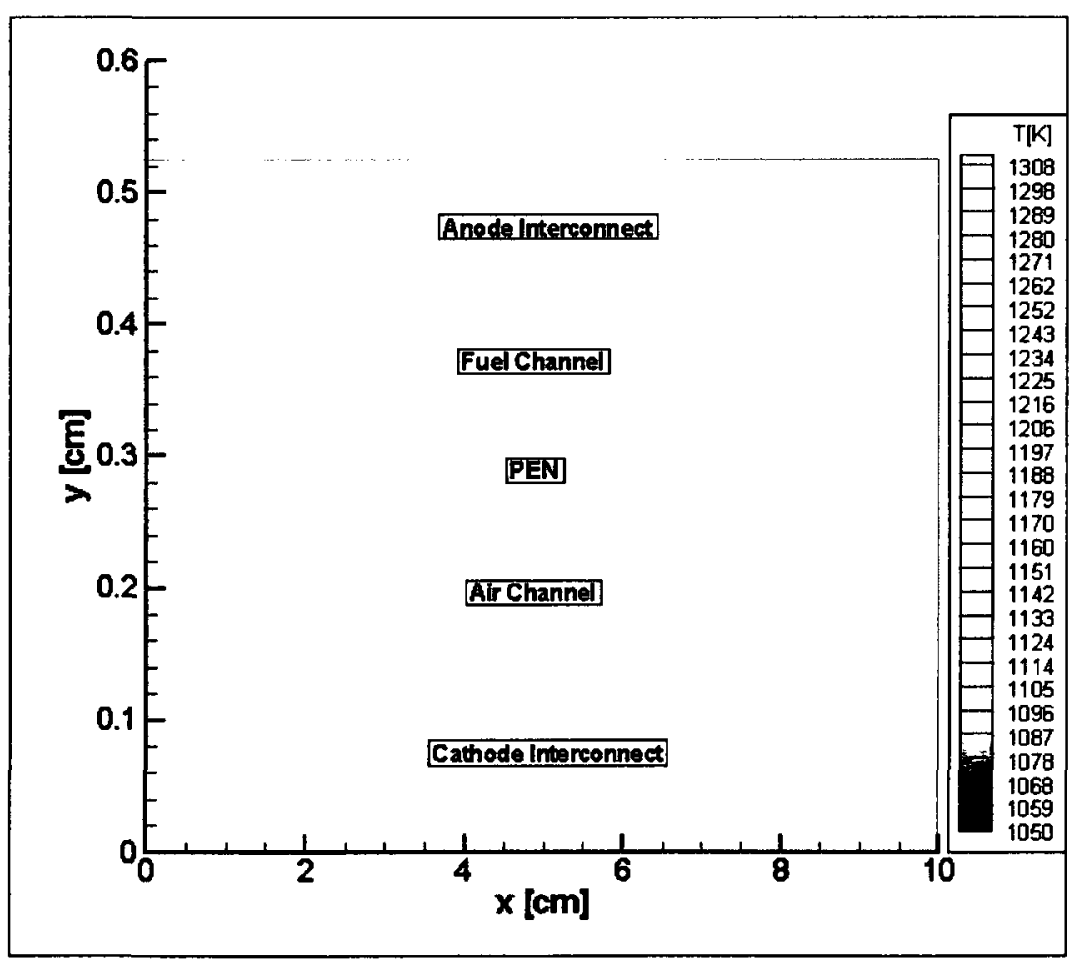

(c) $t=1753 \mathrm{~s}$ 


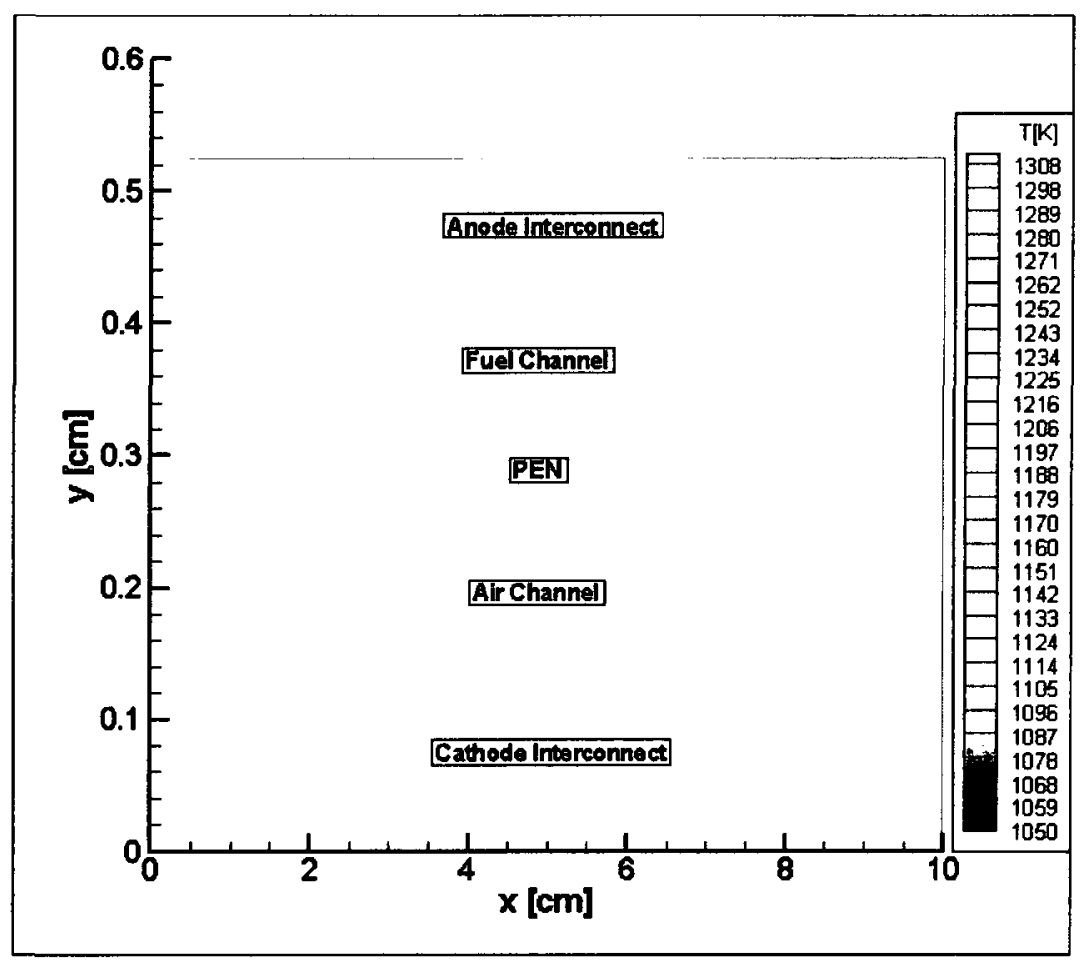

(d) $\mathrm{t}=2013 \mathrm{~s}$

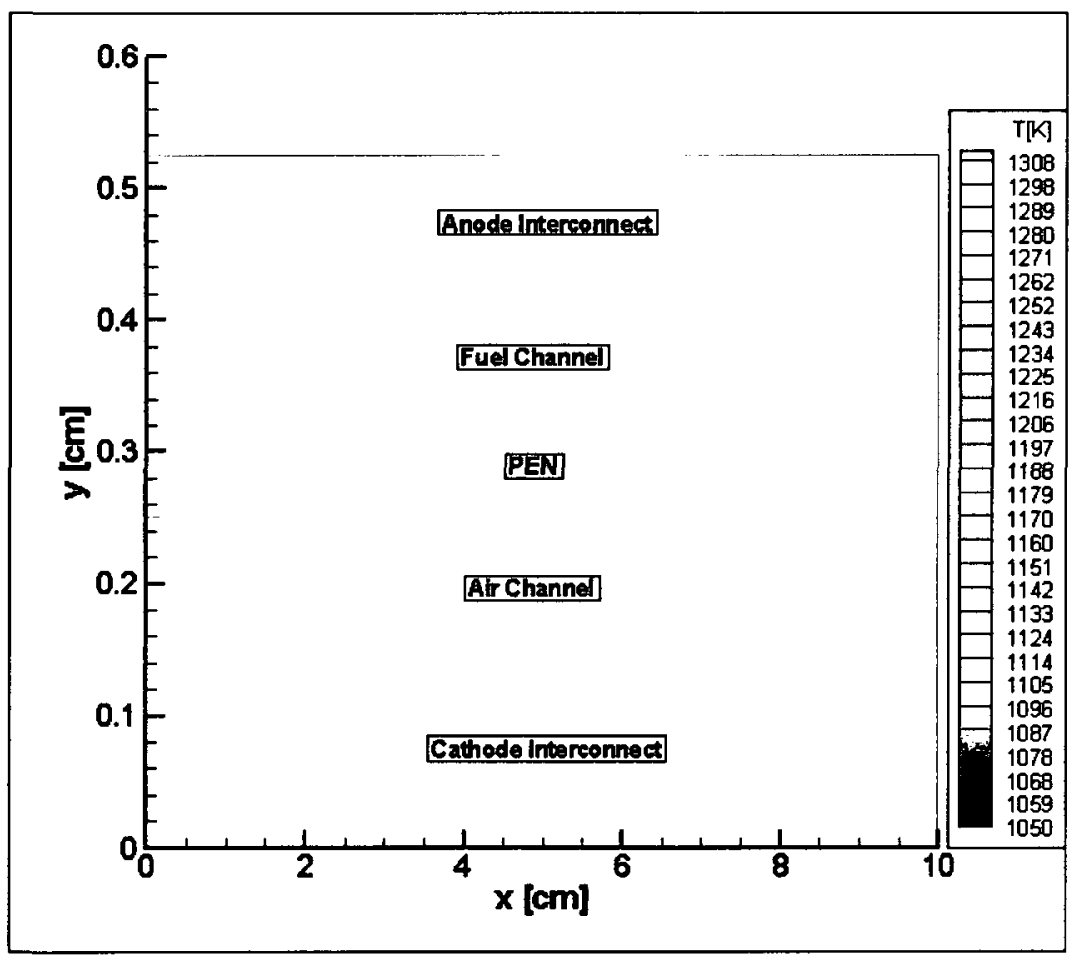

(e) $t=2513 \mathrm{~s}$ 


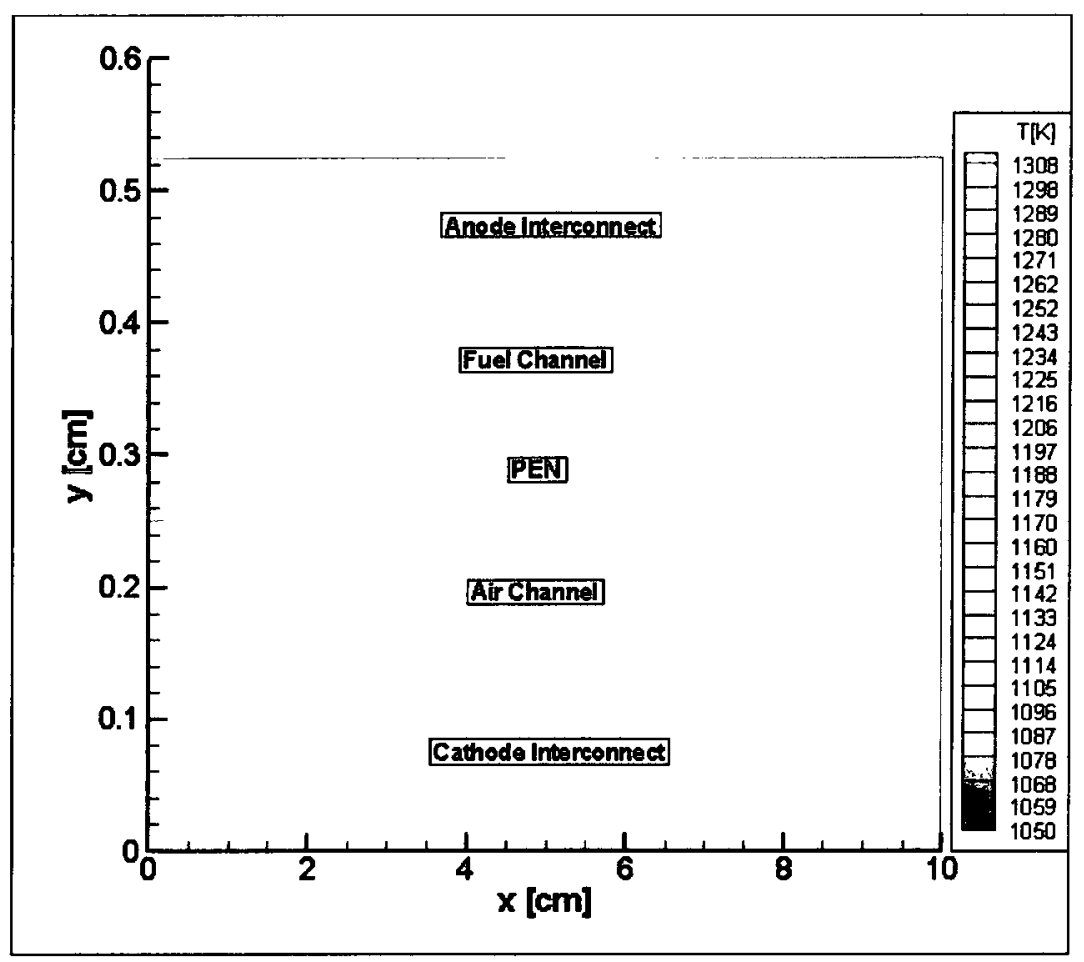

(f) $t=4433 \mathrm{~s}$

Figure 4.64: 2-D temperature distributions for counter-flow SOFC at different time steps.

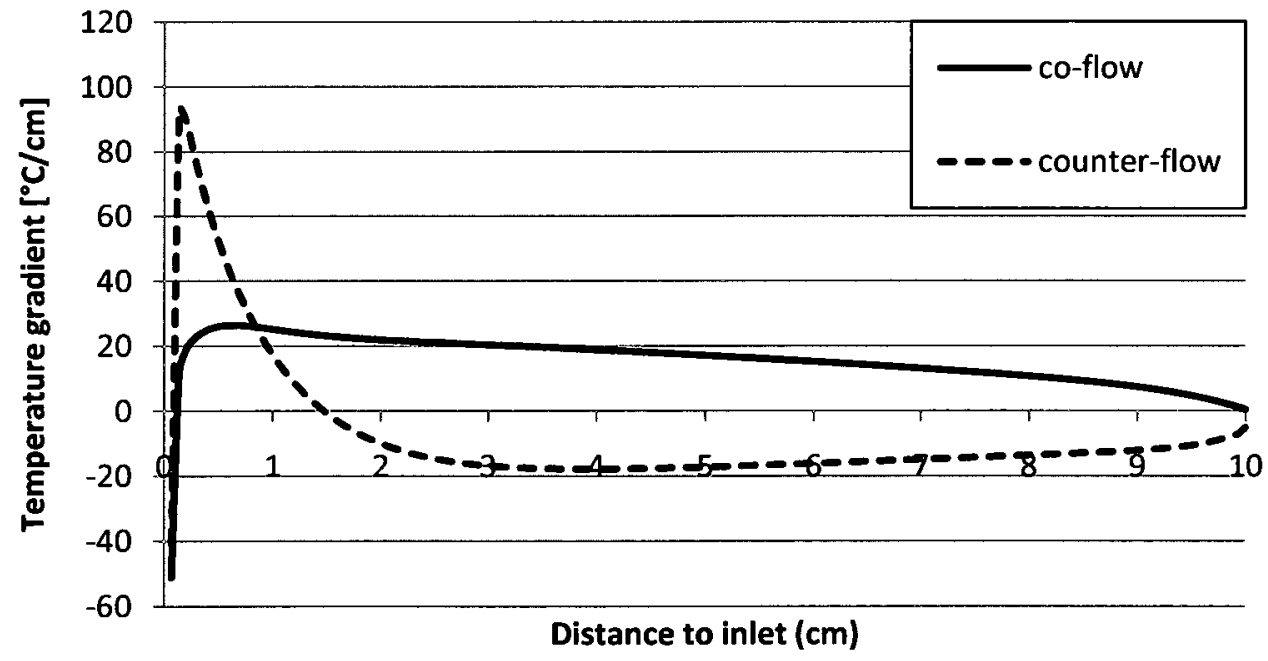

Figure 4.65: Average temperature gradient of the solid structure in the fuel flow direction 
Figures 4.66-4.70 show how the temperature, fuel utilization, average current density, electrical efficiency and power density and change with time for the co-flow and counterflow configurations. For example, these figures show that for the co-flow case, during the start-up period, average current density, fuel utilization, power density, and electrical efficiency increase from 0.18 to $0.27 \mathrm{~A} / \mathrm{cm}^{2}, 0.56$ to $0.85,0.12$ to $0.18 \mathrm{~W} / \mathrm{cm}^{2}$, and 0.42 to 0.63 , respectively.

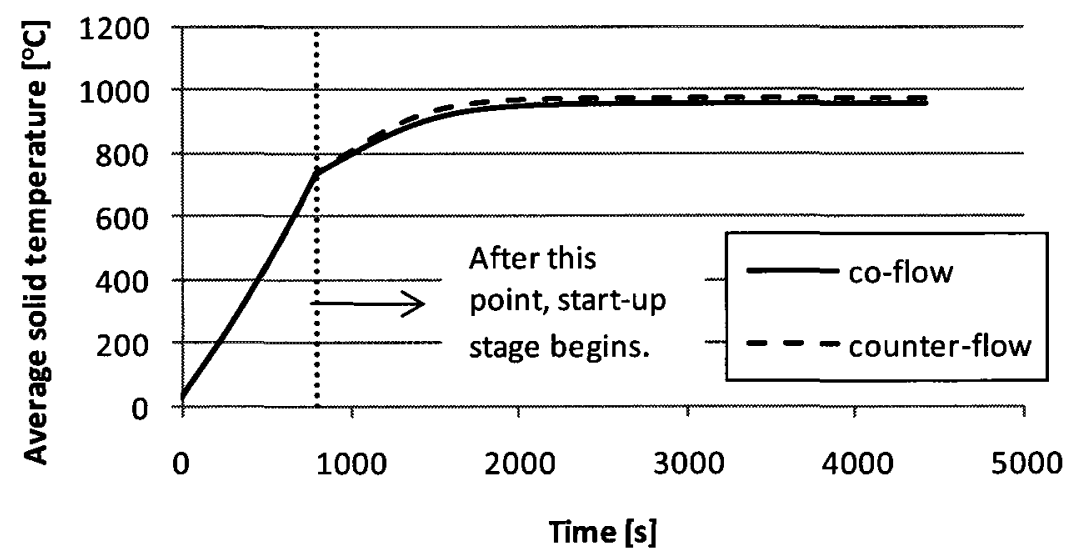

Figure 4.66: Change of average solid temperature with time for the DIR-SOFC operating with a gas mixture.

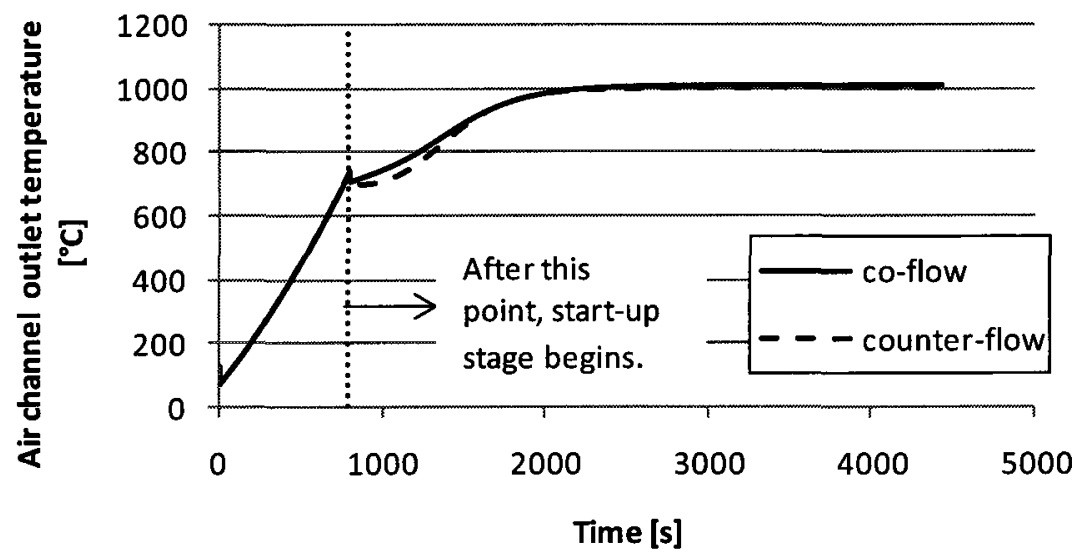

Figure 4.67: Change of air channel outlet temperature with time for the DIR-SOFC operating with a gas mixture. 


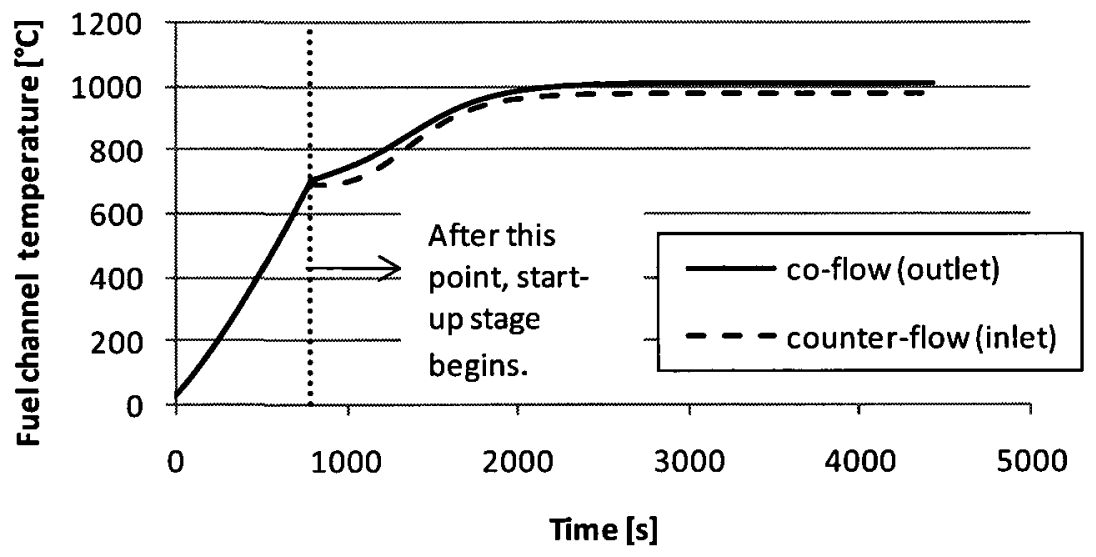

Figure 4.68: Change of fuel channel temperature with time for the DIR-SOFC operating with a gas mixture.

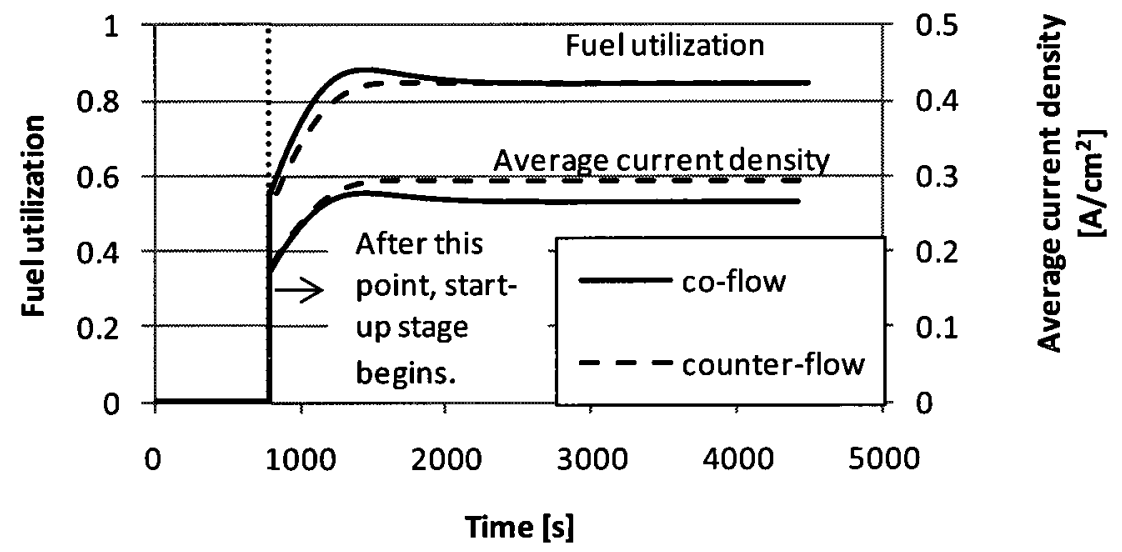

Figure 4.69: Change of fuel utilization and average current density with time for the DIR-SOFC operating with a gas mixture.

\subsection{System Level Modeling}

In this section, energy and exergy analyses, which are discussed in Section 3.8, are applied to several integrated SOFC systems. As a result of these analyses, performances of these systems are assessed, and exergy destructions and losses within these systems are calculated. 


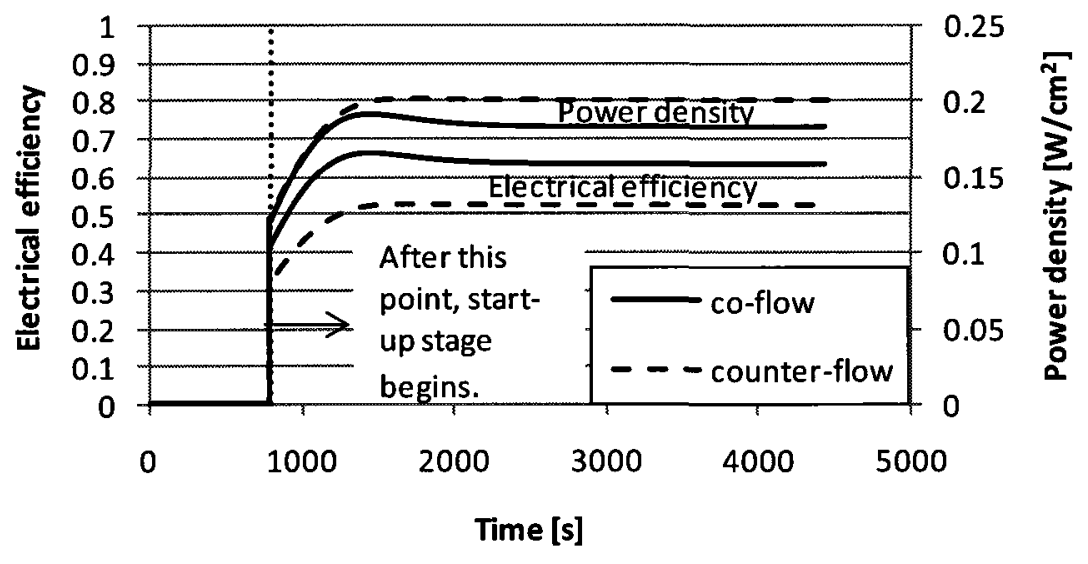

Figure 4.70: Change of electrical efficiency and power density with time for the DIRSOFC operating with a gas mixture.

\subsubsection{SOFC and gas turbine based cogeneration system}

In this study, a cogeneration system based on a pressurized, high temperature, direct internal reforming SOFC is analyzed. In such systems, pressurizing the fuel cell is a necessity since the cell voltage or power output of the cell increases with pressure. In addition, the enthalpy of the HRSG inlet increases because of the decrease in the temperature difference along the recuperator for the air and fuel flow sides; hence, the enthalpy difference rate of the process, fuel utilization ratio, and exergetic efficiency of the system become higher. The description of the system, and the modeling technique and equations are given in Section 3.8.3.1. The input data used in energy and exergy analysis of the system is given in Table 4.12.

Using the modeling technique mentioned in Section 3.8.3.1 and the input data given in Table 4.12, the calculations are done. First, the recirculation ratio needed to prevent the carbon deposition is found. For this purpose, an initial recirculation ratio of 0.1 is initially 
taken and then it is increased by 0.1 until the carbon activity becomes less than 1 . The variation of carbon activity with recirculation ratio is shown in Table 4.13 . It can be seen from this table that 0.4 is the minimum recirculation ratio needed to prevent the carbon deposition.

Table 4.12: Input data of the system.

\begin{tabular}{|c|c|}
\hline Fuel & Methane \\
\hline Environmental temperature & $25^{\circ} \mathrm{C}$ \\
\hline Environmental pressure & $100 \mathrm{kPa}$ \\
\hline Net electrical work output of the system & $1 \mathrm{MW}$ \\
\hline \multicolumn{2}{|l|}{ SOFC } \\
\hline Exit Temperature & $1000^{\circ} \mathrm{C}$ \\
\hline $\begin{array}{l}\text { Temperature difference between } \\
\text { exit and inlet }\end{array}$ & $100^{\circ} \mathrm{C}$ \\
\hline Pressure & $1500 \mathrm{kPa}$ \\
\hline Operating voltage & $0.7 \mathrm{~V}$ \\
\hline Active surface area of a single cell & $100 \mathrm{~cm}^{2}$ \\
\hline Fuel utilization ratio & 0.85 \\
\hline Thickness of anode & $50 \mu \mathrm{m}$ \\
\hline Thickness of electrolyte & $150 \mu \mathrm{m}$ \\
\hline Thickness of cathode & $50 \mu \mathrm{m}$ \\
\hline Thickness of interconnect & $5 \mathrm{~mm}$ \\
\hline \multicolumn{2}{|l|}{ HRSG (Heat Recovery Steam Generator) } \\
\hline Steam drum pressure & $1200 \mathrm{kPa}$ \\
\hline Pinch point & $10^{\circ} \mathrm{C}$ \\
\hline Evaporator approach temperature & $10^{\circ} \mathrm{C}$ \\
\hline Condensate return temperature & $25^{\circ} \mathrm{C}$ \\
\hline Heat loss from HRSG & $2 \%$ \\
\hline Pressure drop on the air side & $5 \%$ \\
\hline \multicolumn{2}{|l|}{ Gas Turbine } \\
\hline Pressure ratio & $5: 1$ \\
\hline Isentropic efficiency & 0.85 \\
\hline Electric generator efficiency & 0.98 \\
\hline Isentropic efficiency of compressors & 0.85 \\
\hline
\end{tabular}


Table 4.13: Carbon activity for different recirculation ratios.

\begin{tabular}{|c|c|}
\hline Recirculation ratio, $r$ & Carbon activity, $\alpha_{c}$ \\
\hline 0.1 & 10.14 \\
\hline 0.2 & 2.65 \\
\hline 0.3 & 1.16 \\
\hline 0.4 & 0.59 \\
\hline
\end{tabular}

For the recirculation ratio of 0.4 , it is found that the air utilization ratio is $17 \%$ and the power output of a single cell is $46.17 \mathrm{~W}$. The remaining thermodynamic properties, physical and chemical exergy flow rates, and total exergy flow rates of the states of the system are shown in Table 4.14. From this table, it can be interpreted that state 7, which is the exit of the combustor, has the highest energy quality since its total flow exergy rate is higher than other states. If we invent a device and bring this state into equilibrium with its environment, we may achieve $2.7 \mathrm{MW}$ work output. After applying the exergy balances, the exergy destruction rates and exergy loss rates are calculated together with their relevant ratios. These results are shown in Table 4.15, and Figures 4.71 and 4.72. From Table 4.15, it can be seen that the control volume enclosing the SOFC and the combustor has the highest exergy destruction which is mainly due to the combustion of the depleted air and fuel streams of the fuel cell. They account for the $12.5 \%$ of the exergy of the fuel and $40.5 \%$ of the total exergy destructions. The only exergy loss to the environment is the exergy flow rate of the stack, which is $7 \%$ of the exergy of the fuel. 
Table 4.14: Thermodynamic properties and exergy flow rates of the states.

\begin{tabular}{|l|c|r|r|r|r|r|}
\hline State & $\dot{m}(\mathrm{~kg} / \mathrm{s})$ & \multicolumn{1}{|c|}{$\left(^{\circ} \mathrm{C}\right)$} & $\mathrm{P}(\mathrm{kPa})$ & $\dot{E} x_{p h}(\mathrm{~kW})$ & $\dot{E} x_{c h}(\mathrm{~kW})$ & $\dot{E} x(\mathrm{~kW})$ \\
\hline 1 & 0.032318 & 25.0 & 101.3 & 0.000 & 1660.600 & 1660.600 \\
\hline 2 & 0.032318 & 277.6 & 1519.9 & 19.546 & 1660.600 & 1680.146 \\
\hline 3 & 2.815823 & 25.0 & 101.3 & 0.000 & 0.000 & 0.000 \\
\hline 4 & 2.815823 & 420.3 & 1519.9 & 1079.644 & 0.000 & 1079.644 \\
\hline 5 & 0.032318 & 782.3 & 1519.9 & 59.292 & 1660.600 & 1719.892 \\
\hline 6 & 2.815823 & 900.0 & 1519.9 & 2113.568 & 0.000 & 2113.568 \\
\hline 7 & 2.848142 & 1093.4 & 1519.9 & 2704.008 & 3.817 & 2707.825 \\
\hline 8 & 2.848142 & 722.1 & 304.0 & 1347.052 & 3.817 & 1350.869 \\
\hline 9 & 2.848142 & 223.0 & 106.4 & 150.848 & 3.817 & 154.666 \\
\hline 10 & 2.848142 & 190.0 & 101.3 & 113.163 & 3.817 & 116.980 \\
\hline 11 & 0.036413 & 188.0 & 1200.0 & 30.786 & 0.091 & 30.877 \\
\hline 12 & 0.036413 & 25.0 & 1200.0 & 0.000 & 0.091 & 0.091 \\
\hline
\end{tabular}

Table 4.15: Exergy destructions and losses.

\begin{tabular}{|c|r|}
\hline Control Volume (CV) & $\dot{E} x_{D}, \dot{E} x_{L}(\mathrm{~kW})$ \\
\hline CV1 & 1.785 \\
\hline CV2 & 77.887 \\
\hline CV3 & 122.534 \\
\hline CV4 & 207.601 \\
\hline CV5 & 96.126 \\
\hline CV6 & 6.900 \\
\hline Stream10 & 116.980 \\
\hline
\end{tabular}
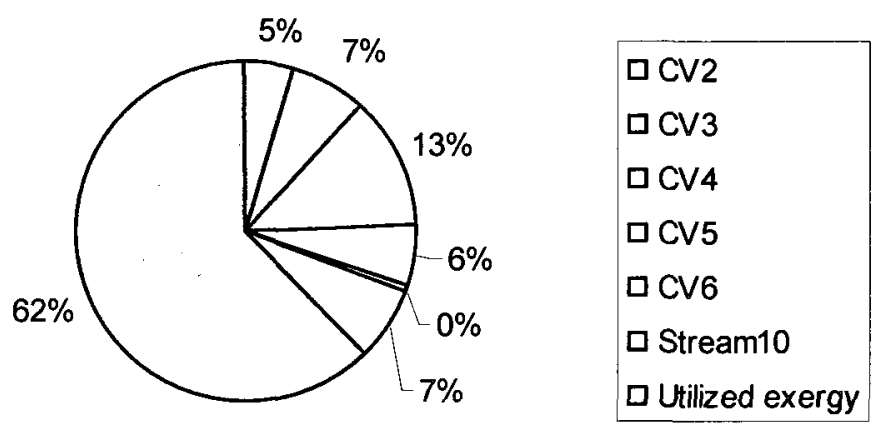

Figure 4.71: Exergy destructions and losses compared to the exergy of the fuel. 


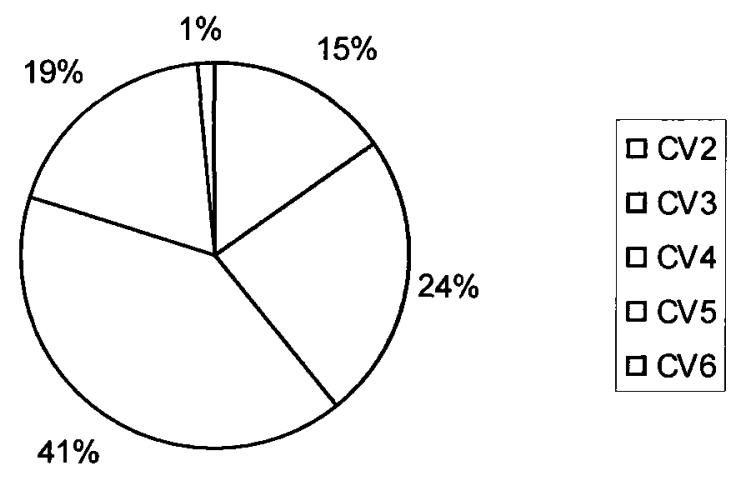

Figure 4.72: Exergy destructions of the components compared to the total exergy destruction.

The fuel utilization ratio and exergetic efficiency of the system are found to be $68 \%$ and $62 \%$, respectively, for the base case. Ambient temperature also affects the performance of the system analyzed as shown in Figure 4.73. A decrease in ambient temperature causes an increase in net electrical power output of the system due to the decrease in the power input to the compressors; but the inlet temperature of HRSG reduces which in turn decreases the amount of steam produced in the HRSG. When the performance assessment parameters are calculated, it is found that fuel utilization efficiency increases whereas exergetic efficiency decreases with an increase with the environmental temperature. As it can be followed from this figure, there are only a few percentage differences between these efficiencies. However, since the exergetic efficiency gives more meaningful values compared to fuel utilization efficiency, it may be suggested that the reader should consider the values of this parameter for the performance of the system. 


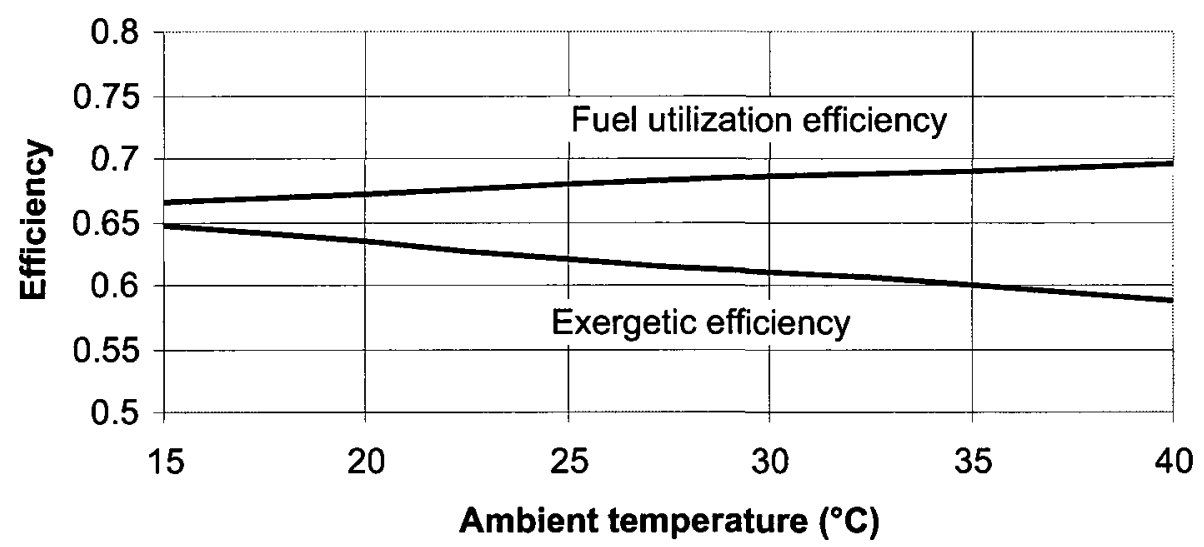

Figure 4.73: Effect of ambient temperature on the fuel utilization efficiency and exergetic efficiency of the system.

In conventional cogeneration systems, a gas turbine is used as the electricity production device in general and its exhaust heat is recovered and utilized to produce steam. In the book by Bejan et al. [111], a gas turbine based cogeneration system is analyzed and it is found that this system has $50 \%$ exergetic efficiency. Hence, this study shows that fuel cell based cogeneration systems are very promising to obtain better performance.

\subsubsection{SOFC and biomass gasification system - Study I}

In this study, the system described in Section 3.8.3.2 is analyzed for a case where wood is used as the fuel. Performance of the fuel cell at different operating temperature levels is studied. The changes of the operating cell voltage, air utilization ratio, power output of the SOFC, and electrical efficiency of the system with current density are investigated.

Different temperature levels for SOFC are considered, which are low, intermediate, and high. The manufacturing types of the fuel cells studied are chosen according to these 
temperature levels. The input data and modeling parameters used in this study are shown in Table 4.16.

Table 4.16: Input data and modeling parameters used in the case study.

\begin{tabular}{|l|l|}
\hline Fuel & Wood \\
\hline Ultimate analysis of biomass [\%wt dry basis] & $50 \% \mathrm{C}, 6 \% \mathrm{H}, 44 \% \mathrm{O}$ \\
\hline Moisture content in biomass [\%wt] & $20 \%$ \\
\hline Environmental temperature & $25{ }^{\circ} \mathrm{C}$ \\
\hline Temperature of air entering biomass gasifier & $400{ }^{\circ} \mathrm{C}$ \\
\hline Temperature of syngas exiting biomass gasifier & $70{ }^{\circ} \mathrm{C}^{\mathrm{a}}, 800{ }^{\circ} \mathrm{C}^{\mathrm{b}}, 900^{\circ} \mathrm{C}^{\mathrm{c}}$ \\
\hline Temperature of air and fuel entering SOFC & $650^{\circ} \mathrm{C}^{\mathrm{a}}, 750{ }^{\circ} \mathrm{C}^{\mathrm{b}}, 850^{\circ} \mathrm{C}^{\mathrm{c}}$ \\
\hline $\begin{array}{l}\text { Temperature difference between the inlet and exit } \\
\text { of gas channels of SOFC }\end{array}$ & $100{ }^{\circ} \mathrm{C}$ \\
\hline Pressure of the cell & $100 \mathrm{kPa}$ \\
\hline Fuel utilization ratio of the fuel cell & 0.75 \\
\hline Active surface area of a single cell & $100 \mathrm{~cm}^{2}$ \\
\hline Exchange current density of anode & $0.53 \mathrm{~A} / \mathrm{cm}^{2}$ \\
\hline Exchange current density of cathode & $0.2 \mathrm{~A} / \mathrm{cm}^{2}$ \\
\hline Effective gaseous diffusivity through the anode & $0.2 \mathrm{~cm}^{2} / \mathrm{s}$ \\
\hline Effective gaseous diffusivity through the cathode & $0.05 \mathrm{~cm}^{2} / \mathrm{s}$ \\
\hline Thickness of anode & $500 \mu \mathrm{m}^{\mathrm{a}, \mathrm{b},} 50 \mu \mathrm{m}^{\mathrm{c}}$ \\
\hline Thickness of electrolyte & $10 \mu \mathrm{m}^{\mathrm{a}, \mathrm{b},} 150 \mu \mathrm{m}^{\mathrm{c}}$ \\
\hline Thickness of cathode & $50 \mu \mathrm{m}^{\mathrm{a}, \mathrm{b}, \mathrm{c}}$ \\
\hline
\end{tabular}

${ }^{a}$ Case-1: Low-temperature and anode supported SOFC

${ }^{b}$ Case-2: Intermediate-temperature and anode supported SOFC

${ }^{c}$ Case-3: High-temperature and electrolyte supported SOFC

Using the ultimate analysis given in Table 4.16, wood may be represented as $\mathrm{CH}_{1.44} \mathrm{O}_{0.66}$. A thermodynamic modeling of the gasification system enables us to find the syngas 
composition entering the gas clean-up system. Figure 4.74 shows the syngas composition at different gasifier temperatures. As expected, $\mathrm{N}_{2}$ has the highest share in the composition which changes between $42 \%$ and $49 \%$ with temperature. $\mathrm{CH}_{4}$ concentration is the lowest among the gases, which changes between $4 \%$ and $0.3 \%$ with temperature.

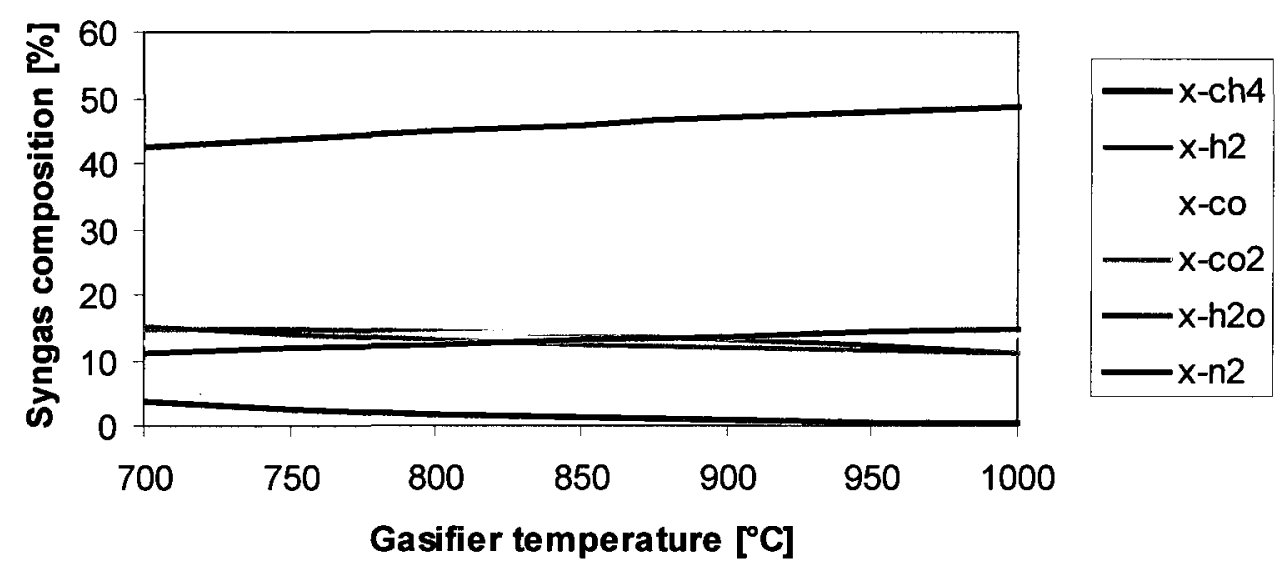

Figure 4.74: Syngas composition for different gasifier temperature.

Using the composition of syngas and other input parameters given in Table 4.16, the cell voltage, air utilization ratio, power output, and electrical efficiency of the system are calculated for different current densities for each case, and shown in Figures 4.75-4.78. It should be noted that without recirculation of the fuel channel exit, carbon activity is found to be less than 1 for all cases, which means there is no possibility of carbon deposition in the viewpoint of thermodynamics. It can be seen from Figure 4.75 that air utilization ratio decreases as current density increases. This shows us that more air should be sent through the air channel to carry away the excess heat from the fuel cell for high current density conditions. On the other hand, case-1 has the highest air utilization ratio, 
which makes this case economically less feasible since sending excess air is costly. Figure 4.76 shows that case- 3 may be operated in a wider current density range; however it has lower cell voltage compared to other cases. The power output of a single cell and electrical efficiency of the system are shown in Figures 4.77 and 4.78, respectively. It can be seen from these figures that case-1 has higher power output and electrical efficiency.

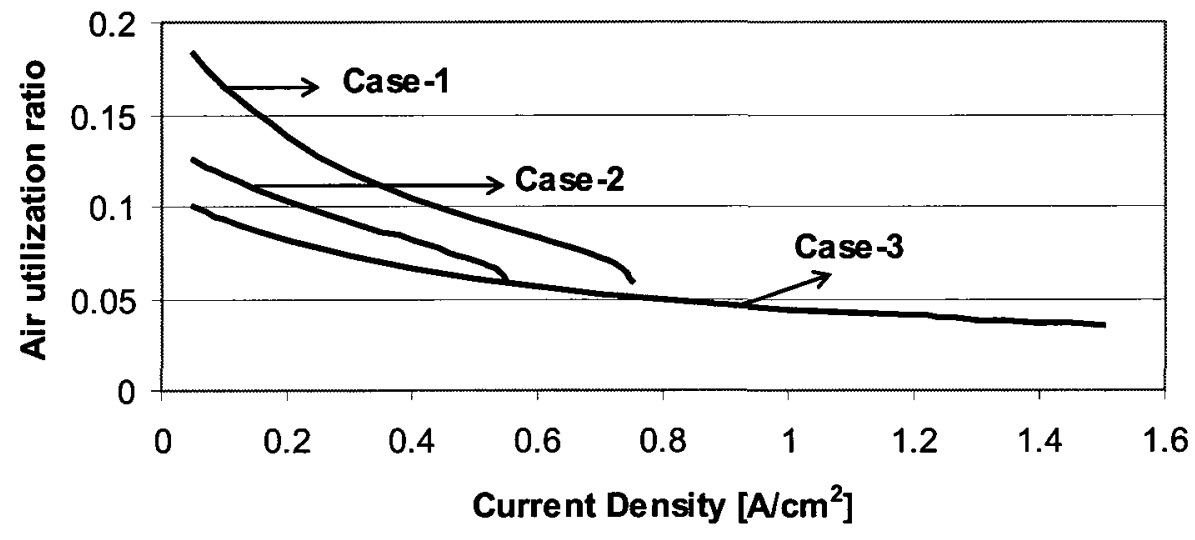

Figure 4.75: Change of air utilization ratio with current density.

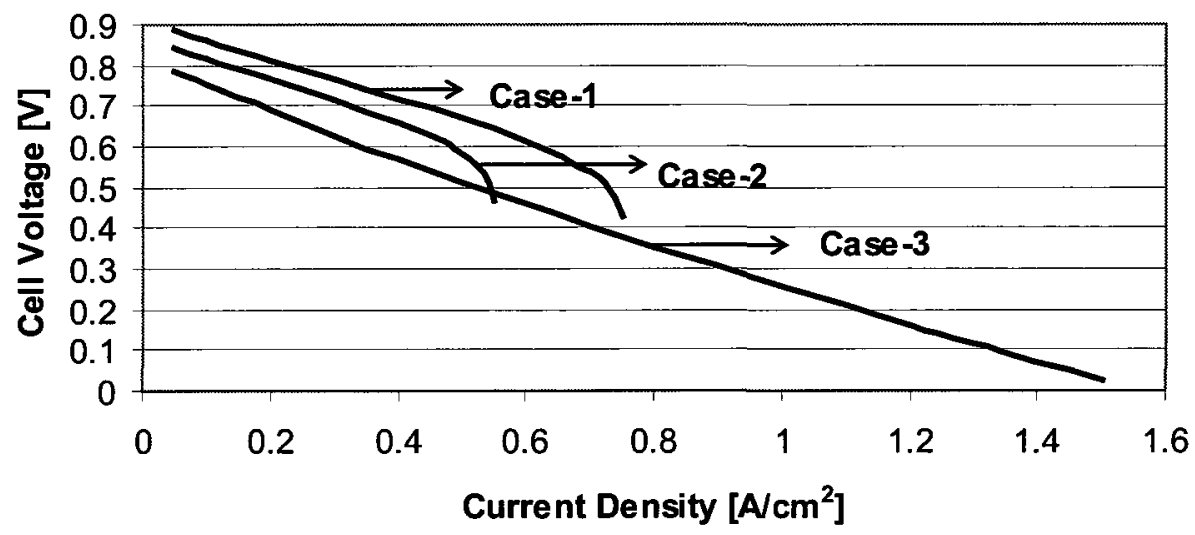

Figure 4.76: Change of cell voltage with current density. 


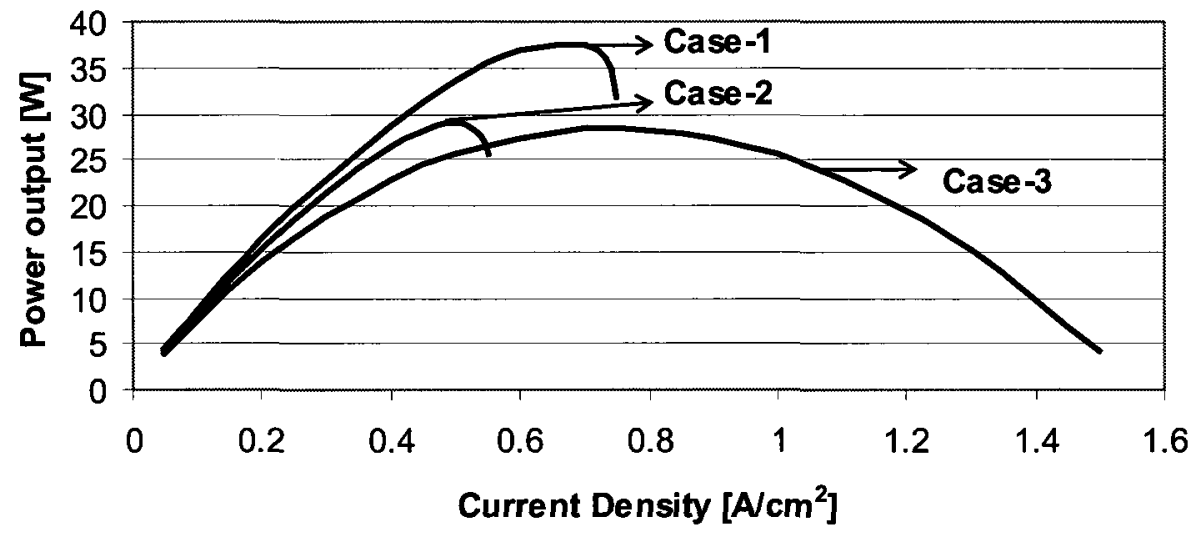

Figure 4.77: Change of power output of a single cell with current density.

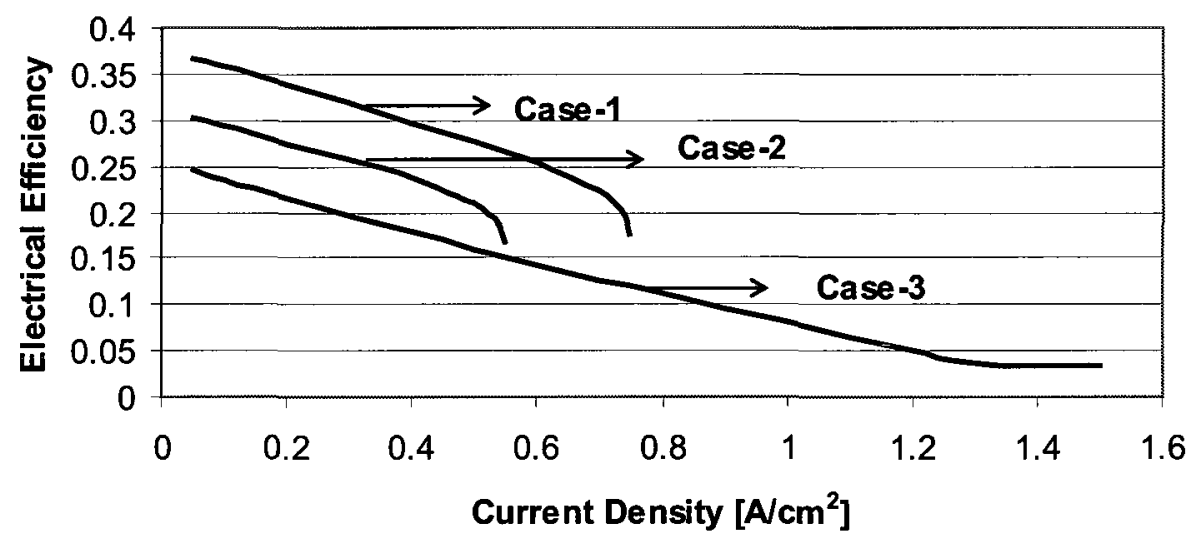

Figure 4.78: Change of electrical efficiency with current density.

\subsubsection{SOFC and biomass gasification system - Study II}

A case study is conducted for the system introduced in Section 3.8.3.3 using the modeling technique discussed in this section. The input data used for this study are given in Table 4.17. 
Table 4.17: Input data used in the case study.

\begin{tabular}{|c|c|}
\hline Environmental temperature & $25^{\circ} \mathrm{C}$ \\
\hline \multicolumn{2}{|l|}{ Fuel } \\
\hline Type of biomass & Wood \\
\hline Ultimate analysis of biomass [\%wt dry basis] & $50 \% \mathrm{C}, 6 \% \mathrm{H}, 44 \% \mathrm{O}$ \\
\hline Moisture content in biomass [\%wt] & $40 \%$ \\
\hline \multicolumn{2}{|l|}{ Gasifier } \\
\hline Moisture content in biomass entering gasifier [\%wt] & $20 \%$ \\
\hline Temperature of syngas exiting gasifier & $900^{\circ} \mathrm{C}$ \\
\hline $\begin{array}{l}\text { Molar ratio of steam entering to gasifier to } \\
\text { drybiomass }\end{array}$ & 0.1 \\
\hline Molar composition of enriched oxygen & $0.35 \mathrm{O}_{2}, 0.65 \mathrm{~N}_{2}$ \\
\hline \multicolumn{2}{|l|}{ SOFC } \\
\hline Power requirement of SOFC & $10 \mathrm{~kW}$ \\
\hline Number of cells per stack & 50 \\
\hline Temperature of syngas entering SOFC & $850^{\circ} \mathrm{C}$ \\
\hline Temperature of air entering SOFC & $850^{\circ} \mathrm{C}$ \\
\hline Pressure of the cell & $100 \mathrm{kPa}$ \\
\hline Cell voltage & 0.65 \\
\hline Excess air coefficient & 7 \\
\hline Active cell area & $10 \times 10 \mathrm{~cm}^{2}$ \\
\hline Number of repeat elements per single cell & 18 \\
\hline Flow configuration & Co-flow \\
\hline Manufacturing type & Electrolyte-supported \\
\hline Thickness of air channel & $0.1 \mathrm{~cm}$ \\
\hline Thickness of fuel channel & $0.1 \mathrm{~cm}$ \\
\hline Thickness of interconnect & $0.3 \mathrm{~cm}$ \\
\hline Thickness of anode & $0.005 \mathrm{~cm}$ \\
\hline Thickness of electrolyte & $0.015 \mathrm{~cm}$ \\
\hline Thickness of cathode & $0.005 \mathrm{~cm}$ \\
\hline Emissivity of PEN & 0.8 \\
\hline Emissivity of interconnect & 0.1 \\
\hline Diffusivity of anode & $0.91 \mathrm{~cm}^{2} / \mathrm{s}$ \\
\hline Diffusivity of cathode & $0.22 \mathrm{~cm}^{2} / \mathrm{s}$ \\
\hline Porosity of anode & 0.5 \\
\hline Porosity of cathode & 0.5 \\
\hline Turtuosity of anode & 4 \\
\hline Turtuosity of cathode & 4 \\
\hline \multicolumn{2}{|l|}{ Balance of Plant } \\
\hline Temperature of exhaust gas leaving the system & $127^{\circ} \mathrm{C}$ \\
\hline Pressure ratio of blowers & 1.18 \\
\hline Isentropic efficiency of blowers & 0.53 \\
\hline Pressure ratio of pump & 1.2 \\
\hline Isentropic efficiency of pump & 0.8 \\
\hline Inverter efficiency & 0.95 \\
\hline
\end{tabular}


Using the input data shown in Table 4.17, syngas composition is first calculated and shown in Table 4.18. As it can be seen from this table, when enriched oxygen is used instead of air, molar ratio of all species except nitrogen increases due to sending less amount of nitrogen to the gasifier. In the case of using steam as gasification agent, the molar ratio of gases that are used as fuel in SOFC, i.e. $\mathrm{CH}_{4}, \mathrm{H}_{2}$ and $\mathrm{CO}$ is higher than the cases when we use air or enriched oxygen; however the molar ratio of $\mathrm{H}_{2} \mathrm{O}$ is lower than the other cases according to chemical equilibrium calculations.

Table 4.18: Syngas compositions calculated for different cases.

\begin{tabular}{|l|c|c|c|c|c|c|}
\hline & $x_{\mathrm{CH}_{4}}$ & $x_{\mathrm{H}_{2}}$ & $x_{\mathrm{CO}}$ & $x_{\mathrm{CO}_{2}}$ & $x_{\mathrm{H}_{2} \mathrm{O}}$ & $x_{\mathrm{N}_{2}}$ \\
\hline Case1: Air & $0.14 \%$ & $11.22 \%$ & $8.16 \%$ & $12.95 \%$ & $22.68 \%$ & $44.84 \%$ \\
\hline Case2: Enriched $\mathrm{O}_{2}$ & $0.28 \%$ & $15.74 \%$ & $11.40 \%$ & $16.37 \%$ & $28.80 \%$ & $27.41 \%$ \\
\hline Case3: Steam & $2.15 \%$ & $43.37 \%$ & $27.38 \%$ & $8.98 \%$ & $18.12 \%$ & $0.00 \%$ \\
\hline
\end{tabular}

After finding the syngas composition, transient heat transfer code discussed in Section 3.7 is used to find the fuel cell related output parameters. First, recirculation ratio is taken as zero and the code is run until a fuel utilization of 0.85 is obtained. At this point, the maximum carbon activity through the channel the length is checked. If this value is less than 1 for all the nodes, then there is no carbon deposition problem. If this value is higher than 1 for any nodes, then the calculations should be repeated with higher recirculation ratios until the carbon deposition is prevented. Figure 4.79 shows that the maximum carbon activity is less than 1 for all the nodes for all cases even if we do not recirculate the depleted fuel. 


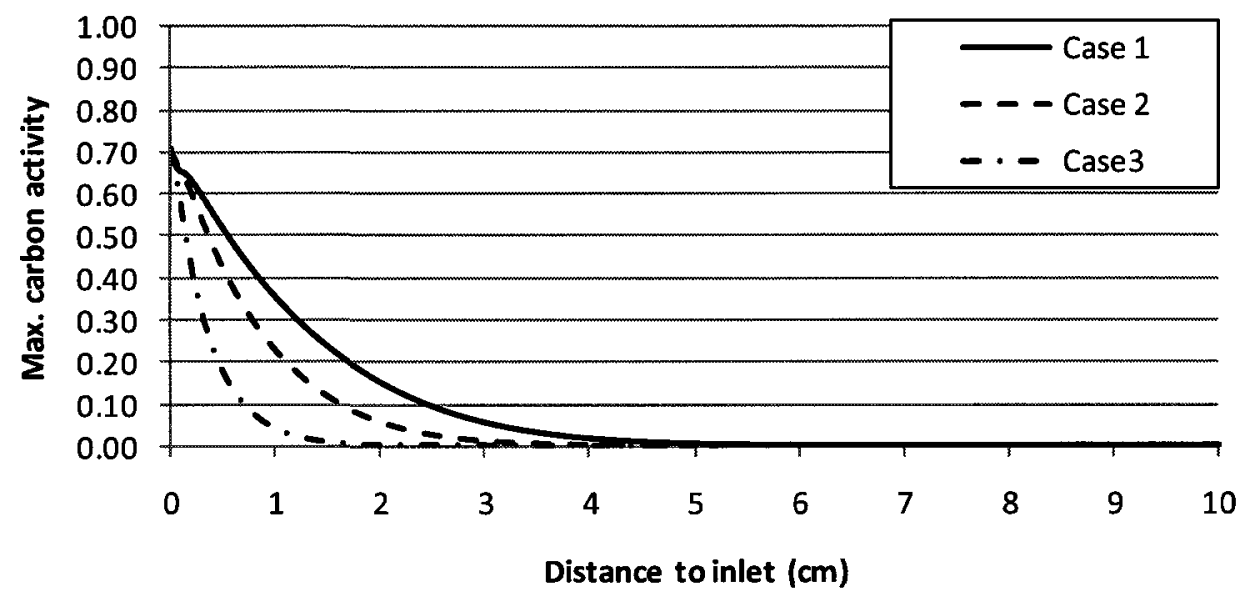

Figure 4.79: Change of maximum carbon activity with distance.

Figure 4.80 shows the current density distribution for each case. Since the molar ratio of gas species used as fuel in $\mathrm{SOFC}$, i.e. $\mathrm{CH}_{4}, \mathrm{H}_{2}$ and $\mathrm{CO}$, is higher for case 3 , higher current densities for each node are obtained for this case compared to other cases. From Table 4.19 , it can be seen that average current densities for cases 1,2 , and 3 are 0.240 , 0.246 , and $0.343 \mathrm{~A} / \mathrm{cm}^{2}$, respectively. From this table, it can also be interpreted that power density for case- 3 is higher than the other cases since we assume the cell voltage as constant in the modeling and average current density is higher for case- 3 than other cases. Another result that is found is that 13 stacks are needed for cases 1 and 2, whereas only 9 stacks are needed for case 3 . This shows that the purchase equipment cost for case- 3 is lower than the other cases. 


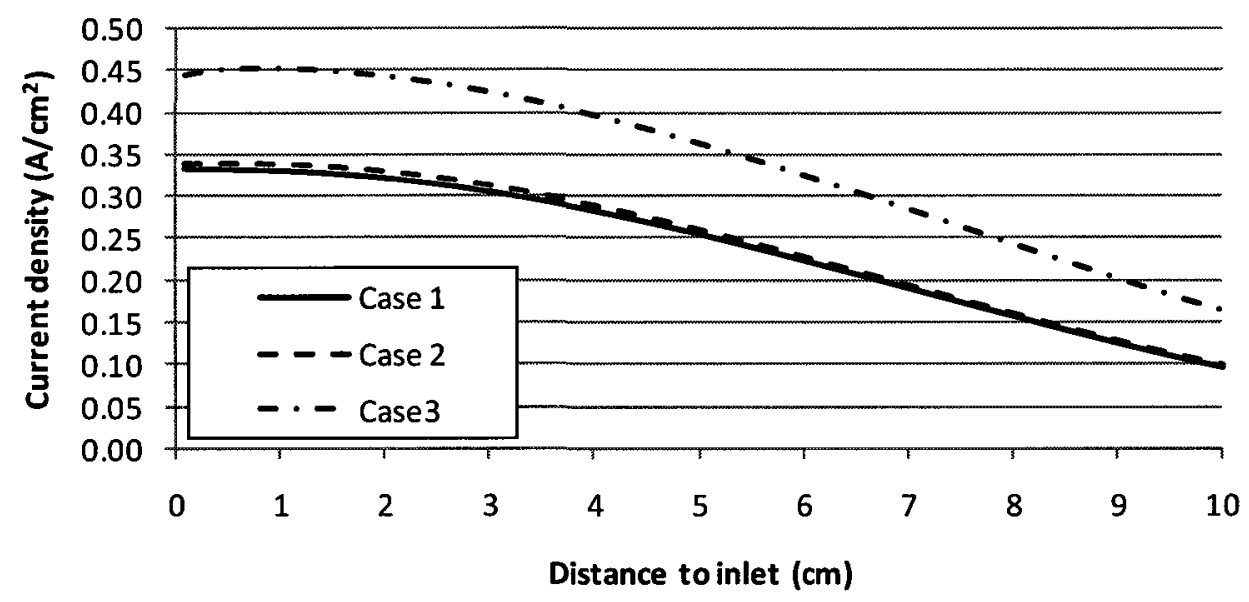

Figure 4.80: Change of current density with distance.

Table 4.19: Output parameters of the SOFC model.

\begin{tabular}{|l|l|l|l|l|l|l|}
\hline & \multicolumn{1}{|c|}{$r$} & \multicolumn{1}{|c|}{$R e$} & $\begin{array}{c}i_{\text {c,ave }} \\
{\left[\mathrm{A} / \mathrm{cm}^{2}\right]}\end{array}$ & \multicolumn{1}{|c|}{$U_{F}$} & $\begin{array}{l}W_{\text {sofc }} \\
{\left[\mathrm{W} / \mathrm{cm}^{2}\right]}\end{array}$ & $n_{\text {stack }}$ \\
\hline Case1: Air & 0 & 10.0 & 0.240 & 0.85 & 0.156 & 13 \\
\hline Case2: Enriched $\mathrm{O}_{2}$ & 0 & 6.5 & 0.246 & 0.85 & 0.160 & 13 \\
\hline Case3: Steam & 0 & 1.5 & 0.343 & 0.85 & 0.223 & 9 \\
\hline
\end{tabular}

The 2-D temperature profiles of SOFC are shown in Figures 4.81-4.83. From these figures, it is seen that temperature gradient in the flow direction is the highest in case 3 . Case 2 and case 1 follow it, respectively. It should be noted that the temperature gradients are still less than the maximum allowable value that could cause thermomechanical instability. 


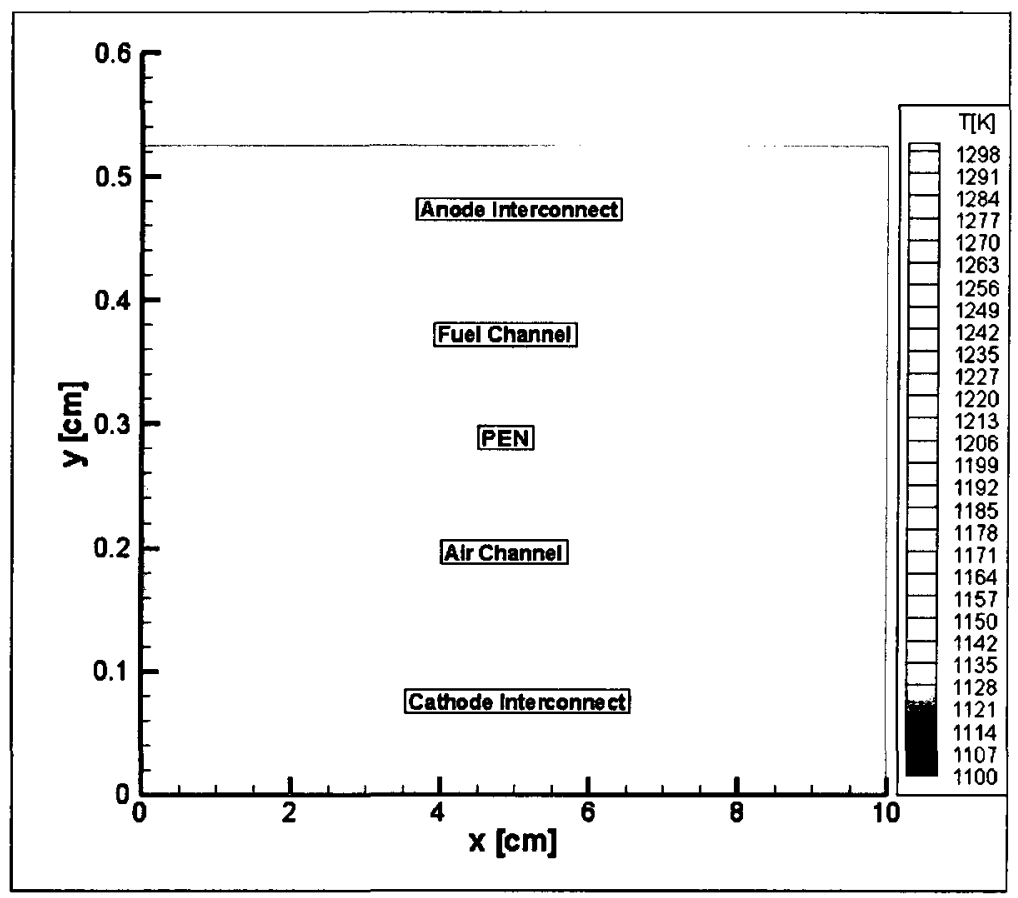

Figure 4.81: 2-D temperature profile of SOFC for Case-1 (air gasification).

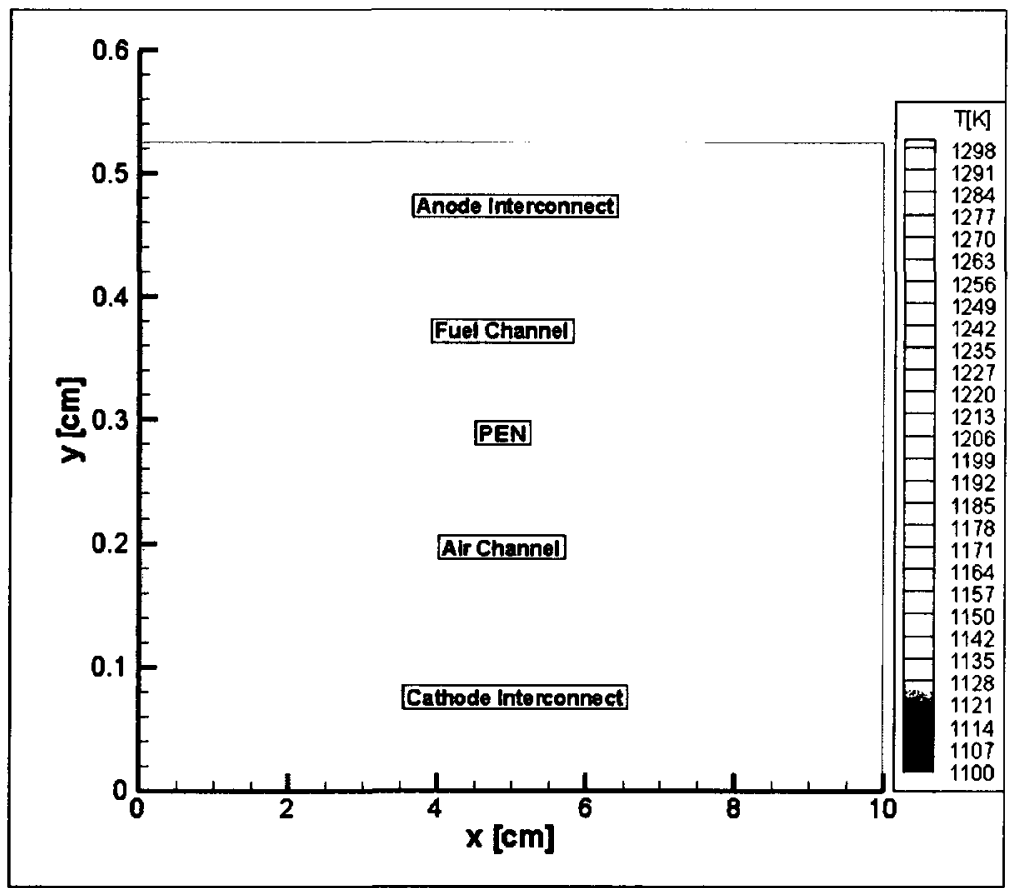

Figure 4.82: 2-D temperature profile of SOFC for Case-2 (Enriched oxygen gasification). 


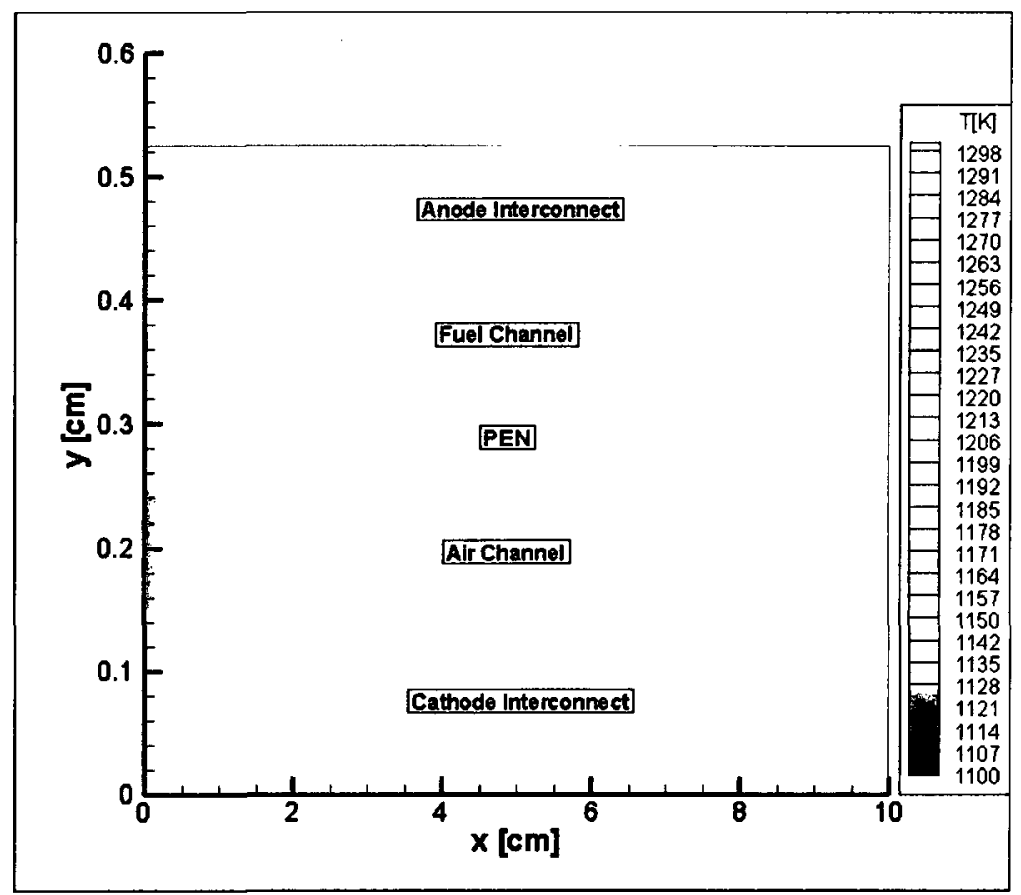

Figure 4.83: 2-D temperature profile of SOFC for Case-3 (Steam gasification).

The mass flow rates of substances entering the system are given in Table 4.20. For case 1, we need to feed more biomass to the system, which increases the cost of fuel. In addition, wood needs to be cut into small pieces before feeding to the system, hence equipment and operation cost for pre-treatment of wood increases for this case. The energy input for the pretreatment operation of wood also increases. It should be noted that pretreatment of wood except drying is not taken into account in the analyses. From this table, the mass flow rate of air and water fed to the system, and steam produced and sent to the users can be seen. For case-3, fewer amounts of air and water are fed to the system, which in turn decreases the costs associated with the operation of blowers and pump. However, less amount of steam is produced for this case due to sending high amount of steam to the gasifier for initiating the gasification reactions. 
Table 4.20: Mass flow rate of substances entering the system.

\begin{tabular}{|l|l|l|l|l|l|}
\hline & $\begin{array}{l}\dot{m}_{\text {biomass }} \\
{[\mathrm{g} / \mathrm{s}]}\end{array}$ & $\begin{array}{l}\dot{m}_{\text {air }}(\mathrm{B} 1) \\
{[\mathrm{g} / \mathrm{s}]}\end{array}$ & $\begin{array}{l}\dot{m}_{\text {air }}(\mathrm{B} 2) \\
{[\mathrm{g} / \mathrm{s}]}\end{array}$ & $\begin{array}{l}\dot{m}_{\text {water }} \\
{[\mathrm{g} / \mathrm{s}]}\end{array}$ & $\begin{array}{l}\dot{m}_{\text {steam }} \\
{[\mathrm{g} / \mathrm{s}]}\end{array}$ \\
\hline Case1: Air & 4.048 & 7.796 & 45.648 & 7.654 & 7.654 \\
\hline Case2: Enriched $\mathrm{O}_{2}$ & 3.867 & 6.989 & 46.841 & 6.604 & 6.604 \\
\hline Case3: Steam & 1.826 & - & 45.219 & 0.7670 & 0.6847 \\
\hline
\end{tabular}

The power input to the auxiliary components, and power output from the system are shown in Table 4.21. It can be followed from this table that net power output for case- 2 is the highest, which is mainly due to higher amount of power obtained for the given number of stacks. Change of enthalpy rate of the process is found to be the highest for case- 1 and lowest in case 3 . This is because allothermal gasification is used in case- 3 and considerable amount of energy is spent in the gasification process, hence less energy remains for producing steam.

Table 4.21: Power demand for auxiliary components, net power and heat output.

\begin{tabular}{|l|c|l|l|l|l|l|}
\hline & $\begin{array}{c}\dot{W}_{\text {SOFC }} \\
{[\mathrm{W}]}\end{array}$ & $\begin{array}{c}\dot{W}_{\text {blower-1 }}[\mathrm{W}] \\
{\left[\begin{array}{|l}\dot{W}_{\text {blower-2 }} \\
{[\mathrm{W}]}\end{array}\right.}\end{array}$ & $\begin{array}{c}\dot{W}_{\text {pump }} \\
{[\mathrm{W}]}\end{array}$ & $\begin{array}{c}\dot{W}_{\text {net }} \\
{[\mathrm{W}]}\end{array}$ & $\begin{array}{c}\Delta \dot{H}_{\text {process }} \\
{[\mathrm{W}]}\end{array}$ \\
\hline Case1: Air & 10140 & 227.5 & 1332.1 & 0.2 & 8073.2 & 19741.3 \\
\hline Case2: Enriched $\mathrm{O}_{2}$ & 10384 & 204.0 & 1366.9 & 0.2 & 8293.7 & 17032.9 \\
\hline Case3: Steam & 10031 & - & 1319.6 & 0.02 & 8210.2 & 1765.9 \\
\hline
\end{tabular}

The electrical efficiency, fuel utilization efficiency, power-to-heat ratio, and exergetic efficiency are chosen as performance assessment parameters in this study. Results are shown in Table 4.22. It can be seen from this table that case 3 (steam gasification) has the highest electrical efficiency. However, it has also the lowest fuel utilization efficiency 
since considerable amount of steam is sent to the gasifier and less steam is sent for process heating purposes. In general, producing electricity is more expensive than producing heat. If we compare the power-to-heat ratios, we can see that case 3 is the highest. It may be interpreted from this result that the primary purpose of using the system in case-3 should be producing electricity rather than producing heat. Exergetic efficiency is another way of comparing the overall system performance. In this comparison, the quality of the energy forms together with the quantity of the energy forms is considered. It is seen from Table 4.22 that exergetic efficiency for case- 3 is the highest. When we combine all the results for performance assessment parameters, we can conclude that steam should be selected as a gasification agent to have a better performance in terms of thermodynamics and economics.

Table 4.22: Performance assessment parameters.

\begin{tabular}{|l|l|l|l|c|}
\hline & \multicolumn{1}{|c|}{$\eta_{e l}$} & \multicolumn{1}{|c|}{$F U E$} & \multicolumn{1}{c|}{ PHR } & $\varepsilon$ \\
\hline Case1: Air & $18.5 \%$ & $63.9 \%$ & 0.409 & $30.9 \%$ \\
\hline Case2: Enriched $\mathrm{O}_{2}$ & $19.9 \%$ & $60.9 \%$ & 0.487 & $30.7 \%$ \\
\hline Case3: Steam & $41.8 \%$ & $50.8 \%$ & 4.649 & $39.1 \%$ \\
\hline
\end{tabular}

We can also use combined air/steam or enriched oxygen/steam gasification agents in the systems. In these cases, molar ratio of oxidant to dry biomass and molar ratio of steam to dry biomass can be altered to get different results. However, we can expect that the outputs will be between each single case. For example, if we choose enriched oxygen/steam gasification, it is expected that electrical efficiency will be between $19.9 \%$ and $41.8 \%$ and fuel utilization efficiency will be between $50.8 \%$ and $60.9 \%$. 
Exergy destructions and losses and their relevant ratios are calculated and the results are shown in Tables 4.23-4.25. The results show that, for cases 1 and 2, the largest portion of exergy is destructed in the gasifier. This destruction accounts for $31.02 \%$ for case- 1 and $30.89 \%$ for case- 2 of the exergy of the fuel, and $48.60 \%$ for case- 1 and $48.15 \%$ for case- 2 of the total exergy destructions. For case-3, the magnitude of exergy destruction for gasifier is much lower than that for cases 1 and 2 because of using allothermal gasification for this case. In this case, the highest exergy is destructed in the heat exchanger, which is $25.65 \%$ of the exergy of the fuel and $46.44 \%$ of the total exergy destructions. When we compare the exergy losses to environment, it is seen that case-3 has the highest exergy loss, which is equal to the $5.63 \%$ of the exergy of the fuel.

Table 4.23: Exergy destructions in the components and exergy loss to the environment.

\begin{tabular}{|l|l|l|l|}
\hline & Case 1 & Case 2 & Case 3 \\
\hline Exergy Destructions $[W]$ & \multicolumn{2}{|l|}{} \\
\hline SOFC & 664 & 692 & 845 \\
\hline Gasifier & 15727 & 14952 & 837 \\
\hline Afterburner & 1622 & 1800 & 1490 \\
\hline Dryer & 3018 & 2884 & 1336 \\
\hline Gas cleanup & 678 & 507 & 164 \\
\hline Heat exchanger & 6421 & 6453 & 5834 \\
\hline Blower-1 & 217 & 195 & - \\
\hline Blower-2 & 1272 & 1305 & 1260 \\
\hline ASU & - & 4 & - \\
\hline Steam generator & 2235 & 1740 & 295 \\
\hline Water pump & 0 & 0 & 0 \\
\hline Inverter & 507 & 519 & 502 \\
\hline Exergy loss $[W]$ & 2676 & 2489 & 1281 \\
\hline
\end{tabular}


Table 4.24: Exergy destruction ratios.

\begin{tabular}{|l|r|r|l|l|l|l|}
\hline & \multicolumn{2}{|l|}{ Case 1 } & \multicolumn{2}{c|}{ Case 2 } & \multicolumn{2}{c|}{ Case 3 } \\
\hline & $\begin{array}{l}y_{D} \\
{[\%]}\end{array}$ & $\begin{array}{l}y_{D}^{*} \\
{[\%]}\end{array}$ & $\begin{array}{l}y_{D} \\
{[\%]}\end{array}$ & $\begin{array}{l}y_{D}^{*} \\
{[\%]}\end{array}$ & $\begin{array}{l}y_{D} \\
{[\%]}\end{array}$ & $\begin{array}{l}y_{D}^{*} \\
{[\%]}\end{array}$ \\
\hline SOFC & 1.31 & 2.05 & 1.43 & 2.23 & 3.71 & 6.72 \\
\hline Gasifier & 31.02 & 48.60 & 30.89 & 48.15 & 3.67 & 6.67 \\
\hline Afterburner & 3.20 & 5.01 & 3.72 & 5.80 & 6.55 & 11.86 \\
\hline Dryer & 5.95 & 9.33 & 5.96 & 9.29 & 5.88 & 10.64 \\
\hline Gas cleanup & 1.34 & 2.09 & 1.05 & 1.63 & 0.72 & 1.30 \\
\hline Heat exchanger & 12.66 & 19.84 & 13.33 & 20.78 & 25.65 & 46.44 \\
\hline Blower-1 & 0.43 & 0.67 & 0.40 & 0.63 & 0.00 & 0.00 \\
\hline Blower-2 & 2.51 & 3.93 & 2.70 & 4.20 & 5.54 & 10.03 \\
\hline ASU & - & - & 0.00 & 0.01 & 0.00 & 0.00 \\
\hline Steam generator & 4.41 & 6.91 & 3.59 & 5.61 & 1.30 & 2.35 \\
\hline Water pump & 0.00 & 0.00 & 0.00 & 0.00 & 0.00 & 0.00 \\
\hline Inverter & 1.00 & 1.57 & 1.07 & 1.67 & 2.21 & 3.99 \\
\hline
\end{tabular}

Table 4.25: Exergy loss ratio.

\begin{tabular}{|l|l|c|c|}
\hline & Case 1 & Case 2 & Case 3 \\
\hline$y_{L}[\%]$ & 5.28 & 5.14 & 5.63 \\
\hline
\end{tabular}

\subsection{Summary}

The results of the several case studies applied to the models and the validation of these models are presented and discussed in this chapter. These models include a thermodynamic, a carbon deposition, a transient heat transfer, and a system level model.

The thermodynamic model of the DIR-SOFC is validated with an experimental data found in the literature. It is shown that the results are in good agreement. Effects of fuel utilization and recirculation ratio on the performance of the cell are investigated. It is 
found that the effect of recirculation ratio is not very significant for low current densities. However, for high current densities, as recirculation ratio increases, mass flow rate of fuel, air utilization ratio, cell voltage, power output, and electrical efficiency of the cell decrease. The study of the effect of fuel utilization shows that a wider range of current density may be selected for lower fuel utilization ratios. As fuel utilization ratio increases, mass flow rate of fuel, air utilization ratio, terminal voltage, and power output of the cell decrease; whereas electrical efficiency of the cell increases.

The carbon deposition model is applied to two cases in which methane and a gas mixture obtained from pyrolysis are used. The effects of temperature level and fuel utilization are first studied. The results show that the possibility of carbon deposition is more severe at the inlet of the fuel channel than the exit. For the input data taken in these case studies, it is found for case-1 (fuel as methane) that as the fuel utilization ratio changes between 0.5 and 0.85 , minimum recirculation ratio changes between 0.78 and $0.68,0.65$ and 0.51 , and 0.55 and 0.4 for LT-SOFC, IT-SOFC and HT-SOFC, respectively. For case-2 (fuel as gas mixture obtained from pyrolysis), as the fuel utilization ratio changes between 0.5 and 0.85 , minimum recirculation ratio changes between 0.75 and $0.62,0.46$ and 0.3 , and 0.13 and 0.07 for LT-SOFC, IT-SOFC and HT-SOFC, respectively. Then, the effect of chemical composition of gases obtained from biomass gasification is studied. It is shown that twin fluid bed option has the highest electrical efficiency, and the multi-solid fluid bed follows it. Air-blown downdraft and updraft options have the lowest electrical efficiencies. 
A transient heat transfer model is developed to simulate the heat-up and start-up stages of a SOFC. For validation purposes, the author first developed a model, which is called Model-V1, using the same assumption for polarizations as the benchmark tests. Then, the model is further improved by altering this assumption and considering different analytical equations for ohmic, activation, and concentration polarizations. The new model is called Model-V2. It is shown that the results of the model are in very good agreement with the benchmark test. The input data for the case studies are chosen consistently with the benchmark tests. These case studies are: a SOFC fueled with humidified hydrogen and a SOFC fueled with gas mixture consisting of $\mathrm{CH}_{4}, \mathrm{H}_{2}, \mathrm{CO}, \mathrm{CO}_{2}, \mathrm{H}_{2} \mathrm{O}$ and $\mathrm{N}_{2}$. For the first case study (fuel as humidified hydrogen), it is shown that the transient behaviors for coand counter-flow configurations do not differ significantly. However, the counter-flow configuration takes slightly more time to reach the steady state condition. At this condition, counter-flow configuration has a better performance, e.g. electrical efficiency, for low Reynolds numbers that we obtain meaningful amount of fuel utilization, e.g. fuel utilization of 0.85 . For the input data considered, it is also found that counter-flow configuration has a higher electrical efficiency for the excess air coefficient up to 9. If we take the excess air coefficient higher than 9, co-flow configuration has a higher electrical efficiency. For case-2 (fuel as a gas mixture), it is shown that the temperature at the flow direction drops suddenly due to the endothermic steam reforming reaction and then increases through the channel due to exothermic electrochemical and water-gas shift reactions. It is found that temperature reaches a higher value at the steady state condition for counter-flow configuration compared to co-flow configuration. The transient behavior of the cell is also investigated for this case. 
In system level modeling, several integrated SOFC systems are studied through energy and exergy analyses. In the first study, a SOFC and gas turbine based cogeneration system is analyzed. It is found that the fuel utilization ratio and exergetic efficiency of the system are $68 \%$ and $62 \%$, respectively. It is also shown that as the environmental temperature increases, fuel utilization efficiency increases whereas exergetic efficiency decreases. In the second study, a SOFC and biomass gasification system is studied to assess the performance of SOFC. The changes of the operating cell voltage, air utilization ratio, power output of the SOFC, and electrical efficiency of the system with current density are investigated for different temperatures of SOFC. It is found that for the case in which the SOFC operates at the lowest temperature level, higher power output and electrical efficiency are achieved. However, air utilization is lower for this case which makes this case economically less feasible. In the third study, an integrated SOFC and biomass gasification system is studied in detail. The performance of the system for different gasification agents, i.e. air, enriched oxygen and steam, is assessed. It is found that when we use steam as the gasification agent, we obtain the highest electrical efficiency, power-to-heat ratio and exergetic efficiency, but the lowest fuel utilization efficiency. It is also shown for case-3 (steam gasification) that the highest exergy destruction is in the heat exchanger that is used to increase the temperature of the blower, which accounts for $25.65 \%$ of the exergy of the fuel and $46.44 \%$ of the total exergy destructions. 


\section{CHAPTER 5}

\section{REDUCTION OF GREENHOUSE GAS EMISSIONS}

\section{USING VARIOUS THERMAL SYSTEMS IN A LANDFILL SITE}

\subsection{Introduction}

Global warming, which is a specific case of global climate change, refers to the increase in the average temperature of the atmosphere and oceans in recent decades, and the projected continuation of this increase. The drivers of climate change are seen as: changes in the atmospheric concentrations of GHGs and aerosols, land cover, and solar radiation [117]. According to the Intergovernmental Panel on Climate Change [117], most of the increase in global average temperatures since the mid- $20^{\text {th }}$ century is linked to the observed increase in the anthropogenic GHG concentrations.

The four long-lived GHGs, which are released due to human activity, are: $\mathrm{CO}_{2}, \mathrm{CH}_{4}, \mathrm{~N}_{2} \mathrm{O}$ and halocarbons. The effect of these gases on global warming is assessed using an index called 'global warming potential' (GWP), which is a measure of how much a given mass of $\mathrm{GHG}$ contributes to global warming relative to a reference gas (usually $\mathrm{CO}_{2}$ ) for which the GWP is set to 1 . For a 100-year time horizon, GWPs of $\mathrm{CO}_{2}, \mathrm{CH}_{4}$, and $\mathrm{N}_{2} \mathrm{O}$ are reported to be: 1, 25 and 298, respectively [117]. Using this index, one can calculate the equivalent $\mathrm{CO}_{2}$ emission by multiplying the emission of a GHG by its GWP. 
Municipal solid waste may have significant effects on the production of GHG as well as other environmental problems and human health if it is disposed in landfills where there are no treatments and processes. There are several steps in the production of GHG from waste. Waste is first decomposed by aerobic bacteria until all the oxygen is consumed. Then, organic acids are produced in the absence of oxygen, which is followed by methanogenic state in which organic materials are decomposed into $\mathrm{CH}_{4}$ and $\mathrm{CO}_{2}$. The leachate is also produced, which may contaminate the groundwater. There are also explosion risks due to the release of flammable gases, e.g. $\mathrm{CH}_{4}$. To prevent the health and environmental effects of landfills, these sites should be properly designed and operated. For example, while the groundwater may be protected by using liners and leachate collection systems; gas collection, treatment and processing systems must be used to reduce the GHG effect.

Energy may be produced from MSW through technologies such as: incineration, gasification, and generation of biogas and its utilization. Landfill gas can be converted into fuel and energy forms by direct combustion, chemical energy storage, introducing it into the natural gas grid, and electricity generation. Electricity generation from landfill gas can be accomplished by technologies such as the internal combustion engine, gas turbine, the Stirling engine and fuel cells. Bove and Lunghi [118] compared several technologies used to generate electricity from landfill gases, and showed that the internal combustion engine, which is the most widely used technology due to economical reasons, presents the poorest environmental performance. On the contrary, fuel cells are shown to be the cleanest electricity generating systems; however they are not yet economically 
feasible. There are different types of fuel cells and most of them may be fueled by LFG. However, low temperature fuel cells need a reformer to convert the fuel into hydrogen. Additionally, in all fuel cell types, LFG should be cleaned according to the impurity tolerance levels of the fuel cell. Lombardi et al. [119] compared conventional treatments with the following alternatives: the direct LFG feeding to a fuel cell; the production of a hydrogen-rich gas, by means of steam reforming and $\mathrm{CO}_{2}$ capture, to feed a stationary $\mathrm{FC}$; and the production of a hydrogen-rich gas, by means of steam reforming and $\mathrm{CO}_{2}$ capture, to feed a vehicle FC. Their study reveals that LFG reforming to a vehicle FC has the lowest specific greenhouse effect emission. Spiegel et al. [120] demonstrated the operation of a commercial phosphoric acid fuel cell (PAFC) with LFG. Their system produces up to $137 \mathrm{~kW}$ power, $37.1 \%$ efficiency at $120 \mathrm{~kW}$, and exceptionally low secondary emissions. Lunghi et al. [121] conducted life cycle assessment analysis of a molten carbonate fuel cell (MCFC) system for LFG recovery for an evaluation of environmental consequences, and to provide a guide for further environmental impact reduction. Duerr et al. [122] analyzed a biogas fueled alkaline fuel cell (AFC). They chose the AFC because of its very low freezing point of the potassium hydroxide electrolyte $\left(\sim-50^{\circ} \mathrm{C}\right)$.

In this study, GHG emissions from an uncontrolled landfill site are compared with those from controlled landfill sites in which flaring, conventional electricity generation technologies such as internal combustion engine (ICE) and gas turbine (GT), and an emerging technology, the SOFC, are utilized. For this comparison, GHG emission from each technology is first found for each year of its lifetime for a selected case study using 
the method developed by the author. Then, the global warming impact ratio and specific lifetime GHG emission are calculated for each case. Consequently, the most effective technology is determined. It should be noted that GHG emissions are calculated using on site direct emissions (from flaring, ICE, GT or SOFC), without taking into consideration the life-cycle emissions occurring during manufacture of the infrastructure (engine, flares, cells, pipes), production and delivery of auxiliary materials, auxiliary energy consumption, gas cleaning treatment and so on.

\subsection{Landfill Processes}

In a landfill site, LFG, which is composed of methane, carbon dioxide and non-methane organic compound (NMOC), i.e. ethane, butane, hexane, hydrogen sulfide, etc., is generated due to a series of biological processes. Over time, the amount of gas generated increases until such time the site reaches its capacity. Subsequently, the amount of gas generated begins to decrease due to the reduction in the organic material components. Because of the adverse environmental effects of the LFG, this gas should be collected and properly utilized by flaring or electricity generation technologies. In the following subsections, LFG generation and collection processes are discussed.

\subsubsection{Calculation of landfill gas generation}

Landfill gas generation from MSW can be calculated using the software called LandGEM, which was developed by the U.S. Environmental Protection Agency [123]. This software is based on a $1^{\text {st }}$ order decomposition rate equation for quantifying 
emissions from the decomposition of landfilled waste in MSW landfills, which is shown in Equation (5.1) [124].

$$
Q_{C H_{4}}=\sum_{i=1}^{n} \sum_{j=0.1}^{1} k \cdot L_{o} \cdot\left(\frac{M_{i}}{10}\right) \cdot e^{-k \cdot t_{i j}}
$$

From Equation (5.1), annual methane generation in a year can be calculated. Generally, it is assumed that landfill gas has a composition of $50 \% \mathrm{CH}_{4}$ and $50 \% \mathrm{CO}_{2}$. Hence, total landfill gas generation may be found by doubling the result from Equation (5.1). Methane generation rate, $\mathrm{k}$, is a function of factors such as moisture content, availability of nutrients for methane-generating bacteria, $\mathrm{pH}$, and temperature of the waste mass. The potential methane generation capacity, $\mathrm{L}_{\mathrm{o}}$, depends on the type and composition of the waste placed in the landfill. The Clean Air Act (CAA) default values, which are based on federal regulations for MSW landfills laid out by the CAA for $k$ and $L_{0}$, are, 0.05 year ${ }^{-1}$ and $170 \mathrm{~m}^{3} /$ ton, respectively [124].

\subsubsection{Landfill gas collection}

Landfill gas generated by the decomposition of organic materials should be collected in a well designed and managed site due to environmental, health and energetic considerations. The quantity of gas collected is estimated by multiplying the generated landfill gas by collection efficiency. According to the EPA [123], collection efficiencies at well designed landfills typically range from $60 \%$ to $85 \%$, with an average of $75 \%$. A very well designed collection system, i.e. $85 \%$ efficiency, should have the following features: a composite bottom liner consisting of a synthetic (plastic) layer over 2 feet ( 0.6 
meter) of clay or similar material; soil cover applied over newly deposited refuse on a daily basis; no significant off-site lateral migration of landfill gas; a comprehensive landfill gas collection system with vertical wells and/or horizontal collectors providing $100 \%$ collection system coverage of all areas with waste within a few years after the waste is deposited; a gas collection system which is operating effectively so that all wells are fully functioning (i.e., relatively free of liquids and drawing landfill gas under vacuum) [125].

The GHG emission routes in a well-designed landfill site with a collection system are shown in Figure 5.1. These routes will be discussed in detail in the following sections.

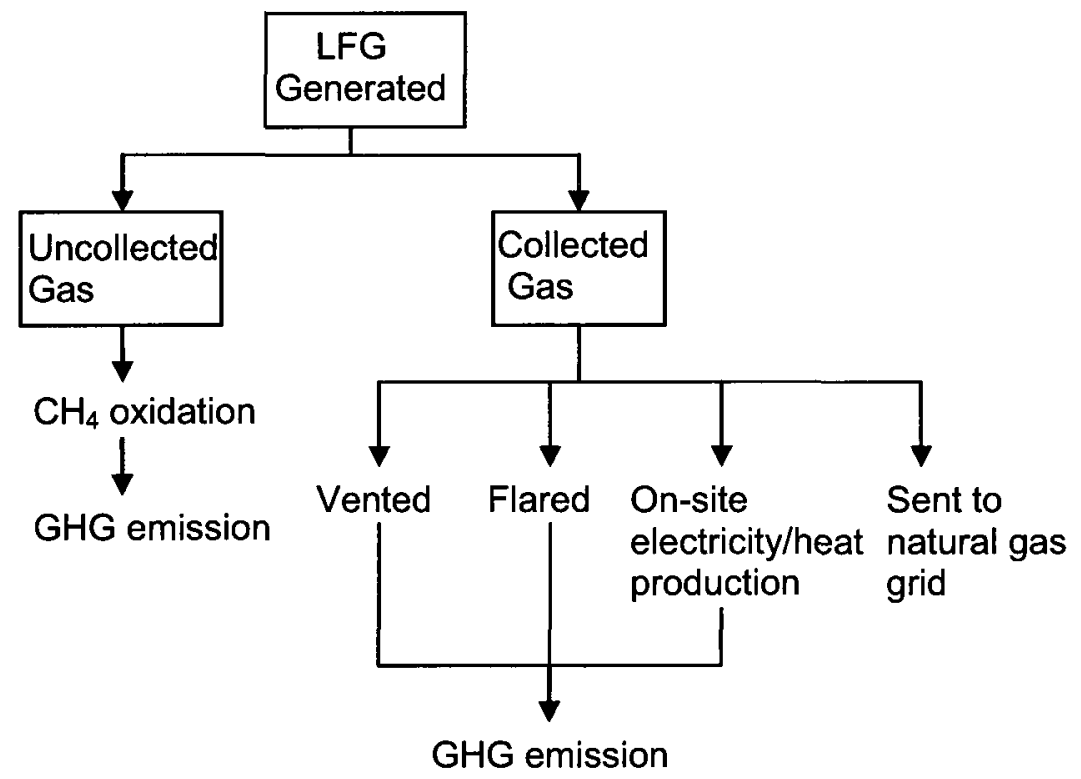

Figure 5.1: Greenhouse gas emission routes in a landfill site with LFG collection system. 


\subsection{Thermal Systems Considered}

Flaring (direct combustion) is the traditional approach to utilize the collected LFG for reducing the GHGs in a landfill site. The flaring of LFG is an economical approach, and also it reduces the risk of explosion of uncontrolled LFG emissions. The operation principle of landfill gas flare is simple; LFG is ignited by bringing it into contact with a supply of air. Different configurations of conduit and chambers can be used for this purpose. In today's market, open and closed flare types are available. Open flares burn landfill gas as open flames, whereas closed flares burn landfill gas in a vertical, cylindrical or rectilinear enclosure. Details of these flare types may be found in the report by Environment Agency and Scottish Environment Protection Agency [126]. On the other hand, since the collected gas has a considerable amount of heating value, it may be utilized to produce electricity and/or heat. The most commonly used technology for utilizing LFG is internal combustion engines, followed by gas turbines. Additionally, SOFC are very promising candidates to be used in landfill sites in the future due to their advantages discussed in the previous and following sections. These technologies are discussed in detail in the following subsections.

\subsubsection{Internal combustion engine}

The internal combustion engine (ICE) is the most widely used technology for electricity generation from LFG, mainly because of its economical feasibility. These engines are attractive because they are compact and easy to transport. The main disadvantage is the high amounts of $\mathrm{NO}_{\mathrm{x}}$ and $\mathrm{CO}$ emissions produced by these engines as compared with other technologies, which contribute to the air pollution. Lean-burn spark ignition 
engines are the most common type of ICE used in landfill sites. When these engines are operated using LFG, engine power ratings are commonly reduced by 5 to 10 percent [127] compared to operation using natural gas. It should be noted that before the LFG is fed to the ICE, moisture and particulates must be removed according to the tolerance limits of the engine, so as not to reduce the engine efficiency and reliability and increase the necessity for more regular maintenance.

The power output of these engines varies between $300 \mathrm{~kW}$ and $3.6 \mathrm{MW}$ for an individual unit [128]. Generally, many ICEs operate together according to the LFG generated to

produce more power. A typical landfill site operating with this type of engine should also include a gas flare to burn any LFG collected in excess of maximum requirements of the engine, to burn LFG when the generated gases are low enough to justify the operation of the engine, and to operate during the maintenance.

\subsubsection{Gas turbine}

Gas turbine is the second most popular technology that utilizes LFG. The majority of gas turbines presently operating at landfills are the simple cycle, single shaft type. They are very similar to natural gas turbines except that, because of the low heating value, the number of fuel regulating valves and injectors are doubled [129]. During its operation, large quantities of air enter the compressor. After the air is compressed, it mixes with fuel in the combustor, and the combusted gas expands in the turbine where power is produced. Some amount of this power is used to drive the compressor. 
Compared to ICEs, gas turbines have lower $\mathrm{NO}_{\mathrm{x}}$ and $\mathrm{CO}$ emissions, and also fewer moving parts. Their exhaust can also be utilized in a cogeneration application. However, if electricity generation is more important in an application, the gas turbine is disadvantageous since it has a lower electrical efficiency than the ICE. Other disadvantages are having a high capital cost, being sensitive to LFG supply loads and ambient air temperature variations, and not being suitable for moderate size landfills. For small size landfills, microturbines are generally selected instead of gas turbines.

\subsubsection{Solid oxide fuel cell}

The SOFC is an emerging technology that is expected to replace conventional energy systems like ICEs and gas turbines once it has become economically competitive. The SOFC has higher electrical efficiency, lower emissions, a higher exhaust gas temperature that makes it possible to be used in cogeneration applications, quieter operation and fewer moving parts compared to conventional systems. For more information on SOFC, please refer to Chapter 2.

There have been demonstrations of SOFC operation using biogas, e.g. [130, 131]. These demonstrations include biogas production from wastewater in a sewage treatment plant and animal waste. It has been recently reported that a planar SOFC unit in Finland, which will produce $20 \mathrm{~kW}$ of electric power and $14-17 \mathrm{~kW}$ of thermal output, is believed to be the first SOFC in the world that is fueled by LFG [132]. 


\subsection{Analysis of Greenhouse Gas Emissions}

In this section, a method for calculating GHG emission from a landfill site without an active collection system is first described. Then, methods for calculating GHG emissions from landfill sites in which the collected LFG is utilized by flaring, conventional electricity generation technologies such as ICE and GT, and SOFC, are discussed. Finally, some parameters for comparing these technologies are introduced.

\subsubsection{Landfill site without an active collection system}

In a landfill site without an active collection system, not all of the methane generated is emitted to the atmosphere. A portion of the methane generated is oxidized while passing through soil and landfill covers. The fraction of methane that is oxidized is generally taken as $10 \%$ [133]. The oxidation of methane reaction is given as Equation (5.2).

$$
\mathrm{CH}_{4}+2 \mathrm{O}_{2} \rightarrow \mathrm{CO}_{2}+2 \mathrm{H}_{2} \mathrm{O}
$$

If we neglect the NMOC portion of the LFG, total GHG emissions from this kind of a site may be expressed as shown in Equation (5.3). It should be noted that the equations in this paper are derived for a LFG composition of $50 \% \mathrm{CH}_{4}$ and $50 \% \mathrm{CO}_{2}$. However, similar equations may be derived with simple modifications to these equations for different ratios of $\mathrm{CH}_{4}$ and $\mathrm{CO}_{2}$. 


$$
\begin{aligned}
& \mathrm{m}_{\text {GHG.uncoll }}= \\
& \sum_{y=1}^{t_{\text {final }}}\left(m_{\mathrm{CH}_{4} . \text { gen }} \times(1-\mathrm{OX}) \times \mathrm{GWP}_{\mathrm{CH}_{4}}+\left(m_{\mathrm{CO}_{2} \cdot \text { gen }}+O X \times m_{\mathrm{CH}_{4} . g e n} \times \frac{\rho_{\mathrm{CO}_{2}}}{\rho_{\mathrm{CH}_{4}}}\right)\right)
\end{aligned}
$$

\subsubsection{Landfill site with an active collection system}

In a landfill site with an active collection system, LFG is recovered by vertical wells or horizontal collectors. The recovered gas can be flared, or utilized to generate electricity by technologies such as gas turbines, ICEs or fuel cells. In the following subsections, the methodologies for calculating the GHG emissions, when flaring and these electricity generating technologies are used in a landfill site, are discussed.

\subsubsection{Flaring}

The combustion of methane may also be represented by Equation (5.2). If we assume that all the collected gas is flared, and a small portion of the collected gas is vented during the routine and unscheduled maintenance, total GHG emissions from the site can be found by using Equation (5.4).

$$
\mathrm{m}_{\mathrm{GHG} . \text { coll }}=\sum_{y=1}^{t_{\text {final }}}\left(\left(1-\eta_{\text {coll }}\right) \times\left(\mathrm{m}_{\mathrm{GHG} \text {.uncoll }}\right)_{y}+\eta_{\text {coll }} \times\left(\mathrm{m}_{\mathrm{GHG} . \text { flare }}\right)_{y}\right)
$$

where GHG generated due to flaring is; 
$m_{\text {GHG.flare }}=m_{\mathrm{CH}_{4} \text {.gen }} \times$ vent $\times \mathrm{GWP}_{\mathrm{CH}_{4}}+\left(\mathrm{m}_{\mathrm{CO}_{2} \text {.gen }}+(1-\right.$ vent $\left.) \times m_{\mathrm{CH}_{4} . \text { gen }} \times \frac{\rho_{\mathrm{CO}_{2}}}{\rho_{\mathrm{CH}_{4}}}\right)$

\subsubsection{Electricity Generation Technologies from LFG}

\subsection{Internal Combustion Engine}

GHG emissions per energy output of ICEs suitable for LFG operation are given in the literature [119]. Using this emission data, amount of collected LFG, electrical efficiency of the ICE, days of operation of the engine per year and higher heating value of the fuel, one may calculate the total GHG emissions from such a landfill site using Equation (5.6). In this equation, it is assumed that after year, $t_{\text {down }}$, engines stop operating and collected LFG is burned. There is also enough number of ICEs that can utilize LFG even at the year when its generation is at maximum level.

$$
\begin{aligned}
& \mathrm{m}_{\text {GHG.coll }}=\sum_{y=1}^{t_{\text {down }}}\left(\left(1-\eta_{\text {coll }}\right) \times\left(\mathrm{m}_{\mathrm{GHG} \text {.uncoll }}\right)_{y}+\eta_{\text {coll }} \times\left(\mathrm{m}_{\mathrm{GHG} . \mathrm{ICE}}\right)_{y}\right)+ \\
& \sum_{y=t_{\text {down }}}^{t_{\text {final }}}\left(\left(1-\eta_{\text {coll }}\right) \times\left(m_{G H G . \text { uncoll }}\right)_{y}+\eta_{\text {coll }} \times\left(m_{\text {GHG.flare }}\right)_{y}\right)
\end{aligned}
$$

where GHG generated from ICE can be calculated as;

$$
\mathrm{m}_{\mathrm{GHG} . I C E}=(\tau / 365) \times\left(m_{\text {LFG.gen }} \times h h v \times \eta_{I C E} \times \varepsilon_{I C E} / 3600\right)+(1-\tau / 365) \times \mathrm{m}_{\mathrm{GHG}} \text { flare }
$$




\subsection{Gas turbine}

Since there is insufficient data in the literature regarding GHG emissions from LFG fueled gas turbines, a simple model is developed by the author. In this model, it is assumed that air gas composition is: $77.48 \% \mathrm{~N}_{2}, 20.59 \mathrm{O}_{2}, 0.03 \% \mathrm{CO}_{2}$ and $1.9 \% \mathrm{H}_{2} \mathrm{O}$. For the fuel-air ratio, $\bar{\lambda}$, the combustion equation may be written as shown in Equation (5.8).

$$
\begin{aligned}
& \bar{\lambda}\left(0.5 \mathrm{CH}_{4}+0.5 \mathrm{CO}_{2}\right)+0.7748 \mathrm{~N}_{2}+0.2059 \mathrm{O}_{2}+0.0003 \mathrm{CO}_{2}+0.019 \mathrm{H}_{2} \mathrm{O} \rightarrow \\
& (1+\bar{\lambda})\left(x_{\mathrm{N}_{2}} \mathrm{~N}_{2}+x_{\mathrm{O}_{2}} \mathrm{O}_{2}+x_{\mathrm{CO}_{2}} \mathrm{CO}_{2}+x_{\mathrm{H}_{2} \mathrm{O}} \mathrm{H}_{2} \mathrm{O}\right)
\end{aligned}
$$

The exit gas composition of the combustor may be shown using Equations (5.9)-(5.12).

$$
\begin{aligned}
& x_{N_{2}}=\frac{0.7748}{1+\bar{\lambda}} \\
& x_{\mathrm{O}_{2}}=\frac{0 . .2059-\bar{\lambda}}{1+\bar{\lambda}} \\
& x_{\mathrm{CO}_{2}}=\frac{\bar{\lambda}+0.0003}{1+\bar{\lambda}} \\
& x_{\mathrm{H}_{2} \mathrm{O}}=\frac{0.019+\bar{\lambda}}{1+\bar{\lambda}}
\end{aligned}
$$

Applying an energy balance around the control volume enclosing the combustor, as shown in Equation (5.13), $\bar{\lambda}$ hence exit gas composition may be calculated. 
$0=-0.02 \cdot \dot{N}_{f} \cdot L H V+\dot{N}_{f} \cdot \bar{h}_{f}+\dot{N}_{c, i} \cdot \bar{h}_{c, i}-\dot{N}_{c, o} \cdot \bar{h}_{c, o}$

The first term in the right hand side of Equation (5.13) denotes the assumed heat loss from the combustor.

The total GHG emissions from a landfill site, where a gas turbine is used for electricity production, may be calculated using Equation (5.6), if the $m_{\text {GHG.ICE }}$ is replaced with $m_{\text {GHG.GT }}$ which is shown in Equation (5.14).

$\mathrm{m}_{\mathrm{GHG} . \mathrm{GT}}=(\tau / 365) \times\left(m_{\text {LFG.gen }} \times \frac{\bar{\lambda}+0.0003}{\bar{\lambda}} \times \frac{M_{\mathrm{CO}_{2}}}{M_{\text {LFG }}}\right)+(1-\tau / 365) \times \mathrm{m}_{\mathrm{GHG} . f l a r e}$

\subsection{Solid oxide fuel cell}

GHG emissions per LFG entering the system may be found using the model discussed in Section 4.2. After finding the GHG emissions from the SOFC, the total GHG emissions from the landfill site may be calculated in a similar method as conducted with ICEs and gas turbines.

\subsubsection{Comparison of LFG utilization technologies}

Two parameters are proposed for comparing the usefulness of technologies in reducing the global warming in landfill sites. The first parameter is called 'global warming impact ratio', as shown in Equation (5.15). This ratio quantifies the GHG emission reduction when an active collection system is used. If there is no emission from the landfill site 
when an active system is used, this ratio is equal to $100 \%$. If this ratio is equal to one, it also means there is no contribution to global warming from this landfill site.

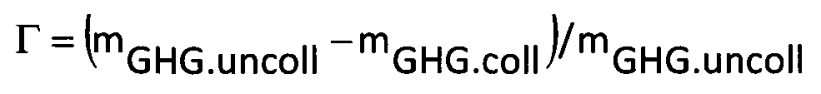

The second parameter is called 'specific lifetime GHG emission' which may be defined as the ratio of the total GHG emission from the landfill site in its lifetime to the total amount of useful energy produced from LFG. This ratio is shown in Equation (5.16) and is useful to compare GHG emissions for the same amount of power produced from different technologies. From the point of view of global warming and energy, the lower the ratio is, the more effective the technology is.

$$
\sigma=\frac{m_{G H G . c o l l}}{\left(m_{\mathrm{CH}_{4} . g e n}+m_{\mathrm{CO}_{2} . g e n}\right) \times \eta_{\text {coll }} \times \tau / 365 \times h h v / 3.6 \times \eta_{e l}}
$$

\subsection{Case Study}

For the case study, it is considered that the landfill site, which is filled with municipal solid waste, opened in 2008 and it will accept waste for 20 years. The annual waste acceptance rate is taken as 200,000 ton/year. Clean Air Act (CAA) default values, which are based on federal regulations for MSW landfills laid out by CAA, are considered for the methane generation rate and the potential methane generation capacity. The LFG 
composition is considered as $50 \% \mathrm{CH}_{4}$ and $50 \% \mathrm{CO}_{2}$. Other input data are given in Table 5.1. The results obtained using the data in Table 5.1 are presented in the following section.

Table 5.1: Input data for case studies.

\begin{tabular}{|l|l|}
\hline Fraction of oxidized methane & $10 \%$ \\
\hline Fraction of vented gas in flare & $1 \%$ \\
\hline Collection efficiency & $75 \%$ \\
\hline The year that the electricity production ends & 2088 \\
\hline $\begin{array}{l}\text { Number of days that electricity producing } \\
\text { technology operates per year }\end{array}$ & 320 \\
\hline Higher heating value of LFG & $14829 \mathrm{MJ} /$ tones \\
\hline Specific GHG emission ratio of ICE & 0.551 tonnes.CO $/ \mathrm{MWh}[119]$ \\
\hline Electrical efficiency of ICE & $35 \%$ \\
\hline Combustion chamber inlet temperature of GT & $850 \mathrm{~K}$ \\
\hline Gas turbine inlet temperature & $1520 \mathrm{~K}$ \\
\hline Gas turbine electrical efficiency & $28 \%$ \\
\hline Operating cell voltage of SOFC & $0.65 \mathrm{~V}$ \\
\hline Fuel utilization ratio of SOFC & $85 \%$ \\
\hline Inlet gas temperature of SOFC & $850^{\circ} \mathrm{C}$ \\
\hline Exit gas temperature of SOFC & $950^{\circ} \mathrm{C}$ \\
\hline Active surface area of a single cell & $100 \mathrm{~cm}$ \\
\hline
\end{tabular}

\subsection{Results and Discussion}

Generated and collected LFG, and GHG emissions for each scenario were calculated using the methodology described in Section 5.4. Then, to find the most effective technology, a comparison of the different scenarios was carried out.

Annual gas generation rates for all components of the LFG, i.e. methane, carbon dioxide and NMOC, were calculated by LandGEM software. The results are shown in Figure 5.2. As can be seen from this figure, LFG generation increases until the final year it accepts 
the waste. Then it decreases exponentially. For this landfill site, which has a 20 year lifetime, the site continues releasing GHGs for 120 years more after it stops accepting waste as can be seen from this figure. Taking an average collection efficiency of $75 \%$, collected and uncollected LFG and its components were calculated for each year and shown in Figure 5.3.

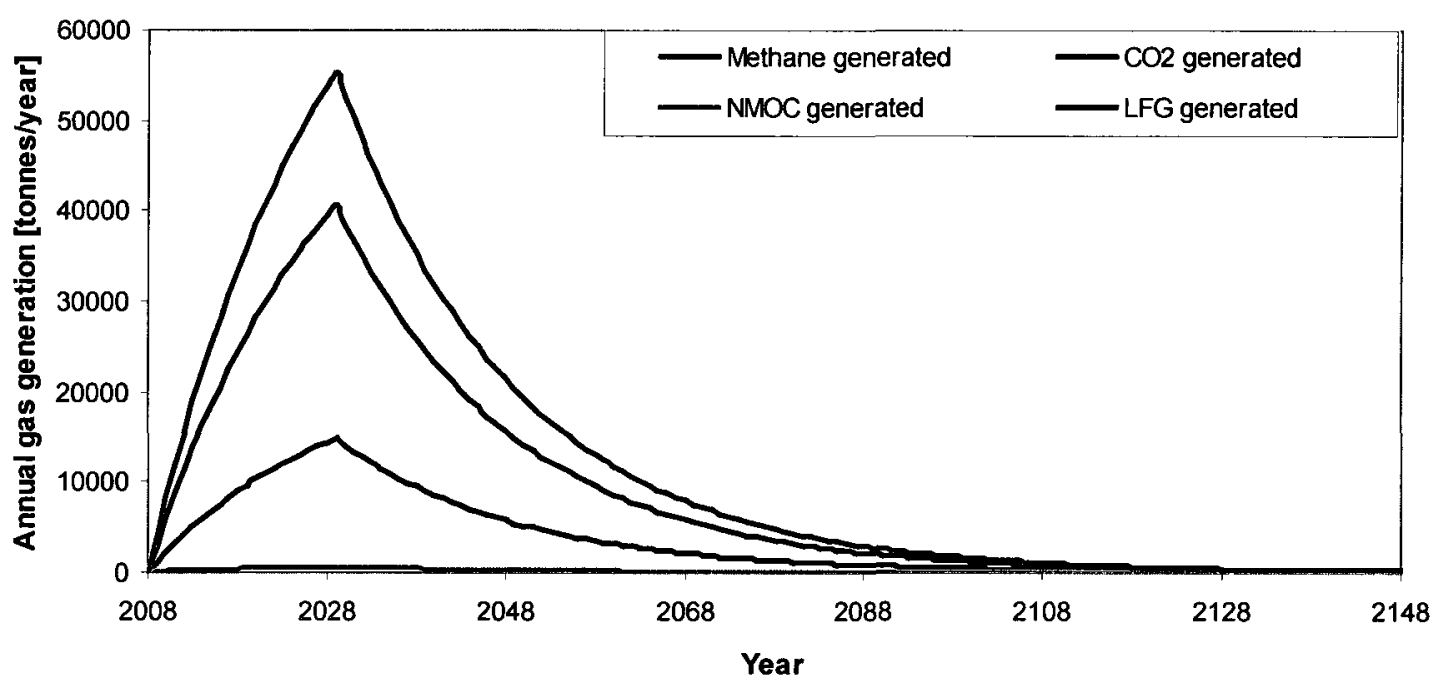

Figure 5.2: Annual gas generation of $L F G$ and its components.

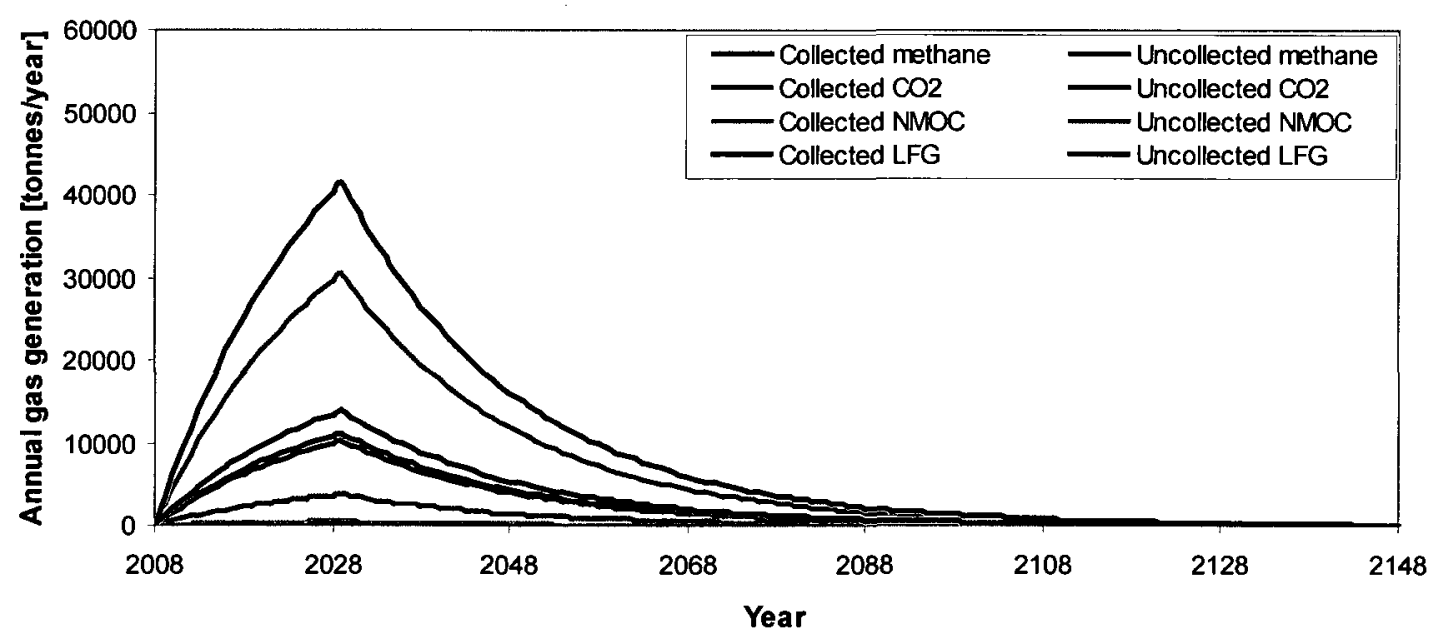

Figure 5.3: Collected and uncollected amount of LFG and its components. 
For a landfill site without an active collection system, some amount of methane will be oxidized and converted into carbon dioxide. Remaining gases will be released into the atmosphere. Given that high amounts of methane, which is 25 times more contributing to global warming than carbon dioxide, are released in this case, this gas should be collected and utilized since it has a considerable amount of heating value and high global warming potential. In this study, different technologies for utilizing the collected gas were considered. These include flaring, and electricity generation technologies such as ICE, gas turbine and SOFC. Annual GHG emission from the landfill site for each technology is shown in Figure 5.4. For example, in the final year that the site will accept waste, i.e. $2028 ; 366831$ tonnes- $\mathrm{CO}_{2}$.eq could be released to the atmosphere from a site without an active collection system. Using the most economical solution, which is flaring, GHG emissions would be much lower, 153456 tonnes- $\mathrm{CO}_{2}$.eq. However, there is no electricity production when flaring is used. In the case where a gas turbine is used to utilize the LFG, GHG emissions would be slightly lower than the case of flaring, which is found to be 151404 tonnes- $\mathrm{CO}_{2}$.eq. The most effective technologies for reducing $\mathrm{GHG}$ emissions are ICE and SOFC. For the peak year, when ICE and SOFC are utilized, the site produces GHG emissions of 127430 and 134208 tonnes- $\mathrm{CO}_{2}$.eq, respectively. It should be noted that, for all technologies, it is considered in the calculations that many power generators of the same type operate together, and they may be replaced with new ones if necessary. Additionally, after the year 2088, due to the low methane generation, it is assumed that collected gas will be sent to gas flare instead of the power generator. 


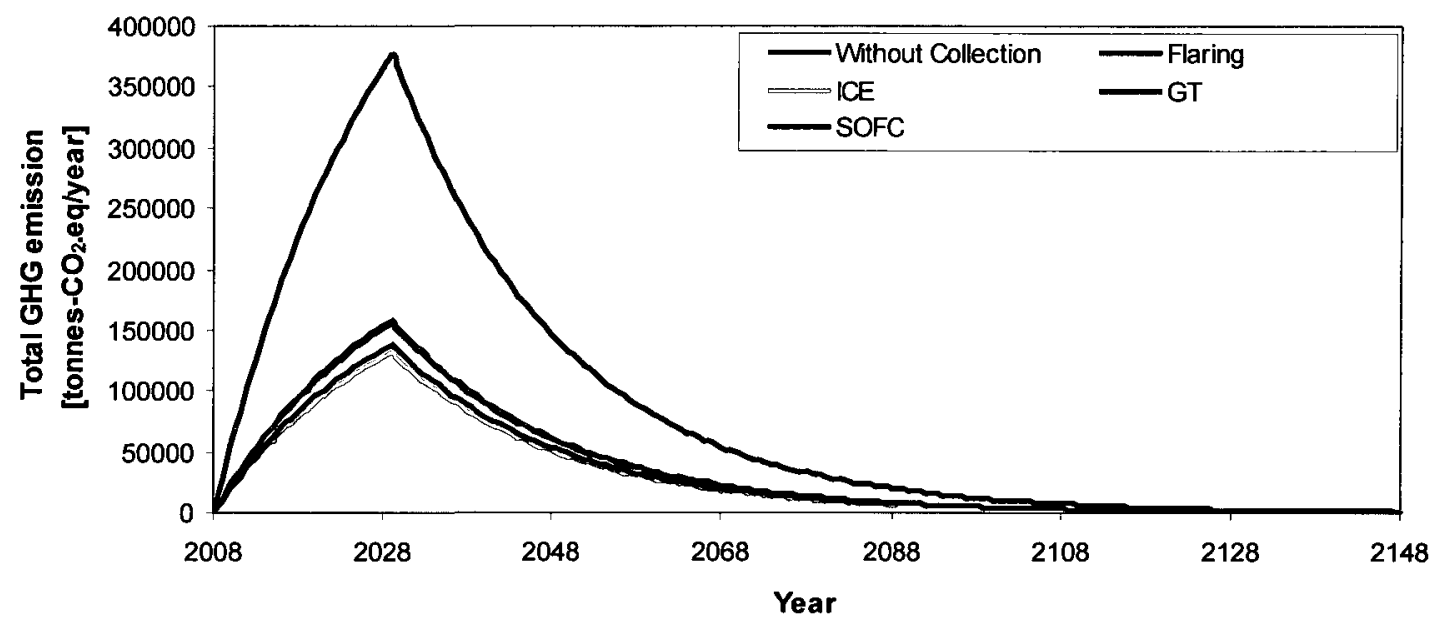

Figure 5.4: Total GHG emissions for various LFG utilization methods.

As previously mentioned, the results obtained by using the methodology discussed in Section 5.4 were used in constructing Figure 5.4. When modeling an ICE, the specific GHG emission ratio of the ICE, which has unit of tonnes. $\mathrm{CO}_{2} / \mathrm{MWh}$ of an existing engine, was taken from the literature [119] and used in Equation (5.7). In the case of the gas turbine, a simple model was developed as discussed in Section 5.4.2.2.2. Using input data given in Table 5.1, the fuel/air ratio on a molar basis was calculated to be 0.070935 . According to this ratio, exit gas composition of the gas turbine was found to be $72.3 \%$ $\mathrm{N}_{2}, 12.6 \% \mathrm{O}_{2}, 6.7 \% \mathrm{CO}_{2}$ and $8.4 \% \mathrm{H}_{2} \mathrm{O}$. Finally, in the case of the SOFC, the model is discussed in Section 5.4.2.2.3. Using input data given in Table 5.1, performance of a single cell can be found and is shown in Figure 5.5. For the type of fuel used in this study, it is reasonable to assume a $0.65 \mathrm{~V}$ cell voltage. At this voltage, the corresponding current density and electrical efficiency is $0.28 \mathrm{~A} / \mathrm{cm}^{2}$ and $40.3 \%$, respectively. It is also 
found that for 1 ton of LFG entering a SOFC system, 0.98595 ton $\mathrm{CO}_{2}$.eq GHG is emitted to the atmosphere.

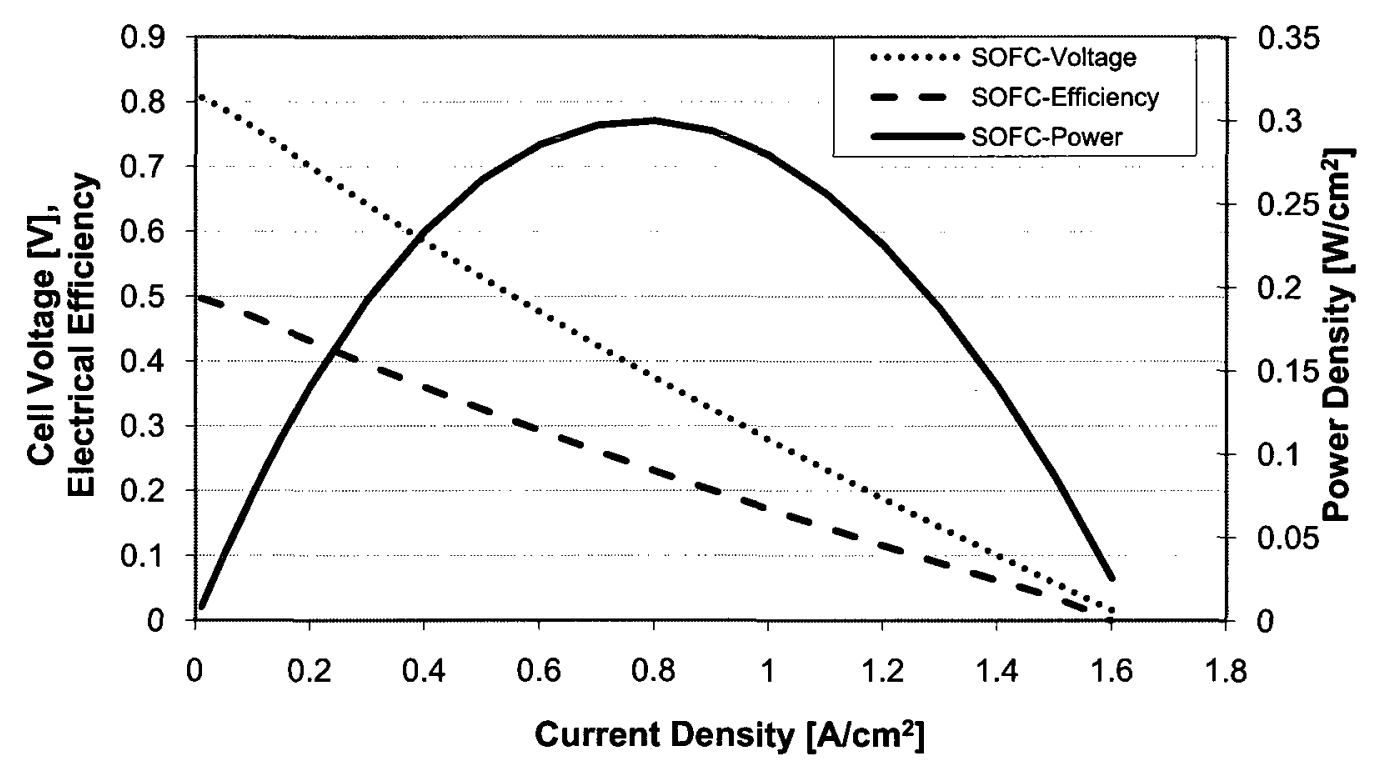

Figure 5.5: Performance of the SOFC.

Figure 5.6 shows the comparison between different technologies operating at controlled landfill sites in terms of their effect on production of GHGs. As shown in Figure 5.6, the simplest solution, which is flaring, will reduce the GHGs by $58 \%$. Hence, this result reveals the fact that an active collection system together with a gas flare would be very effective in reducing the GHG emission if an economical solution is desired and there is no consideration of getting benefit from this gas to convert it into electricity. This figure also shows that using an ICE results in the highest global warming impact ratio, which is slightly higher than the ratio when SOFC is used. The gas turbine has the least global 
warming reduction potential of the electricity production technologies studied in this paper.

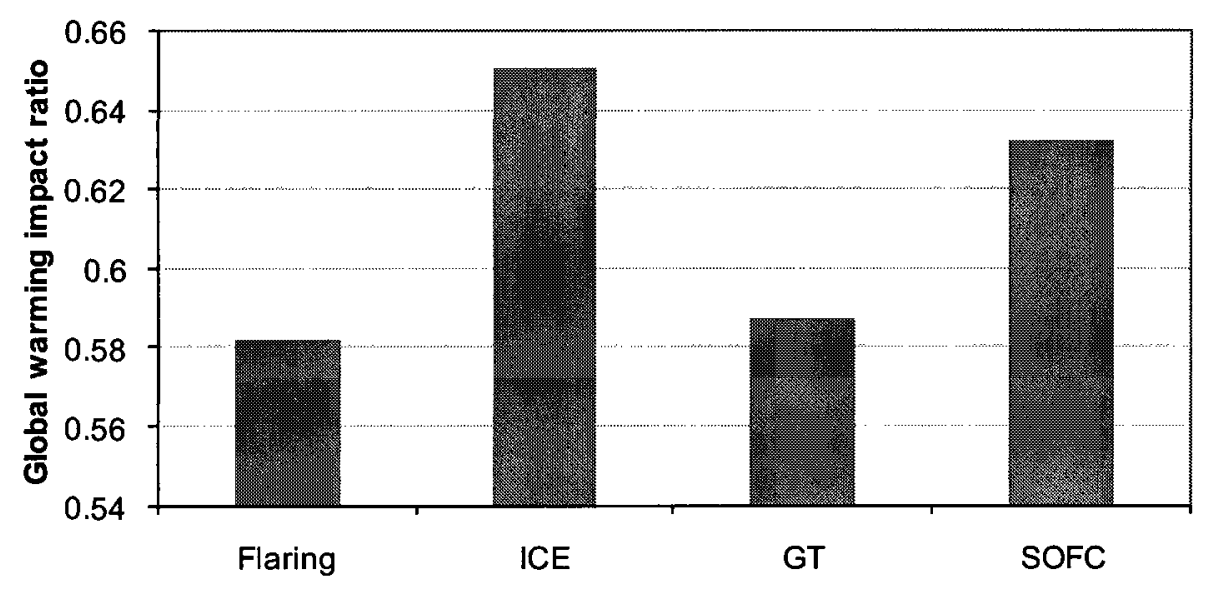

Figure 5.6: Global warming impact ratio for different scenarios.

Since each technology has different electrical efficiency and global warming potential, a more meaningful comparison between the controlled landfill sites studied may be conducted calculating the total GHG emissions in the lifetime per total amount of energy produced for each technology. The results of this comparison are shown in Figure 5.7. It may be seen from this figure that the SOFC has the lowest specific lifetime GHG emission among the technologies studied, which is 2.3836 tonnes $\mathrm{CO}_{2} . \mathrm{eq} / \mathrm{MWh}$, when the SOFC is only used for electricity generation. Since the SOFC has a high exhaust temperature, useful heat may be produced which would increase the fuel utilization efficiency of the system. Producing work and heat at the same time, which is called cogeneration, the specific lifetime GHG emission may be further reduced to 1.1217 tonnes $\mathrm{CO}_{2}$.eq/MWh, as shown in Figure 5.7. 


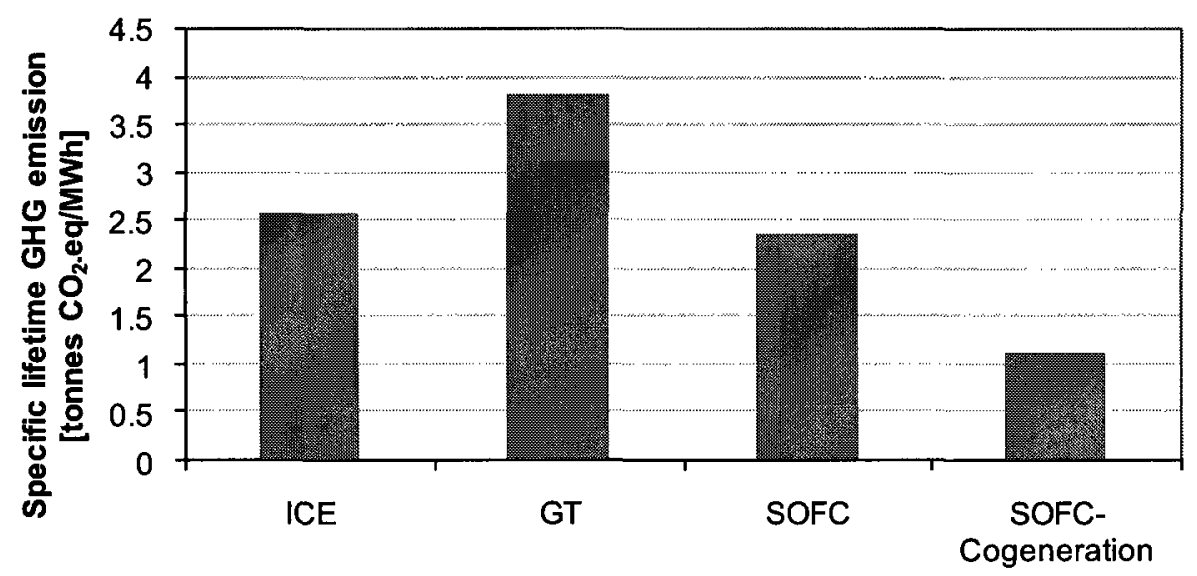

Figure 5.7: Specific lifetime GHG emission for different scenarios.

\subsection{Summary}

Greenhouse gas emissions from uncontrolled and controlled landfill sites are compared. In the controlled landfill sites, the following systems are used for utilizing the landfill gas: flaring, internal combustion engine, gas turbine, and SOFC. For comparison, GHG emission from each system is first found for each year of its lifetime using the models developed by the author. Then, the global warming impact ratio and specific lifetime GHG emission are calculated to determine the most effective system in reducing the GHG emissions.

The results show that flaring, which is the simplest and most economical solution, reduces the total GHG emissions in the lifetime of the site by $58 \%$ compared to the uncontrolled case. Among the different technologies, the SOFC seems to be the best option to reduce GHG emissions. This technology reduces the GHG emissions by $63 \%$, 
and has a specific lifetime GHG emission of 2.38 tonnes $\mathrm{CO}_{2}$.eq/MWh when it only produces electricity and 1.12 tonnes $\mathrm{CO}_{2} . \mathrm{eq} / \mathrm{MWh}$ when it is used in a cogeneration application. 


\section{CHAPTER 6}

\section{CONCLUSIONS AND RECOMMENDATIONS}

\subsection{Conclusions}

SOFCs are considered as one of the most feasible energy conversion devices for converting the fuel to heat and electricity due to its advantages such as ability to integrate with bottoming cycles, high efficiency, fuel flexibility, and low greenhouse gas emissions. The performance of such devices can be assessed through modeling. In this thesis, several models of SOFC were developed at different levels including cell, stack and system levels. These models include a thermodynamic model, a carbon deposition model, a transient heat transfer model, and a system level model using energy and exergy analyses. Additionally, the effectiveness of SOFC on reducing greenhouse gases was discussed through a case study in which landfill gases are utilized by various thermal systems.

A new 0-D model for DIR-SOFC was developed using the principles of thermodynamics and electrochemistry. In this model, the recirculation of the anode exit gas stream and a multi-gas mixture as the fuel were considered. The effects of recirculation ratio and fuel utilization ratio on the performance of the SOFC were studied. It is found that lower recirculation ratios and higher fuel utilization increases the performance of the system in terms of thermodynamics viewpoint. 
A new approach to modeling carbon deposition in DIR-SOFC was proposed. In this approach, carbon deposition was prevented by adjusting the recirculation ratio. The effect of temperature level and the chemical composition of the fuel on the carbon deposition possibility were studied. The results were illustrated in $\mathrm{C}-\mathrm{H}-\mathrm{O}$ triangular phase diagrams. The change of activity and the minimum recirculation ratio with temperature and fuel utilization ratio were also calculated. It can be concluded from this study that in order to operate the SOFC with a minimum recirculation ratio to prevent carbon deposition as required for higher thermodynamic performance, the maximum possible operating temperature level and fuel utilization ratio should be chosen accordingly. For the range of operating data investigated, such a condition was achieved at the fuel utilization of 0.85 for HT-SOFC. According to the thermodynamic considerations, the minimum recirculation ratio should be 0.4 and 0.07 for a HT-SOFC operating with methane and a typical cleaned gas produced from pyrolysis, respectively, at a fuel utilization of 0.85 . It was also shown that gases produced from advanced gasification systems, such as twin-fluid bed and multi-solid fluid bed, yield higher electrical efficiency for SOFC compared to those produced from downdraft and updraft gasifiers.

A new transient, quasi 2-D heat transfer model of SOFC was developed. In this model, all the polarizations (e.g. ohmic, activation and concentration), and heat transfer modes (e.g. conduction, convection and radiation) were taken into account. The transient model gives the change of output parameters, such as temperature, fuel utilization, average current density, electrical efficiency, power density and molar fraction of gases with time at the heat-up and start-up stages for co- and counter-flow configurations. Two cases were 
studied in which the input data that were taken was found to be consistent with the benchmark tests for validation purposes. These case studies were: SOFC fed with humidified hydrogen and DIR-SOFC fed with a gas mixture. For validation, a model using the same assumption on polarizations with the benchmark tests was first developed. Then, the model was further improved by altering this assumption and using updated electrochemical relations on polarizations. It was found that the results were in very good agreement. The results of the first case study showed that the transient behaviors for coand counter-flow configurations do not differ significantly. They have similar trend but the counter-flow configuration takes slightly more time to reach the steady state condition. It was also found that counter-flow configuration has a better performance, e.g. electrical efficiency, for low Reynolds numbers which is needed to obtain high fuel utilization. The effect of excess air coefficient on the performance was studied. It was shown that taking this coefficient high provides better electrical efficiency. A comparison between the two configurations for the input data taken showed that counter-flow configuration has a higher electrical efficiency for the excess air coefficient up to 9. For higher values of this coefficient, co-flow configuration has a higher electrical efficiency. As a final parametric study, the effect of gas channel thickness on the performance of the cell was studied. It was shown that fuel utilization and electrical efficiency decreases whereas average current density and power density increases with an increase in the gas channel thickness. In the second case study, transient behavior of the cell was investigated. The results were validated using the benchmark test and Braun's thesis $[107,108]$. It was also found that the results are in very good agreement. 
In system level modeling, three cases were analyzed through energy and exergy analyses. These cases included a SOFC and gas turbine cogeneration system and two SOFC and biomass gasification systems. The results of the case study, in which the SOFC and gas turbine cogeneration system was analyzed, showed that this system has a $68 \%$ fuel utilization efficiency and $62 \%$ exergetic efficiency. It was also shown that this system has a better thermodynamic performance compared to its competing technologies. In the second case study, a biomass gasification and SOFC system was analyzed to assess the performance of the SOFC in this integrated system. The results of this study showed that if we chose to operate the SOFC at low temperature level, we get higher electrical efficiency from SOFC but we also obtain higher air utilization ratio, which increases the operation cost of the system. In the third study, a detailed modeling of SOFC and biomass gasification system was done and the effect of gasification agent on the performance of the system was discussed. This study showed that steam gasification yields the highest electrical efficiency, power-to-heat ratio and exergetic efficiency, but the lowest fuel utilization efficiency.

The effect of SOFC on greenhouse gas (GHG) reduction was assessed through a case study in which several technologies were used to utilize the landfill gas. In this study, GHG emissions from an uncontrolled landfill site were compared with those from controlled landfill sites in which flaring, conventional electricity generation technologies such as ICE and GT, and SOFC were utilized. It was shown that even with the simplest solution, which is flaring, total GHG emissions in the lifetime of the site can be reduced by $58 \%$ compared to the uncontrolled case. Among the different technologies, the SOFC 
seems to be the best option, as it reduced the GHG emissions by $63 \%$, and had a specific lifetime GHG emission of 2.38 tonnes $\mathrm{CO}_{2}$.eq/MWh when it only produced electricity and 1.12 tonnes $\mathrm{CO}_{2}$.eq/MWh when it was used in a cogeneration application. Hence, this study has shown that SOFC is very effective in combating global warming.

\subsection{Recommendations}

The recommendations for future research in the area of SOFC modeling are given below.

- In this thesis, 0-D and quasi 2-D SOFC models were developed for co- and counterflow configurations. A 3-D model can be developed to obtain better results for these configurations. This kind of a model can also be developed for cross-flow configuration.

- In this thesis, the control volume was selected as the repeat element in the middle of the stack with adiabatic boundary conditions. It was assumed that all the cells in the stack have the same characteristics with this repeat element. The model can be further improved by considering the heat interactions between the adjacent cells in stack level.

- Carbon deposition model was developed based on thermodynamics equilibrium. A better model can be developed by considering simultaneous elementary mechanisms using a homogeneous kinetic model.

- Different degradation modes in a SOFC can be analyzed. These modes include mechanical issues such as: interfacial thermal stress, sealing and crack propagation; and chemical and electrochemical issues such as: sulfur poisoning, microstructure 
change (including grain growth to cause the reduction of three phase boundary), and accidental oxidation and reduction.

- In this thesis, heat-up and start-up simulations were carried out. Load change can also be analyzed using the transient heat transfer model developed in this study.

- Energy and exergy analyses were applied in system level modeling for assessing the thermodynamic performance of the integrated SOFC systems. Thermoeconomics can also be applied to these systems to find the cost flow within the system and cost of the final products.

- A multidisciplinary optimization can be carried out to maximize the efficiency, and minimize the cost and greenhouse gas emissions of integrated SOFC systems. 


\section{REFERENCES}

1. Larminie J., Dicks, A., 2003, Fuel cell systems explained, $2^{\text {nd }}$ ed., John Wiley, UK, pp.157-158.

2. Cowey, K., Green, K.J., Mepsted, G.O., Reeve, R., 2004, Portable and military fuel cells, Current Opinion in Solid State \& Materials Science, 8, pp.367-371.

3. Goldemberg, J., Johansson, T.B. (editors), 2004, World energy assessment: overview 2004 update. United Nations Development Programme, New York, U.S.A.

4. Petruzzi, L., Cocchi, S., Fineschi, F., 2003, A global thermo-electrochemical model for SOFC systems design and engineering, Journal of Power Sources, 118. pp.96-107.

5. American Methanol Institute, 2000, Beyond the internal combustion engine: the promise of methanol fuel cell vehicles. Executive Summary, Washington, D.C.

6. Singhal, S.C, 2000, Science and technology of solid oxide fuel cells, MRS Bulletin, 25(3), pp.6-21.

7. Gardner, F.J., Day, M.J., Brandon, N.P., Pashley, M.N., Cassidy, M., 2000, SOFC technology development at Rolls-Royce, Journal of Power Sources, 86. pp.122-129.

8. Recknagle, K.P., Williford, R.E., Chick, L.A., Rector. D.R., Khaleel, M.A., 2003, Three-dimensional thermo-fluid electrochemical modeling of planar SOFC stacks, Journal of Power Sources, 113, pp.109-114.

9. Assabumrungrat, S., Sangtongkitcharoen, W., Laosiripojana, N., Arpornwichanop, A., Charojrochkul, S., Praserthdam, P., 2005, Effects of electrolyte type and flow pattern on performance of methanol-fuelled solid oxide fuel cells, Journal of Power Sources, 148, pp.18-23. 
10. Singhal, S.C., Kendall, K., 2003, High temperature solid oxide fuel cells fundamentals, design and applications, Elsevier, UK.

11. Assabumrungrat, S., Laosiripojana, N., Pavarajarn, V., Sangtongkitcharoen, W., Tangjitmatee, A., Praserthdam, P., 2005, Thermodynamic analysis of carbon formation in a solid oxide fuel cell with a direct internal reformer fuelled by methanol, Journal of Power Sources, 139, pp.55-60.

12. Douvartzides, S., Coutelieris, F., Tsiakaras, P., 2004, Exergy analysis of a solid oxide fuel cell power plant fed by either ethanol or methane, Journal of Power Sources, 131, pp.224-230.

13. Yin, Y. Zhu, W., Xia, C., Gao, C., Meng, G., 2004, Low-temperature SOFC using biomass-produced gases as fuels, Journal of Applied Electrochemistry, 34, pp.12871291.

14. Omosun, A.O., Bauen, A., Brandon, N.P., Adjiman, C.S., Hart, D., 2004, Modelling system efficiencies and costs of two biomass-fuelled SOFC systems, Journal of Power Sources, 131, pp.96-106.

15. Wojcik, A., Middleton, H., Damopoulos, I., Van herle, J., 2003, Ammonia as a fuel in solid oxide fuel cells, Journal of Power Sources, 118, pp.342-348.

16. Lu, Y., Schaefer, L., 2004, A solid oxide fuel cell system fed with hydrogen sulfide and natural gas, Journal of Power Sources, 135, pp.184-191.

17. International Energy Agency, 2007, Renewables in global energy supply, An IEA Fact Sheet, France. 
18. Mitchell, C.P., Bridgwater, A.V., Stevens, D.J., Toft, A.J., Watters, M.P., 1995, Technoeconomic assessment of biomass to energy, Biomass and Bioenergy, 9, pp.205-226.

19. Franco, A., Giannini, N., 2005, Perspectives for the use of biomass as fuel in combined cycle power plants, International Journal of Thermal Sciences, 44, pp.163177.

20. Xenergy, 2002, Toward a renewable power supply: the use of bio-based fuels in stationary fuel cells.

21. Schmersahl, R., Scholz, V., 2005, Testing a PEM fuel cell system with biogas fuel, Agricultural Engineering International, the CIGR Ejournal, 7, Manuscript EE 05002.

22. Lin. Y., Tanaka, S., 2006, Ethanol fermentation from biomass resources: current state and prospects, Applied Microbiology and Biotechnology, 69, pp.627-642.

23. Sime, R., Stucki, S., Biollaz, S., Wiasmitinow, A., 2002, Linking Wood Gasification with SOFC Hybrid Processes, Proceedings, $5^{\text {th }}$ European SOFC Forum, Lucerne, Switzerland.

24. Tsiakaras, P., Demin, A., 2001, Thermodynamic analysis of a solid oxide fuel cell system fuelled by ethanol, Journal of Power Sources, 102, pp.210-217.

25. Jenne, M., 2003, Demonstration project - Sulzer Hexis SOFC system for biogas (fermentation gas) operation, Powerpoint Presentation, ESF Workshop, January 2930, 2003.

26. Dayton, D.C., 2001, Fuel Cell Integration-A Study of the Impacts of Gas Quality and Impurities, Milestone Completion Report, National Renewable Energy Laboratory, U.S.A. 
27. McKendry, P., 2002, Energy production from biomass (part 2): conversion technologies, Bioresource Technology, 83, pp.47-54.

28. Department of Foreign Affairs and International Trade, 2002, Fuel Cell Technologies Ltd., CanadExport, 20(10), pp.1-4.

29. Bridgwater, A.V., Peacocke, G.V.C., 2000, Fast pyrolysis processes for biomass, Renewable and Sustainable Energy Reviews, 4, pp. 1-73.

30. Wang, D., Czernik, S., Chornet, E., 1998, Production of hydrogen from biomass by catalytic steam reforming of fast pyrolysis oil, Energy \& Fuels, 12, pp.19-24.

31. Brammer, J.G., Bridgwater, A.V., 1999, Drying technologies for an integrated gasification bio-energy plant, Renewable and Sustainable Energy Reviews, 3, pp.243-289.

32. Bridgwater, A.V., 2003, Renewable fuels and chemicals by thermal processing of biomass, Chemical Engineering Journal, 91, pp.87-102.

33. Bain, R.L., 2004, Biomass gasification overview, Presentation, National Renewable Energy Laboratory.

34. Singhal, S.C., 2000, Science and technology of solid oxide fuel cells, MRS Bulletin, 25(3), pp.16-21.

35. FP5-Energy, Environment and Sustainable Development Programme, Demonstration of a MWel Class Power System using High Temperature Fuel Cells (SOFC) combined with Micro-Turbine Generators (IMWSOFC), webpage: http://ec.europa.eu/research/energy/pdf/efchp_fuelcell7.pdf. 
36. Hutton, P.N., Musich, M.A., Patel, N., Timpe, R.C., 2002, Development and testing of an SOFC-gasification system, Quarterly Report, Energy \& Environmental Research Center of University of North Dakota.

37. Skreiberg, O., 2005, The biosofc project-technology development for integrated solid oxide fuel cell el. generation, biomass gasification and high temperature gas cleaning, Presentation, Bioenergy, Trondheim, Norway.

38. Nielsen, M.B., Green fuel cell-fuel cell fuelled by gasification gas, Presentation, Force Technology.

39. Karl, J., Karellas, S., 2004, Highly efficient sofc systems with indirect gasification, Proceedings of the $6^{\text {th }}$ European Solid Oxide Fuel Cell Forum, Lucerne, Switzerland.

40. Demin, A.K., Alderucci, V., Ielo, I., Fadeev, G.I., Maggio, G., Giordano, N., Antonucci, V., 1992, Thermodynamic analysis of methane fueled solid oxide fuel cell system, International Journal of Hydrogen Energy, pp. 451-458.

41. Rao, A.D., 2001, A thermodynamic analysis of tubular SOFC based hybrid systems, $\mathrm{PhD}$ thesis, University of California, Irvine.

42. Palsson, J., 2002, Thermodynamic modelling and performance of combined solid oxide fuel cell and gas turbine systems, $\mathrm{PhD}$ thesis, Lund University.

43. Motloch, C.G., 1998, Thermochemical modeling and performance of a methanereforming solid oxide fuel cell, $\mathrm{PhD}$ thesis, Idaho State University.

44. Yakabe, H., Ogiwara, T., Hishinuma, M., Yasuda, I., 2001, 3-D model calculation for planar SOFC, Journal of Power Sources, 102, pp.144-154.

45. Pasaogullari U., Wang, C., 2003, Computational fluid dynamics modeling of solid oxide fuel cells, Proceedings of SOFC VIII. 
46. Hall, D.J., Colclaser, R.D., 1999, Transient Modeling and Simulation of a Tubular Solid Oxide Fuel Cell, IEEE Transactions on Energy Conversion, 14(3), pp.749-753.

47. Li, J., Cao, G., Zhu, X., and Tu, H., 2007, Two-dimensional dynamic simulation of a direct internal reforming solid oxide fuel cell, Journal of Power Sources, 171, pp. $585-600$.

48. Damm, D.L., and Fedorov, A.G, 2006, Reduced-order transient thermal modeling for SOFC heating and cooling, Journal of Power Sources, 159, pp.956-967.

49. Ferrari, M.L., Traverso, A., Magistri, L., and Massardo, A.F., 2005, Influence of the anodic recirculation transient behaviour on the SOFC hybrid system performance, Journal of Power Sources, 149, pp.22-32.

50. Rancruel, D., and von Spakovsky, M., 2005, Investigation of the Start-up Strategy for a Solid Oxide Fuel Cell Based Auxiliary Power Unit under Transient Conditions, Int. J. of Thermodynamics, 8(2), pp.103-113.

51. Apfel, H., Rzepka, M., Tu, H., and Stimming, U., 2006, Thermal start-up behaviour and thermal management of SOFC's, Journal of Power Sources, 154, pp.370-378.

52. Larrain, D, 2005, Solid oxide fuel cell stack simulation and optimization, including experimental validation and transient behaviour, Ph.D. thesis, École Polytechnique Federale De Lausanne.

53. Thorud, B., Stiller, C., Weydahl, T., Bolland, O., and Karoliussen, H., 2004, Partload and load change simulation of tubular SOFC systems, Proc. The 6th European Solid Oxide Fuel Cell Forum, Lucerne, Switzerland, pp.716-729.

54. Assabumrungrat, S., Laosiripojana, N., Pavarajarn, V., Sangtongkitcharoen, W., Tangjitmatee, A., Praserthdam, P., 2005, Thermodynamic analysis of carbon 
formation in a solid oxide fuel cell with a direct internal reformer fuelled by methanol, Journal of Power Sources 139, pp.55-60.

55. Sangtongkitcharoen, W., Assabumrungrat, S., Pavarajarn, V., Laosiripojana, N., Praserthdam, P., 2005, Comparison of carbon formation boundary in different modes of solid oxide fuel cells fueled by methane, Journal of Power Sources, 142, pp.75-80.

56. Singh, D., Hernandez-Pacheco, E., Hutton, P.N., Patel, N., Mann, M.D, 2005, Carbon deposition in an SOFC fueled by tar-laden biomass gas: a thermodynamic analysis, Journal of Power Sources, 142, pp.194-199.

57. Koh, J., Kang, B., Lim, C.H., Yoo, Y., 2001, Thermodynamic analysis of carbon deposition and electrochemical oxidation of methane for SOFC anodes, Electrochemical and Solid-State Letters, 4(2), pp.A12-A15.

58. Sasaki, K., Teraoka, Y., 2003, Equilibria in fuel cell gases I. Equilibrium compositions and reforming conditions, Journal of the Electrochemical Society 150(7), pp.A878-A884.

59. Takeguchi, T., Kani, Y., Yano, T., Kikuchi, R., Eguchi, K., Tsujimoto, K., Uchida, Y., Ueno, A., Omoshiki, K., Aizawa, M., 2002, Study on steam reforming of CH4 and C2 hydrocarbons and carbon deposition on Ni-YSZ cermets, Journal of Power Sources 112, pp.588-595.

60. Finnerty, C.M., Coe, N.J., Cunningham, R.H., Ormerod, R.M., 1998, Carbon formation on and deactivation of nickel-based/zirconia anodes in solid oxide fuel cells running on methane, Catalysis Today, 46, pp.137-145. 
61. Koh, J., Yoo, Y., Park, J., Lim, H.C., 2002, Carbon deposition and cell performance of Ni-YSZ anode support SOFC with methane fuel, Solid State Ionics, 149, pp.157166.

62. Macek, J., Novosel, B., Marinsek, M., 2007, Ni-YSZ SOFC anodes-Minimization of carbon deposition, Journal of the European Ceramic Society, 27, pp.487-491.

63. Horita, T., Yamaji, K., Kato, T., Kishimoto, H., Xiong, Y., Sakai, N., MBrito, M.E., Yokokawa, H., 2005, Imaging of $\mathrm{CH} 4$ decomposition around the Ni/YSZ interfaces under anodic polarization, Journal of Power Sources, 145, pp.133-138.

64. Palsson, J., Selimovic, A., Sjunnesson, L., 2000, Combined solid oxide fuel cell and gas turbine systems for efficient power and heat generation, Journal of Power Sources, 86, pp.442-448.

65. Winkler, W., Lorenz, H., 2002, The design of stationary and mobile solid oxide fuel cell - gas turbine systems, Journal of Power Sources, 105, pp.222-227.

66. Koyama, M., Kraines, S., Tanaka, K., Wallace D., Yamada K., Komiyama H., 2004, Integrated model framework for the evaluation of an SOFC/GT system as a centralized power source, International Journal of Energy Research, 28, pp.13-30.

67. Kivisaari T., Björnbom P., Sylwan C., Jacquinot B., Jansen D., de Groot A., 2004, The feasibility of a coal gasifier combined with a high-temperature fuel cell, Chemical Engineering Journal, 100, pp.167-180.

68. Kuchonthara P., Bhattacharya S., Tsutsumi A., 2005, Combination of thermochemical recuperative coal gasification cycle and fuel cell for power generation, Fuel, 84, pp.1019-1021. 
69. Ghosh. S., De. S., 2006, Energy analysis of a cogeneration plant using coal gasification and solid oxide fuel cell, Energy, 31, pp.345-363.

70. Ntziachristos, L., Kouridis, C., Samaras, Z., Pattas, K., 2005, A wind-power fuel-cell hybrid system study on the non-interconnected Aegean islands grid, Renewable Energy, 30, pp.1471-1487.

71. Aloui, T., Halouani, K., 2007, Analytical modeling of polarizations in a solid oxide fuel cell using biomass syngas product as fuel, Applied Thermal Engineering, 27, pp.731-737.

72. Yin, Y., Zhu, W., Xia, C., Gao, C., Meng, G., 2004, Low-temperature SOFC using biomass-produced gases as fuels, Journal of Applied Electrochemistry, 34, pp.12871291

73. Panopoulos, K.D., Fryda, L.E., Karl, J., Poulou, S., Kakaras, E., 2006, High temperature solid oxide fuel cell integrated with novel allothermal biomass gasification Part I: Modelling and feasibility study, Journal of Power Sources, 159, pp.570-585.

74. Panopoulos, K.D., Fryda, L.E., Karl, J., Poulou, S., Kakaras, E., 2006, High temperature solid oxide fuel cell integrated with novel allothermal biomass gasification Part II: Exergy analysis, Journal of Power Sources, 159, pp.586-594.

75. Cordiner, S., Feola, M., Mulone,V., Romanelli, F., 2007, Analysis of a SOFC energy generation system fuelled with biomass reformate, Applied Thermal Engineering, 27, pp. $738-747$.

76. Athanasiou, C., Coutelieris, F., Vakouftsi, E., Skoulou, V., Antonakou, E., Marnellos, G., Zabaniotou, A., 2007, From biomass to electricity through integrated 
gasification/SOFC system-optimization and energy balance, International Journal of Hydrogen Energy, 32, pp.337-342.

77. Vasileiadis, S., Ziaka-Vasileiadou, Z., 2004, Biomass reforming process for integrated solid oxide-fuel cell power generation, Chemical Engineering Science, 59, pp.4853-4859.

78. Liberati, G., Spazzafumo, G., 2002, Perspectives for Waste/Landfill Gas Fuelled SOFC Plants, Proceedings, $5^{\text {th }}$ European SOFC Forum, Lucerne, Switzerland.

79. Colpan, C.O., Yesin, T., 2006, Energetic, exergetic and thermoeconomic analysis of Bilkent combined cycle cogeneration plant, International Journal of Energy Research, 30 , pp. $875-894$.

80. Colpan, C.O., Yesin, T., 2006, Thermodynamic and thermoeconomic comparison of combined cycle cogeneration systems, International Journal of Exergy, 3(3), pp.272290.

81. Syahrul S., Hamdullahpur F., Dincer I., 2002, Exergy analysis of fluidized bed drying of moist particles, Exergy, An International Journal, 2, pp.87-98.

82. Rosen, M.A., Pedinelli, N., Dincer, I., 1999, Energy and exergy analyses of cold thermal storage systems, International Journal of Energy Research, 23(12), pp.10291038.

83. Dincer, I., 2002, On energetic, exergetic and environmental aspects of drying systems, International Journal of Energy Research, 26(8)., pp.717-727.

84. Ghosh, D., De, S., 2003, Thermodynamic performance study of an integrated gasification fuel cell combined cycle-an energy analysis, Proceedings of the Institution of Mechanical Engineers-A, 217(2), pp.137-147. 
85. Ghosh, D., De, S., 2003, Thermodynamic performance study of an integrated gasification fuel cell combined cycle-an exergy analysis, Proceedings of the Institution of Mechanical Engineers-A, 217(6), pp.575-581.

86. Douvartzides, S.L., Coutelieris, F.A., Tsiakaras, P.E., 2003, On the systematic optimization of ethanol fed SOFC-based electricity generating systems in terms of energy and exergy, Journal of Power Sources, 114, pp.203-212.

87. Calise, F., Palombo, A., Vanoli, L., 2006, Design and partial load exergy analysis of hybrid SOFC-GT power plant, Journal of Power Sources, 158, pp.225-244.

88. Achenbach, E., 1994, Three-dimensional and time-dependent simulation of a planar solid oxide fuel cell stack, Journal of Power Sources, 49, pp.333-348.

89. Mandin, P., Bernay, C., Tran-Dac, S., Broto, A., Abes, D., Cassir, M, 2005, SOFC modelling and numerical simulation of performances, Fuel Cells, 1, pp.71-78.

90. Larrain, D., 2005, Solid oxide fuel cell stack simulation and optimization, including experimental validation and transient behaviour, $\mathrm{PhD}$ thesis, École Polytechnique Federale De Lausanne.

91. Al-Qattan, A.M., 2004, Design and analysis of distributed feed solid oxide fuel cell stacks, $\mathrm{PhD}$ thesis, Illinois Institute of Technology.

92. Hernandez-Pacheco, E., 2004, Electro-thermal model for a solid oxide fuel cell, $\mathrm{PhD}$ thesis, University of North Dakota.

93. Winkler, W., 2002, Thermodynamics, "In" Singhal, S.C. and K. Kendall, High temperature solid oxide fuel cells - fundamentals, design and applications, Chapter 3, UK:Elsevier. 
94. Koch, S., 2002, Contact resistance of ceramic interfaces between materials used for solid oxide fuel cell applications, $\mathrm{PhD}$ thesis, Technical University of Denmark.

95. Bossel, U.G., 1992, Final report on SOFC data facts and figures, Berne, CH:Swiss Federal Office of Energy.

96. Bessette II, N.F., Wepfer, W.J., Winnick, J., 1995, A mathematical model of a solid oxide fuel cell, Journal of the Electrochemical Society, 142(11), pp.3792-3800.

97. Ahmed, S., McPheeters, C., Kumar, R., 1991, Thermal-hydraulic model of a monolithic solid oxide fuel cell, Journal of the Electrochemical Society, 138 (9), pp. 2712-2718.

98. Iwata, M., Hikosaka, T., Morita, M., Iwanari, T., Ito, K., Onda, K., Esaki, Y., Sakaki, Y., Nagata, S., 2000, Performance analysis of planar-type unit SOFC considering current and temperature distributions, Solid State Ionics, 132, pp. 297-308.

99. Kim, J., Virkar, A.V., Fung, K., Mehta, K., Singhal. S.C., 1999, Polarization effects in intermediate temperature, anode-supported solid oxide fuel cells, Journal of the Electrochemical Society, 146(1), pp. 69-78.

100. Perry, R.H., Green, O.W., 1997, Perry's chemical engineers' handbook., 7th ed., U.S.A.: McGraw-Hill.

101. Clarke, S.H., Dicks, A.L., Pointon, K., Smith, T.A., Swann, A., 1997, Catalytic aspects of the steam reforming of hydrocarbons in internal reforming fuel cells, Catalysis Today, 38, pp.411-423.

102. Cairns, E.J., Tevebaugh, A.D., 1964, CHO gas phase compositions in equilibrium with carbon, and carbon deposition boundaries at one atmosphere, Journal of Chemical and Engineering Data, 9(3), pp.453-462. 
103. Broers, G.H.J., Treijtel, B.W., 1965, Carbon deposition boundaries and other constant parameter curves, in the triangular representation of $\mathrm{C}-\mathrm{H}-\mathrm{O}$ equilibria, with applications to fuel cells, Advanced Energy Conversion, 5, pp.365-382.

104. Chase Jr., M.W., Davies, C.A., Downey, J.R., Frurip Jr., D.J., McDonald, R.A., Syverud, A.N., 1985, JANAF thermochemical tables, 3rd ed, Journal of Physical and Chemical Reference Data, 14, Supplement No. 1.

105. Shah, R.K, 1978, Laminar flow forced convection in ducts: a source book for compact heat exchanger analytical data, New York, Academic Press.

106. Selimovic A., Kemm, M., Torisson, T., Assadi, M., 2005, Steady state and transient thermal stress analysis in planar solid oxide fuel cells, Journal of Power Sources, 145 , pp. $463-469$.

107. Achenbach, E., 1994, Status of the IEA-bench mark test 1 on stack-modelling, IEAWorkshop, Rome.

108. Braun, R.J., 2002, Optimal design and operation of solid oxide fuel cell systems for small-scale stationary applications, $\mathrm{PhD}$ thesis, University of Wisconsin-Madison.

109. Incropera, F.P., Dewitt, D.P., 1996. Fundamentals of heat and mass transfer, $4^{\text {th }} \mathrm{ed}$., John Wiley\& Sons.

110. Ozisik, N., 1994, Finite difference methods in heat transfer, CRC-Press, U.S.A.

111. Bejan, A., Tsatsaronis G., Moran M., 1996, Thermal design and optimization, John Wiley and Sons Inc., U.S.A.

112. Szargut, J., 2005, Exergy method-Technical and ecological applications, WIT Press, Boston. 
113. Tao, G., Armstrong, T., Virkar, A., 2005, Intermediate temperature solid oxide fuel cell (IT-SOFC) research and development activities at MSRI, Nineteenth Annual ACERC\&ICES Conference, Utah.

114. Bridgwater, A.V., 1995, The technical and economic feasibility of biomass gasification for power generation, Fuel, 74(5), pp.631-653.

115. Chan, S.H., Low, C.F., Ding, O.L., 2002, Energy and exergy analysis of simple solid-oxide fuel-cell power systems, Journal of Power Systems, 103, pp.188-200.

116. Chan, S.H., Xia, Z.T., 2002, Polarization effects in electrolyte/electrode-supported solid oxide fuel cells, Journal of Applied Electrochemistry, 32, pp. 339-347.

117. Intergovernmental Panel on Climate Change (IPCC), 2007, Climate change 2007: Synthesis report, An Assessment of the Intergovernmental Panel on Climate Change.

118. Bove, R., Lunghi, P., 2006, Electric power generation from landfill gas using traditional and innovative technologies, Energy Conversion and Management, 47, pp.1391-1401.

119. Lombardi, L., Carnevale, E., Corti, A., 2006, Greenhouse effect reduction and energy recovery from waste landfill, Energy, 31, pp.3208-3219.

120. Spiegel, R.J., Preston, J.L., Trocciola, J.C., 1999, Fuel cell operation on landfill gas at Penrose Power Station, Energy, 24, pp.723-742.

121. Lunghi, P., Bove, R., Desideri, U., 2004, Life-cycle-assessment of fuel-cells-based landfill-gas energy conversion technologies, Journal of Power Sources, 131, pp.120126. 
122. Duerr, M., Gair, S., Cruden, A., McDonald, J., 2007, Hydrogen and electrical energy from organic waste treatment, International Journal of Hydrogen Energy, 32, pp. $705-709$.

123. EPA, 1998, Compilation of air pollutant emission factors, AP-42, Volume 1: Stationary Point and Area Sources, 5th ed., Chapter 2.4, Office of Air Quality Planning and Standards, Research Triangle Park, NC, U.S: Environmental Protection Agency.

124. Alexander, A., Burklin, C., Singleton, A., 2005, Landfill gas emissions model (landgem) version 3.02 user's guide, Washington, U.S.A, United States Environmental Protection Agency.

125. Stege, A., 2003, User's manual mexico landfill gas model version 1.0, Prepared for SEDESOL IIE CONAE.

126. Environment Agency and Scottish Environment Protection Agency, 2002, Guidance on landfill gas flaring.

127. SCS Engineers, 1994, Implementation guide for landfill gas recovery projects in the northeast, Final Report.

128. Environment Agency and Scottish Environment Protection Agency, 2004, Guidance for monitoring landfill gas engine emissions.

129. SCS Engineers, 1997, Comparative analysis of landfill gas utilization technologies.

130. News, 2005, GTI runs SOFC on gasified chicken waste, Fuel Cells Bulletin, 9:4.

131. News, 2007, TMI demos SOFC using agricultural waste, Fuel Cells Bulletin. 9:4.

132. News, 2008, Wärtsilä to deliver SOFC system using landfill gas, Fuel Cells Bulletin, 3:1. 
133. Climate Leaders, 2004, Direct emissions from municipal solid waste landfilling, U.S. Environmental Protection Agency. 